\title{
The High Temperature Synthesis of Transition Metal Oxo-Carboxylate Polynuclear Complexes
}

\author{
By \\ Jonathan Taylor \\ A thesis submitted in partial fulfilment of the \\ requirements for the degree of
}

MSc (Hons)

Victoria University of Wellington 


\section{Abstract}

Oxo-carboxylate polynuclear complexes contain more than one metal ion bridged by oxo and carboxylate bridges. One method of synthesis for these complexes is the so called high temperature synthesis where a solid precursor is heated at a temperature between 200$500^{\circ} \mathrm{C}$. This research has shown that thermal analytical techniques, EGA-MS and TGA, are an effective way of determining the processes that are occurring at different temperatures during the heating. Thermal analysis may also be used to determine the optimal temperature at which to perform the high temperature synthesis.

From the thermal analysis of different compounds used in the high temperature synthesis, it is observed that the product is influenced by the carboxylate ligand and the metal ions present in the precursor. Factors such as the anion, solvent of crystallisation or nuclearity of the complex are seen to have no influence on product formation at higher temperatures. It is proposed that a precursor whose corresponding acid of the bridging carboxylate has a low boiling point will require a lower synthesis temperature to form complexes of the same nuclearity and structure than precursors with carboxylate ligands whose acid has a higher boiling point. 


\section{Statement of Authorship}

All work described in this thesis was carried out at Victoria University of Wellington between February 2005 and December 2006.

Except where specific reference is made in the main text of this thesis, this thesis contains no material extracted in whole or part from a thesis, dissertation, or research paper presented by me for another degree or diploma.

No other person's work (published or unpublished) has been used without due acknowledgement in the main text of the thesis.

This Thesis has not been submitted for the award of any other degree or diploma in any other tertiary institution. 


\section{Acknowledgements}

This research would not have been possible without the help and support of several people who I would now like to thank.

First and foremost I must thank my supervisor Dr David Weatherburn for introducing me to oxo-carboxylate polynuclear complexes and their high temperature synthesis. His ability to find the positives out of unexpected results allowed me keep going during my research. Also his input into this thesis has been greatly appreciated.

I would also like to thank Mark Bowden and Alexander Kirchner of Industrial Research Limited (IRL) of Wellington for the use of their EGA-MS and the discussion of the data. I would especially like to thank Alex for his time he spent running the experiments and collecting the raw data.

The crystal structures shown in this thesis would not have been possible without the help of Dr. Jan Wikaira from Canterbury University who collected the raw crystallography data.

A special thanks goes to all the chemistry lecturers that have taught me during my time at Victoria University. Their enthusiasm and teaching has allowed my interest in chemistry to grow over these past five years.

Finally I would like to thank my family for all the support that they have given me during my time at university. I would especially like to thank my father for his interest and enthusiasm in my research work. 


\section{Contents}

1 INTRODUCTION

1

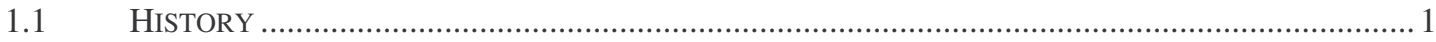

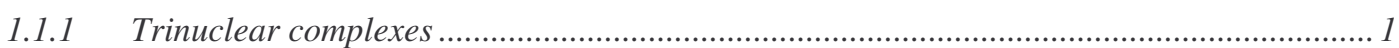

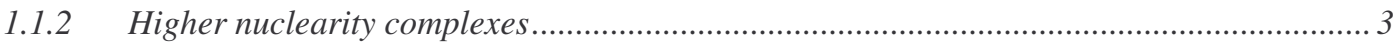

1.2 STRUCTURE

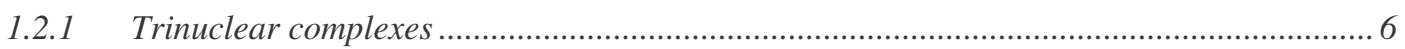

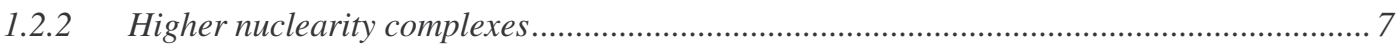

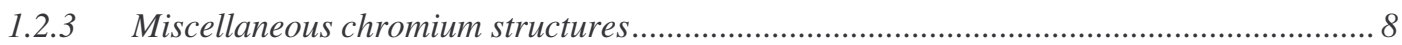

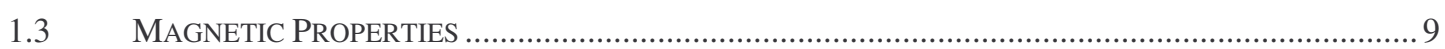

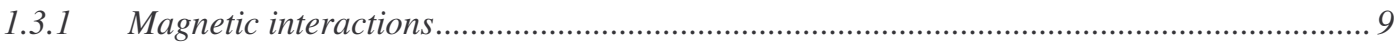

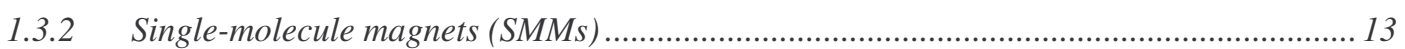

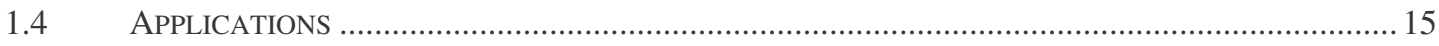

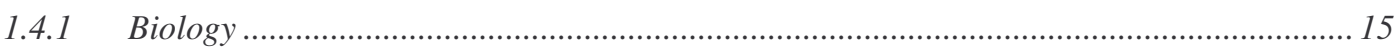

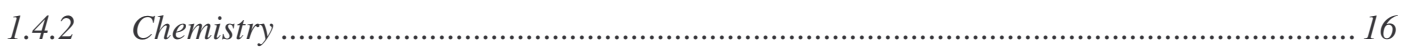

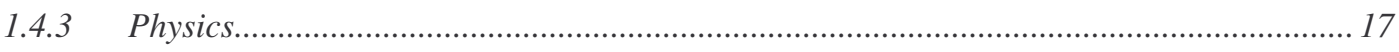

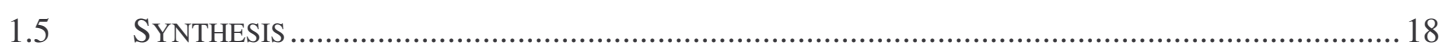

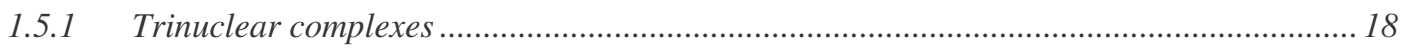

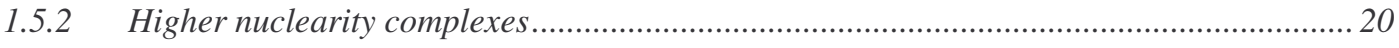

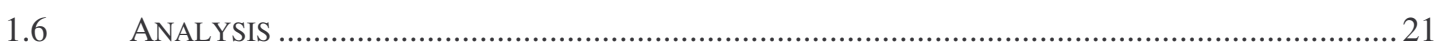

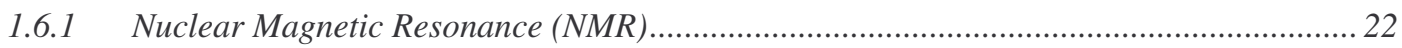

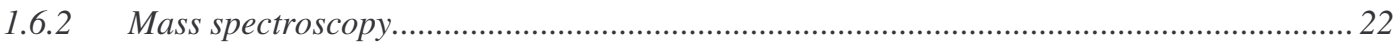

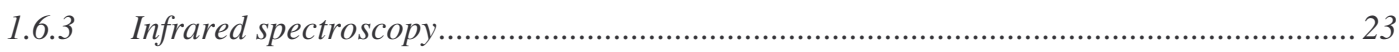

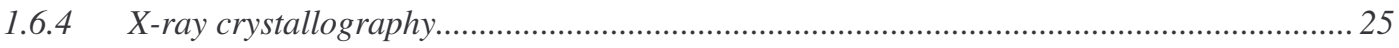

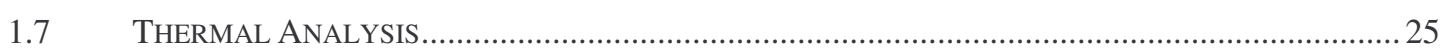

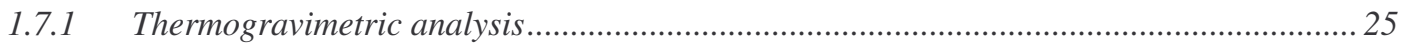

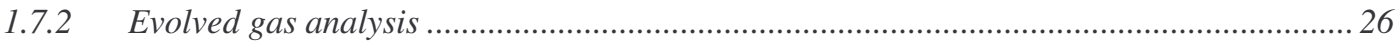

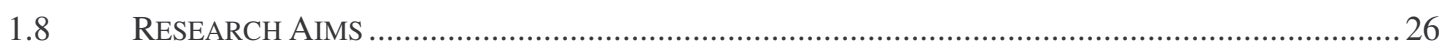

2 SYNTHESIS AND CHARACTERIZATION ……....................................................................... 27

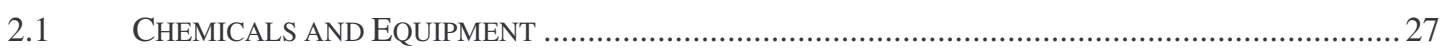

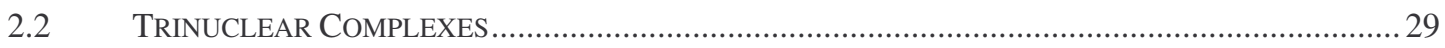

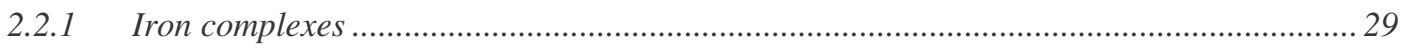

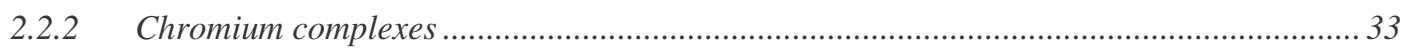

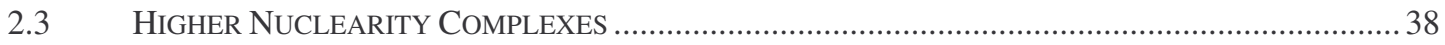

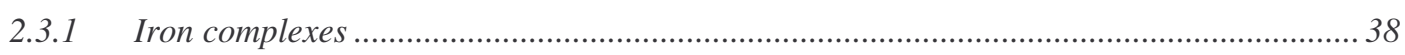

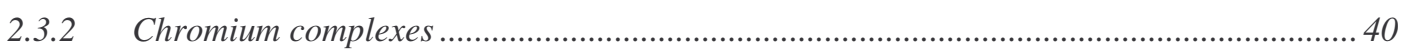


3.1 X-RAY CRYSTALLOGRAPHY

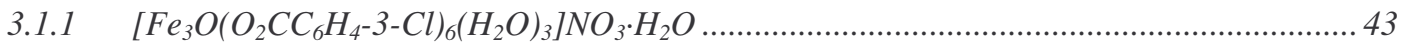

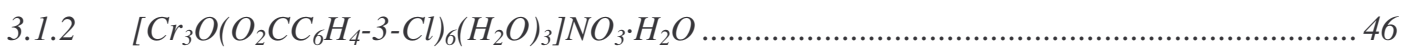

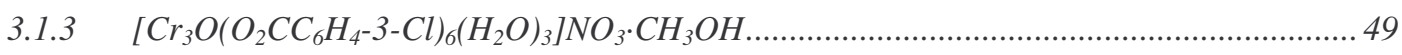

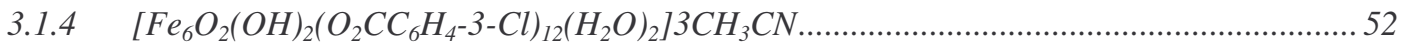

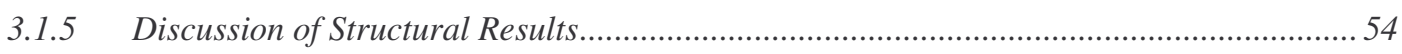

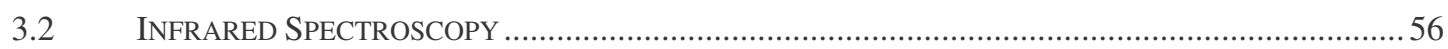

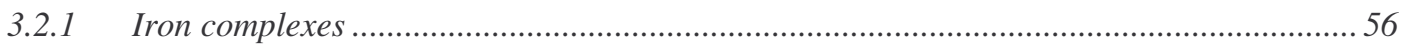

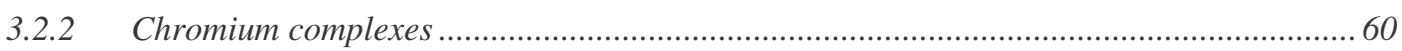

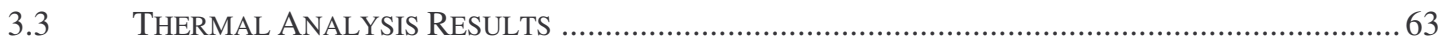

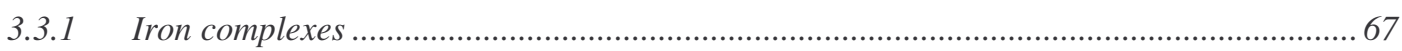

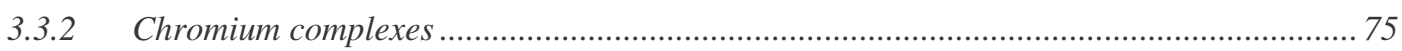

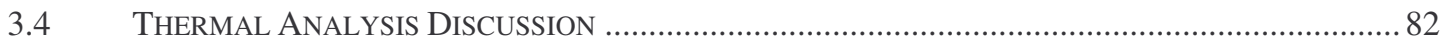

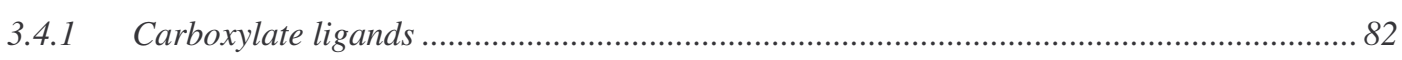

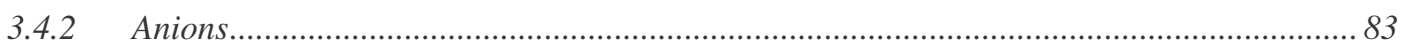

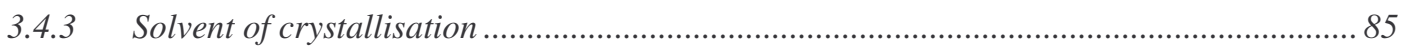

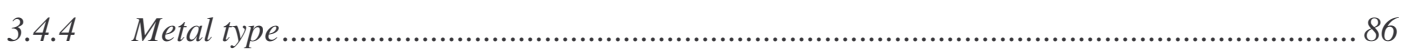

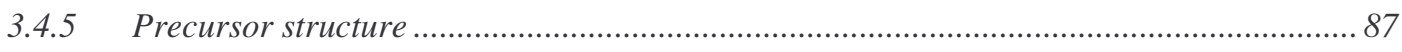

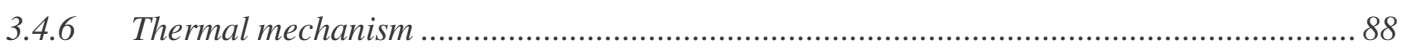

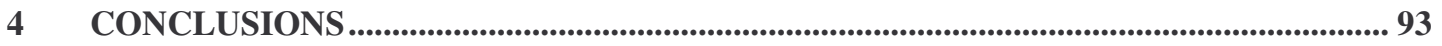

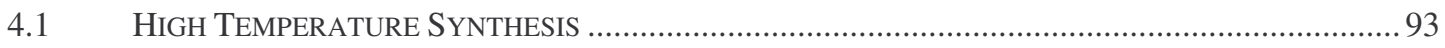

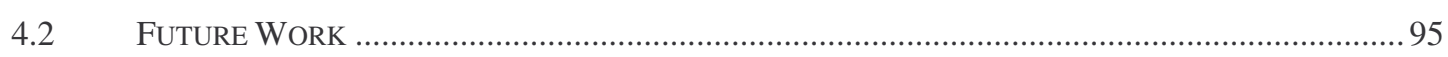

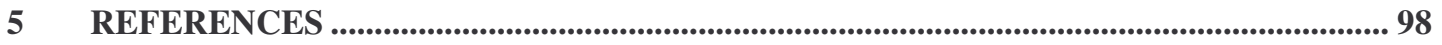

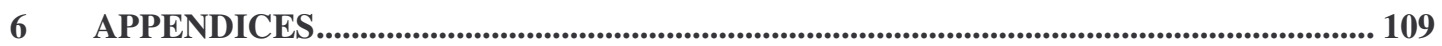

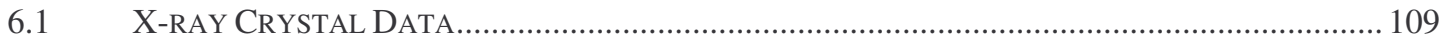

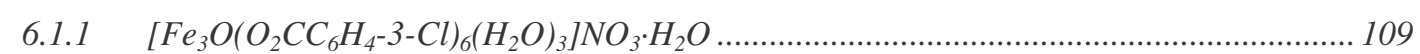

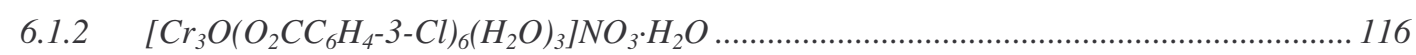

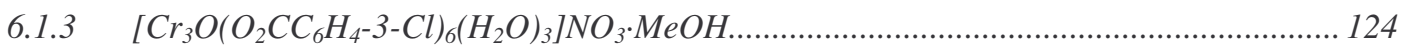

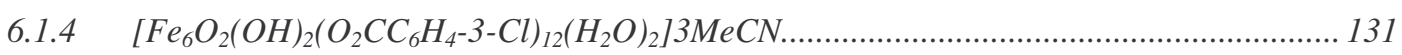




\section{Abbreviations and Definitions}

Carboxylate: $\quad$ Refers to either the salt of a carboxylic acid or a carboxylate bridge of a polynuclear complex

EGA-MS: $\quad$ Evolved Gas Analysis using a mass spectrometer as the detector

Heteronuclear: A polynuclear complex that contains different types of metal ions

Hexanuclear: A polynuclear complex that contains six metal ions

High nuclearity: A polynuclear complex that contains more than three metal ions

Homonuclear: A polynuclear complex that contains only one type of metal

IR: $\quad$ Infrared spectroscopy

Low nuclearity: A polynuclear complex that contains less than four metal ions

M carboxylate: A polynuclear complex containing $\mathrm{M}$ metal ions and carboxylate bridges

M: $\quad$ Any transition metal

$\mathrm{M}_{3} \mathrm{O}: \quad$ A metal triangle bonded to a central oxygen

MeCN: Acetonitrile, $\mathrm{CH}_{3} \mathrm{CN}$

$\mathrm{MeOH}: \quad$ Methanol, $\mathrm{CH}_{3} \mathrm{OH}$

Mixed metal: As for heteronuclear

Mixed valent: A polynuclear complex that contains metal ions in two different oxidation states

MS: $\quad$ Mass Spectrometer

$\mathrm{M}_{\mathrm{x}}$ carboxylate: A polynuclear complex that contains $\mathrm{x}$ metal ions in the metal core bridged by carboxylate bridges

$\mathrm{M}_{\mathrm{x}}$ : A polynuclear complex that contains $\mathrm{x}$ metal ions in the metal core

Nuclearity: The number of metal ions in the metal core

OAc: $\quad$ Ethanoate bridge, $\mathrm{CH}_{3} \mathrm{COO}$

Octanuclear: A polynuclear complex that contains eight metal ions

OEt: $\quad$ Deprotonated ethanol bridge, $\mathrm{CH}_{3} \mathrm{CH}_{2} \mathrm{O}$

Ph: $\quad$ Phenyl substituent, $-\mathrm{C}_{6} \mathrm{H}_{5}$

py: Pyridine

SMM Single-molecule magnet

TGA: Thermogravimetric Analysis

Undecanuclear: A polynuclear complex that contains eleven metal ions 


\section{List of Figures}

Figure 1: General structure for trinuclear complexes.

Figure 2: Examples of (a) a cube structure, $\left[\mathrm{Cr}_{12} \mathrm{O}_{8}(\mathrm{OH})_{4}\left(\mathrm{O}_{2} \mathrm{CCHMe}_{2}\right)_{16}\left(\mathrm{HOCCHMe}_{2}\right)_{4}\right]$ and (b) a wheel

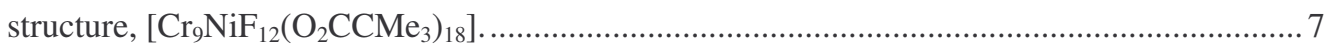

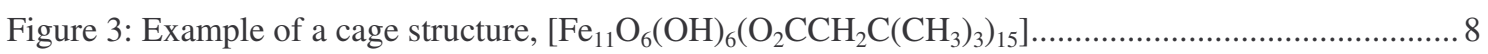

Figure 4: Structure of a dinuclear chromium complex with a hydroxide or oxide bridge........................ 8

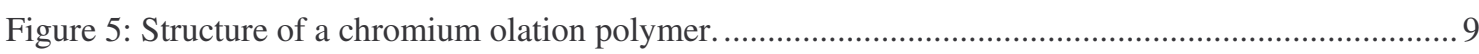

Figure 6: The molecular orbital arising from (a) a small MOM angle giving a ferromagnetic interaction and (b) a large MOM angle giving an antiferromagnetic interaction .................................. 11

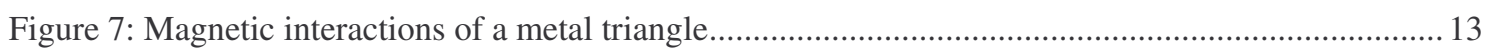

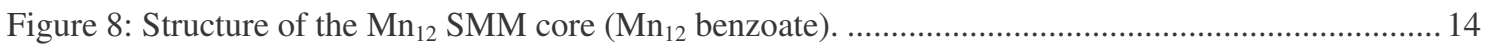

Figure 9: The three polymerisation reactions of norbornene catalysed by a polynuclear complex........... 17

Figure 10: Energy wells of a SMM with a spin state $S=5$ showing a) no quantum tunnelling b) thermally assisted quantum tunnelling and $\mathrm{c}$ ) pure quantum tunnelling......................................... 18

Figure 11: Stretching modes of the metal core observed in IR or Raman spectroscopy.........................2 24

Figure 12: Crystal Structure of $\left[\mathrm{Fe}_{3} \mathrm{O}\left(\mathrm{O}_{2} \mathrm{CC}_{6} \mathrm{H}_{4}-3-\mathrm{Cl}\right)_{6}\left(\mathrm{H}_{2} \mathrm{O}\right)_{3}\right]^{+}$with $50 \%$ thermal ellipsoids (hydrogen atoms omitted for clarity)

Figure 13: Unit cell of $\left[\mathrm{Fe}_{3} \mathrm{O}\left(\mathrm{O}_{2} \mathrm{CC}_{6} \mathrm{H}_{4}-3-\mathrm{Cl}\right)_{6}\left(\mathrm{H}_{2} \mathrm{O}\right)_{3}\right] \mathrm{NO}_{3} \cdot \mathrm{H}_{2} \mathrm{O}$ looking down the $(010)$ plane showing the hydrogen bonding between the cations.

Figure 14: Crystal Structure of $\left[\mathrm{Cr}_{3} \mathrm{O}\left(\mathrm{O}_{2} \mathrm{CC}_{6} \mathrm{H}_{4}-3-\mathrm{Cl}\right)_{6}\left(\mathrm{H}_{2} \mathrm{O}\right)_{3}\right]^{+}$with $50 \%$ probability ellipsoids (hydrogen atoms omitted for clarity).

Figure 15: Unit cell of $\left[\mathrm{Cr}_{3} \mathrm{O}\left(\mathrm{O}_{2} \mathrm{CC}_{6} \mathrm{H}_{4}-3-\mathrm{Cl}\right)_{6}\left(\mathrm{H}_{2} \mathrm{O}\right)_{3}\right] \mathrm{NO}_{3} \cdot \mathrm{H}_{2} \mathrm{O}$ looking down the $(010)$ plane showing the hydrogen bonding between the cations.

Figure 16: Crystal structure of $\left[\mathrm{Cr}_{3} \mathrm{O}\left(\mathrm{O}_{2} \mathrm{CC}_{6} \mathrm{H}_{4}-3-\mathrm{Cl}\right)_{6}\left(\mathrm{H}_{2} \mathrm{O}\right)_{3}\right]^{+}$with $50 \%$ thermal ellipsoids (hydrogen atoms omitted for clarity)

Figure 17: Unit cell of $\left[\mathrm{Cr}_{3} \mathrm{O}\left(\mathrm{O}_{2} \mathrm{CC}_{6} \mathrm{H}_{4}-3-\mathrm{Cl}\right)_{6}\left(\mathrm{H}_{2} \mathrm{O}\right)_{3}\right] \mathrm{NO}_{3} \cdot \mathrm{MeOH}$ looking down the (011) plane showing the hydrogen bonding between the cations.... 51

Figure 18: Crystal structure of $\left[\mathrm{Fe}_{6} \mathrm{O}_{2}(\mathrm{OH})_{2}\left(\mathrm{O}_{2} \mathrm{CC}_{6} \mathrm{H}_{4}-3-\mathrm{Cl}\right)_{12}\left(\mathrm{H}_{2} \mathrm{O}\right)_{2}\right]^{+}$with $50 \%$ thermal ellipsoids (hydrogen atoms omitted for clarity). 52

Figure 19: Unit cell of $\left[\mathrm{Fe}_{6} \mathrm{O}_{2}(\mathrm{OH})_{2}\left(\mathrm{O}_{2} \mathrm{CC}_{6} \mathrm{H}_{4}-3-\mathrm{Cl}\right)_{12}\left(\mathrm{H}_{2} \mathrm{O}\right)_{2}\right] 3 \mathrm{MeCN}$ looking down the (010) plane.....54

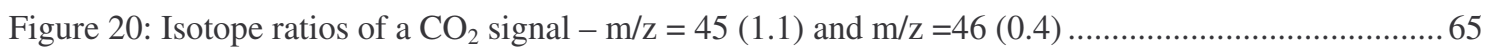

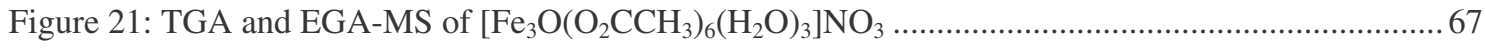

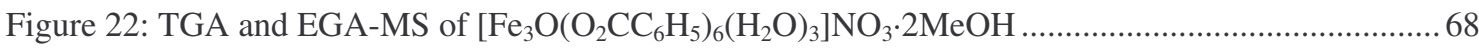

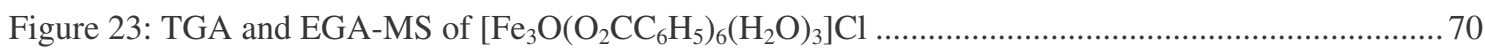

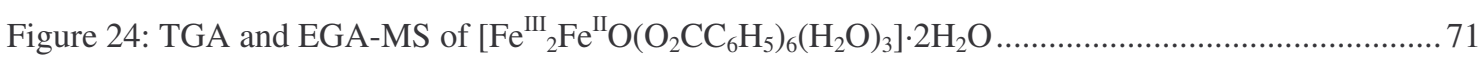

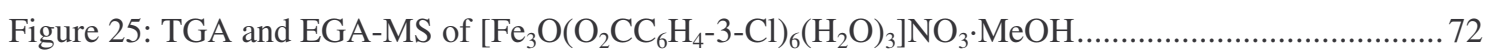

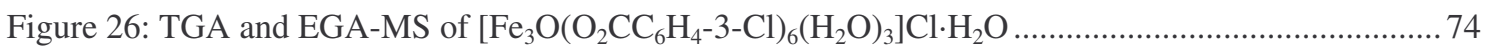

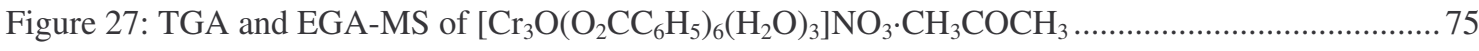

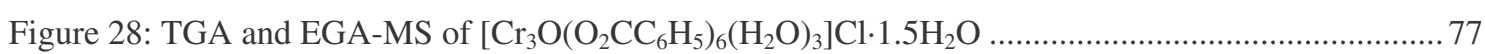


Figure 29: TGA and EGA-MS of $\left[\mathrm{Cr}_{3} \mathrm{O}\left(\mathrm{O}_{2} \mathrm{CC}_{6} \mathrm{H}_{5}\right)_{6}\left(\mathrm{H}_{2} \mathrm{O}\right)_{3}\right] \mathrm{SCN}$ 78

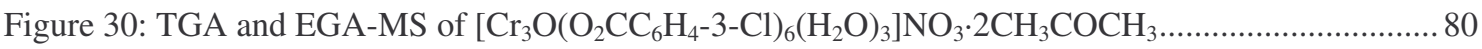

Figure 31: TGA and EGA-MS of $\left[\mathrm{Cr}_{2 \mathrm{n}}\left\{(\mathrm{OH})\left(\mathrm{O}_{2} \mathrm{CPh}\right)_{2}\right\}_{2 \mathrm{n}-1}\right]\left(\mathrm{NO}_{3}\right)_{3-\mathrm{x}} \cdot\left(\mathrm{O}_{2} \mathrm{CPh}\right)_{\mathrm{x}} \cdot \mathrm{yH}_{2} \mathrm{O} \ldots \ldots \ldots \ldots \ldots \ldots \ldots . . . . . . . . . . . . .1$

Figure 32: Formation of organic and metal radicals from the homolytic cleavage of the carboxylate

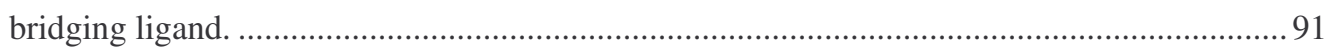

Figure 33: Proposed mechanism for the reductive elimination of a benzoate ligand............................. 92

\section{List of tables}

Table 1: Selected bond lengths $[\AA]$ and angles $\left[^{\circ}\right]$ for $\left[\mathrm{Fe}_{3} \mathrm{O}\left(\mathrm{O}_{2} \mathrm{CC}_{6} \mathrm{H}_{4}-3-\mathrm{Cl}\right)_{6}\left(\mathrm{H}_{2} \mathrm{O}\right)_{3}\right] \mathrm{NO}_{3} \cdot \mathrm{H}_{2} \mathrm{O}$. 44

Table 2: Selected bond lengths $[\AA]$ and angles $\left[{ }^{\circ}\right]$ for $\left[\mathrm{Cr}_{3} \mathrm{O}\left(\mathrm{O}_{2} \mathrm{CC}_{6} \mathrm{H}_{4}-3-\mathrm{Cl}\right)_{6}\left(\mathrm{H}_{2} \mathrm{O}\right)_{3}\right] \mathrm{NO}_{3} \cdot \mathrm{H}_{2} \mathrm{O}$. .47

Table 3: Selected bond lengths $[\AA]$ and angles $\left[{ }^{\circ}\right]$ for $\left[\mathrm{Cr}_{3} \mathrm{O}\left(\mathrm{O}_{2} \mathrm{CC}_{6} \mathrm{H}_{4}-3-\mathrm{Cl}\right)_{6}\left(\mathrm{H}_{2} \mathrm{O}\right)_{3}\right] \mathrm{NO}_{3} \cdot \mathrm{MeOH}$.........50

Table 4: Selected bond lengths $[\AA]$ and angles $\left[{ }^{\circ}\right]$ for $\left[\mathrm{Fe}_{6} \mathrm{O}_{2}(\mathrm{OH})_{2}\left(\mathrm{O}_{2} \mathrm{CC}_{6} \mathrm{H}_{4}-3-\mathrm{Cl}\right)_{12}\left(\mathrm{H}_{2} \mathrm{O}\right)_{2}\right] 3 \mathrm{MeCN}$....5 53

Table 5: Possible ion fragments and corresponding $\mathrm{m} / \mathrm{z}$ values. 64 


\section{Introduction}

Polynuclear transition metal oxo-carboxylate complexes contain more than one metal ion linked by carboxylate ligands, and an oxide and/or a hydroxide ion. This research involved the investigation of two areas of polynuclear complex chemistry - trinuclear complexes (complexes with three metal ions) and higher nuclearity complexes (complexes with more than three metal ions) formed via a so called high temperature synthesis. The purpose of investigating trinuclear complexes is that they were used in this research as a precursor in the formation of the higher nuclearity polynuclear complexes.

\subsection{History}

\subsubsection{Trinuclear complexes}

The most common polynuclear complex is the trinuclear complex which contains three metal ions and a central oxide. The first mention of a trinuclear complex was in 1908 by the German chemist Weinland who published a paper describing the synthesis of chromium(III), iron(III), aluminium(III) and mixed metal chromium(III)/iron(III) acetate complexes $^{[1]}$. In the next year Alfred Werner independently synthesised chromium(III) acetate and formate trinuclear complexes ${ }^{[2]}$. Both chemists were able to establish that the complexes contained three metal ions and six acetate ligands but the exact structure was unknown. Whilst Werner did not publish any more papers on trinuclear complexes, over the next 22 years, Weinland went on to publish many more papers on trinuclear complexes concentrating largely on the acetate and formate complexes of chromium and iron. $\mathrm{He}$ also synthesised complexes with different carboxylates $^{[3]}$ and metal ions ${ }^{[4]}$, mixed metal 
complexes, i.e. complexes that contain more than one type of metal, and mixed valent complexes where the metals are in different oxidation states.

Up until 1960, these trinuclear complexes were formulated as $\left[\mathrm{M}_{3-\mathrm{x}} \mathrm{M}_{\mathrm{x}}(\mathrm{OH})_{2}\left(\mathrm{O}_{2} \mathrm{CR}\right)_{6}\right]^{\mathrm{n}+}$ where $\mathrm{M}$ is a trivalent metal ion and $\mathrm{M}^{\prime}$ is a divalent metal ion or a trivalent ion of the same or a different metal. The hydroxyl group was thought to be associated with the complex due to the alkaline properties shown by the trinuclear complexes.

The arrangement of the atoms in trinuclear complexes were unknown until 1928 when the physicist Welo proposed that the three metal ions of the complex formed a triangle. ${ }^{[5]} \mathrm{He}$ came to this conclusion by studying the magnetic properties of several different iron and chromium trinuclear complexes. This conclusion was received with doubt by many scientists until the structure was determined in 1960 by Orge $^{[6]}$ and then confirmed by Xray crystallography in $1965^{[7]}$. Orgel determined the correct structure by studying the coordination spheres and bond lengths of the atoms. The structure proposed by Orgel differed from the previously structure in that it included an oxide ion rather than two hydroxide ions and three terminal ligands. The structure was now formulated as $\left[\mathrm{M}_{3-\mathrm{x}} \mathrm{M}_{\mathrm{x}}^{\prime} \mathrm{O}\left(\mathrm{O}_{2} \mathrm{CR}\right)_{6} \mathrm{~L}_{3}\right]^{\mathrm{n}+}$ where $\mathrm{M}$ is trivalent and $\mathrm{M}^{\prime}$ is either divalent or a different trivalent metal and $\mathrm{L}$ is a monodentate ligand. When $\mathrm{x}=0$ or $\mathrm{x}=1$ and $\mathrm{M}^{\prime}$ is the same metal as $\mathrm{M}$, the complex is known as a homonuclear complex. When $\mathrm{x}=1$ and $\mathrm{M}$ ' is a different metal from $\mathrm{M}$, the complex is known as a heteronuclear or mixed metal complex. If $\mathrm{M}^{\prime}$ is a divalent ion then the complex is known as a mixed valent complex and the complex is neutral, i.e. $\mathrm{n}=0$. A complex that contains three trivalent metal ions will have a single positive charge, i.e. $\mathrm{n}=1$. 
Trinuclear complexes of this type have been synthesised using a large range of different metals, carboxylate and monodentate ligands ${ }^{1}$. Trivalent metal ions that have been used are $\operatorname{aluminium}^{[8]}$ titanium $^{[9]}$ (not a pure trinuclear complex), $\operatorname{vanadium}^{[10]}$, $\operatorname{chromium}^{[3,}{ }^{7,}{ }^{11]}$, manganese $\mathrm{e}^{[12,13]} \operatorname{iron}^{[4,14,15]}$, cobalt ${ }^{[16]}$, ruthenium ${ }^{[17-19]}, \operatorname{rhodium}^{[20,21]}$ and iridium $^{[18,22]}$. Divalent metals that have been incorporated include magnesium ${ }^{[23]}$, chromium ${ }^{[24,25]}$, manganese ${ }^{[26-28]}, \operatorname{iron}^{[29,30]}$, cobalt $^{[31,32]}$, nickel ${ }^{[33,34]}$, zinc ${ }^{[23]}$ and copper ${ }^{[35]}$. These complexes

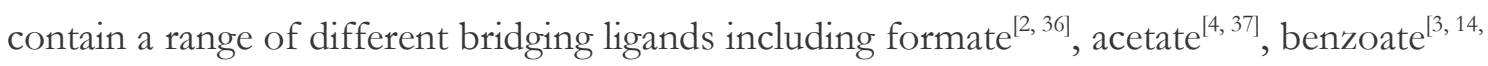
${ }^{38]}$, the halogenated derivatives of these ligands ${ }^{[23]}$, long chain fatty acids ${ }^{[39,40]}$ and amino $\operatorname{acids}^{[41,42]}$. Common terminal ligands that are used are water, pyridine and pyridine derivatives, and alcohols such as methanol and ethanol. Homonuclear, mixed valent complexes are commonly $\left.\operatorname{iron}^{[30,} 43\right]$ or manganese $\left.{ }^{[38,} 44\right]$ however chromium ${ }^{[24]}$ and vanadium $^{[45]}$ complexes have also been synthesised. Finally, there have been two reported cases of a homonuclear complex with all three metals in the +2 oxidation state, an iron ${ }^{[46]}$ and manganese complex ${ }^{[4]}$.

\subsubsection{Higher nuclearity complexes}

In order for complexes of higher nuclearity to be formed, the conditions used in the synthesis of the trinuclear complexes were changed such as increased reaction temperatures and/or longer reaction times. Although Weinland published several papers reporting complexes that contained more than three metal ions, it was later proved that these complexes were in fact trinuclear complexes. The reported $\mathrm{Fe}_{6} \mathrm{Ni}_{3}$ and $\mathrm{Fe}_{9} \mathrm{Ni}_{4}$ acetate complexes ${ }^{[48]}$ were in fact the corresponding heteronuclear trinuclear complexes i.e. $\mathrm{Fe}_{2} \mathrm{Ni}$ acetate complex. He may have synthesised polynuclear complexes but without X-ray crystallography, he was not able to confirm their structures.

\footnotetext{
${ }^{1}$ The following examples are intended as illustrations only and are by no means a complete list of the reported complexes in the literature
} 
The first crystal structure of a higher nuclearity complex of this type was not obtained until 1980 when a $\mathrm{Mn}_{12}$ acetate complex, $\left[\mathrm{Mn}_{12}(\mathrm{OAc})_{16}\left(\mathrm{H}_{2} \mathrm{O}\right)_{4} \mathrm{O}_{12}\right] \cdot 2 \mathrm{HOAc} \cdot 4 \mathrm{H}_{2} \mathrm{O}$, was synthesised and characterised ${ }^{[49]}$. Additional manganese complexes that have been obtained and characterised by X-ray crystallography are a $\mathrm{Mn}_{4}$ acetate, ${ }^{[50]} \mathrm{Mn}_{9}$ benzoate ${ }^{[51]}$ and $\mathrm{Mn}_{10}$ benzoate complex ${ }^{[52]}$. Other examples of iron complexes that have been obtained and characterized by $\mathrm{X}$-ray crystallography are the $\mathrm{Fe}_{6}$ benzoate ${ }^{[53]}$ and $\mathrm{Fe}_{11}$ benzoate complexes $^{[54]}$.

Until 1989, the only polynuclear chromium complexes that had been synthesised were either di- or trinuclear complexes. The solvothermal synthetic method used for the synthesis of higher nuclearity iron complexes could not be used to synthesise the higher nuclearity chromium complexes due to the inertness of the $\mathrm{Cr}$ (III) ion. In 1989, a Russian group led by Gerbeleu were able to synthesize a $\mathrm{Cr}_{12}$ trimethylacetate (pivalate) complex, $\left[\mathrm{Cr}_{12} \mathrm{O}_{9}(\mathrm{OH})_{3}\left(\mathrm{O}_{2} \mathrm{CC}\left(\mathrm{CH}_{3}\right)_{3}\right)_{15}\right]$, by heating a solid chromium pivalate complex, $\left[\mathrm{Cr}(\mathrm{OH})\left(\mathrm{O}_{2} \mathrm{CC}\left(\mathrm{CH}_{3}\right)_{3}\right)_{2}\right]_{\mathrm{n}}$, at a temperature of $300-330^{\circ} \mathrm{C}$ under nitrogen in an oil bath ${ }^{[55]}$. In 1991 the same group heated the solid precursor at $400^{\circ} \mathrm{C}$ under nitrogen in a tube furnace ${ }^{[56]}$. After cooling to room temperature, the product was collected from the furnace tube walls. This has since been known as the high temperature synthesis method. The complex was initially reported as $\left[\mathrm{Cr}_{12} \mathrm{O}_{12}\left(\mathrm{O}_{2} \mathrm{CC}\left(\mathrm{CH}_{3}\right)_{3}\right)_{15}\right]$ but subsequent research ${ }^{[57,58]}$ has shown that the correct formula is the one above where all the chromium is trivalent and there are three hydroxide bridges present. In 1999, Winpenny et al., using the high temperature synthesis, were able to synthesize $\mathrm{Cr}_{8}$ complexes by heating a solid chromium precursor, $\left[\mathrm{Cr}(\mathrm{OH})\left(\mathrm{O}_{2} \mathrm{CPh}\right)_{2}\right]_{\mathrm{n}}$, to a temperature of $200^{\circ} \mathrm{C}$ and $400^{\circ} \mathrm{C}^{[59]}$. At the two different temperatures, different $\mathrm{Cr}_{8}$ complexes, $\left[\mathrm{Cr}_{8}(\mathrm{OH})_{8}\left(\mathrm{O}_{2} \mathrm{CPh}\right)_{16}\right]$ and $\left[\mathrm{Cr}_{8} \mathrm{O}_{4}\left(\mathrm{O}_{2} \mathrm{CPh}\right)_{16}\right]$, were formed with a wheel and cubane structure respectively (see Section 1.2.2). 
In 1991 the first vanadium oxo-carboxylate higher nuclearity complex, $\left[\mathrm{K}\left\{\mathrm{V}_{4} \mathrm{O}_{4}(\mathrm{~m}-\mathrm{O})_{4}(\mathrm{~m}\right.\right.$ $\mathrm{O}_{2} \mathrm{CCH}_{2}$-tert- $\left.\left.\left.\mathrm{Bu}\right)_{4}\right\}\right]\left[\mathrm{O}_{2} \mathrm{CCH}_{2}\right.$-tert-Bu] 2 -tert- $\mathrm{BuCH}_{2} \mathrm{CO}_{2} \mathrm{H}$ was synthesised and a crystal structure obtained ${ }^{[00]}$. Octanuclear and decanuclear complexes have since been obtained when two complexes, $\left[\mathrm{V}_{8}(\mathrm{OEt})_{8}(\mathrm{OH})_{4}\left(\mathrm{O}_{2} \mathrm{CPh}\right)_{12}\right]$ and $\left[\mathrm{V}_{10}(\mathrm{OMe})_{20}\left(\mathrm{O}_{2} \mathrm{CMe}\right)_{10}\right]$, were synthesised using the solvothermal technique ${ }^{[61]}$.

In 1993 it was discovered that the $\mathrm{Mn}_{12}$ acetate complex had interesting magnetic properties at low temperatures. ${ }^{[62]}$ The complex was found to act as a single magnet and was the first example of the so called single-molecule magnet, SMM (to be discussed in Section 1.3.2). The discovery of these so called single-molecule magnets led to widespread interest in high nuclearity polynuclear complexes, particularly manganese complexes.

Currently, fourteen high nuclearity polynuclear complexes synthesised using a high temperature synthesis have been reported in the literature. Metals that have been used are vanadium $^{[63]}$, manganese ${ }^{[64]}$, chromium ${ }^{[56,59,64-66]}$ and iron $^{[67]}$ and the metal cores produced are either $\mathrm{M}_{4}, \mathrm{M}_{6}, \mathrm{M}_{8}, \mathrm{M}_{11}$ or $\mathrm{M}_{12}$. Carboxylate bridging ligands that have been used are 2,2-dimethylpropanoate (pivalate), 2-methylpropanoate (isobutyrate), 3,3-dimethylbutanoate, 4-chlorobenzoate, acetate, benzoate and propanoate ligands. The majority of complexes reported in literature are chromium complexes with benzoate as the most common bridging ligand used. There are also four additional vanadium complexes that have been synthesised ${ }^{[63]}$ but these were formed by heating the crude material from the high temperature synthesis in four different alcohols. It is therefore likely that the heating process has formed a common precursor rather than the different final products that were isolated. 


\subsection{Structure}

\subsubsection{Trinuclear complexes}

For trinuclear complexes with the formula $\left[\mathrm{M}_{3-\mathrm{x}} \mathrm{M}_{\mathrm{x}}{ }_{\mathrm{O}} \mathrm{O}\left(\mathrm{O}_{2} \mathrm{CR}\right)_{6} \mathrm{~L}_{3}\right]^{0,+}$, the three metal ions are bonded to a central oxide ion in a triangular arrangement. Depending on the nature of the metal ions and magnetic interactions present, the metal triangle can either have a scalene or isosceles shape. The metal triangle is unlikely to form an equilateral triangle due to magnetic interactions distorting the shape. Crystal structures of homo- or heteronuclear homovalent complexes commonly appear to have either an equilateral or pseudoequilateral triangle. However, this is probably an averaging of the magnetic interactions which may interchange during the thermal motion of the complex (see Section 1.3.1). The metal centres are bridged by the carboxylate ligands with each pair of metal ions being bridged by two carboxylate ligands. Finally, there is a terminal ligand, L, bound to each of the metal ions. Each of the metal ions are therefore six coordinate and have a distorted octahedral shape. The central oxygen is three coordinate and has a slightly distorted trigonal planer shape. A general structure of trinuclear complexes is shown below (Figure 1):

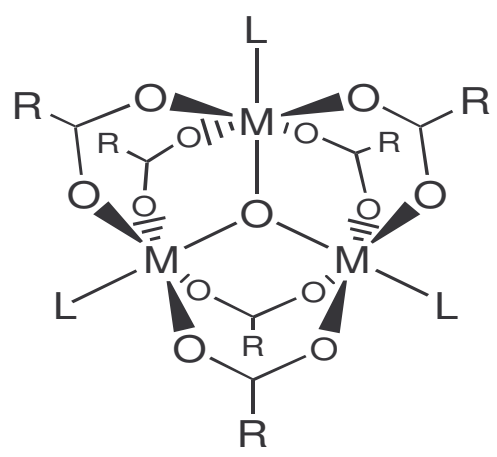

Figure 1: General structure for trinuclear complexes. 


\subsubsection{Higher nuclearity complexes}

There are many different structures of higher nuclearity polynuclear complexes, several of which have been formed by the high temperature synthesis method. When the metal and oxide ions form a cube, the complex is known as having a cube or cubane structure (Figure 2a). When the metal ions and ligands form in a ring, the complex is known as having a wheel structure (Figure 2b). When the metal oxide core forms a metal cluster with no defined shape, then the complex is known as having a cage structure (Figure 3). Cage structures are the most common and consist of the metal ions forming a cluster with either a symmetric or asymmetric shape. There is also another type of structure that has not been given a name. Some $\mathrm{M}_{6}$ complexes have a structure that consists of two trinuclear complexes joined together by hydroxide bridges. This structure is neither a wheel, cube nor cage so when described in this thesis, complexes of this sort shall be known as having a 'wing' or 'winged' structure.
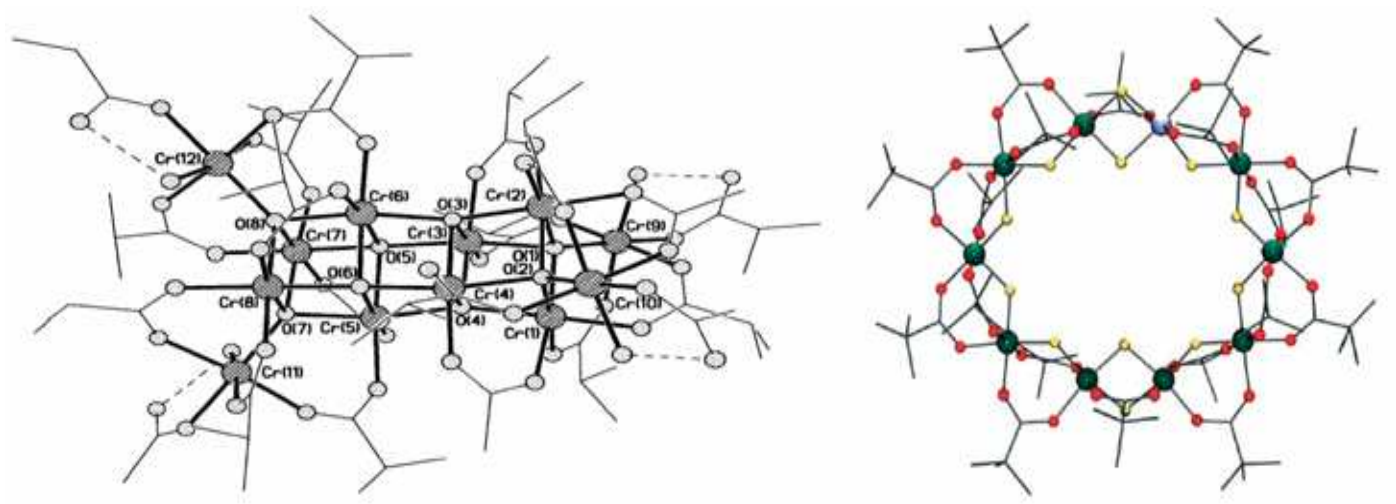

Figure 2: Examples of (a) a cube structure, $\left[\mathrm{Cr}_{12} \mathrm{O}_{8}(\mathrm{OH})_{4}\left(\mathrm{O}_{2} \mathrm{CCHMe}_{2}\right)_{16}\left(\mathrm{HOCCHMe}_{2}\right)_{4}\right]^{[66]}$ and (b) a wheel structure, $\left[\mathrm{Cr}_{9} \mathrm{NiF}_{12}\left(\mathrm{O}_{2} \mathrm{CCMe}_{3}\right)_{18}\right]^{[688}$. 


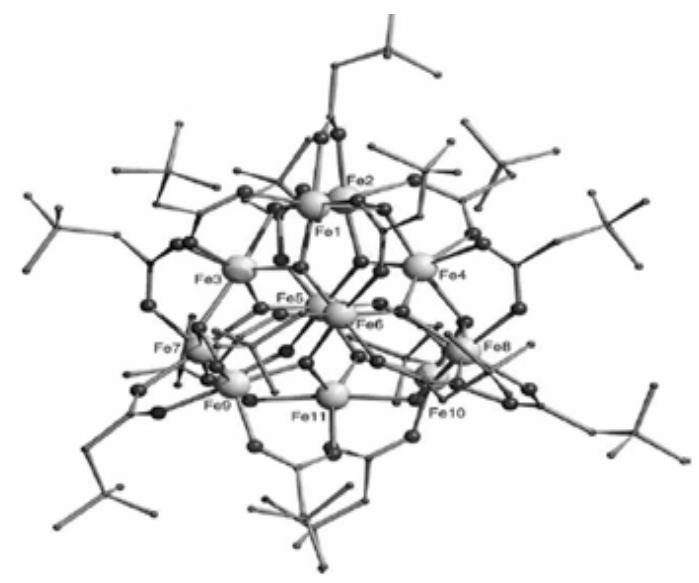

Figure 3: Example of a cage structure, $\left[\mathrm{Fe}_{11} \mathrm{O}_{6}(\mathrm{OH})_{6}\left(\mathrm{O}_{2} \mathrm{CCH}_{2} \mathrm{C}\left(\mathrm{CH}_{3}\right)_{3}\right)_{15}\right]^{[67]}$

\subsubsection{Miscellaneous chromium structures}

Other types of chromium polynuclear complexes that are relevant to this research are dinuclear complexes ${ }^{[69]}$ and olation polymers ${ }^{[70]}$. Dinuclear complexes contain two metal ions bridged by either one or two carboxylate bridges and by two or one hydroxide or oxide bridges so that there are three bridges in total (Figure 4). The most common arrangement is to have two carboxylate bridges and a single hydroxide/oxide bridge. In order to be six coordinate, the metal has either water or a carboxylate ligand coordinated at the other three octahedral sites. The presence of a terminally coordinated carboxylate ligand depends on the amount of carboxylate present during the synthesis. The charge on the dinuclear complex is either +3 (hydroxide) or +2 (oxide) and may be balanced by either an anion or the carboxylate or a mixture of the two.
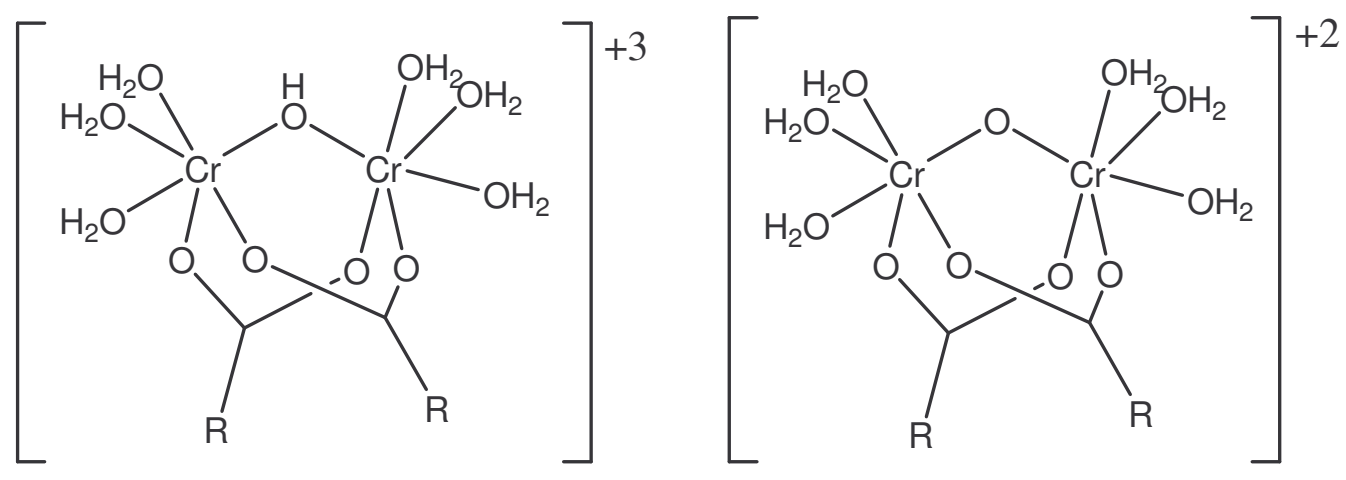

Figure 4: Structure of a dinuclear chromium complex with a hydroxide or oxide bridge. 
The chromium olation polymer can be thought of as an extension of the dinuclear complex. The polymer has more than two metal ions linked in a chain via two carboxylate bridges and a hydroxide bridge (Figure 5). Because the chain is extended by adding a $\mathrm{Cr}(\mathrm{OH})\left(\mathrm{O}_{2} \mathrm{CR}\right)_{2}$ unit, which has a neutral charge, the charge on the polymer will always remain as +3 and so will have three anions.

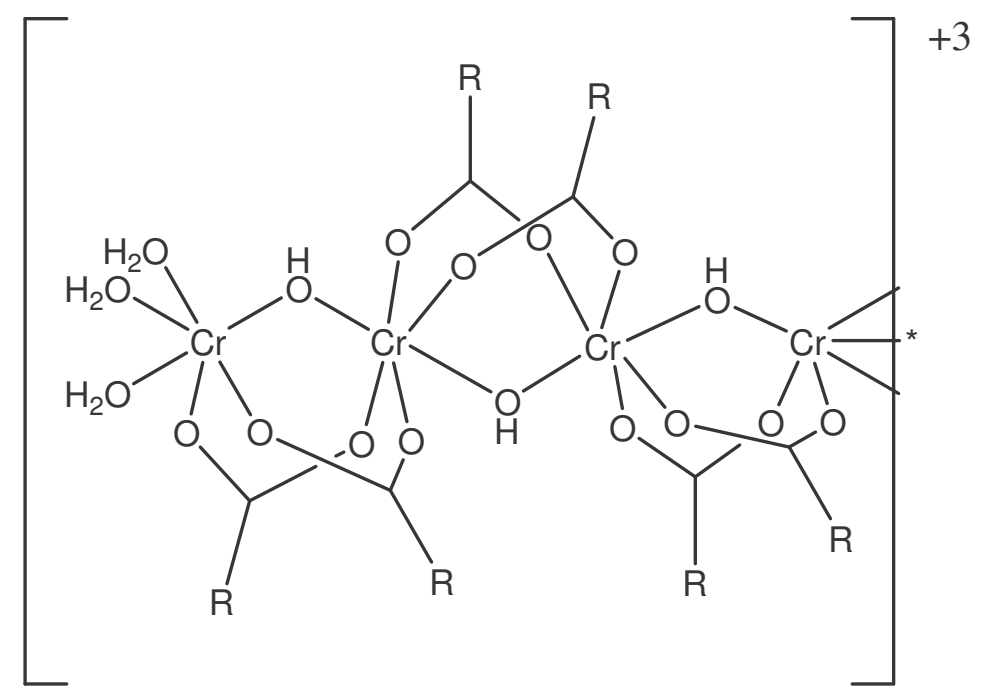

Figure 5: Structure of a chromium olation polymer.

\subsection{Magnetic Properties}

\subsubsection{Magnetic interactions}

Two metal centres can interact with each other in three different ways giving rise to different magnetic properties:

- Non-interacting metal centres have magnetic properties that are the same as seen in the mononuclear complex of the same metal.

- Strongly interacting metals result in a metal-metal bond and have an overall diamagnetic magnetic property. 
- Weakly interacting metals give rise to a wide range of differing magnetic properties. Oxo-carboxylate polynuclear complexes contain metal centres that weakly interact with each other.

The magnetic properties of polynuclear complexes are due to the spin of the unpaired electrons on the metal centres. The electron spins on two metal centres in an oxocarboxylate complex can have two interactions - a ferromagnetic interaction where both the spins are parallel or an antiferromagnetic interaction where the electron spins are opposite to each other. The different interactions between the spins can be determined by the bond angle between the two metal centres and the bridging oxygen. Studies of hydroxide bridged copper dimers ${ }^{[71]}$ have shown that when the metal centres are close together, i.e. a small $\mathrm{CuOCu}$ angle $\left(<\sim 97^{\circ}\right)$, the spins will have a ferromagnetic interaction and when the metal centres are further away, i.e. a large $\mathrm{CuOCu}$ angle $\left(>\sim 97^{\circ}\right)$, the interaction is antiferromagnetic. The angle at which the interaction swaps between ferromagnetic and antiferromagnetic depends on several factors such as metal type and other bridging ligands present. For example, a carboxylate bridge lowers the strength of an antiferromagnetic interaction. This observation of angle dependence can be explained by looking at the simplified electron arrangement in the molecule orbital (Figure 6). 


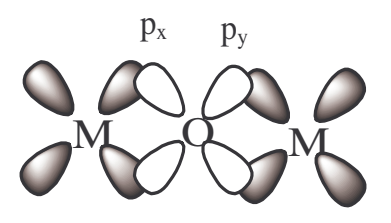

$\mathrm{d}^{2}-\mathrm{y}^{2}$

$d_{x^{2}-y^{2}}$
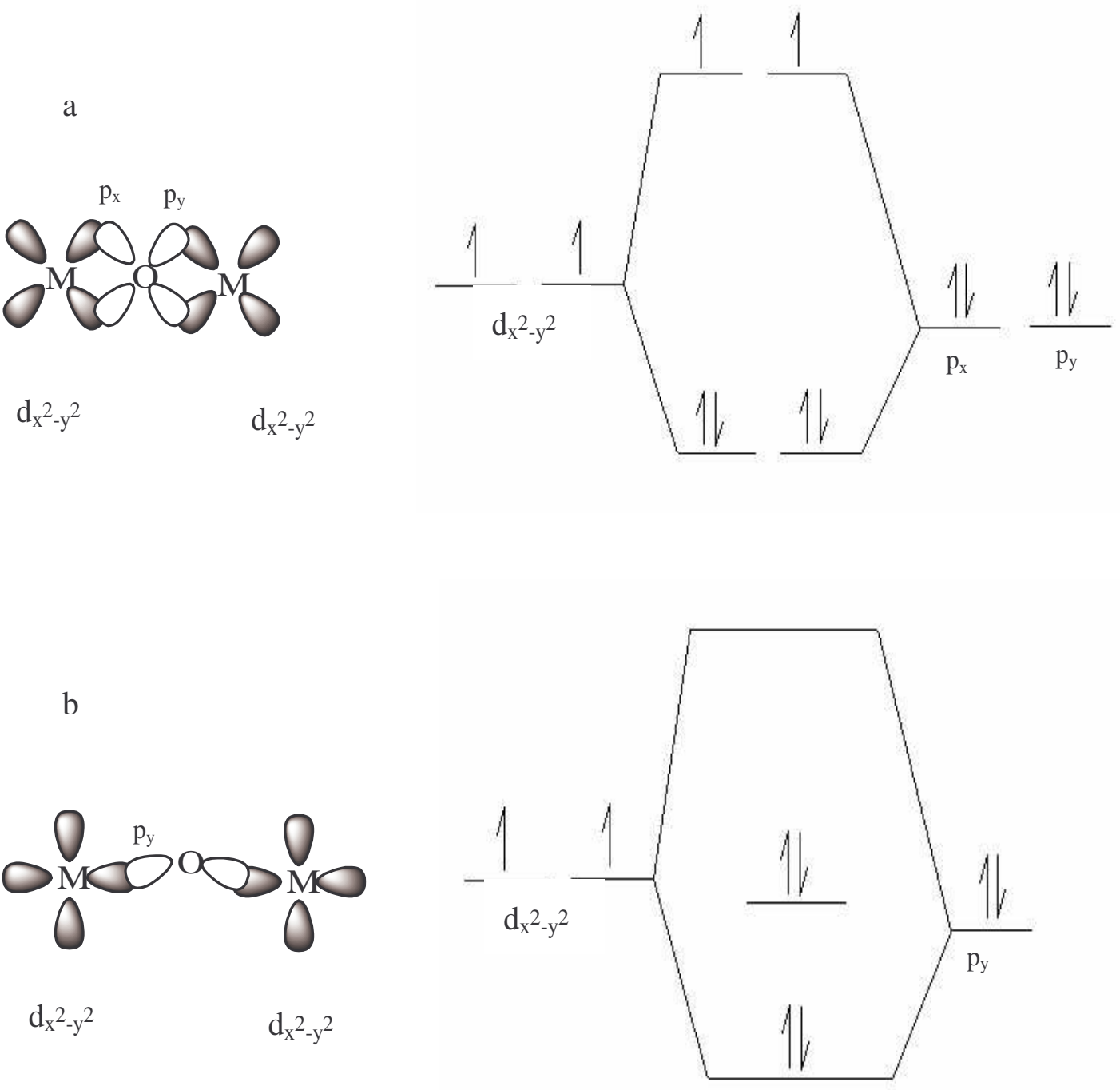

Figure 6: The molecular orbital arising from (a) a small MOM angle giving a ferromagnetic interaction and (b) a large MOM angle giving an antiferromagnetic interaction

In a small $\mathrm{MOM}$ angle of around $90^{\circ}$, the $\mathrm{d}_{\mathrm{x}^{2}-\mathrm{y}^{2}}$ orbitals of the metal centres are more likely to interact with the $\mathrm{p}_{\mathrm{x}}$ and $\mathrm{p}_{\mathrm{y}}$ orbitals of the bridging oxygen (Figure 6a). This results in doubly degenerate bonding and an anti-bonding orbital. When the two electrons from the two metals and the four electrons from the two oxygen orbitals fill the molecular orbital, two electrons fill the anti-bonding orbital with a parallel spin i.e. a ferromagnetic interaction. In a large MOM angle, the $\mathrm{d}_{x^{2}-y^{2}}$ orbitals of the metal centres are more likely to interact with either the $\mathrm{p}_{\mathrm{x}}$ or $\mathrm{p}_{\mathrm{y}}$ orbital of the bridging oxygen (Figure $6 \mathrm{~b}$ ). This results in 
bonding, non-bonding and anti-bonding orbitals. When the two electrons from the two metals and the two electrons from the oxygen orbital fill the molecular orbital, two electrons fill the non-bonding orbital with an anti-parallel spin i.e. an antiferromagnetic interaction $^{[72]}$.

For trinuclear complexes, where the metal centres have antiferromagnetic interactions, it can be seen that not all the metals can have opposite electron spins and that one pair of metal centres will have parallel spins. The two antiferromagnetic and one ferromagnetic interactions cause a distortion to the structure of the trinuclear complex. This is due to the MOM angle of the ferromagnetic interacting metals decreasing and the angle of the antiferromagnetic interacting metals increasing. The reported cases of trinuclear complexes with metal centres in an equilateral triangle are probably due to an averaging of the magnetic interactions from the thermal motion of the complex. Higher nuclearity complexes have a larger number of interacting metal centres so trying to predict the spin ground state is much more difficult than for trinuclear complexes.

The different interactions between the metal centres in the polynuclear complexes can lead to a property that is known as spin frustration. Because the spin on the metal is either up or down, there are a number of combinations of different interactions that a complex can have. Each separate arrangement of spins and interactions for the polynuclear complex has a different energy level. When two of these energy levels are degenerate at the ground state then the complex will contain one metal centre or more that is either spin up or down. When this occurs, the metal centre(s) and the complex are known to be spin frustrated. For example, in a metal triangle $\mathrm{ABC}$ (Figure 7) where $J_{\mathrm{AB}}$ is a strong antiferromagnetic interaction, the spin of $\mathrm{C}$ will depend on the strength of the $J_{\mathrm{AC}}$ and $J_{\mathrm{BC}}$ interactions. If the 
energy of the molecule with $J_{\mathrm{AC}}>J_{\mathrm{BC}}$ is the same as the energy for $J_{\mathrm{BC}}>J_{\mathrm{AC}}$ then the spin on $\mathrm{C}$ may either be up or down and will therefore be classed as spin frustrated ${ }^{[73]}$.

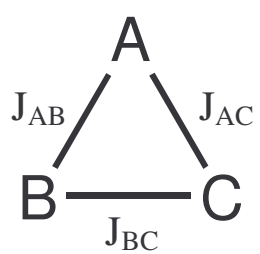

Figure 7: Magnetic interactions of a metal triangle

\subsubsection{Single-molecule magnets (SMMs)}

The use of magnets and magnetism has changed the world and provided benefits to man ever since their discovery. Magnets can now be found in a large number of everyday things from a speaker system to credit cards. In 1993, the previously synthesised $\mathrm{Mn}_{12}$ acetate, $\left[\mathrm{Mn}_{12} \mathrm{O}_{12}\left(\mathrm{OCCH}_{3}\right)_{16}\left(\mathrm{H}_{2} \mathrm{O}\right)_{4}\right],{ }^{[49]}$ and a newly prepared $\mathrm{Mn}_{12}$ benzoate, $\left[\mathrm{Mn}_{12} \mathrm{O}_{12}\left(\mathrm{OCC}_{6} \mathrm{H}_{5}\right)_{16}\left(\mathrm{H}_{2} \mathrm{O}\right)_{4}\right]$ (Figure 8), complex were found to have interesting magnetic properties at very low temperatures $(\sim 3 \mathrm{~K})^{[62]}$. When these complexes are placed in a magnetic field the magnetic spins of the complex align in one direction. When the magnetic field is removed, the magnetism of the complex will slowly return to the magnetic ground state (this may take up to two months for the $\mathrm{Mn}_{12}$ acetate complex at $\sim 2 \mathrm{~K}^{[74]}$ ). This is an example of superparamagnetism as each $\mathrm{Mn}_{12}$ molecule is acting as a single magnetic domain when placed in the magnetic field. $\mathrm{Mn}_{12}$ molecules act like a single magnet and this has led to these molecules being termed as single-molecule magnets (SMMs). 


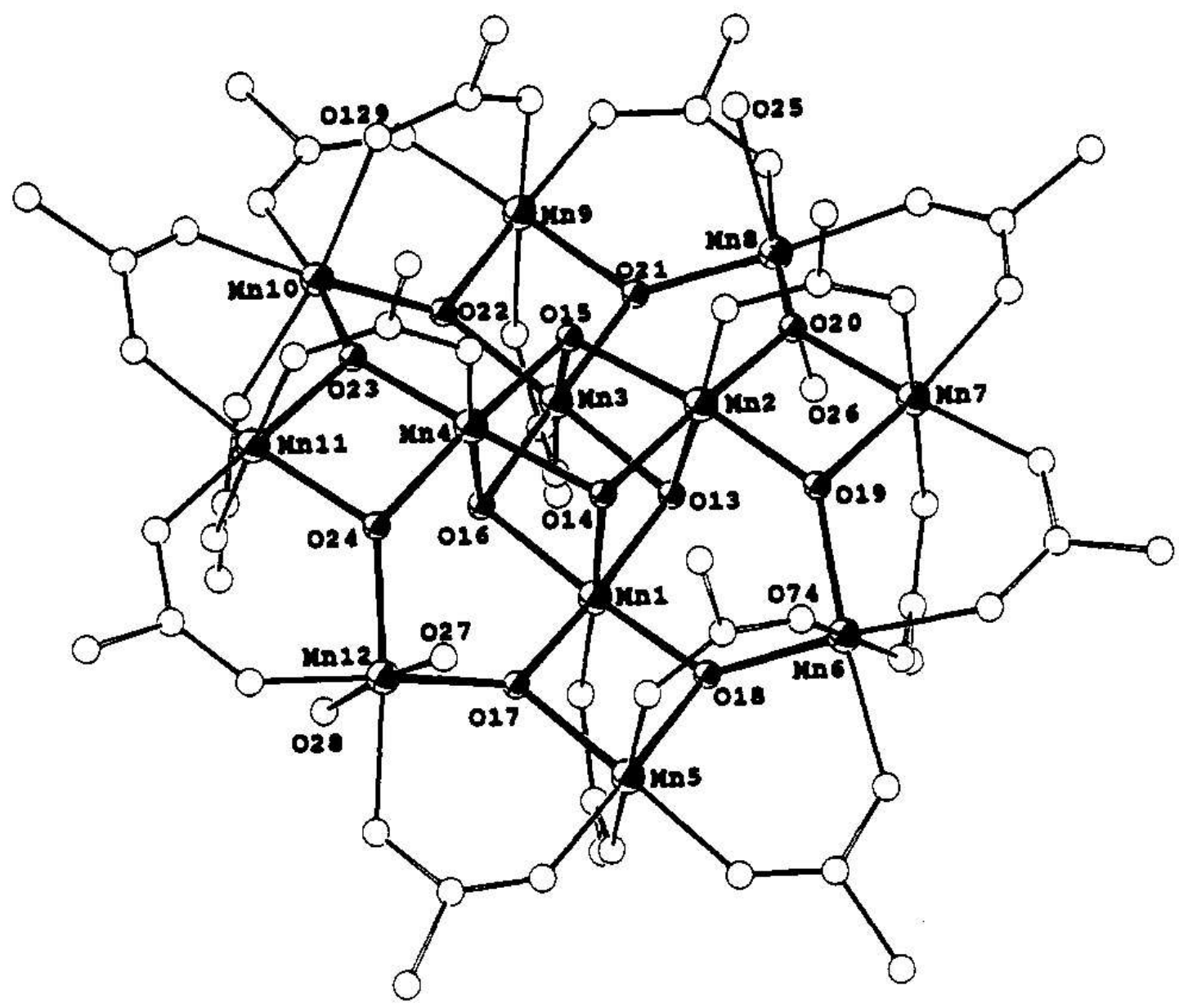

Figure 8: Structure of the $\mathrm{Mn}_{12} \mathrm{SMM}$ core ( $\mathrm{Mn}_{12}$ benzoate).

Complexes with other metals (vanadium ${ }^{[75]}$, $\operatorname{rron}^{[76,77]}$, cobalt $\mathrm{t}^{[78]}$ and nickel ${ }^{[79]}$ ) have also been synthesised that are SMMs. Currently, none of the complexes synthesised have SMM properties above a temperature of $3 \mathrm{~K}$. The original $\mathrm{Mn}_{12}$ exists as a $\mathrm{SMM}$ at a temperature of $2.8 \mathrm{~K}$ which is higher than for any other molecule. The advantage of a SMM that exists at closer to room temperature is that it would be able to replace currently used magnets with nanoscale magnets. The smaller size means that SMMs could be used in molecular electronics providing an advantage over larger scale circuits leading to a decrease in the size of everyday items.

Complexes with higher nuclearity potentially have more unpaired electrons which may give rise to a high spin ground state. The slow relaxation seen in some of these complexes arise 
when the complex is placed in a magnetic field. The spins of the unpaired electrons on the metal centres align themselves with the direction of the magnetic field. When the applied magnetic field is removed or reversed, there is an energy barrier for the spins to move back to their original state. This energy barrier causes the slow relaxation rate of the complex's magnetization. To observe the slow relaxation of the complex, the magnetization of the complex vs. the applied magnetic field is plotted giving a hysteresis curve as the magnetization of the complex lags behind the applied field. The observation of a hysteresis curve does not mean that the polynuclear complex is a SMM. For a polynuclear complex to be referred as a SMM, it must also have a large-spin ground state with appreciable magnetic anisotropy and a negative zero-field splitting parameter. These requirements give rise to the large energy barrier to relaxation back to the ground state when the magnetic field is removed.

\subsection{Applications}

Polynuclear complexes can be used in several different applications and are of interest to several scientific disciplines.

\subsubsection{Biology}

The main use of higher nuclearity polynuclear complexes in biology is as a model for natural metal clusters in the study of biological systems ${ }^{[80,81]}$. A large number of proteins in nature contain metal clusters and so polynuclear complexes can be used as models to determine how the clusters are formed or as a model for processes such as the electron transfer in a protein. Ferritin is an extreme example of a protein containing a metal cluster - the core of the protein can hold up to 4500 iron centres. High nuclearity iron complexes have been studied in order to determine a mechanism for the formation of the ferritin metal core ${ }^{[53,82,83]}$. 
Chromium has been shown to be an essential element to animals and so polynuclear complexes have been suggested as a source of chromium for chromium deficiencies ${ }^{[84]}$. Another area of research is the use of trinuclear chromium complexes in the treatment of Type II diabetes. When $\left[\mathrm{Cr}_{3} \mathrm{O}\left(\mathrm{O}_{2} \mathrm{CCH}_{2} \mathrm{CH}_{3}\right)_{6}\left(\mathrm{H}_{2} \mathrm{O}\right)_{3}\right]^{+}$was fed to rats that had a condition similar to Type II diabetes ${ }^{[85]}$, it was found that the rat had a positive response such as lowering of high density lipoprotein (HDL) and low density lipoprotein (LDL) cholesterol, triglycerides, insulin levels and lower 2-hour plasma insulin levels. When the rats were fed with mononuclear chromium complexes, none of these effects were observed.

\subsubsection{Chemistry}

Another area of research into polynuclear complexes is their use as catalysts in chemical reactions. These include trinuclear $\mathrm{Fe}$ and $\mathrm{Cr}$ complexes and $\mathrm{Fe} / \mathrm{Ni}, \mathrm{Cr} / \mathrm{Ni}$ mixed metal complexes, that have been used as catalysts for three different polymerisation reactions of norbornene (Figure 9) ${ }^{[86]}$; iron and iron/zinc complexes in hydrocarbon-oxidising catalysed Gif type reactions ${ }^{[87]}$ and iron trinuclear complexes used as a catalyst in the formation of single walled nanotubes ${ }^{[88]}$. It has been found that in most cases the polynuclear complex is a more efficient catalyst than mononuclear complexes. However the most widely researched application of the higher nuclearity polynuclear complexes is their ability to become SMMs. 


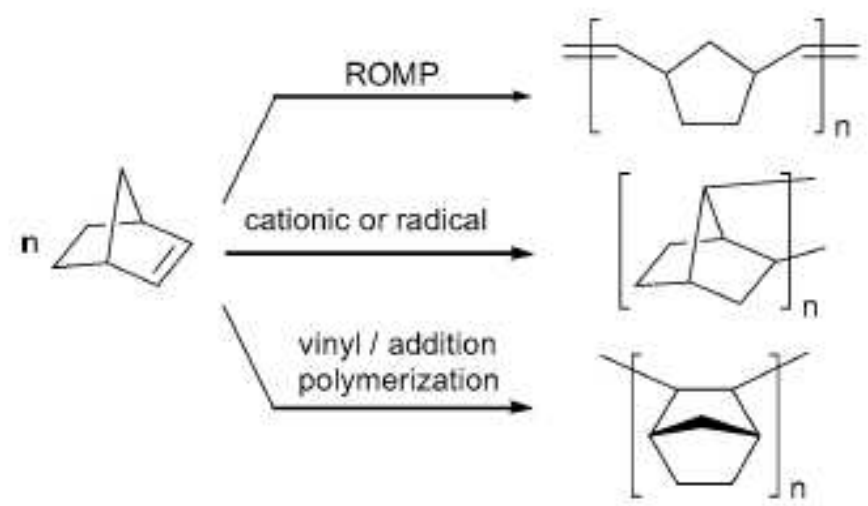

Figure 9: The three polymerisation reactions of norbornene catalysed by a polynuclear complex.

\subsubsection{Physics}

The slow relaxation of magnetism in some of the higher nuclearity polynuclear complexes has been shown to exhibit a quantum tunnelling mechanism ${ }^{[89-92]}$. When the magnetization returns to the ground state it does not do so by going over the energy barrier. For example, a SMM with a spin state of $\mathrm{M}_{\mathrm{S}}=10$ at the ground state is placed in a magnetic field so that the spin state becomes $M_{S}=-10$, does not return to $M_{S}=10$ when the field is removed by going from $\mathrm{M}_{\mathrm{S}}=-10 \rightarrow \mathrm{M}_{\mathrm{S}}=-9 \rightarrow \mathrm{M}_{\mathrm{S}}=-8 \rightarrow \ldots \rightarrow \mathrm{M}_{\mathrm{S}}=0 \rightarrow \ldots \rightarrow \mathrm{M}_{\mathrm{S}}=$ $9 \rightarrow \mathrm{M}_{\mathrm{S}}=10$ (Figure 10a). Instead, it has been observed that the spin state can tunnel from one spin state to another so that it does not go through all the levels (Figure 10b-c). This only occurs if the two spin states are equal in energy and may be observed by steps in the hysteresis curve ${ }^{[3]}$. The quantum tunnelling mechanism has meant that physicists have been able to use these complexes in the study of quantum effects ${ }^{[89,94,95]}$. This has led to research in the use of higher nuclearity polynuclear complexes as quantum bits (or qubits) which are used in quantum computing ${ }^{[96-98]}$ and are equivalent to binary units in classical computing. The advantage of quantum computers is that they have the potential to perform the same functions as conventional computers but on a smaller scale. 


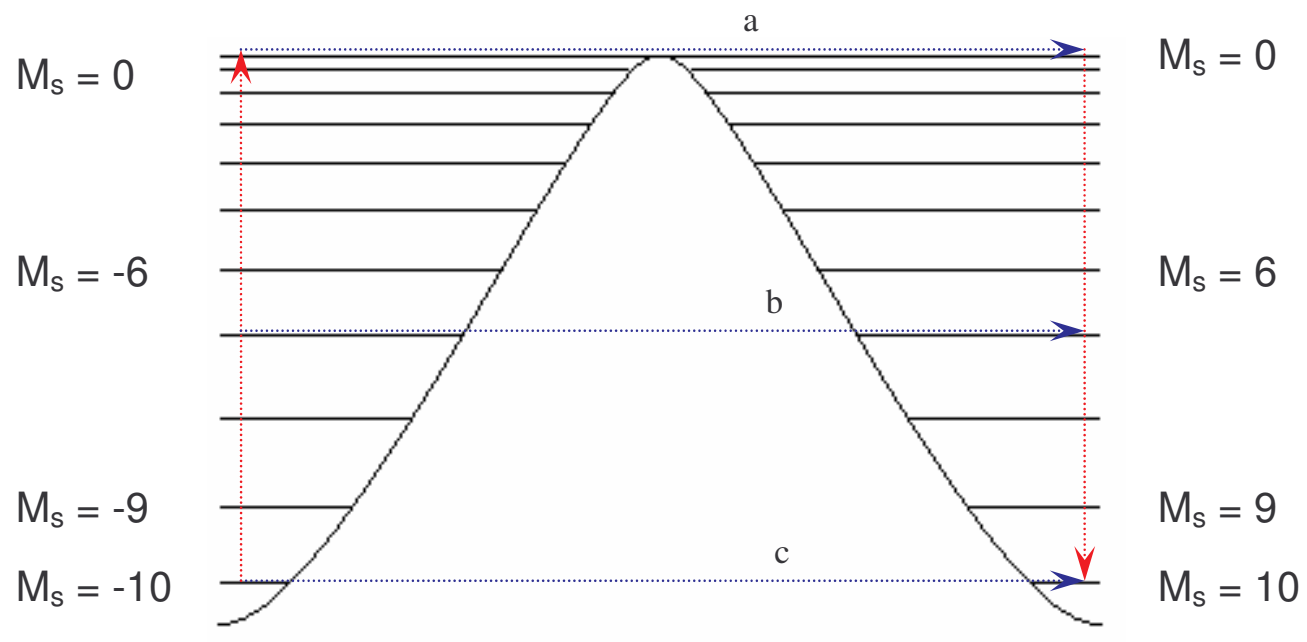

Figure 10: Energy wells of a $S M M$ with a spin state $S=5$ showing a) no quantum tunnelling b) thermally assisted quantum tunnelling and c) pure quantum tunnelling.

Because a SMM relies on the energy barrier to the return of the spin to the ground state, the presence of quantum tunnelling in a SMM is a disadvantage as it lowers this energy barrier.

\subsection{Synthesis}

\subsubsection{Trinuclear complexes}

There are several different methods to synthesize trinuclear complexes all of which are relatively simple and can be performed in a single reaction vessel. Most of the methods used today are based on the methods that were initially developed by Weinland in his research.

The terminal ligand of the complex depends on the solvent in which the reaction was carried out in. The terminal ligand may then be replaced by dissolving the complex in an excess of a different solvent. In order to synthesise a homonuclear complex, a single metal salt of the metal required is used in the reaction and if a heteronuclear complex is to be synthesised, two metal salts of the different metal centres are required. A homonuclear 
mixed valent complex can be prepared by using the divalent metal salt and allowing partial oxidation to occur.

\subsubsection{Carboxylic acid method}

In the carboxylic acid method, a mixture of the metal salts (generally hydrated nitrate or chloride salts), the carboxylic acid and potassium or sodium hydroxide (in a 1:2:2 ratio) is heated to a moderate temperature of around $50^{\circ} \mathrm{C}$ whereupon the trinuclear complex will precipitate out. The reaction is generally performed in water to give the aqua complex although the reaction can also be carried out in an alcohol, pyridine or pyridine derivative solvent. One drawback to this method is that the metal hydroxide can form.

Sometimes the moderate temperatures of the above method are not sufficient to form the trinuclear complex. Therefore, another method used in the synthesis of trinuclear complexes is the reflux method where the metal salt and carboxylic acid are refluxed in acetone, an alcohol or pyridine for several hours. This is particularly useful for chromium complexes where, due to the inertness of $\mathrm{Cr}(\mathrm{III})$, the olation polymer rather than the trinuclear complex forms at moderate temperatures. There have been no reported examples of the reflux method being used in the synthesis of mixed metal complexes.

\subsubsection{Carboxylate method}

In his first paper on trinuclear complexes in $1908^{[1]}$, Weinland used a synthesis that is now known as the carboxylate method. In this method, the complex is synthesised by heating a mixture of the metal salt(s) and the sodium or potassium carboxylate salt to moderate temperatures. The advantage of this method is the prevention of the formation of the 
metal hydroxide due to the trinuclear complex being synthesized in the absence of a hydroxide ion.

The drawback to the carboxylate and carboxylic acid methods is that they can lead to the precipitation of large amounts of the sodium or potassium carboxylate salt. In order to prevent this from occurring, the anhydride method can be used.

\subsubsection{Anhydride method}

The anhydride method was first developed by Weinland in $1913^{[99]}$. This method involves the slow addition of the metal salt(s) to an acid anhydride to give the corresponding carboxylate complex. An advantage of this method is that because there are only two reactants used in the reaction, there is only a small chance of any undesirable side products being formed such as the metal hydroxide or alkali metal carboxylate salt.

\subsubsection{Higher nuclearity complexes}

The mechanism in the formation of higher nuclearity polynuclear complexes can be thought of as the removal of terminal ligands and bridging ligands followed by the formation of bonds between two or more precursor complexes. This can be done by several different ways:

\subsubsection{High temperature synthesis}

In this method, the ligands are removed by heating a metal carboxylate precursor to temperatures of between $200-500^{\circ} \mathrm{C}$ for 5-60 minutes under nitrogen in a tube furnace. Generally the metal carboxylate precursor is a trinuclear complex but for chromium compounds, the chromium olation product, $\left[\mathrm{Cr}_{2}(\mathrm{OH})\left(\mathrm{O}_{2} \mathrm{CR}\right)_{2}\right]_{\mathrm{n}}$, has also been used as a 
precursor. The advantage of using a polynuclear complex as a precursor is that the metal oxygen core is already present and so the higher nuclearity complex is formed by several precursor metal cores combining together.

\subsubsection{Solvothermal}

In this method, a solvent is used to replace bridging ligands at high temperatures but which is itself replaced on cooling by the bridging ligands to form a complex of higher nuclearity. A metal salt, such as the nitrate or perchlorate salt, and a carboxylic acid or its carboxylate salt are dissolved in a solvent and either heated at higher temperatures or stirred for longer periods of time than is used in the synthesis of trinuclear complexes. Trinuclear complexes can also be used as the starting material in the synthesis.

\subsubsection{Microwave}

The use of a microwave oven as an alternative heating source is becoming increasingly common in chemical synthesis. The use of a microwave oven in the synthesis of a higher nuclearity complex was reported recently when Brechin et al. ${ }^{[100]}$ synthesised a $\mathrm{Fe}_{8}$ salicylaldoxime (2-hydroxybenzaldehyde oxime, saoH ${ }_{2}$ complex, $\left[\mathrm{Fe}_{8} \mathrm{O}_{4}(\mathrm{sao})_{8}(\mathrm{py})_{4}\right] \cdot 4 \mathrm{py}$. The synthesis was carried out by heating iron acetate $\left(\mathrm{Fe}\left(\mathrm{O}_{2} \mathrm{CCH}_{3}\right)_{2}\right), \mathrm{saoH}_{2}$ and pyridine for two minutes inside a microwave oven.

\subsection{Analysis}

In order to determine if the product formed is a polynuclear complex, several different characterisation techniques may be used: 


\subsubsection{Nuclear Magnetic Resonance (NMR)}

Carbon, ${ }^{13} \mathrm{C}$, and proton, ${ }^{1} \mathrm{H}$, nuclear magnetic resonance (NMR) are widely used in organic chemistry to determine structures of organic molecules. This technique is generally not used for polynuclear complexes as the spectrum produced contains broad peaks due to the paramagnetism of the metal centres. However, there have been several papers published where NMR has been successfully used in the studies of trinuclear complexes ${ }^{[29,30,76,101,102]}$. The success in using NMR is due to the antiferromagnetic interactions of the metal centres leading to a decrease in the effective magnetic moment of the metal.

For example, in order to observe the peaks of atoms that are in close proximity to the metal centres and that are usually broadened beyond detection, Vincent $e t$ al used ${ }^{1} \mathrm{H}$ NMR and ${ }^{2} \mathrm{H}$ NMR in combination to study chromium trinuclear complexes ${ }^{[103]}$. Proton peaks that are not observed in the ${ }^{1} \mathrm{H}$ NMR can be observed in the ${ }^{2} \mathrm{H}$ NMR spectrum by looking at the corresponding deuteron peak. The peak in the ${ }^{2} \mathrm{H}$ NMR spectrum can be narrower by a factor of up to 42 than the corresponding peak in the ${ }^{1} \mathrm{H}$ NMR as calculated from the ratio of the gyromagnetic ratios for the proton and deuteron i.e. $\gamma_{\mathrm{H}}{ }^{2} / \gamma_{\mathrm{D}}{ }^{2}=42.5$. Studies of a pyridine based chromium trinuclear complexes have shown a broadening pattern in the pyridine ligands of $\mathrm{H} 4<\mathrm{H} 3<\mathrm{H} 2$ where $\mathrm{H} 2$ is the proton on $\mathrm{C} 2$ (i.e. the carbon bonded to the nitrogen), $\mathrm{H} 3$ is the proton on $\mathrm{C} 3$ and $\mathrm{H} 4$ is the proton on $\mathrm{C} 4$. This broadening pattern and an alternating sense of shift between $\mathrm{H} 3$ and $\mathrm{H} 4$ indicate that there is a strong $\pi$-delocalization pathway.

\subsubsection{Mass spectroscopy}

Mass spectroscopy is a technique that has been used in the study of several different trinuclear complexes ${ }^{[104-107]}$ but there are few papers on the use of mass spectroscopy in the 
study of higher nuclearity polynuclear complexes ${ }^{[58,59]}$. From a mass spectrum, it is possible to determine the number of metal centres and bridging ligands present in the molecule but it can be difficult to determine structural information. If the ligand on the complex contains an element which contains more than one abundant isomer, such as chlorine, the number of ligands present in the complex is able to be calculated. This is done by looking at the pattern of the $[M],[M+2],[M+4]$, etc. peaks which will become more and more complex as the number of the ligands in the molecule increases. This complex pattern will be unique to a certain number of ligands present in the molecule and so the number of ligands present can be determined. However, a disadvantage of mass spectroscopy is that as the complex size increases, and correspondingly the mass of the complex increases, the ratio of metal centres and ligands becomes more difficult to determine.

\subsubsection{Infrared spectroscopy}

Infrared and Raman spectroscopy can be used to determine whether or not the metaloxygen core is present in the structure due to the presence of metal-oxygen stretching frequencies found in the fingerprint region below $800 \mathrm{~cm}^{-1}$. It is particularly useful for trinuclear complexes due to the large number of complexes that have been synthesized and studied. By varying the ligands and metal centres of the complexes and observing the shift of the peaks in the IR spectrum, the different structural features of the complex can be linked to the peaks on the spectrum. These structural features and the corresponding peaks were compiled in a review article by Cannon and White in $1988^{[108]}$. Below $800 \mathrm{~cm}^{-1}$, the peaks are due to $v_{d}\left(\mathrm{MO}_{4}\right), v_{\mathrm{as}}\left(\mathrm{MO}_{3}\right)$, and $\delta_{\text {sym }}\left(\mathrm{MO}_{3}\right)$ in the IR spectrum and $v_{\mathrm{s}}\left(\mathrm{MO}_{4}\right), v_{\mathrm{s}}$ $\left(\mathrm{MO}_{3}\right)$ in the Raman spectrum (Figure 11). Above $800 \mathrm{~cm}^{-1}$, the peaks are due to the stretching frequencies of the bridging and terminal ligands although some peaks due to these ligands are found below $800 \mathrm{~cm}^{-1}$. For heteronuclear and mixed valent complexes, 
the $v_{\text {as }}\left(\mathrm{M}_{3} \mathrm{O}\right)$ peak is split and so therefore can be used as proof for the formation of the heteronuclear complex. Because the higher nuclearity polynuclear complexes have not been as extensively studied and the large range of different structures that can form, the stretching frequencies observed in the IR spectra have not yet been linked to any structural features of the complex.
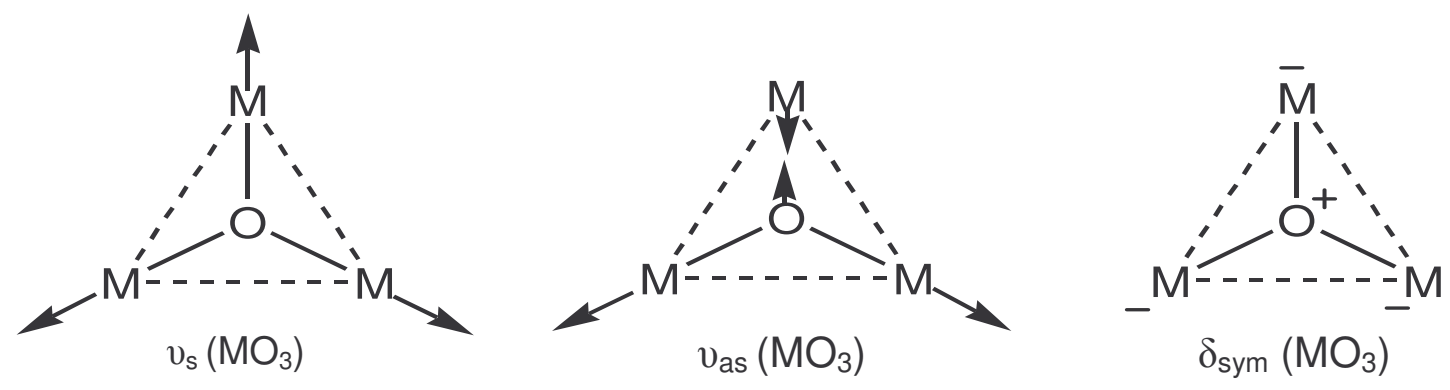

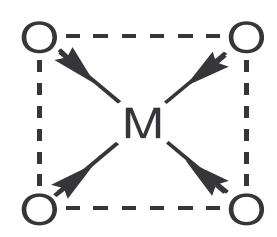

$v_{\mathrm{s}}\left(\mathrm{MO}_{4}\right)$

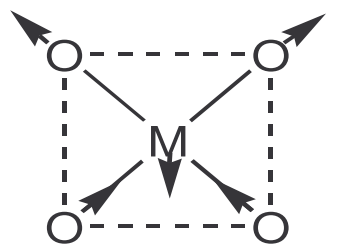

$v_{d}\left(\mathrm{MO}_{4}\right)$

Figure 11: Stretching modes of the metal core observed in IR or Raman spectroscopy.

Another way of determining if a compound is trinuclear or not is to look at the $\mathrm{CO}_{2}$ stretching frequencies of the carboxylate bridge ${ }^{[109]}$. The $\mathrm{CO}_{2}$ of the carboxylate has two vibrations, a symmetric $\left(\mathrm{v}_{\text {sym }}\left(\mathrm{CO}_{2}^{-}\right)\right)$and an asymmetric $\left(\mathrm{v}_{\text {sym }}\left(\mathrm{CO}_{2}^{-}\right)\right)$vibration. By looking at the difference of the two vibrations $\left(\Delta\left(\mathrm{CO}_{2}\right)\right)$, the bridging mode of the carboxylate can be determined. If the carboxylate is bound to the metal through only one of the oxygen atoms, then $\Delta\left(\mathrm{CO}_{2}\right)$ will be larger than the $\Delta\left(\mathrm{CO}_{2}\right)$ observed in the free carboxylate. When the carboxylate is bound to the one metal ion via both the oxygen atoms then the $\Delta\left(\mathrm{CO}_{2}\right)$ will be much smaller than the $\Delta\left(\mathrm{CO}_{2}\right)$ of the free ion. When the carboxylate bridge is 
bound to two metal ions as seen in the polynuclear complexes, then the $\Delta\left(\mathrm{CO}_{2}\right)$ will have a similar value $\left( \pm 40 \mathrm{~cm}^{-1}\right)$ to that for the free ion.

\subsubsection{X-ray crystallography}

X-ray crystallography is by far the best way for determining the structure of a polynuclear complex as it not only shows the number of metal centres present but it also illustrates the structure of the complex. However, a drawback of this method is the need for crystals of the correct size and shape to be grown before any analysis can be done. Also, the crystals isolated may not be the main or only product of the reaction. In addition, metal ions with a similar number of electrons in mixed metal complexes are unable to be distinguished from each other. This means that it is not possible to determine the exact number of each different type of metal ion in the complex by X-ray crystallography.

\subsection{Thermal Analysis}

Previous thermal analysis of trinuclear complexes has studied the decomposition of the complex and the formation of the metal oxide ${ }^{[110,111]}$ rather than the formation of higher nuclearity complexes. For this research, thermoanalytical techniques were used to study what occurs during the high temperature synthesis. Two analytical methods were used:

\subsubsection{Thermogravimetric analysis}

Thermogravimetric analysis (TGA) is used to observe mass changes that occur as a sample is heated. When the precursors to the high temperature synthesis are analysed using TGA, a mass loss is always observed. TGA can be used to determine at what temperatures and what parts of the precursor are removed. 


\subsubsection{Evolved gas analysis}

Evolved gas analysis (EGA) is a technique which determines the nature and/or amount of gaseous product that is evolved during the controlled heating of a sample. The sample is heated in a furnace that is connected to a detector, such as a mass spectrometer (EGAMS), which will detect and determine the nature of the gases that are evolved during the heating process and the temperature at which this occurs. From the data of an EGA-MS, a plot of different mass fragment intensities versus furnace temperature can be obtained. As for the TGA, EGA-MS has only been used in the study of the decomposition of the precursors rather than in the study of the formation of high nuclearity complexes ${ }^{[110-112]}$.

\subsection{Research Aims}

There seems to be very little control over the structure and nuclearity of the isolated product in the synthesis of higher nuclearity complexes. For complexes formed via the high temperature process there is apparently no control whatsoever. This unpredictability of the product formed is a drawback in the use of the high temperature method for the synthesis of polynuclear complexes. Previous papers have referred to heating the precursors to certain temperatures with no mention of any reasoning as to why. The aim of this research was to establish if there was a relationship between the product formed, the precursor and the synthesis temperature. Such a relationship should enable some control over the nature of the complex formed. 


\section{Synthesis and Characterization}

\subsection{Chemicals and Equipment}

Chemicals used in the synthesis of the complexes were obtained from the chemical stores at the School of Chemical and Physical Sciences at Victoria University. These chemicals were sourced from a wide range of different manufacturers. The grade of chemical used was laboratory grade.

In the high temperature synthesis of polynuclear complexes, samples were placed in a quartz crucible and heated inside a quartz furnace tube in the middle of a Shinbo GCS-300 tube furnace. Due to a broken thermostat on the furnace, the temperature of the synthesis was measured by an Extech 421501 Type K thermometer with the thermocouple placed on the outside of the furnace tube directly above the sample. In order to ensure that the sample was at the same temperature as was measured, longer heating times were used than has been previously reported.

All the synthesised complexes were analysed using infrared spectroscopy and selected compounds by elemental analysis. Infrared spectra were measured as $\mathrm{KBr}$ pellets using a Perkin-Elmer Spectrum One FT-IR spectrometer. The elemental analyses of selected complexes were obtained from Otago University.

Although electrospray mass spectroscopy (ESMS) has previously been used to examine polynuclear complexes, use of ESMS in this research proved to be unsuccessful. The mass spectrometer located at the school is set up for the use of analysing organic molecules 
which meant that the conditions were not ideal in order to ionise the polynuclear complexes. Although the conditions were changed to a previously reported setting, no useful results could be obtained. Without the time to optimise these conditions, ESMS was not used as an analytical technique in this research work.

X-ray crystallographic data was obtained for four of the prepared compounds using a Bruker Nonius diffractometer equipped with a graphite monochrometer and a CCD area detector located at Canterbury University. The structure was solved with Shelxs, refined with Shelx-9 $7^{[113]}$ and visualised by Mercury $1.4 \cdot 1^{[114]}$.

Thermogravimetric analysis (TGA) was performed on selected samples using a Shimadzu TGA-50H. Evolved gas analysis was obtained by heating the samples in one of two tube furnaces which was coupled to an Ametek dycor quadrupole mass spectrometer set for positive ionisation. The two furnaces used were heated by either $\mathrm{SiC}$ rods or a $\mathrm{NiCr}$ winding. There were limitations to the use of this EGA-MS setup, which are:

1. The mass spectrometer could only detect ion fragments of $\mathrm{m} / \mathrm{z}=100$ or less.

2. At lower temperatures $\left(<100^{\circ} \mathrm{C}\right)$, the temperature reading was not very accurate.

3. For gaseous products such as acetone and benzene, the evolved gas could condense in the tube linking the furnace and mass spectrometer. This results in a tailing of the signal as the gas goes through a process of condensation and then evaporation along the tube.

4. Water could not be detected by the mass spectrometer as it absorbed onto the silica capillary tube as the gas stream enters the mass spectrometer. Any signal that was seen due to the water is therefore a very broad peak. 
5. Evolved gases that have $\mathrm{m} / \mathrm{z}=14$ and 28 are difficult to detect due to signals from the nitrogen carrier gas. The gas may also contain $\mathrm{O}_{2}$ as an impurity leading to the $\mathrm{m} / \mathrm{z}=32$ signal being difficult to detect.

The raw TGA and EGA-MS data was analysed and manipulated using Microsoft Excel 97.

\subsection{Low Nuclearity Complexes}

The chemical formula of the following compounds were determined by infrared spectroscopy and thermal analysis and is discussed in detail in Chapter 3.

\subsubsection{Iron complexes}

\subsubsection{1 $\left[\mathrm{Fe}_{3} \mathrm{O}\left(\mathrm{O}_{2} \mathrm{CCH}_{3}\right)_{6}(\mathrm{py})_{3}\right] \mathrm{NO}_{3}$}

The above complex was synthesised in the attempted synthesis of an iron/zinc mixed metal complex ${ }^{[23]}$. A solution of $3.79 \mathrm{~g} \mathrm{Fe}\left(\mathrm{NO}_{3}\right)_{3} \cdot 9 \mathrm{H}_{2} \mathrm{O}(9.4 \mathrm{mmol})$ in $10 \mathrm{~cm}^{3}$ ethanol was added to a solution of $11.10 \mathrm{~g} \mathrm{Zn}\left(\mathrm{NO}_{3}\right)_{2} \cdot 6 \mathrm{H}_{2} \mathrm{O}(37 \mathrm{mmol})$ in $19 \mathrm{~cm}^{3}$ acetic acid $(330$ mmol). To the deep red mixture, $10 \mathrm{~cm}^{3}$ acetic anhydride, $15 \mathrm{~cm}^{3}$ ethanol and $15 \mathrm{~cm}^{3}$ pyridine was added. The mixture was heated and stirred for 10 minutes before being allowed to cool. After a day a dark green crystalline material formed which was collected via vacuum filtration. Analysis of the product indicates that the iron trinuclear complex has formed and not the mixed metal complex (yield $=2.4 \mathrm{~g}, 93 \%$ ). Upon standing, the pyridine terminal ligands of the complex are replaced by atmospheric water.

IR: 1594(s) ${ }^{1}, 1488(\mathrm{vw}), 1448(\mathrm{w}), 1384(\mathrm{w}), 1345(\mathrm{w}), 1239(\mathrm{~m}), 1157(\mathrm{w}), 1069(\mathrm{~m}), 1043(\mathrm{~m})$, 881(vw), 832(vw), 767(m), 698(m), 658(m), 638(w), 604(m), 521(vw), 433(w) cm².

\footnotetext{
${ }^{1}$ Relative intensity: $\mathrm{s}=$ strong, $\mathrm{m}=$ medium, $\mathrm{w}=$ weak, $\mathrm{vw}=$ very weak.
} 


\subsubsection{2 $\left[\mathrm{Fe}_{3} \mathrm{O}\left(\mathrm{O}_{2} \mathrm{CC}_{6} \mathrm{H}_{5}\right)_{6}\left(\mathrm{H}_{2} \mathrm{O}\right)_{3}\right] \mathrm{NO}_{3} \cdot 2 \mathrm{CH}_{3} \mathrm{OH}$}

The above was prepared according to the previously reported method ${ }^{[67]} .6 .82 \mathrm{~g} \mathrm{KOH}$ $(0.12 \mathrm{~mol})$ and $15.17 \mathrm{~g}$ benzoic acid $(0.12 \mathrm{~mol})$ were dissolved in a $150 \mathrm{~cm}^{3} 1: 1$ mixture of water and methanol. To this solution $23.31 \mathrm{~g}$ of $\mathrm{Fe}\left(\mathrm{NO}_{3}\right)_{3} \cdot 9 \mathrm{H}_{2} \mathrm{O}(0.058 \mathrm{~mol})$ was added resulting in the instantaneous formation of an orange precipitate. The orange precipitate was collected via vacuum filtration. The precipitate was then recrystallised from methanol to give a red/brown crystalline material (yield $=15.4 \mathrm{~g}, 76 \%$ ).

IR: 1601(m), 1566(m), 1514(vw), 1494(w), 1414(s), 1283(w), 1177(w), 1070(vw), 1026(vw), 1001(vw), 992(vw), 840(vw), 824(vw), 818(vw), 717(m), 686(w), 673(w), 628(w), 568(vw), $486(\mathrm{~m}) \mathrm{cm}^{-1}$.

\subsubsection{3 $\left[\mathrm{Fe}_{3} \mathrm{O}\left(\mathrm{O}_{2} \mathrm{CC}_{6} \mathrm{H}_{5}\right)_{6}\left(\mathrm{H}_{2} \mathrm{O}\right)_{3}\right] \mathrm{Cl} \cdot \mathrm{H}_{2} \mathrm{O}$}

A solution of $2.22 \mathrm{~g}$ sodium benzoate $(15 \mathrm{mmol})$ in $15 \mathrm{~cm}^{3}$ water was added to a solution of $1.00 \mathrm{~g} \mathrm{FeCl} \cdot 9 \mathrm{H}_{2} \mathrm{O}(3 \mathrm{mmol})$ in $20 \mathrm{~cm}^{3}$ methanol. A peach/orange precipitate formed instantly and was collected via vacuum filtration and dried under vacuo (yield $=1.85 \mathrm{~g}$, $66 \%)$

IR: 1622(vw), 1601(m), 1564(m), 1546(w), 1518(w), 1493(w), 1446(w), 1406(s), 1360(vw), 1307(vw), 1260(vw), 1178(w), 1158(vw), 1099(vw), 1071(w), 1025(w), 975(vw), 936(vw), 873(vw), 841(vw), 819(vw), 721(m), 687(w), 675(m), 632(w), 621(w), 544(vw), 481(m) $\mathrm{cm}^{-1}$.

\subsubsection{4 $\left[\mathrm{Fe}_{3} \mathrm{O}\left(\mathrm{O}_{2} \mathrm{CC}_{6} \mathrm{H}_{4}-3-\mathrm{Cl}\right)_{6}\left(\mathrm{H}_{2} \mathrm{O}\right)_{3}\right] \mathrm{NO}_{3} \cdot \mathrm{CH}_{3} \mathrm{OH}$}

$4.30 \mathrm{~g} \mathrm{KOH}(77 \mathrm{mmol})$ dissolved in $100 \mathrm{~cm}^{3}$ water was added to a solution of $11.20 \mathrm{~g}$ 3-chlorobenzoic acid $(72 \mathrm{mmol})$ in $100 \mathrm{~cm}^{3}$ methanol. To this solution, $14.66 \mathrm{~g}$ 
$\mathrm{Fe}\left(\mathrm{NO}_{3}\right)_{3} \cdot 9 \mathrm{H}_{2} \mathrm{O}(36 \mathrm{mmol})$ was added resulting in the instantaneous formation of an orange precipitate which, over the next minute of stirring, changed colour to form a thick dark red solid. This dark red solid was collected via vacuum filtration and was then dissolved and refluxed in methanol for 30 minutes. After refluxing, an orange powder had formed and was collected via vacuum filtration and dried in vacuo (yield $=9.0 \mathrm{~g}, 59 \%$ ).

IR: 1604(m), 1563(m), 1524(w), 1473(w), 1427(s), 1397(s), 1314(vw), 1296(vw), $1270(\mathrm{w})$, 1159(w), 1113(vw), 1104(vw), 1088(w), 1073(w), 1034(vw), 1007(vw), 911(vw), 879(w), 822(vw), 760(m), 732(m), 673(m), 658(w), 633(m), 539(vw), 478(m) $\mathrm{cm}^{-1}$.

Elemental Analysis: Fe: 13.49; C: 41.99; O: 23.89; H: 2.37; N: 0.63; Cl: 17.64\%

(Calculated for $\left[\mathrm{Fe}_{3} \mathrm{O}\left(\mathrm{O}_{2} \mathrm{CC}_{6} \mathrm{H}_{4}-3-\mathrm{Cl}_{6}\left(\mathrm{H}_{2} \mathrm{O}\right)_{3}\right] \mathrm{NO}_{3}\right.$ : Fe: 13.59; C: 40.91; O: 24.66; H: 2.45; $\mathrm{N}: 1.14 ; \mathrm{Cl}: 17.25 \%)$.

\section{$\left[\mathrm{Fe}_{3} \mathrm{O}\left(\mathrm{O}_{2} \mathrm{CC}_{6} \mathrm{H}_{4}-3-\mathrm{Cl}\right)_{6}\left(\mathrm{H}_{2} \mathrm{O}\right)_{3}\right] \mathrm{NO}_{3} \cdot \mathrm{H}_{2} \mathrm{O}:$}

Suitable crystals for X-ray analysis were obtained by dissolving a sample of the orange powder in a hot acetone solution and allowing the solution to cool slowly by placing the solution into a test tube in a Dewar flask of hot water. Crystals formed after two days.

X-ray Crystallography: orthogonal, $P c a 2_{1}, Z=4 ; R_{1}=0.0481 ; a=21.212(4) \AA, b=$ 10.9832(19) $\AA, c=21.254(4) ; V_{\text {cell }}=4,951.69 \AA^{3}$.

\subsubsection{5 $\left[\mathrm{Fe}_{3} \mathrm{O}\left(\mathrm{O}_{2} \mathrm{CC}_{6} \mathrm{H}_{4}-3-\mathrm{Cl}\right)_{6}\left(\mathrm{H}_{2} \mathrm{O}\right)_{3}\right] \mathrm{Cl} \cdot \mathrm{H}_{2} \mathrm{O}$}

$4.69 \mathrm{~g}$ of 3-chlorobenzoic acid $(30 \mathrm{mmol})$ was added to a solution of $3.47 \mathrm{~g} \mathrm{KOH}$ (62 $\mathrm{mmol}$ ) in $75 \mathrm{~cm}^{3}$ water. The solvent was then removed completely under reduced pressure 
and the resulting potassium 3-chlorobenzoate collected. $2.41 \mathrm{~g}$ of the freshly prepared potassium 3-chlorobenzoate $(12 \mathrm{mmol})$ was dissolved in $10 \mathrm{~cm}^{3}$ water and was added to a solution of $1.46 \mathrm{~g} \mathrm{FeCl}_{3} \cdot 9 \mathrm{H}_{2} \mathrm{O}(4 \mathrm{mmol})$ in $15 \mathrm{~cm}^{3}$ methanol. An orange precipitate formed instantly. This precipitate was collected via vacuum filtration and dried in vacuo (yield $=1.7 \mathrm{~g}, 94 \%$.

IR: 1597(m), 1561(m), 1527(m), 1473(w), 1427(s), 1397(s), 1296(vw), 1270(w), $1160(\mathrm{w})$, 1088(vw), 1073(w), 1051(vw), 1003(vw), 923(vw), 901(vw), 878(w), 816(vw), 760(m), 733(m), 673(w), 658(w), 636(w), 481(m) $\mathrm{cm}^{-1}$.

\subsubsection{6 $\left[\mathrm{Fe}^{\mathrm{III}}{ }_{2} \mathrm{Fe} \mathrm{O}^{\mathrm{II}}\left(\mathrm{O}_{2} \mathrm{CC}_{6} \mathrm{H}_{5}\right)_{6}\left(\mathrm{H}_{2} \mathrm{O}\right)_{3}\right] \cdot 2 \mathrm{H}_{2} \mathrm{O}$}

The above was prepared according to the previously reported method ${ }^{[83]}$. In order to prevent oxidation of the iron (II) to iron (III), diethyl ether was mixed into the water used in the following synthesis to remove aqueous oxygen. $2.30 \mathrm{~g} \mathrm{FeCl} \cdot 4 \mathrm{H}_{2} \mathrm{O}(12 \mathrm{mmol})$ was dissolved in $25 \mathrm{~cm}^{3}$ water and any undissolved solid removed via gravity filtration. The iron solution was then added to a solution of $3.64 \mathrm{~g}$ sodium benzoate $(24 \mathrm{mmol})$ in $50 \mathrm{~cm}^{3}$ water which resulted in the instantaneous formation of a peach coloured precipitate. The mixture was left to stir. After 20 minutes, the precipitate had gone from the peach colour to a brown colour and a skin had formed on top of the solution. After one hour, $15 \mathrm{~cm}^{3}$ of acetonitrile was added resulting in the precipitate becoming slightly paler in colour. The solution was then left to stir overnight (approx. 17 hours) before being collected via vacuum filtration and dried in vacuo (yield $=0.52 \mathrm{~g}, 14 \%$ ). 
IR: 1599(m), 1559(m), 1493(w), 1447(w), 1404(s), 1307(w), 1262(vw), 1233(vw), $1177(w)$, 1157(vw), 1148(vw), 1097(vw), 1070(w), 1051(vw), 1025(w), 1003(vw), 938(vw), 872(vw), 839(vw), 817(vw), 719(m), 674(w), 617(vw), 591(vw), 542(vw), 477(w) $\mathrm{cm}^{-1}$.

\subsubsection{7 $\left[\mathrm{Fe}_{3} \mathrm{O}\left(\mathrm{O}_{2} \mathrm{CCH}\left(\mathrm{C}_{6} \mathrm{H}_{5}\right)_{2}\right)_{6}\left(\mathrm{H}_{2} \mathrm{O}\right)_{3}\right] \mathrm{NO}_{3}$}

The above complex was synthesised in the attempted synthesis of the iron/cobalt mixed metal complex ${ }^{[23]}$. $2.16 \mathrm{~g}$ of $\mathrm{Fe}\left(\mathrm{NO}_{3}\right)_{3} \cdot 9 \mathrm{H}_{2} \mathrm{O}(5 \mathrm{mmol})$ and $4.27 \mathrm{~g}$ of $\mathrm{Co}\left(\mathrm{NO}_{3}\right)_{2} \cdot 6 \mathrm{H}_{2} \mathrm{O}(15$ mmol) was refluxed in $50 \mathrm{~cm}^{3}$ methanol for 35 minutes. The solution was allowed to cool and left for slow evaporation. After 3 days crystalline material had formed and was collected via vacuum filtration (yield $=2.7 \mathrm{~g}, 96 \%$ ).

IR: 1600(s), 1494(m), 1453(w), 1406(s), 1285(m), 1260(w), 1174(vw), 1156(vw), 1079(w), 1030(m), 1003(m), 973(vw), 914(vw), 882(vw), 843(vw), 826(vw), 781(vw), 743(m), 697(m), 619(m), 568(w), 518(w), 492(vw), 421(m) $\mathrm{cm}^{-1}$.

\subsubsection{Chromium complexes}

\subsubsection{1 $\left[\mathrm{Cr}_{3} \mathrm{O}\left(\mathrm{O}_{2} \mathrm{CC}_{6} \mathrm{H}_{5}\right)_{6}\left(\mathrm{H}_{2} \mathrm{O}\right)_{3}\right] \mathrm{NO}_{3} \cdot \mathrm{CH}_{3} \mathrm{COCH}_{3}$}

The above was prepared according to the literature method ${ }^{[115]} \cdot 8.30 \mathrm{~g} \mathrm{Cr}\left(\mathrm{NO}_{3}\right)_{3} \cdot 9 \mathrm{H}_{2} \mathrm{O}(21$ mmol) and $4.78 \mathrm{~g}$ benzoic acid $\left(39 \mathrm{mmol}\right.$ ) were dissolved in $100 \mathrm{~cm}^{3}$ acetone forming a dark blue solution with a light blue precipitate. The mixture was refluxed for 5 hours during which time the precipitate became greener in colour before dissolving and the solution changed colour from dark blue to dark green. The solution was then gravity filtered before being reduced in volume to approximately $30 \mathrm{~cm}^{3}$ under reduced pressure 
on a rotary evaporator. Crystalline material formed from the slow evaporation of the solution and collected by vacuum filtration $(4.9 \mathrm{~g}, 66 \%)$

IR: 1697(w), 1610(m), 1573(m), 1523(vw), 1495(w), 1415(s), 1384(w), 1319(vw), 1232(vw), 1180(vw), 1159(w), 1073(w), 1025(w), 1001(vw), 941(w), 845(vw), 828(vw), 817(vw), $720(\mathrm{~m}), 680(\mathrm{~m}), 665(\mathrm{w}), 527(\mathrm{~m}), 515(\mathrm{~m}) \mathrm{cm}^{-1}$.

\subsubsection{2 $\left[\mathrm{Cr}_{3} \mathrm{O}\left(\mathrm{O}_{2} \mathrm{CC}_{6} \mathrm{H}_{5}\right)_{6}\left(\mathrm{H}_{2} \mathrm{O}\right)_{3}\right]\left(\mathrm{O}_{2} \mathrm{CC}_{6} \mathrm{H}_{5}\right)$}

The above was prepared according to the literature method ${ }^{[116]} \cdot 5.72 \mathrm{~g}$ of $\mathrm{CrO}_{3}(0.57 \mathrm{~mol})$ was placed in a round bottom flask with an attached water condenser and cooled on an ice bath. $5 \mathrm{~cm}^{3}$ of water was added followed by the slow, drop wise addition of a solution of $24.68 \mathrm{~g}$ benzoic acid $(0.20 \mathrm{~mol})$ in $75 \mathrm{~cm}^{3}$ ethanol with stirring. When the addition of the benzoic acid no longer resulted in a vigorous reaction, the rate of addition was increased. The reaction mixture was then refluxed for 3 hours. The resulting green solution was hot gravity filtered and then allowed to cool to room temperature. A green solid formed which was collected by gravity filtration. The remaining solution was reduced in volume under reduced pressure and the resulting solid was collected by vacuum filtration. The collected solids were combined and washed with $5 \mathrm{~cm}^{3}$ ethanol followed by diethyl ether and then dried in air (yield $=9.5 \mathrm{~g}, 46 \%$ ).

IR: 1692(w), 1624(m), 1614(m), 1573(m), 1532(vw), 1494(w), 1420(s), 1324(vw), 1289(vw), 1228(vw), 1178(w), 1160(vw), $1121(\mathrm{vw}), 1092(\mathrm{vw}), 1072(\mathrm{vw}), 1041(\mathrm{vw}), 1026(\mathrm{w}), 1006(\mathrm{vw})$, 936(vw), 879(vw), 846(vw), 816(w), 718(m), 683(m), 666(m), 530(m), 514(m) cm 


\subsubsection{3 $\left[\mathrm{Cr}_{3} \mathrm{O}\left(\mathrm{O}_{2} \mathrm{CC}_{6} \mathrm{H}_{5}\right)_{6}\left(\mathrm{H}_{2} \mathrm{O}\right)_{3}\right] \mathrm{Cl} \cdot 1.5 \mathrm{H}_{2} \mathrm{O}$}

$1.01 \mathrm{~g}$ of $\left[\mathrm{Cr}_{3} \mathrm{O}\left(\mathrm{O}_{2} \mathrm{CC}_{6} \mathrm{H}_{5}\right)_{6}\left(\mathrm{H}_{2} \mathrm{O}\right)_{3}\right]\left(\mathrm{O}_{2} \mathrm{CC}_{6} \mathrm{H}_{5}\right)(0.94 \mathrm{mmol})$ was partially dissolved in $12 \mathrm{~cm}^{3}$ $\mathrm{HCl}\left(2 \mathrm{~mol} \cdot \mathrm{dm}^{-3}\right)$. The $\mathrm{HCl}$ was removed using a rotary evaporator with a bath temperature of $90^{\circ} \mathrm{C}$. To the resulting solid, $12 \mathrm{~cm}^{3}$ of a $6 \mathrm{~mol} . \mathrm{dm}^{-3} \mathrm{HCl}$ solution was added followed by $10 \mathrm{~cm}^{3}$ diethyl ether and the solution was stirred for about 10 minutes. The undissolved solid was then collected via gravity filtration. The acid and ether addition was repeated until IR analysis of the filtered solid indicated that all the nitrate anions had been replaced. The final green solid was dried in vacuo (yield $=0.76 \mathrm{~g}, 82 \%$ )

IR: 1624(m), 1613(m), 1572(s), 1525(vw), 1494(w), 1422(s), 1417(s), 1316(vw), 1179(w), 1159(vw), 1100(vw), 1072(vw), 1026(w), 1002(vw), 939(vw), 846(vw), 817(vw), 720(m), 680(w), 668(w), 528(w), 513(w) $\mathrm{cm}^{-1}$.

\subsubsection{4 $\left[\mathrm{Cr}_{3} \mathrm{O}\left(\mathrm{O}_{2} \mathrm{CC}_{6} \mathrm{H}_{5}\right)_{6}\left(\mathrm{H}_{2} \mathrm{O}\right)_{3}\right] \mathrm{SCN}$}

$1.20 \mathrm{~g}$ potassium thiocyanate $(12 \mathrm{mmol})$ was dissolved in a minimal amount of methanol with slight heating and stirring. Once all the potassium thiocyanate was dissolved, $3.05 \mathrm{~g}$ of $\left[\mathrm{Cr}_{3} \mathrm{O}\left(\mathrm{O}_{2} \mathrm{CC}_{6} \mathrm{H}_{5}\right)_{6}\left(\mathrm{H}_{2} \mathrm{O}\right)_{3}\right]\left(\mathrm{O}_{2} \mathrm{CC}_{6} \mathrm{H}_{5}\right)(2.8 \mathrm{mmol})$ was added to the solution and stirred for 10 minutes. The resulting dark green precipitate was collected via vacuum filtration and washed with methanol (yield $=2.1 \mathrm{~g}, 73 \%$ ).

IR: 2120(w), 1623(m), 1614(m), 1573(m), 1533(vw), 1494(w), 1419(s), 1315(vw), 1178(w), 1159(vw), 1100(vw), 1071(vw), 1026(w), 938(vw), 846(vw), 816(vw), 718(m), 681(w), 665(w), 529(w), 513(w) $\mathrm{cm}^{-1}$. 


\subsubsection{5 $\left[\mathrm{Cr}_{3} \mathrm{O}\left(\mathrm{O}_{2} \mathrm{CC}_{6} \mathrm{H}_{4}-3-\mathrm{Cl}\right)_{6}\left(\mathrm{H}_{2} \mathrm{O}\right)_{3}\right] \mathrm{NO}_{3} \cdot 2 \mathrm{CH}_{3} \mathrm{COCH}_{3}$}

The above was prepared according to the literature method ${ }^{[15]}$. $5.97 \mathrm{~g} \mathrm{Cr}\left(\mathrm{NO}_{3}\right)_{3} \cdot 9 \mathrm{H}_{2} \mathrm{O}(15$ mmol) and $4.69 \mathrm{~g} \mathrm{3-chlorobenzoic} \mathrm{acid}\left(30 \mathrm{mmol}\right.$ ) were dissolved in $100 \mathrm{~cm}^{3}$ acetone forming a dark blue solution with a light blue precipitate. The mixture was then heated to reflux whereupon the initial precipitate became greener in colour before dissolving after around 5-10 minutes and, at the same time, the solution colour went from dark blue to dark green. Reflux was continued for 4.5 hours. The solution was then gravity filtered and reduced in volume to approximately $40 \mathrm{~cm}^{3}$ under reduced pressure on a rotary evaporator (yield $=3.2 \mathrm{~g}, 49 \%$ ). Crystals suitable for X-ray analysis were obtained by slow evaporation of an acetone solution.

IR: 1697(w), 1621(s), 1569(s), 1536(vw), 1475(w), 1432(s), 1403(s), 1308(vw), $1297(\mathrm{vw})$, 1271(w), 1164(vw), 1108(vw), 1089(w), 1074(w), 1050(vw), 1034(vw), 1003(vw), 984(vw), 922(vw), 901(vw), 885(w), 825(w), 817(w), 759(m), 736(m), 673(m), 657(m), 626(vw), $528(\mathrm{~m}), 514(\mathrm{~m}) \mathrm{cm}^{-1}$.

Elemental Analysis: Cr: 13.13; C: 41.46; O: 24.65; H: 2.47; N: 0.89; Cl: 17.41\%

(Calculated for $\left[\mathrm{Cr}_{3} \mathrm{O}\left(\mathrm{O}_{2} \mathrm{CC}_{6} \mathrm{H}_{4}-3-\mathrm{Cl}_{6}\left(\mathrm{H}_{2} \mathrm{O}\right)_{3}\right] \mathrm{NO}_{3}\right.$ : Cr: 12.77; C: 41.30; O: 24.91; H: 2.48; $\mathrm{N}: 1.15 ; \mathrm{Cl}: 17.41 \%)$.

X-ray Crystallography: orthogonal, $P c a 2_{1}, Z=4 ; R_{1}=0.0550 ; a=21.2756(8) \AA, b=$ 10.9534(4) $\AA, c=21.4030(9) ; V_{\text {cell }}=4,987.76 \AA^{3}$. 


\subsubsection{6 $\left[\mathrm{Cr}_{3} \mathrm{O}\left(\mathrm{O}_{2} \mathrm{CC}_{6} \mathrm{H}_{4}-3-\mathrm{Cl}\right)_{6}\left(\mathrm{H}_{2} \mathrm{O}\right)_{3}\right] \mathrm{NO}_{3} \cdot \mathrm{CH}_{3} \mathrm{OH}$ :}

In an attempt to synthesise a higher nuclearity complex, $0.2930 \mathrm{~g}$ of $\left[\mathrm{Cr}_{3} \mathrm{O}\left(\mathrm{O}_{2} \mathrm{CC}_{6} \mathrm{H}_{4}-3-\mathrm{Cl}\right)_{6}\left(\mathrm{H}_{2} \mathrm{O}\right)_{3}\right] \mathrm{NO}_{3} \cdot \mathrm{CH}_{3} \mathrm{COCH}_{3}(0.23 \mathrm{mmol})$ was heated in an oven to $110^{\circ} \mathrm{C}$ in air for 20 minutes. The crude material $(0.2646 \mathrm{~g}$, mass loss $=9.69 \%)$ was then dissolved in methanol and left for slow evaporation for 36 days resulting in the growth of X-ray suitable crystals.

IR: 1623(s), 1569(s), 1535(vw), 1474(w), 1431(s), 1403(s), 1296(w), 1270(w), 1162(w), 1114(vw), 1089(w), 1074(w), 1023(vw), 921(vw), 901(vw), 884(w), 759(m), 738(m), 673(m), 656(m), 627(vw), 530(m), 514(m) $\mathrm{cm}^{-1}$.

X-ray Crystallography: orthogonal, $P c b a, Z=4 ; R_{1}=0.0806 ; a=21.1426(8) \AA, b=$ 21.6319(9) $\AA, c=21.9931(8) ; V_{\text {cell }}=10,058.6 \AA^{3}$.

\subsubsection{7 $\left[\mathrm{Cr}_{2 n}\left\{(\mathrm{OH})\left(\mathrm{O}_{2} \mathrm{CC}_{6} \mathrm{H}_{5}\right)_{2}\right\}_{2 n-1}\right]\left(\mathrm{NO}_{3}\right)_{3-x} \cdot\left(\mathrm{O}_{2} \mathrm{CC}_{6} \mathrm{H}_{5}\right)_{x} \cdot \mathrm{yH}_{2} \mathrm{O}$}

$6.04 \mathrm{~g}$ of benzoic acid (49 mmol) was dissolved in a mixture of $80 \mathrm{~cm}^{3}$ water and $15 \mathrm{~cm}^{3}$ methanol. Once all the solid had dissolved, $3.33 \mathrm{~g}$ of $\mathrm{KOH}(59 \mathrm{mmol})$ was added, and the mixture was stirred for several minutes before $10.03 \mathrm{~g}$ of $\mathrm{Cr}\left(\mathrm{NO}_{3}\right)_{3} \cdot 9 \mathrm{H}_{2} \mathrm{O}(25 \mathrm{mmol})$ was added. A dark blue precipitate instantly formed which was collected via vacuum filtration and the blue powder was then dried in vacuo (yield $=8.9 \mathrm{~g}^{1}$ ).

IR: 1694(w), 1600(vw), 1529(m), 1493(m), 1416(s), 1315(vw), 1308(vw), 1281(vw), 1177(w), 1069(w), 1025(w), 935(w), 845(vw), 816(vw), 718(m), 682(m), 528(m) $\mathrm{cm}^{-1}$.

\footnotetext{
${ }^{1}$ Due to the variable composition of the final product, a percent yield is unable to be determined
} 


\subsection{High Nuclearity Complexes}

The chemical formula of the following compounds were determined by infrared spectroscopy and thermal analysis and is discussed in detail in Chapter 3.

\subsubsection{Iron complexes}

\subsubsection{1 $\left[\mathrm{Fe}_{6} \mathrm{O}_{2}(\mathrm{OH})_{2}\left(\mathrm{O}_{2} \mathrm{CC}_{6} \mathrm{H}_{4}-3-\mathrm{Cl}\right)_{12}\left(\mathrm{H}_{2} \mathrm{O}\right)_{2}\right]$}

The winged $\mathrm{Fe}_{6} 3$-chlorobenzoate complex was synthesised by two different methods.

1. $0.5723 \mathrm{~g}$ of $\left[\mathrm{Fe}_{3} \mathrm{O}\left(\mathrm{O}_{2} \mathrm{CC}_{6} \mathrm{H}_{4}-3-\mathrm{Cl}\right)_{6}\left(\mathrm{H}_{2} \mathrm{O}\right)_{3}\right] \mathrm{NO}_{3} \cdot \mathrm{CH}_{3} \mathrm{OH}(0.45 \mathrm{mmol})$ was heated in a tube furnace at $200^{\circ} \mathrm{C}$ for 20 minutes before the product was allowed to cool to room temperature. The crude product (0.0392 g, 6.85\% mass loss), was dissolved in acetonitrile and gravity filtered. Crystals suitable for X-ray analysis were obtained by slow evaporation of the acetonitrile solution after 26 days.

IR: 1608(m), 1597(w), 1563(m), 1537(m), 1472(w), 1428(s), 1397(s), 1295(vw), 1269(m), 1157(w), 1087(w), 1072(w), 1002(vw), 923(vw), 901(w), 877(w), 816(vw), 759(m), 733(m), 673(w), 657(w), 618(w), 601(w), 537(vw), 478(m) $\mathrm{cm}^{-1}$.

X-ray Crystallography: monoclinic, $C 2 / c, Z=8 ; R_{1}=0.0547 ; a=30.1319(8) \AA, b=$ $14.8342(4) \AA, c=25.9512(6)(8) ; V_{\text {cell }}=10,482.8 \AA^{3}$.

2. $0.2141 \mathrm{~g}$ of $\left[\mathrm{Fe}_{3} \mathrm{O}\left(\mathrm{O}_{2} \mathrm{CC}_{6} \mathrm{H}_{4}-3-\mathrm{Cl}\right)_{6}\left(\mathrm{H}_{2} \mathrm{O}\right)_{3}\right] \mathrm{Cl} \cdot \mathrm{H}_{2} \mathrm{O}(0.17 \mathrm{mmol})$ was heated in a tube furnace at $290^{\circ} \mathrm{C}$ for 30 minutes before the product was allowed to cool to room temperature. The crude product weighed $0.1867 \mathrm{~g}$, a mass loss of $12.8 \%$. 
IR: 1597(w), 1506(s), 1473(w), 1430(s), 1397(s), 1295(vw), 1268(w), 1181(vw), 1156(w), 1104(vw), 1086(vw), 1070(w), 1004(vw), 922(vw), 900(w), 878(w), 815(w), 756(m), 736(m), 671(w), 658(w), 600(w), 480(m) $\mathrm{cm}^{-1}$.

\subsubsection{2 $\left[\mathrm{Fe}_{6} \mathrm{O}_{2}(\mathrm{OH})_{2}\left(\mathrm{O}_{2} \mathrm{CC}_{6} \mathrm{H}_{5}\right)_{12}\left(\mathrm{H}_{2} \mathrm{O}\right)_{2}\right]$}

The winged $\mathrm{Fe}_{6}$ benzoate complex was synthesised by two different methods.

1. $0.2994 \mathrm{~g}$ of $\left[\mathrm{Fe}_{3} \mathrm{O}\left(\mathrm{O}_{2} \mathrm{CPh}\right)_{6}\left(\mathrm{H}_{2} \mathrm{O}\right)_{3}\right] \mathrm{Cl}(0.30 \mathrm{mmol})$ was heated in a tube furnace at $260^{\circ} \mathrm{C}$ for 30 minutes before the product was allowed to cool to room temperature. The crude product weighed $0.2370 \mathrm{~g}$, a mass loss of $20.8 \%$.

IR: 1600(m), $1529(\mathrm{~m}), 1493(\mathrm{w}), 1448(\mathrm{vw}), 1414(\mathrm{~s}), 1308(\mathrm{w}), 1177(\mathrm{w}), 1069(\mathrm{vw}), 1025(\mathrm{w})$, 937(w), 870(vw), 840(vw), 817(vw), 716(m), 685(w), 674(w), 612(vw), 481(m) $\mathrm{cm}^{-1}$.

2. $0.0600 \mathrm{~g}$ of $\left[\mathrm{Fe}^{\mathrm{III}}{ }_{2} \mathrm{Fe}^{\mathrm{II}} \mathrm{O}\left(\mathrm{O}_{2} \mathrm{CPh}\right)_{6}\left(\mathrm{H}_{2} \mathrm{O}\right)_{3}\right] \cdot 2 \mathrm{H}_{2} \mathrm{O}(0.06 \mathrm{mmol})$ was heated in a tube furnace at $250^{\circ} \mathrm{C}$ for 30 minutes before the product was allowed to cool to room temperature. The crude product weighed $0.0522 \mathrm{~g}$, a mass loss of $13.0 \%$.

IR: $1599(\mathrm{~m}), 1520(\mathrm{~m}), 1492(\mathrm{w}), 1448(\mathrm{vw}), 1415(\mathrm{~s}), 1307(\mathrm{vw}), 1279(\mathrm{vw}), 1261(\mathrm{vw})$, 1177(w), 1157(vw), 1098(vw), 1069(w), 1048(vw), 1025(w), 1002(vw), 975(vw), 937(vw), 873(vw), 840(vw), 816(vw), 716(m), 685(w), 676(w), 608(vw), 585(vw), 479(w) cm ${ }^{-1}$.

\subsubsection{3 $\left[\mathrm{Fe}_{11} \mathrm{O}_{6}(\mathrm{OH})_{6}\left(\mathrm{O}_{2} \mathrm{CC}_{6} \mathrm{H}_{4}-3-\mathrm{Cl}\right)_{15}\right]$}

$0.3908 \mathrm{~g}\left[\mathrm{Fe}_{3} \mathrm{O}\left(\mathrm{O}_{2} \mathrm{CC}_{6} \mathrm{H}_{4}-3-\mathrm{Cl}_{6}\left(\mathrm{H}_{2} \mathrm{O}\right)_{3}\right] \mathrm{Cl} \cdot \mathrm{H}_{2} \mathrm{O}(0.32 \mathrm{mmol})\right.$ was heated in a tube furnace at $360^{\circ} \mathrm{C}$ for 30 minutes before the product was allowed to cool to room temperature. The crude product weighed $0.2908 \mathrm{~g}$, a mass loss of $25.6 \%$. 
IR: 1594(m), 1543(s), 1473(w), 1430(s), 1394(s), 1269(w), 1156(w), 1087(vw), 1072(w), 1052(vw), 1001(vw), 980(vw), 922(vw), 901(vw), 894(vw), 875(w), 817(w), 764(m), 734(m), 673(w), 657(w), 586(w), 478(w) $\mathrm{cm}^{-1}$.

\subsubsection{4 $\left[\mathrm{Fe}_{11} \mathrm{O}_{6}(\mathrm{OH})_{6}\left(\mathrm{O}_{2} \mathrm{CCH}\left(\mathrm{C}_{6} \mathrm{H}_{5}\right)_{2}\right)_{15}\right]$}

$0.3301 \mathrm{~g}$ of $\left[\mathrm{Fe}_{3} \mathrm{O}\left(\mathrm{O}_{2} \mathrm{CCHPh}_{2}\right)_{6}\left(\mathrm{H}_{2} \mathrm{O}\right)_{3}\right] \mathrm{NO}_{3}(0.21 \mathrm{mmol})$ was heated in a tube furnace at $320^{\circ} \mathrm{C}$ for 20 minutes before the product was allowed to cool to room temperature. The crude product weighed $0.2228 \mathrm{~g}$, a mass loss of $32.5 \%$.

IR: 1574(w), 1538(s), 1493(m), 1449(w), 1405(s), 1337(w), 1296(vw), 1259(w), 1172(vw), 1156(vw), 1076(w), 1031(w), 1003(vw), 971(vw), 912(vw), 874(w), 841(w), 782(vw), 744(m), 724(m), 696(s), 646(w), 618(vw), 565(w), 518(vw), 478(vw), 451(vw), 430(w) $\mathrm{cm}^{-1}$.

\subsubsection{Chromium complexes}

The structures of the following chromium higher nuclearity complexes could not be determined by X-ray crystallography. The structures have been proposed after comparing the compounds with the products of heating of a trinuclear chromium pivalate precursor ${ }^{[65]}$ and the above iron 3-chlorobenzoate complex. This is explained in more detail in Chapter 3.

\subsubsection{1 $\left[\mathrm{Cr}_{6} \mathrm{O}_{2}(\mathrm{OH})_{2}\left(\mathrm{O}_{2} \mathrm{CC}_{6} \mathrm{H}_{4}-3-\mathrm{Cl}\right)_{12}\left(\mathrm{H}_{2} \mathrm{O}\right)_{2}\right]$ (Proposed)}

$0.7617 \mathrm{~g}$ of $\left[\mathrm{Cr}_{3} \mathrm{O}\left(\mathrm{O}_{2} \mathrm{CC}_{6} \mathrm{H}_{4}-3-\mathrm{Cl}_{6}\left(\mathrm{H}_{2} \mathrm{O}\right)_{3}\right] \mathrm{NO}_{3}(0.62 \mathrm{mmol})\right.$ was heated in a tube furnace at $220^{\circ} \mathrm{C}$ for 10 minutes before the product was allowed to cool to room temperature. The crude product weighed $0.6293 \mathrm{~g}$, a mass loss of $18.39 \%$. This mass loss is consistent with the above formulation. 
IR: 1614(w), 1597(m), 1563(s), 1535(s), 1474(w), 1430(s), 1398(s), 1296(vw), 1270(w), 1160(w), 1088(w), 1073(w), 1051(vw), 1001(vw), 980(vw), 923(vw), 900(vw), 880(w), 815(vw), 760(m), 738(m), 674(w), 659(w), 605(vw), 574(vw), 527(w), 514(w) $\mathrm{cm}^{-1}$.

\subsubsection{2 $\left[\mathrm{Cr}_{6} \mathrm{O}_{2}(\mathrm{OH})_{2}\left(\mathrm{O}_{2} \mathrm{CC}_{6} \mathrm{H}_{4}-3-\mathrm{Cl}\right)_{11}\right] \cdot\left[\mathrm{Cr}_{6} \mathrm{O}_{4}\left(\mathrm{O}_{2} \mathrm{CC}_{6} \mathrm{H}_{4}-3-\mathrm{Cl}\right)_{11}\right]$ (Proposed)}

$0.6743 \mathrm{~g}$ of $\left[\mathrm{Cr}_{3} \mathrm{O}\left(\mathrm{O}_{2} \mathrm{CC}_{6} \mathrm{H}_{4}-3-\mathrm{Cl}_{6}\left(\mathrm{H}_{2} \mathrm{O}\right)_{3}\right] \mathrm{NO}_{3}(0.55 \mathrm{mmol})\right.$ was heated in a tube furnace at $360^{\circ} \mathrm{C}$ for 30 minutes before the product was allowed to cool to room temperature. The crude product weighed $0.5576 \mathrm{~g}$, a mass loss of $17.3 \%$. This mass loss is consistent with the above formulation at this temperature.

IR: 1613(m), 1568(m), 1547(w), 1495(w), 1438(s), 1411(s), 1403(vw), 1297(vw), 1271(w), 1160(w), 1089(w), 1073(w), 899(w), 882(w), 816(vw), 758(m), 739(m), 672(vw), 661(w), 638(w), 592(vw), 556(m), 518(w), 501(vw) $\mathrm{cm}^{-1}$.

\subsubsection{3 $\left[\mathrm{Cr}_{6} \mathrm{O}_{2}(\mathrm{OH})_{2}\left(\mathrm{O}_{2} \mathrm{CC}_{6} \mathrm{H}_{5}\right)_{11}\right] \cdot\left[\mathrm{Cr}_{6} \mathrm{O}_{4}\left(\mathrm{O}_{2} \mathrm{CC}_{6} \mathrm{H}_{5}\right)_{11}\right]$ (Proposed)}

1. $0.2213 \mathrm{~g}\left[\mathrm{Cr}_{3} \mathrm{O}\left(\mathrm{O}_{2} \mathrm{CPh}\right)_{6}\left(\mathrm{H}_{2} \mathrm{O}\right)_{3}\right] \mathrm{Cl}(0.22 \mathrm{mmol})$ was heated in a tube furnace at $320^{\circ} \mathrm{C}$ for 30 minutes before the product was allowed to cool to room temperature. The crude product weighed $0.1806 \mathrm{~g}$, a mass loss of $18.39 \%$.

IR: 1622(vw), 1611(m), 1572(m), 1541(w), 1505(vw), 1495(w), 1451(vw), 1420(s), 1309(vw), 1178(w), 1158(vw), 1097(vw), 1069(w), 1026(w), 1002(vw), 975(vw), 937(vw), 875(w), 847(vw), 817(vw), 716(m), 684(w), 634(vw), 616(vw), 590(vw), 556(m), 515(w), $480(\mathrm{vw}) \mathrm{cm}^{-1}$. 
2. $0.3242 \mathrm{~g}\left[\mathrm{Cr}_{3} \mathrm{O}\left(\mathrm{O}_{2} \mathrm{CPh}\right)_{6}\left(\mathrm{H}_{2} \mathrm{O}\right)_{3}\right] \mathrm{SCN}(0.22 \mathrm{mmol})$ was heated in a tube furnace at $320^{\circ} \mathrm{C}$ for 30 minutes before the product was allowed to cool to room temperature. The crude product weighed $0.2818 \mathrm{~g}$, a mass loss of $13.08 \%$. This mass loss is consistent with the above formulation. The crude was dissolved in acetonitrile and the solution placed into a test tube and left for slow evaporation. After 7 days triangular shaped crystals had formed above the solution.

IR: 2089(w), 1611(m), 1572(m), 1550(w), 1506(vw), 1494(w), 1420(s), 1353(vw), $1309(\mathrm{vw})$, 1261(vw), 1179(w), 1158(vw), 1070(w), 1026(w), 1002(vw), 938(vw), 875(vw), 846(vw), 816(vw), $717(\mathrm{~m}), 683(\mathrm{w}), 636(\mathrm{vw}), 625(\mathrm{vw}), 616(\mathrm{vw}), 558(\mathrm{w}), 515(\mathrm{w}) \mathrm{cm}^{-1}$. 


\section{Results and Discussion}

\subsection{X-ray Crystallography}

\subsection{1 $\left[\mathrm{Fe}_{3} \mathrm{O}\left(\mathrm{O}_{2} \mathrm{CC}_{6} \mathrm{H}_{4}-3-\mathrm{Cl}\right)_{6}\left(\mathrm{H}_{2} \mathrm{O}\right)_{3}\right] \mathrm{NO}_{3} \cdot \mathrm{H}_{2} \mathrm{O}$}

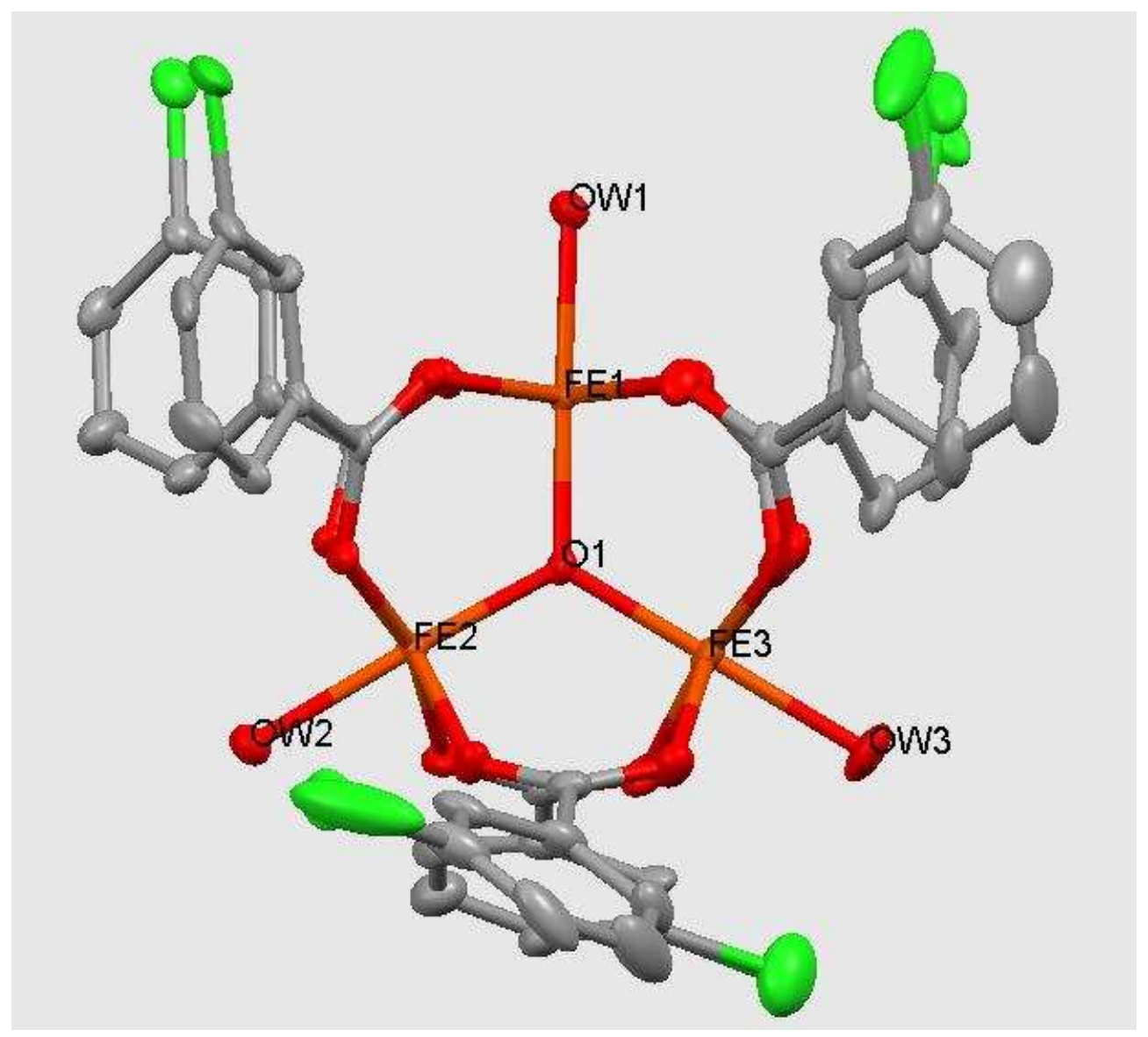

Figure 12: Crystal Structure of $\left[\mathrm{Fe}_{3} \mathrm{O}\left(\mathrm{O}_{2} \mathrm{CC}_{6} \mathrm{H}_{4}-3-\mathrm{Cl}\right)_{6}\left(\mathrm{H}_{2} \mathrm{O}\right)_{3}\right]^{+}$with $50 \%$ thermal ellipsoids (hydrogen atoms omitted for clarity).

$\left[\mathrm{Fe}_{3} \mathrm{O}\left(\mathrm{O}_{2} \mathrm{CC}_{6} \mathrm{H}_{4}-3-\mathrm{Cl}\right)_{6}\left(\mathrm{H}_{2} \mathrm{O}\right)_{3}\right] \mathrm{NO}_{3} \cdot \mathrm{H}_{2} \mathrm{O}$ crystallises in the orthorhombic space group Pca2 1 with $Z=4$. The crystal structure of the cationic trinuclear unit is shown in Figure 12. The structure shows the general trinuclear structure with the iron centres arranged to form a distorted equilateral triangle (Fe-Fe-Fe angles: 59.55, 60.45, 60.00 $; \mathrm{Fe}^{\cdots} \mathrm{Fe}$ distances: 3.313 , 3.298, $3.283 \AA$ ). The complex contains 3-chlorobenzoate bridging ligands, terminal water 
ligands, a nitrate anion and a single water of crystallisation. The chlorine atoms of the carboxylate bridges show some disorder. The hydrogen atoms of the terminal water ligands and of the carboxylates were placed in calculated positions.

Table 1 shows selected bond lengths and angles for $\left[\mathrm{Fe}_{3} \mathrm{O}\left(\mathrm{O}_{2} \mathrm{CC}_{6} \mathrm{H}_{4}-3\right.\right.$ $\left.\mathrm{Cl})_{6}\left(\mathrm{H}_{2} \mathrm{O}\right)_{3}\right] \mathrm{NO}_{3} \cdot \mathrm{H}_{2} \mathrm{O}$ (a complete list can be found in Section 6.1.1.2). The iron to central oxygen bond distances varies slightly with an average Fe-O bond length of $1.904 \AA$. The $\mathrm{Fe}-\mathrm{O}-\mathrm{Fe}$ bond angles are also very similar with an average bond angle of $119.99^{\circ}$. The central oxygen sits $0.018 \AA$ above the iron plane. The average distance of the iron to the oxygen of the terminal water is $2.097 \AA$. The distance between the iron and the oxygen of the carboxylate group varies between 1.980 to $2.026 \AA$ with an average bond distance of $2.007 \AA$.

Table 1: Selected bond lengths $[\AA]$ and angles $\left[{ }^{\circ}\right]$ for $\left[\mathrm{Fe}_{3} \mathrm{O}\left(\mathrm{O}_{2} \mathrm{CC}_{6} \mathrm{H}_{4}-3-\mathrm{Cl}\right)_{6}\left(\mathrm{H}_{2} \mathrm{O}\right)_{3}\right] \mathrm{NO}_{3} \cdot \mathrm{H}_{2} \mathrm{O}$.

\begin{tabular}{|c|c|}
\hline \multicolumn{2}{|l|}{ Bond length } \\
\hline$\overline{\operatorname{Fe}(1)-\mathrm{O}(1)}$ & $1.905(3)$ \\
\hline $\operatorname{Fe}(1)-O(11)$ & $2.015(4)$ \\
\hline $\operatorname{Fe}(1)-\mathrm{O}(12)$ & $2.002(3)$ \\
\hline $\operatorname{Fe}(1)-O(13)$ & $1.980(4)$ \\
\hline $\operatorname{Fe}(1)-O(14)$ & $2.013(3)$ \\
\hline $\mathrm{Fe}(1)-\mathrm{OW} 1$ & $2.079(3)$ \\
\hline $\mathrm{Fe}(2)-\mathrm{O}(1)$ & $1.900(3)$ \\
\hline $\operatorname{Fe}(2)-\mathrm{O}(21)$ & $2.021(4)$ \\
\hline $\mathrm{Fe}(2)-\mathrm{O}(22)$ & $2.001(3)$ \\
\hline $\operatorname{Fe}(2)-\mathrm{O}(23)$ & $1.984(4)$ \\
\hline $\operatorname{Fe}(2)-\mathrm{O}(24)$ & $1.994(4)$ \\
\hline $\operatorname{Fe}(2)$-ow2 & $2.115(4)$ \\
\hline $\operatorname{Fe}(3)-O(1)$ & $1.908(3)$ \\
\hline $\mathrm{Fe}(3)-\mathrm{O}(31)$ & $2.003(4)$ \\
\hline $\operatorname{Fe}(3)-\mathrm{o}(32)$ & $2.026(4)$ \\
\hline $\operatorname{Fe}(3)-\mathrm{O}(33)$ & $2.023(4)$ \\
\hline $\mathrm{Fe}(3)-\mathrm{O}(34)$ & $2.018(4)$ \\
\hline $\mathrm{Fe}(3)-\mathrm{OW} 3$ & $2.098(4)$ \\
\hline \multicolumn{2}{|l|}{ Bond angle } \\
\hline $\mathrm{Fe}(1)-\mathrm{O}(1)-\mathrm{Fe}(2)$ & $119.32(17)$ \\
\hline $\mathrm{Fe}(1)-\mathrm{O}(1)-\mathrm{Fe}(3)$ & $120.64(17)$ \\
\hline $\mathrm{Fe}(2)-\mathrm{O}(1)-\mathrm{Fe}(3)$ & $120.01(17)$ \\
\hline
\end{tabular}


The complex cations are linked via hydrogen bonds between the terminal water ligands and the nitrate anion and water solvent of crystallisation (Figure 13). The oxygen atoms of the nitrate anion are hydrogen bonded to two terminal water ligands (ON1-OW2, ON1-OW3', ON2-OW3') of different complexes and to the water of crystallisation (ON2-OCW1). The water of crystallisation is hydrogen bonded to the nitrate anion, the terminal water ligand (OCW1-OW1") of a third complex and a chlorine atom of the bridging ligand on a fourth complex (OCW1-Cl2"').

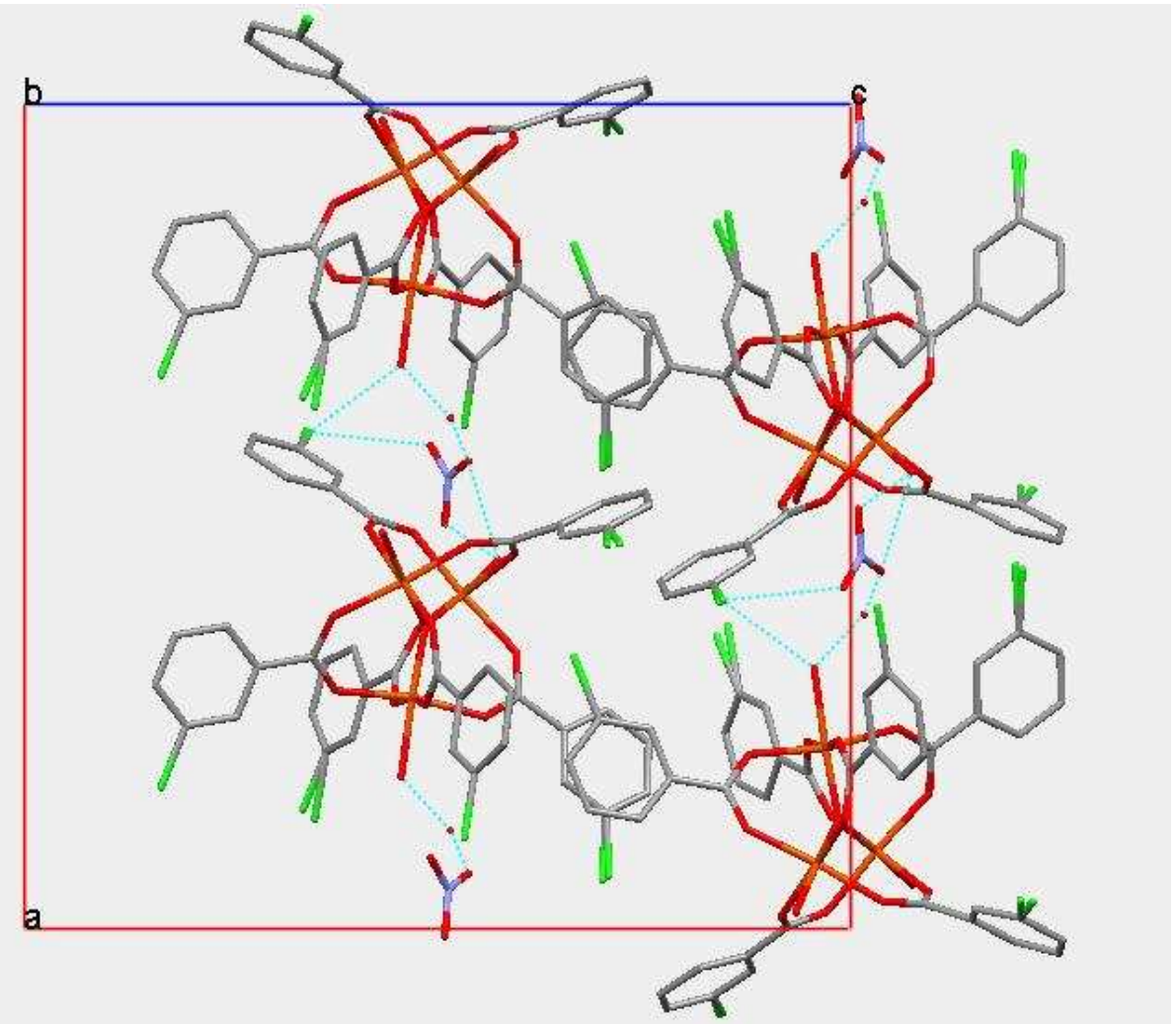

Figure 13: Unit cell of $\left[\mathrm{Fe}_{3} \mathrm{O}\left(\mathrm{O}_{2} \mathrm{CC}_{6} \mathrm{H}_{4}-3-\mathrm{Cl}\right)_{6}\left(\mathrm{H}_{2} \mathrm{O}\right)_{3}\right] \mathrm{NO}_{3} \cdot \mathrm{H}_{2} \mathrm{O}$ looking down the (010) plane showing the hydrogen bonding between the cations. 


\subsection{2 $\left[\mathrm{Cr}_{3} \mathrm{O}\left(\mathrm{O}_{2} \mathrm{CC}_{6} \mathrm{H}_{4}-3-\mathrm{Cl}\right)_{6}\left(\mathrm{H}_{2} \mathrm{O}\right)_{3}\right] \mathrm{NO}_{3} \cdot \mathrm{H}_{2} \mathrm{O}$}

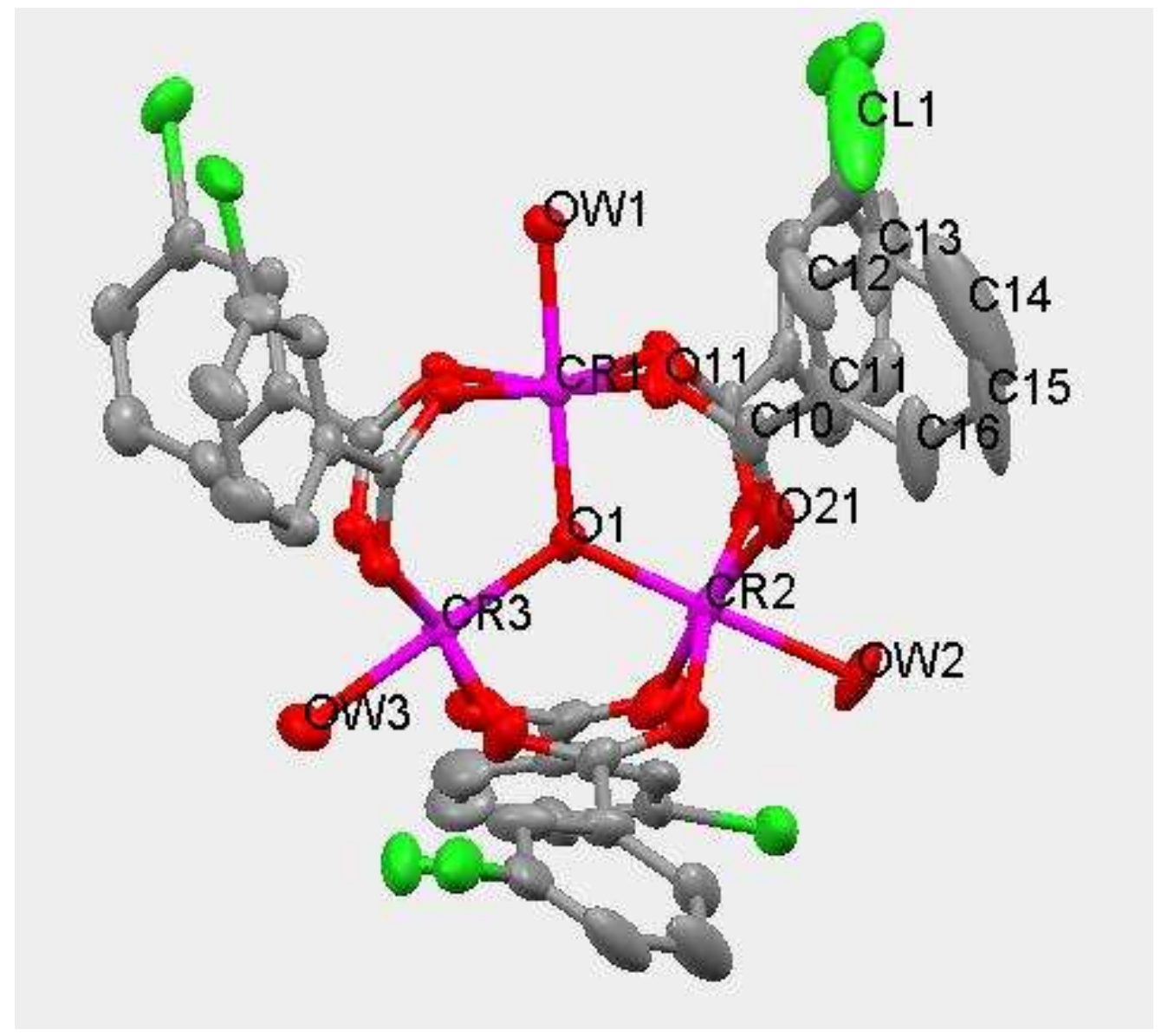

Figure 14: Crystal Structure of $\left[\mathrm{Cr}_{3} \mathrm{O}\left(\mathrm{O}_{2} \mathrm{CC}_{6} \mathrm{H}_{4}-3-\mathrm{Cl}\right)_{6}\left(\mathrm{H}_{2} \mathrm{O}\right)_{3}\right]^{+}$with $50 \%$ probability ellipsoids (hydrogen atoms omitted for clarity).

$\left[\mathrm{Cr}_{3} \mathrm{O}\left(\mathrm{O}_{2} \mathrm{CC}_{6} \mathrm{H}_{4}-3-\mathrm{Cl}\right)_{6}\left(\mathrm{H}_{2} \mathrm{O}\right)_{3}\right] \mathrm{NO}_{3} \cdot \mathrm{H}_{2} \mathrm{O}$ is observed to be isomorphous with the iron complex and crystallises in the orthorhombic space group $P c a 2_{1}$ with $Z=4$. The crystal structure of the cationic trinuclear unit is shown in Figure 14. The structure shows the general trinuclear structure with the chromium centres arranged to form a distorted equilateral triangle (Cr-Cr-Cr angles: 60.41, 59.88, 59.70 ; $\mathrm{Cr} \cdots \mathrm{Cr}$ distances: 3.308, 3.291, $3.285 \AA$ A). The complex contains 3-chlorobenzoate bridging ligands, terminal water ligands, a nitrate anion and a single water of crystallisation. The chlorine atoms of the carboxylate bridges show some disorder. 
Table 2 shows selected bond lengths and angles for $\left[\mathrm{Cr}_{3} \mathrm{O}\left(\mathrm{O}_{2} \mathrm{CC}_{6} \mathrm{H}_{4}-3-\right.\right.$ $\left.\mathrm{Cl}_{6}\left(\mathrm{H}_{2} \mathrm{O}\right)_{3}\right] \mathrm{NO}_{3} \cdot \mathrm{H}_{2} \mathrm{O}$ (a complete list can be found in Section 6.1.2.2). The chromium to central oxygen bond distances varies slightly with an average Cr-O bond length of $1.902 \AA$. The $\mathrm{Cr}-\mathrm{O}-\mathrm{Cr}$ bond angles are also very similar with an average bond angle of $119.99^{\circ}$. The central oxygen sits $0.010 \AA$ above the chromium plane. The average distance of the iron to the oxygen of the terminal water is $2.066 \AA$. The distance between the chromium and the oxygen of the carboxylate group varies between 1.954 to $1.982 \AA$ with an average bond distance of $1.968 \AA$.

Table 2: Selected bond lengths $[\AA]$ and angles $\left[{ }^{\circ}\right]$ for $\left[\mathrm{Cr}_{3} \mathrm{O}\left(\mathrm{O}_{2} \mathrm{CC}_{6} \mathrm{H}_{4}-3-\mathrm{Cl}\right)_{6}\left(\mathrm{H}_{2} \mathrm{O}\right)_{3}\right] \mathrm{NO}_{3} \cdot \mathrm{H}_{2} \mathrm{O}$.

\begin{tabular}{lr} 
Bond length & \\
\hline $\operatorname{Cr}(1)-O(1)$ & $1.899(4)$ \\
$\operatorname{Cr}(1)-O(11)$ & $1.955(4)$ \\
$\operatorname{Cr}(1)-O(14)$ & $1.969(4)$ \\
$\operatorname{Cr}(1)-O(13)$ & $1.972(4)$ \\
$\operatorname{Cr}(1)-O(12)$ & $1.975(3)$ \\
$\operatorname{Cr}(1)-O W 1$ & $2.040(4)$ \\
$\operatorname{Cr}(3)-O(1)$ & $1.903(4)$ \\
$\operatorname{Cr}(3)-O(32)$ & $1.954(4)$ \\
$\operatorname{Cr}(3)-O(34)$ & $1.960(4)$ \\
$\operatorname{Cr}(3)-O(31)$ & $1.963(4)$ \\
$\operatorname{Cr}(3)-O(33)$ & $1.978(4)$ \\
$\operatorname{Cr}(3)-O W 3$ & $2.083(5)$ \\
$\operatorname{Cr}(2)-O(1)$ & $1.904(3)$ \\
$\operatorname{Cr}(2)-O(22)$ & $1.957(4)$ \\
$\operatorname{Cr}(2)-O(21)$ & $1.973(5)$ \\
$\operatorname{Cr}(2)-O(23)$ & $1.978(6)$ \\
$\operatorname{Cr}(2)-O(24)$ & $1.982(4)$ \\
$\operatorname{Cr}(2)-O W 2$ & $2.076(4)$ \\
& \\
Bond angles & \\
$\operatorname{Cr}(1)-O(1)-\operatorname{Cr}(3)$ & $119.49(18)$ \\
$\operatorname{Cr}(1)-O(1)-\operatorname{Cr}(2)$ & $120.89(19)$ \\
$\operatorname{Cr}(3)-O(1)-\operatorname{Cr}(2)$ & $119.60(19)$ \\
&
\end{tabular}

The complex cations are linked via hydrogen bonds between the terminal water ligands and the nitrate anion and water solvent of crystallisation in the same manner as was observed for the isomorphous iron complex (Figure 15). 


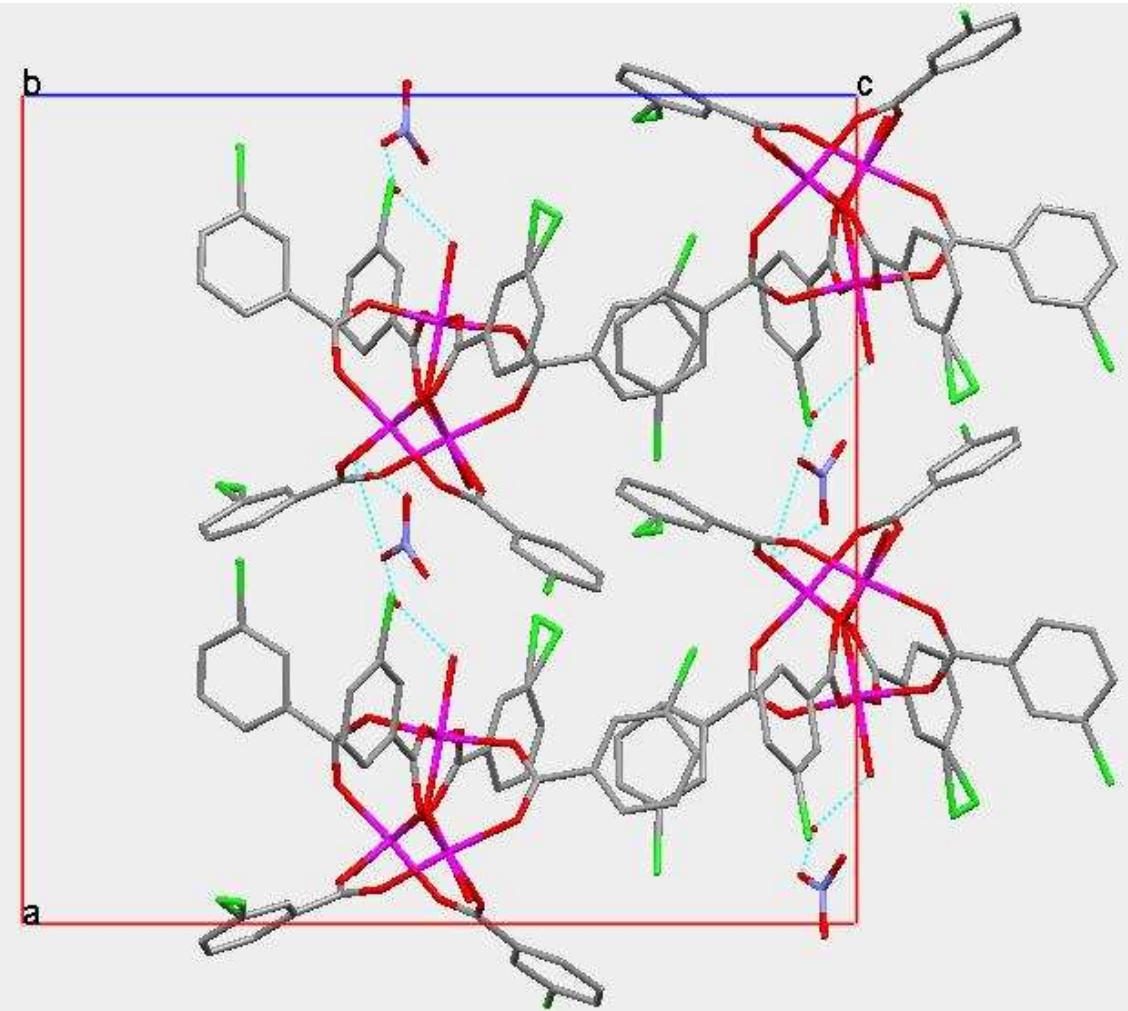

Figure 15: Unit cell of $\left[\mathrm{Cr}_{3} \mathrm{O}\left(\mathrm{O}_{2} \mathrm{CC}_{6} \mathrm{H}_{4}-3-\mathrm{Cl}\right)_{6}\left(\mathrm{H}_{2} \mathrm{O}\right)_{3}\right] \mathrm{NO}_{3} \cdot \mathrm{H}_{2} \mathrm{O}$ looking down the (010) plane showing the hydrogen bonding between the cations. 


\subsection{3 $\left[\mathrm{Cr}_{3} \mathrm{O}\left(\mathrm{O}_{2} \mathrm{CC}_{6} \mathrm{H}_{4}-3-\mathrm{Cl}\right)_{6}\left(\mathrm{H}_{2} \mathrm{O}\right)_{3}\right] \mathrm{NO}_{3} \cdot \mathrm{CH}_{3} \mathrm{OH}$}

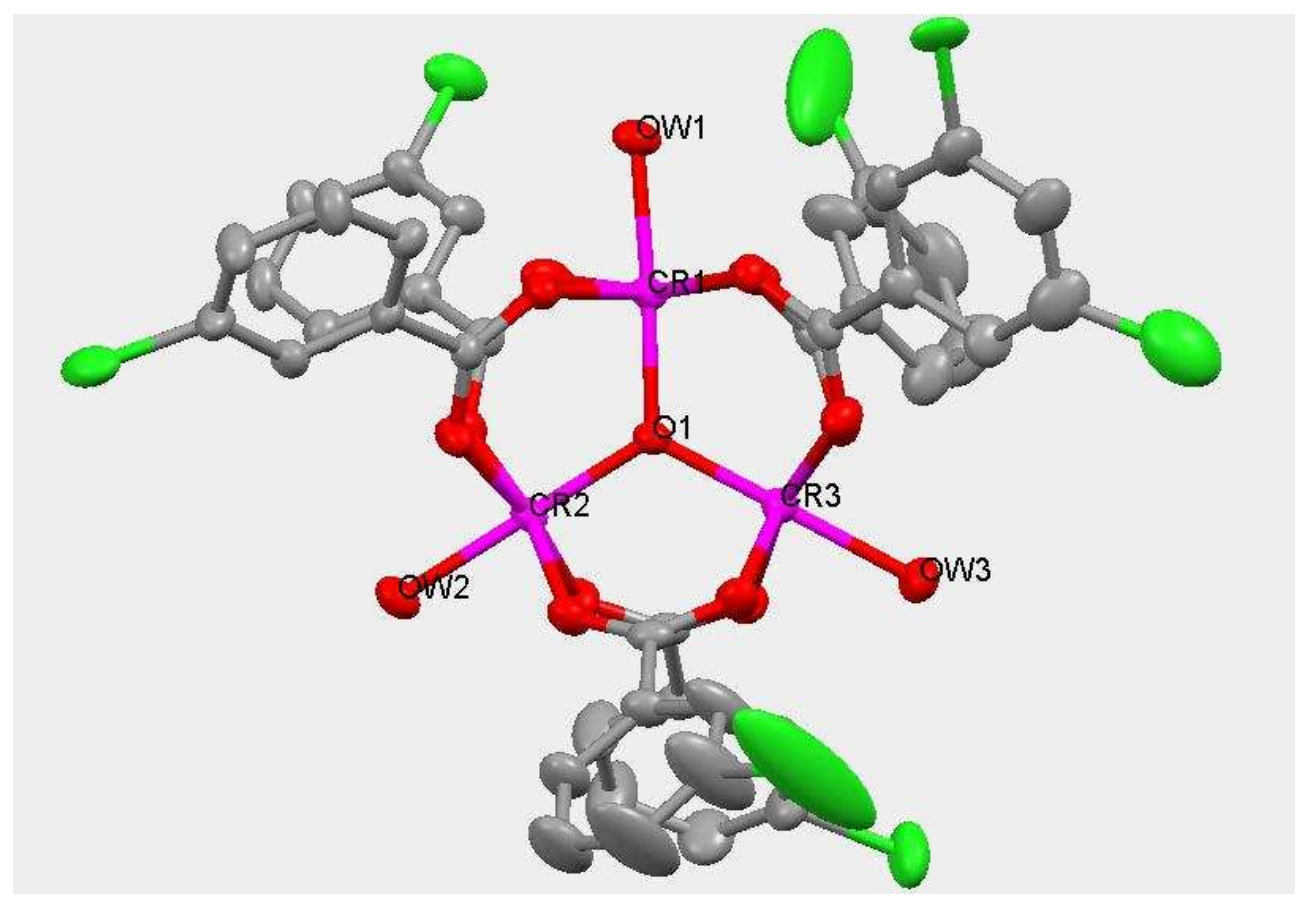

Figure 16: Crystal structure of $\left[\mathrm{Cr}_{3} \mathrm{O}\left(\mathrm{O}_{2} \mathrm{CC}_{6} \mathrm{H}_{4}-3-\mathrm{Cl}\right)_{6}\left(\mathrm{H}_{2} \mathrm{O}\right)_{3}\right]^{+}$with $50 \%$ thermal ellipsoids (hydrogen atoms omitted for clarity).

$\left[\mathrm{Cr}_{3} \mathrm{O}\left(\mathrm{O}_{2} \mathrm{CC}_{6} \mathrm{H}_{4}-3-\mathrm{Cl}\right)_{6}\left(\mathrm{H}_{2} \mathrm{O}\right)_{3}\right] \mathrm{NO}_{3} \cdot \mathrm{MeOH}$ is different from the analogous chromium complex with a water of crystallisation and crystallises in the orthorhombic space group $P b c a$ with $Z=4$. The crystal structure of the cationic trinuclear unit is shown in Figure 16. The structure shows the general trinuclear structure with the chromium centres arranged to form a distorted equilateral triangle (Cr-Cr-Cr angles: 59.35, 60.17, 60.48 ${ }^{\circ}$; $\mathrm{Cr}{ }^{\cdots \cdot} \mathrm{Cr}$ distances: 3.326, 3.289, 3.316 A). The complex contains 3-chlorobenzoate bridging ligands, terminal water ligands, a nitrate anion and a single methanol of crystallisation. The chlorine atoms of the carboxylate bridges show some disorder. The majority of the hydrogen atoms on the carboxylate ligands and half of the terminal water hydrogen atoms were located and refined, all other protons were placed at calculated positions.

Table 3 shows selected bond lengths and angles for $\left[\mathrm{Cr}_{3} \mathrm{O}\left(\mathrm{O}_{2} \mathrm{CC}_{6} \mathrm{H}_{4}-3\right.\right.$ $\left.\mathrm{Cl})_{6}\left(\mathrm{H}_{2} \mathrm{O}\right)_{3}\right] \mathrm{NO}_{3} \cdot \mathrm{MeOH}$ (a complete list can be found in Section 6.1.3.2). The chromium to central oxygen bond distances varies slightly with an average $\mathrm{Cr}-\mathrm{O}$ bond length of 1.911 
$\AA$. The $\mathrm{Cr}-\mathrm{O}-\mathrm{Cr}$ bond angles are also very similar with an average bond angle of $119.98^{\circ}$. The central oxygen sits $0.006 \AA$ above the chromium plane. The average distance of the chromium ions to the oxygen of the terminal water is $2.063 \AA$. The distance between the chromium and the oxygen of the carboxylate group varies between 1.960 to $1.994 \AA$ with an average bond distance of $1.997 \AA$.

Table 3: Selected bond lengths $[\AA ̊ \AA]$ and angles $\left[{ }^{\circ}\right]$ for $\left[\mathrm{Cr}_{3} \mathrm{O}\left(\mathrm{O}_{2} \mathrm{CC}_{6} \mathrm{H}_{4}-3-\mathrm{Cl}_{6}\left(\mathrm{H}_{2} \mathrm{O}\right)_{3}\right] \mathrm{NO}_{3} \cdot \mathrm{MeOH}\right.$.

\begin{tabular}{ll} 
Bond length & \\
\hline $\operatorname{Cr}(1)-O(1)$ & $1.907(4)$ \\
$\operatorname{Cr}(1)-O(11)$ & $1.983(4)$ \\
$\operatorname{Cr}(1)-O(12)$ & $1.979(4)$ \\
$\operatorname{Cr}(1)-O(13)$ & $1.980(4)$ \\
$\operatorname{Cr}(1)-O(14)$ & $1.995(4)$ \\
$\operatorname{Cr}(1)-O W 1$ & $2.053(4)$ \\
$\operatorname{Cr}(3)-O(1)$ & $1.907(4)$ \\
$\operatorname{Cr}(3)-O(31)$ & $1.977(4)$ \\
$\operatorname{Cr}(3)-O(32)$ & $1.958(4)$ \\
$\operatorname{Cr}(3)-O(33)$ & $1.983(4)$ \\
$\operatorname{Cr}(3)-O(34)$ & $1.963(4)$ \\
$\operatorname{Cr}(3)-O W 3$ & $2.082(4)$ \\
$\operatorname{Cr}(2)-O(1)$ & $1.920(4)$ \\
$\operatorname{Cr}(2)-O(21)$ & $1.985(4)$ \\
$\operatorname{Cr}(2)-O(22)$ & $1.968(4)$ \\
$\operatorname{Cr}(2)-O(23)$ & $1.981(4)$ \\
$\operatorname{Cr}(2)-O(24)$ & $1.972(4)$ \\
$\operatorname{Cr}(2)-O W 2$ & $2.055(4)$ \\
$\operatorname{Bond}$ angle & \\
\hline $\operatorname{Cr}(3)-O(1)-\operatorname{Cr}(1)$ & \\
$\operatorname{Cr}(3)-O(1)-\operatorname{Cr}(2)$ & $119.14(19)$ \\
$\operatorname{Cr}(1)-O(1)-\operatorname{Cr}(2)$ & $120.11(18)$ \\
\end{tabular}

The complexes are linked via hydrogen bonds between the terminal water ligands and the nitrate anion and methanol solvent of crystallisation (Figure 17) in the same manner as was observed for the analogous iron and chromium complex. The oxygen atoms of the nitrate anion are hydrogen bonded to two terminal water ligands (O(N1)-OW3, ON3-OW2', ON3-OW3') of different complexes and to the methanol of crystallisation (ON1-OM1). The methanol of crystallisation is hydrogen bonded to the nitrate anion, the terminal water ligand (OM1-OW1") of a third complex and a chlorine atom of the bridging ligand on a fourth complex (OM1-Cl2"'). 


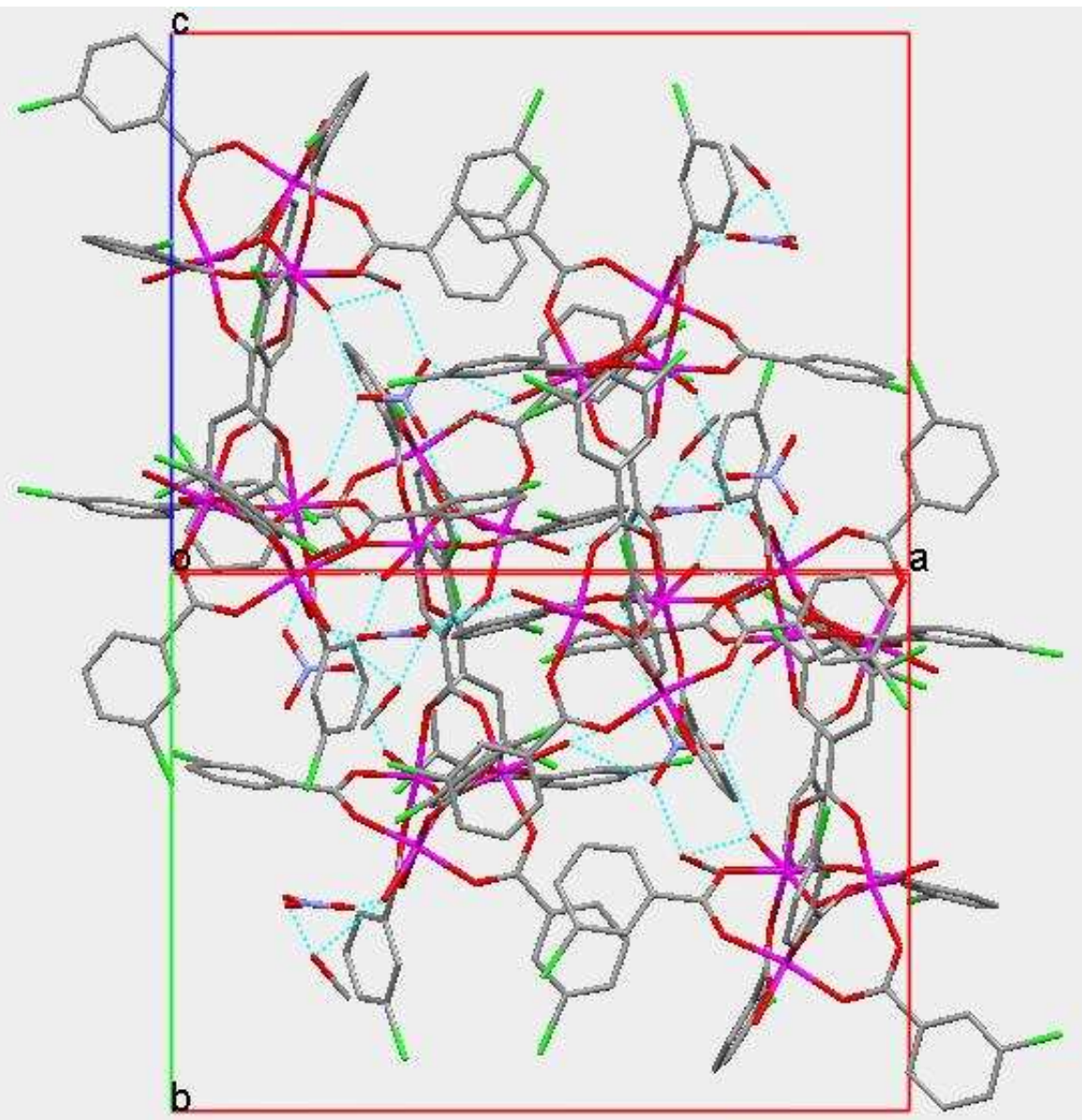

Figure 17: Unit cell of $\left[\mathrm{Cr}_{3} \mathrm{O}\left(\mathrm{O}_{2} \mathrm{CC}_{6} \mathrm{H}_{4}-3-\mathrm{Cl}\right)_{6}\left(\mathrm{H}_{2} \mathrm{O}\right)_{3}\right] \mathrm{NO}_{3} \cdot \mathrm{MeOH}$ looking down the (011) plane showing the hydrogen bonding between the cations. 


\subsection{4 $\left[\mathrm{Fe}_{6} \mathrm{O}_{2}(\mathrm{OH})_{2}\left(\mathrm{O}_{2} \mathrm{CC}_{6} \mathrm{H}_{4}-3-\mathrm{Cl}\right)_{12}\left(\mathrm{H}_{2} \mathrm{O}\right)_{2}\right] 3 \mathrm{CH}_{3} \mathrm{CN}$}

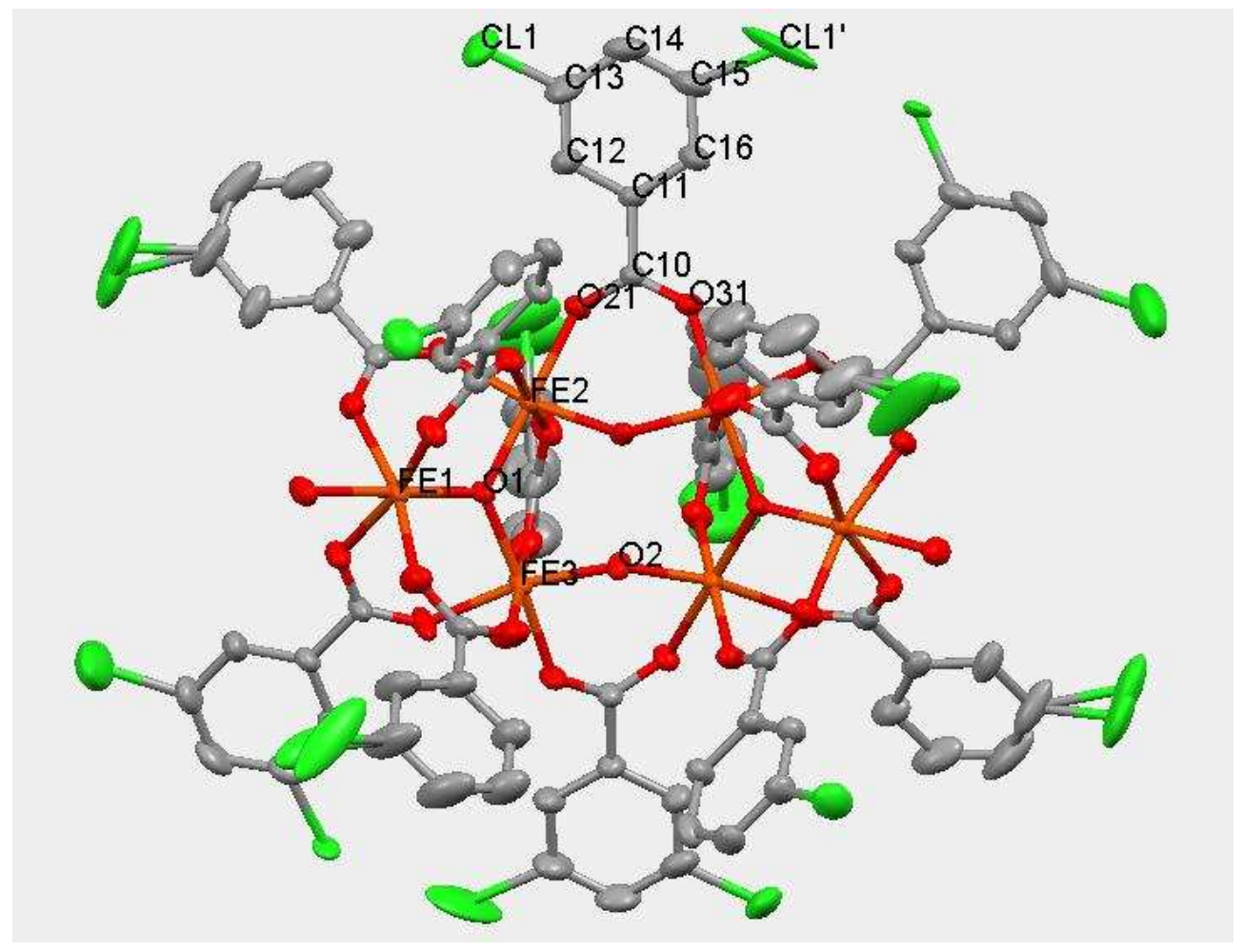

Figure 18: Crystal structure of $\left[\mathrm{Fe}_{6} \mathrm{O}_{2}(\mathrm{OH})_{2}\left(\mathrm{O}_{2} \mathrm{CC}_{6} \mathrm{H}_{4}-3-\mathrm{Cl}\right)_{12}\left(\mathrm{H}_{2} \mathrm{O}\right)_{2}\right]$ with $50 \%$ thermal ellipsoids (hydrogen atoms omitted for clarity).

$\left[\mathrm{Fe}_{6} \mathrm{O}_{2}(\mathrm{OH})_{2}\left(\mathrm{O}_{2} \mathrm{CC}_{6} \mathrm{H}_{4}-3-\mathrm{Cl}\right)_{12}\left(\mathrm{H}_{2} \mathrm{O}\right)_{2}\right] 3 \mathrm{MeCN}$ crystallises in the monoclinic space group $C 2 / c$ with $Z=8$, the crystal structure of which is shown in Figure 18. The complex contains two trinuclear like structures joined by two hydroxide and two carboxylate bridges with the iron centres of the separate trinuclear units arranged in a distorted isosceles triangle (Fe-Fe-Fe angles: 62.78, 58.59, 58.62 ${ }^{\circ}$; Fe'*Fe distances: 3.297, 3.434, $3.296 \AA$ ). The complex contains 3-chlorobenzoate and hydroxide bridging ligands, two terminal water ligands and three acetonitrile molecules of crystallisation. Due to a $C_{2}$ axis of symmetry in the centre of and perpendicular to the plane of the four iron ions, half the complex was generated from symmetry equivalent positions. The chlorine atoms of the carboxylate bridges show some disorder and may occupy two sites. The hydrogen atoms on the hydroxide bridge and acetonitrile molecules were calculated. 
Table 4 shows selected bond lengths and angles for $\left[\mathrm{Fe}_{6} \mathrm{O}_{2}(\mathrm{OH})_{2}\left(\mathrm{O}_{2} \mathrm{CC}_{6} \mathrm{H}_{4}-3-\mathrm{Cl}\right)_{12}\left(\mathrm{H}_{2} \mathrm{O}\right)_{2}\right] 3 \mathrm{MeCN}$ (a complete list can be found in Section 6.1.4.2). There are two long and one shorter iron to central oxygen bonds with $\mathrm{Fe}(1)-\mathrm{O}(1)$ $=1.878 \AA, \mathrm{Fe}(2)-\mathrm{O}(1)=1.955 \AA$ and $\mathrm{Fe}(3)-\mathrm{O}(1)=1.957 \AA$ giving an average $\mathrm{Fe}-\mathrm{O}$ bond length of $1.930 \AA$. The Fe-O-Fe bond angles of the trinuclear units have two similar and one larger angle with an average bond angle of $120.00^{\circ}$. The Fe-O bond distance of the bridging hydroxide is slightly bigger with an average distance of $1.956 \AA$ and the $\mathrm{Fe}-\mathrm{O}-\mathrm{Fe}$ bond angle of the hydroxide bridges is larger than the angles of the trinuclear core at $135.95^{\circ}$. The $\mathrm{O} \cdots \mathrm{O}$ distance between the oxygen atoms of the hydroxide bridges is 2.535 $\AA$. The oxygen atoms of the hydroxide bridges sit $0.588 \AA$ above the hydroxide bridged iron plane and the two remaining iron ions sit $1.462 \AA$ above the plane. The central oxygen ions sit $0.014 \AA$ above the trinuclear iron plane with an angle made between the planes of the two trinuclear units of $115.37^{\circ}$. The distance of the iron to the oxygen of the terminal water is $\mathrm{Fe}(1)-\mathrm{O}(\mathrm{W} 1)=2.114 \AA$ and the distance between the iron and the oxygen of the carboxylate group varies between 1.999 to $2.044 \AA$ with an average bond distance of $2.024 \AA$.

Table 4: Selected bond lengths $[\AA]$ and angles $\left[^{\circ}\right]$ for $\left[\mathrm{Fe}_{6} \mathrm{O}_{2}(\mathrm{OH})_{2}\left(\mathrm{O}_{2} \mathrm{CC}_{6} \mathrm{H}_{4}-3-\mathrm{Cl}\right)_{12}\left(\mathrm{H}_{2} \mathrm{O}\right)_{2}\right] 3 \mathrm{MeCN}$.

\begin{tabular}{|c|c|}
\hline \multicolumn{2}{|l|}{ Bond length } \\
\hline $\operatorname{Fe}(1)-O(1)$ & $1.9550(17)$ \\
\hline $\mathrm{Fe}(1)-\mathrm{O}(2)$ & $1.968(2)$ \\
\hline $\mathrm{Fe}(1)-\mathrm{O}(11)$ & $2.0259(18)$ \\
\hline $\mathrm{Fe}(1)-\mathrm{O}(12)$ & $2.022(2)$ \\
\hline $\mathrm{Fe}(1)-\mathrm{O}(13)$ & $2.043(2)$ \\
\hline $\mathrm{Fe}(1)-\mathrm{O}(14)$ & $2.022(2)$ \\
\hline $\mathrm{Fe}(2)-\mathrm{O}(1)$ & $1.8777(18)$ \\
\hline $\mathrm{Fe}(2)-\mathrm{O}(21)$ & $2.009(2)$ \\
\hline $\mathrm{Fe}(2)-\mathrm{O}(22)$ & $2.042(2)$ \\
\hline $\mathrm{Fe}(2)-\mathrm{O}(23)$ & $2.023(2)$ \\
\hline $\mathrm{Fe}(2)-\mathrm{O}(24)$ & $1.999(2)$ \\
\hline $\mathrm{Fe}(2)-\mathrm{OW} 1$ & $2.114(2)$ \\
\hline $\operatorname{Fe}(3)-O(2)^{1}$ & $1.9443(19)$ \\
\hline $\mathrm{Fe}(3)-\mathrm{O}(1)$ & $1.9568(17)$ \\
\hline $\mathrm{Fe}(3)-\mathrm{O}(31)$ & $2.0441(19)$ \\
\hline $\mathrm{Fe}(3)-\mathrm{O}(32)$ & $2.007(2)$ \\
\hline $\mathrm{Fe}(3)-\mathrm{O}(33)$ & $2.042(3)$ \\
\hline $\mathrm{Fe}(3)-\mathrm{O}(34)$ & $2.010(2)$ \\
\hline
\end{tabular}




$\begin{array}{ll}\text { Bond angle } & \\ \mathrm{Fe}(2)-\mathrm{O}(1)-\mathrm{Fe}(1) & 118.68(9) \\ \mathrm{Fe}(2)-\mathrm{O}(1)-\mathrm{Fe}(3) & 118.52(9) \\ \mathrm{Fe}(1)-\mathrm{O}(1)-\mathrm{Fe}(3) & 122.79(9) \\ \mathrm{Fe}(3)^{1}-\mathrm{O}(2)-\mathrm{Fe}(1) & 135.95(11)\end{array}$

${ }^{1}$ Symmetry transformation used to generate equivalent atoms: $-x+1, y,-z+3 / 2$

There is no extended network of hydrogen bonds linking the complexes as is observed for the trinuclear complexes. Instead, the complexes are linked via weaker van der Waals bonds between the carbon atoms of the carboxylates to the chlorine atoms of neighbouring carboxylate bridges or the carbon of the acetonitrile solvent of crystallisation (Figure 19). Two of the acetonitrile solvents of crystallisation are hydrogen bonded to the terminal water ligand $(\mathrm{O}(\mathrm{W} 1)-\mathrm{N}(1), \mathrm{O}(\mathrm{W} 1)-\mathrm{N}(2))$ whilst the remaining acetonitrile is hydrogen bonded to the oxygen of the hydroxide bridge $(\mathrm{O}(2)-\mathrm{N}(3))$. The acetonitrile is disordered between two sites and may be bonded to either of the two hydroxide bridges.

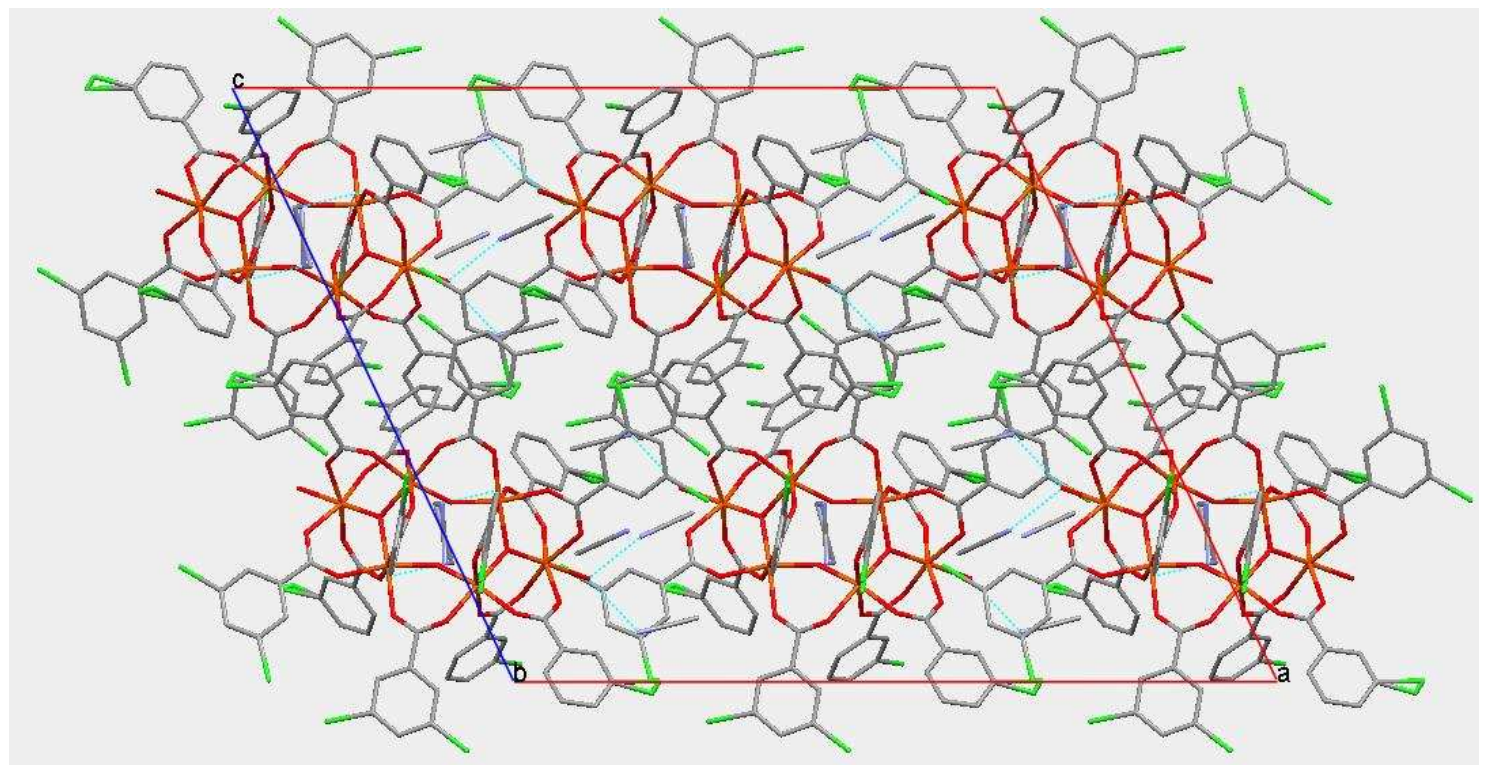

Figure 19: Unit cell of $\left[\mathrm{Fe}_{6} \mathrm{O}_{2}(\mathrm{OH})_{2}\left(\mathrm{O}_{2} \mathrm{CC}_{6} \mathrm{H}_{4}-3-\mathrm{Cl}\right)_{12}\left(\mathrm{H}_{2} \mathrm{O}\right)_{2}\right] 3 \mathrm{MeCN}$ looking down the (010) plane.

\subsubsection{Discussion of Structural Results}

The 3-chlorobenzoate iron and chromium trinuclear complexes all have similar structures and are connected by an identical hydrogen bond network. The aqua solvated complexes are isomorphous however the replacement of the water by a methanol molecule gives rise 
to a different space group. The trinuclear units have similar, nearly equilateral, $\mathrm{M}_{3} \mathrm{O}$ cores with a M-O bond length of around $1.9 \AA$ and a M-O-M bond angle of around $120^{\circ}$. The bond lengths of the metal to the terminal and bridging ligands are different with the bond lengths of the iron complex on average longer than the bond lengths observed for the chromium complexes. This may be explained by the chromium forming stronger metal oxygen bonds than the iron. The shortest M-O bond is between the metal and central oxygen and the longest bond is between the iron and oxygen of the terminal water and may be explained by the trans effect.

The presence of a van der Waals interaction between the chlorine atom on the 3chlorobenzoate and the nitrate may explain the one methanol of crystallisation seen in $\left[\mathrm{Cr}_{3} \mathrm{O}\left(\mathrm{O}_{2} \mathrm{CC}_{6} \mathrm{H}_{4}-3-\mathrm{Cl}\right)_{6}\left(\mathrm{H}_{2} \mathrm{O}\right)_{3}\right] \mathrm{NO}_{3} \cdot \mathrm{MeOH}$. An analogous chromium benzoate complex recrystallised in methanol contained two methanol molecules of crystallisation and crystallises in a $P 2_{1} / n$ space group ${ }^{[117]}$. The second methanol is hydrogen bonded in the same position to the nitrate as the chlorine atom that has a van der Waals interaction with the nitrate.

On going from the iron 3-chlorobenzoate trinuclear to hexanuclear complex, several structural changes are observed. The shape of the $\mathrm{Fe}_{3}$ unit goes from a pseudo-equilateral triangle to a pseudo-isosceles triangle and the average iron to ligand bond distances increase. These changes may be due to the hydroxide bridges having some effect on the bonding around the iron. The pseudo-isosceles shape arises from the lengthening of the iron to central oxide bonds of the hydroxide bonded irons and a shortening of the terminal water bound iron. The Fe-O bond distances are similar to those seen in the trinuclear units of other iron hexanuclear complexes ${ }^{[67,118]}$. The Fe-O bond to the terminal water is longer compared to the analogous bonds of the trinuclear units. This is explained by the shorter 
iron to central oxide which causes a lengthening of the bond to the terminal water due to the trans effect. The $\mathrm{O} \cdots \mathrm{O}$ distance is similar to that seen in other hydroxide bridged hexanuclear winged complexes ${ }^{[53]}$ and is longer than that seen for a direct O-O bond ${ }^{[119]}$. The distance is small enough for hydrogen bonding to occur between the two hydroxide bridges and the calculated hydrogen position occupies this space. These structural features are important as previous research of hexanuclear winged iron complexes ${ }^{[120]}$ has shown that the magnetic interaction is dependent on the angle and the Fe-O bond distance of the hydroxide bridges.

\subsection{Infrared Spectroscopy}

Infrared spectroscopy was used to confirm the formation of the trinuclear precursor and to observe whether structural changes had occurred during the heating process.

\subsubsection{Iron complexes}

\subsubsection{Acetate trinuclear complex}

The IR spectrum of $\left[\mathrm{Fe}_{3} \mathrm{O}\left(\mathrm{O}_{2} \mathrm{CCH}_{3}\right)_{6}\left(\mathrm{H}_{2} \mathrm{O}\right)_{3}\right] \mathrm{NO}_{3}$ shows the characteristic peaks of a trinuclear complex. The stretching frequencies of the metal core are located at $604 \mathrm{~cm}^{-1}$ $\left(\mathrm{v}_{\mathrm{as}}\left(\mathrm{Fe}_{3} \mathrm{O}\right)\right)$ and $433 \mathrm{~cm}^{-1}\left(\mathrm{v}_{\mathrm{d}}\left(\mathrm{FeO}_{4}\right)\right)$. The difference between the carboxylate $\mathrm{CO}_{2}^{-}$ asymmetric and symmetric stretching frequencies, $\Delta\left(\mathrm{CO}_{2}\right)\left(146 \mathrm{~cm}^{-1}\right)$, indicates that the carboxylates are bridged between two metal ions as expected $\left(\Delta\left(\mathrm{CO}_{2}\right)\right.$ of the free acetate ion $=148 \mathrm{~cm}^{-1}$ ). The water bound to the iron is observed as a broad O-H stretching frequency at $3424 \mathrm{~cm}^{-1}$. 


\subsubsection{3-Chlorobenzoate complexes}

The IR spectrum of $\left[\mathrm{Fe}_{3} \mathrm{O}\left(\mathrm{O}_{2} \mathrm{CC}_{6} \mathrm{H}_{4}-3-\mathrm{Cl}_{6}\left(\mathrm{H}_{2} \mathrm{O}\right)_{3}\right] \mathrm{NO}_{3} \cdot \mathrm{CH}_{3} \mathrm{OH}\right.$ shows the characteristic peaks of a trinuclear complex. The stretching frequencies of the metal core are located at $633 \mathrm{~cm}^{-1}\left(\mathrm{U}_{\text {as }}\left(\mathrm{Fe}_{3} \mathrm{O}\right)\right)$ and $478 \mathrm{~cm}^{-1}\left(\mathrm{U}_{\mathrm{d}}\left(\mathrm{FeO}_{4}\right)\right)$. The difference between the carboxylate $\mathrm{CO}_{2}^{-}$ asymmetric and symmetric stretching frequencies, $\Delta\left(\mathrm{CO}_{2}\right)\left(136 \mathrm{~cm}^{-1}\right)$, indicates that the carboxylates are bridged between two metal ions as expected $\left(\Delta\left(\mathrm{CO}_{2}\right)\right.$ of the free 3-chlorobenzoate ion $=167 \mathrm{~cm}^{-1}$ ). The water bound to the iron is observed as a broad O$\mathrm{H}$ stretching frequency at $3413 \mathrm{~cm}^{-1}$. The nitrate anion has stretching frequencies at 1314 and $822 \mathrm{~cm}^{-1}$ and the methanol has stretching frequencies at 3695, 3620, 1034 and 911 $\mathrm{cm}^{-1}$. Upon heating to $200^{\circ} \mathrm{C}$, several changes in the IR spectrum of the crude material were observed. Below $650 \mathrm{~cm}^{-1}$, the $v_{\mathrm{as}}\left(\mathrm{Fe}_{3} \mathrm{O}\right)$ peak at $633 \mathrm{~cm}^{-1}$ decreases in frequency and splits into two peaks at $618 \mathrm{~cm}^{-1}$ and $601 \mathrm{~cm}^{-1}$ whilst the $\mathrm{v}_{\mathrm{d}}\left(\mathrm{FeO}_{4}\right)$ peak at $478 \mathrm{~cm}^{-1}$ remains unchanged. This is consistent with the double trinuclear core in the winged structure of the $\mathrm{Fe}_{6}$ polynuclear complex, $\left[\mathrm{Fe}_{6} \mathrm{O}_{2}(\mathrm{OH})_{2}\left(\mathrm{O}_{2} \mathrm{CC}_{6} \mathrm{H}_{4}-3-\mathrm{Cl}\right)_{12}\left(\mathrm{H}_{2} \mathrm{O}\right)_{2}\right]$, where the $\mathrm{u}_{\text {as }}\left(\mathrm{Fe}_{3} \mathrm{O}\right)$ vibration is influenced more by the formation of the more asymmetric $\mathrm{Fe}_{3} \mathrm{O}$ core. The stretching frequencies of the carboxylate bridges remain largely unchanged apart from the appearance of a peak at $1537 \mathrm{~cm}^{-1}$. This additional peak can be attributed to the carboxylate bridges having different environments compared to the trinuclear complex where the bridges are all in the same environment. The O-H stretching frequency of the coordinated water is lowered from $3425 \mathrm{~cm}^{-1}$ to $3413 \mathrm{~cm}^{-1}$. The peaks due to the nitrate anion and methanol of solvation were not present as is expected in the formation of $\left[\mathrm{Fe}_{6} \mathrm{O}_{2}(\mathrm{OH})_{2}\left(\mathrm{O}_{2} \mathrm{CC}_{6} \mathrm{H}_{4}-3-\mathrm{Cl}\right)_{12}\left(\mathrm{H}_{2} \mathrm{O}\right)_{2}\right]$.

The chloride salt, $\left[\mathrm{Fe}_{3} \mathrm{O}\left(\mathrm{O}_{2} \mathrm{CC}_{6} \mathrm{H}_{4}-3-\mathrm{Cl}\right)_{6}\left(\mathrm{H}_{2} \mathrm{O}\right)_{3}\right] \mathrm{Cl} \cdot \mathrm{H}_{2} \mathrm{O}$, contains the same stretching frequencies (with the exception of the nitrate and methanol peaks) as seen in the nitrate complex, within the precision of the instrument. Because the chloride ion is ionic, there is 
no vibration mode of the ion and therefore its presence can not be determined by the IR spectrum. When this complex is heated to $290^{\circ} \mathrm{C}$, similar changes in the peaks are observed compared to when the nitrate salt was heated to $200^{\circ} \mathrm{C}$. The $v_{\text {as }}\left(\mathrm{Fe}_{3} \mathrm{O}\right)$ stretching frequency of $636 \mathrm{~cm}^{-1}$ is lowered to $600 \mathrm{~cm}^{-1}$ and is most likely split (although the peak at around $618 \mathrm{~cm}^{-1}$ is less intense) and the $\mathrm{v}_{\mathrm{d}}\left(\mathrm{FeO}_{4}\right)$ stretching frequency at around $480 \mathrm{~cm}^{-1}$ broadens. The remaining peaks remain essentially unchanged apart from the appearance of a new peak at $1506 \mathrm{~cm}^{-1}$. It is therefore concluded that at this temperature the majority of the product formed is the $\mathrm{Fe}_{6}$ complex.

When $\left[\mathrm{Fe}_{3} \mathrm{O}\left(\mathrm{O}_{2} \mathrm{CC}_{6} \mathrm{H}_{4}-3-\mathrm{Cl}\right)_{6}\left(\mathrm{H}_{2} \mathrm{O}\right)_{3}\right] \mathrm{Cl} \cdot \mathrm{H}_{2} \mathrm{O}$ is heated to $360^{\circ} \mathrm{C}$, the solid isolated has a broader $v_{a s}\left(F_{3} \mathrm{O}\right)$ peak which has shifted from $636 \mathrm{~cm}^{-1}$ to $586 \mathrm{~cm}^{-1}$ and the $v_{\mathrm{d}}\left(\mathrm{FeO}_{4}\right)$ peak at around $480 \mathrm{~cm}^{-1}$ is lower in intensity and slightly broader. The carboxylate peaks are essentially unchanged apart from the appearance of a new peak at $1543 \mathrm{~cm}^{-1}$. Previous research has shown that when an iron trinuclear benzoate complex, $\left[\mathrm{Fe}_{3} \mathrm{O}\left(\mathrm{O}_{2} \mathrm{CC}_{6} \mathrm{H}_{5}\right)_{6}\left(\mathrm{H}_{2} \mathrm{O}\right)_{3}\right] \mathrm{NO}_{3}$, is heated at $300^{\circ} \mathrm{C}$, an $\mathrm{Fe}_{11}$ complex is formed, $\left[\mathrm{Fe}_{11} \mathrm{O}_{6}(\mathrm{OH})_{6}\left(\mathrm{O}_{2} \mathrm{CPh}\right)_{15}\right]^{[67]}$. The formation of a $\mathrm{Fe}_{11}$ 3-chlorobenzoate complex is consistent with the observed IR spectrum. The core of the $\mathrm{Fe}_{11}$ cage structure consists of an array of $\mathrm{Fe}_{3} \mathrm{O}$ units which explains the presence of the $\mathrm{M}_{3} \mathrm{O}$ vibrations.

\subsubsection{Benzoate complexes}

The IR spectrum of $\left[\mathrm{Fe}_{3} \mathrm{O}\left(\mathrm{O}_{2} \mathrm{CC}_{6} \mathrm{H}_{5}\right)_{6}\left(\mathrm{H}_{2} \mathrm{O}\right)_{3}\right] \mathrm{NO}_{3} \cdot 2 \mathrm{CH}_{3} \mathrm{OH}$ shows the characteristic peaks of a trinuclear complex. The stretching frequencies of the metal core are located at 628 $\mathrm{cm}^{-1}\left(\mathrm{U}_{\mathrm{as}}\left(\mathrm{Fe}_{3} \mathrm{O}\right)\right)$ and $486 \mathrm{~cm}^{-1}\left(\mathrm{U}_{\mathrm{d}}\left(\mathrm{FeO}_{4}\right)\right)$. Comparing the observed $\Delta\left(\mathrm{CO}_{2}\right)$ value $\left(152 \mathrm{~cm}^{-1}\right)$ with the benzoate free ion $\left(138 \mathrm{~cm}^{-1}\right)$ indicates that the carboxylate ligands bridge two metal ions. The coordinated water has a broad O-H stretching frequency at $3416 \mathrm{~cm}^{-1}$. 
The nitrate anion has stretching frequencies at $1283 \mathrm{~cm}^{-1}$ and $824 \mathrm{~cm}^{-1}$ and the methanol has stretching frequencies at 3612 and $3562 \mathrm{~cm}^{-1}$.

The iron benzoate chloride salt, $\left[\mathrm{Fe}_{3} \mathrm{O}\left(\mathrm{O}_{2} \mathrm{CC}_{6} \mathrm{H}_{5}\right)_{6}\left(\mathrm{H}_{2} \mathrm{O}\right)_{3}\right] \mathrm{Cl}$, contains the same stretching frequencies as was observed in the nitrate complex, within the precision of the instrument, with the exception of the absent nitrate and methanol peaks and some small changes in the $\mathrm{M}_{3} \mathrm{O}$ stretching frequencies. The $v_{\text {as }}\left(\mathrm{Fe}_{3} \mathrm{O}\right)$ vibration is split into two with peaks at 632 and $621 \mathrm{~cm}^{-1}$ which may indicate that the chloride is having some sort of influence on the metal core. The remaining vibration, $\mathrm{U}_{\mathrm{d}}\left(\mathrm{FeO}_{4}\right)$, is located at $481 \mathrm{~cm}^{-1}$. When this complex is heated to $260^{\circ} \mathrm{C}$, similar changes in the peaks are observed compared to when the iron 3-chlorobenzoate nitrate and chloride complexes were heated to $200^{\circ} \mathrm{C}$ and $290^{\circ} \mathrm{C}$ respectively. The $\cup_{\text {as }}\left(\mathrm{Fe}_{3} \mathrm{O}\right)$ split increases slightly with bands at 635 and $618 \mathrm{~cm}^{-1}$. A peak appears at $591 \mathrm{~cm}^{-1}$ and the $v_{\mathrm{d}}\left(\mathrm{FeO}_{4}\right)$ stretching frequency shifts to $483 \mathrm{~cm}^{-1}$. The remaining peaks remain essentially unchanged apart from the appearance of a new peak at $1514 \mathrm{~cm}^{-1}$. By comparing the changes in the IR spectra of the product of heating the iron benzoate complexes to the product of heating the iron 3-chlorobenzoate complexes, it can be concluded that heating to a temperature of between $200-300^{\circ} \mathrm{C}$ forms a winged $\mathrm{Fe}_{6}$ complex.

The IR spectrum of $\left[\mathrm{Fe}^{\mathrm{III}}{ }_{2} \mathrm{Fe}^{\mathrm{II}} \mathrm{O}\left(\mathrm{O}_{2} \mathrm{CC}_{6} \mathrm{H}_{5}\right)_{6}\left(\mathrm{H}_{2} \mathrm{O}\right)_{3}\right]_{2} \mathrm{H}_{2} \mathrm{O}$ shows the characteristic peaks of a mixed valent trinuclear complex. The stretching frequencies of the metal core are located at $618 \mathrm{~cm}^{-1}$ and $592 \mathrm{~cm}^{-1}\left(\mathrm{v}_{\mathrm{as}}\left(\mathrm{Fe}_{3} \mathrm{O}\right)\right)$ and $474 \mathrm{~cm}^{-1}\left(\mathrm{v}_{\mathrm{d}}\left(\mathrm{FeO}_{4}\right)\right)$. The splitting of the $\mathrm{v}_{\text {as }}\left(\mathrm{Fe}_{3} \mathrm{O}\right)$ stretching frequency and the absence of any nitrate peaks confirm the formation of a mixed valent complex. Comparison of the observed $\Delta\left(\mathrm{CO}_{2}\right)$ value $\left(155 \mathrm{~cm}^{-1}\right)$ with the benzoate free ion $\left(138 \mathrm{~cm}^{-1}\right)$ indicates that the carboxylates are bridging two metal ions. The presence of the water is confirmed by the broad $\mathrm{O}-\mathrm{H}$ stretching frequency at $3424 \mathrm{~cm}^{-1}$. 
Upon heating to $250^{\circ} \mathrm{C}$, several changes are observed. The stretching frequency of $\mathrm{v}_{\text {as }}\left(\mathrm{Fe}_{3} \mathrm{O}\right)$ decreases to $608 \mathrm{~cm}^{-1}$ and $585 \mathrm{~cm}^{-1}-$ a splitting difference of $23 \mathrm{~cm}^{-1}$ compared to $26 \mathrm{~cm}^{-1}$ in the trinuclear complex. The $v_{\mathrm{d}}\left(\mathrm{FeO}_{4}\right)$ peak shifts to $479 \mathrm{~cm}^{-1}$. The remaining peaks are essentially unchanged apart from the appearance of a peak at $1520 \mathrm{~cm}^{-1}$.

\subsubsection{Diphenylacetate complexes}

The IR spectrum of $\left[\mathrm{Fe}_{3} \mathrm{O}\left(\mathrm{O}_{2} \mathrm{CCHPh}_{2}\right)_{6}\left(\mathrm{H}_{2} \mathrm{O}\right)_{3}\right] \mathrm{NO}_{3}$ shows the characteristic peaks of a trinuclear complex. The stretching frequencies of the metal core are located at $594 \mathrm{~cm}^{-1}$ $\left(\mathrm{v}_{\text {as }}\left(\mathrm{Fe}_{3} \mathrm{O}\right)\right)$ and $421 \mathrm{~cm}^{-1}\left(\mathrm{v}_{\mathrm{d}}\left(\mathrm{FeO}_{4}\right)\right)$. Comparison of the observed $\Delta\left(\mathrm{CO}_{2}\right)$ value $\left(195 \mathrm{~cm}^{-1}\right)$ with the diphenylacetate free ion $\left(185 \mathrm{~cm}^{-1}\right)$ indicates that the carboxylates are bridging two metal ions. The water bound to the iron is observed as a broad $\mathrm{O}-\mathrm{H}$ stretching frequency at $3423 \mathrm{~cm}^{-1}$ and the nitrate anion has stretching frequencies at 1322 and $826 \mathrm{~cm}^{-1}$. When $\left[\mathrm{Fe}_{3} \mathrm{O}\left(\mathrm{O}_{2} \mathrm{CCHPh}\right)_{6}\left(\mathrm{H}_{2} \mathrm{O}\right)_{3}\right] \mathrm{NO}_{3}$ is heated to $320^{\circ} \mathrm{C}$, the $\mathrm{v}_{\mathrm{as}}\left(\mathrm{Fe}_{3} \mathrm{O}\right)$ peak of the crude material shifts from $594 \mathrm{~cm}^{-1}$ to $555 \mathrm{~cm}^{-1}$ and the $\mathrm{u}_{\mathrm{d}}\left(\mathrm{FeO}_{4}\right)$ peak at around lowers in intensity and splits into peaks at 478, 451 and $430 \mathrm{~cm}^{-1}$. The carboxylate peaks are essentially unchanged apart from the appearance of a new peak at $1538 \mathrm{~cm}^{-1}$. The change in the infrared spectrum is similar to that observed for the formation of the $\mathrm{Fe}_{11}$ 3-chlorobenzoate complex from the heating of a $\mathrm{Fe}_{3} 3$-chlorobenzoate precursor. This indicates the formation of the $\mathrm{Fe}_{11}$ diphenylacetate at $320^{\circ} \mathrm{C}$.

\subsubsection{Chromium complexes}

\subsubsection{3-chlorobenzoate complexes}

The IR spectrum of $\left[\mathrm{Cr}_{3} \mathrm{O}\left(\mathrm{O}_{2} \mathrm{CC}_{6} \mathrm{H}_{4}-3-\mathrm{Cl}\right)_{6}\left(\mathrm{H}_{2} \mathrm{O}\right)_{3}\right] \mathrm{NO}_{3} \cdot 2 \mathrm{CH}_{3} \mathrm{COCH}_{3}$ shows the characteristic peaks of a trinuclear complex. The stretching frequencies of the metal core 
are located at $626 \mathrm{~cm}^{-1}\left(\mathrm{U}_{\mathrm{as}}\left(\mathrm{Cr}_{3} \mathrm{O}\right)\right)$ and $528 \mathrm{~cm}^{-1}$ and $514 \mathrm{~cm}^{-1}\left(\mathrm{U}_{\mathrm{d}}\left(\mathrm{CrO}_{4}\right)\right)$. The splitting of $\mathrm{v}_{\mathrm{d}}\left(\mathrm{CrO}_{4}\right)$ indicates that the $\mathrm{CrO}_{4}$ units are coupling under the symmetry of the complex. The $\Delta\left(\mathrm{CO}_{2}\right)$ is equal to $132 \mathrm{~cm}^{-1}$ (free ion $=167 \mathrm{~cm}^{-1}$ ) which indicates that the carboxylates are bridging two chromium ions. The water bound to the chromium is observed as a broad O-H stretching frequency at $3397 \mathrm{~cm}^{-1}$. The nitrate anion has stretching frequencies at 1308 and $825 \mathrm{~cm}^{-1}$ and the acetone has stretching frequencies at 1697 and $1233 \mathrm{~cm}^{-1}$. When the complex is heated to $110^{\circ} \mathrm{C}$, the only change was the disappearance of the peak at $1697 \mathrm{~cm}^{-1}$ indicating the loss of acetone. This is consistent with the crystal structure which shows that the product and precursor salt is the same. When the complex was heated to $220^{\circ} \mathrm{C}$, several changes are observed. The stretching frequency of $v_{\text {as }}\left(\mathrm{Cr}_{3} \mathrm{O}\right)$ at 626 is replaced by a peak at $605 \mathrm{~cm}^{-1}$, the peaks due to acetone and the nitrate anion disappear and a peak at $1535 \mathrm{~cm}^{-1}$ appears. Although these changes are similar to those observed in the formation of $\mathrm{Fe}_{6}$ complex from the heating of a $\mathrm{Fe}_{3}$ complex, there has been no reported case of a $\mathrm{Cr}_{6}$ complex with a winged structure and without a crystal structure, it can not be said that the winged $\mathrm{Cr}_{6}$ complex has been synthesised.

When $\left[\mathrm{Cr}_{3} \mathrm{O}\left(\mathrm{O}_{2} \mathrm{CC}_{6} \mathrm{H}_{4}-3-\mathrm{Cl}\right)_{6}\left(\mathrm{H}_{2} \mathrm{O}\right)_{3}\right] \mathrm{NO}_{3} \cdot 2 \mathrm{CH}_{3} \mathrm{COCH}_{3}$ was heated to $320^{\circ} \mathrm{C}$, a greater number of changes are observed in the IR spectrum. None of the $\mathrm{Cr}_{3} \mathrm{O}$ peaks of the trinuclear complex are observed and are replaced by peaks at 638,556 and $518 \mathrm{~cm}^{-1}$ with shoulders at $628,592,501$ and $480 \mathrm{~cm}^{-1}$. Again, the peaks of the acetone and the nitrate anion are not observed as would be expected from heating to a higher temperature. The remaining peaks remain essentially unchanged apart from the appearance of two new peaks at 1547 and $1495 \mathrm{~cm}^{-1}$. 


\subsubsection{Benzoate complexes}

The IR spectrum of $\left[\mathrm{Cr}_{3} \mathrm{O}\left(\mathrm{O}_{2} \mathrm{CC}_{6} \mathrm{H}_{5}\right)_{6}\left(\mathrm{H}_{2} \mathrm{O}\right)_{3}\right] \mathrm{NO}_{3} \cdot \mathrm{CH}_{3} \mathrm{COCH}_{3}$ shows the characteristic peaks of a trinuclear complex. The stretching frequencies of the metal core are located at $665 \mathrm{~cm}^{-1}\left(\mathrm{v}_{\mathrm{as}}\left(\mathrm{Cr}_{3} \mathrm{O}\right)\right)$ and $527 \mathrm{~cm}^{-1}$ and $515 \mathrm{~cm}^{-1}\left(\mathrm{v}_{\mathrm{d}}\left(\mathrm{CrO}_{4}\right)\right)$. The splitting of $\mathrm{v}_{\mathrm{d}}\left(\mathrm{CrO}_{4}\right)$ indicates that the $\mathrm{CrO}_{4}$ units are coupling in the IR from the symmetry of the complex. The $\Delta\left(\mathrm{CO}_{2}\right)$ is equal to $158 \mathrm{~cm}^{-1}$ (free ion $=138 \mathrm{~cm}^{-1}$ ) which indicates that the carboxylates are bridging two chromium ions. The coordinated water has a broad $\mathrm{O}-\mathrm{H}$ stretching frequency at $3375 \mathrm{~cm}^{-1}$. The nitrate anion gives stretching frequencies at 1319 and $828 \mathrm{~cm}^{-1}$ and the acetone gives stretching frequencies at 1697 and $1232 \mathrm{~cm}^{-1}$.

The IR spectrum of $\left[\mathrm{Cr}_{3} \mathrm{O}\left(\mathrm{O}_{2} \mathrm{CC}_{6} \mathrm{H}_{5}\right)_{6}\left(\mathrm{H}_{2} \mathrm{O}\right)_{3}\right] \mathrm{O}_{2} \mathrm{CC}_{6} \mathrm{H}_{5}$ contains the same stretching frequencies (with the exception of the nitrate peaks) as were seen in the nitrate complex within the margin of error for the instrument. The stretching frequencies of the metal core are located at $666 \mathrm{~cm}^{-1}\left(\mathrm{U}_{\mathrm{as}}\left(\mathrm{Cr}_{3} \mathrm{O}\right)\right)$ and $530 \mathrm{~cm}^{-1}$ and $514 \mathrm{~cm}^{-1}\left(\mathrm{U}_{\mathrm{d}}\left(\mathrm{CrO}_{4}\right)\right)$. The nitrate stretching frequencies are replaced by those of the benzoate at 1692, 1228 and $1041 \mathrm{~cm}^{-1}$.

In the IR of the chloride complex, $\left[\mathrm{Cr}_{3} \mathrm{O}\left(\mathrm{O}_{2} \mathrm{CC}_{6} \mathrm{H}_{5}\right)_{6}\left(\mathrm{H}_{2} \mathrm{O}\right)_{3}\right] \mathrm{Cl} \cdot 1.5 \mathrm{H}_{2} \mathrm{O}$, synthesised from the benzoate complex, the stretching frequencies of the benzoate anion are absent indicating that the benzoate has been replaced by a chloride ion. Upon heating the chloride complex to $320^{\circ} \mathrm{C}$, a similar change in the spectra is observed compared to the spectra of the product of heating the $\mathrm{Cr}_{3} 3$-chlorobenzoate complex to $320^{\circ} \mathrm{C}$. $\mathrm{The}^{\mathrm{C}} \mathrm{r}_{3} \mathrm{O}$ peaks of the trinuclear complex are replaced by peaks at 634,556 and $515 \mathrm{~cm}^{-1}$ with shoulders at 626,590 and $480 \mathrm{~cm}^{-1}$. The remaining peaks remain essentially unchanged apart from the appearance of two new peaks at 1541 and $1505 \mathrm{~cm}^{-1}$. 
On changing from the benzoate to the thiocyanate salt, $\left[\mathrm{Cr}_{3} \mathrm{O}\left(\mathrm{O}_{2} \mathrm{CC}_{6} \mathrm{H}_{5}\right)_{6}\left(\mathrm{H}_{2} \mathrm{O}\right)_{3}\right] \mathrm{SCN}$, two changes are noted indicating replacement of the benzoate with a thiocyanate anion. Firstly the benzoate stretching frequencies are absent and secondly, a peak at $2120 \mathrm{~cm}^{-1}$ is observed. Upon heating the thiocyanate complex to $320^{\circ} \mathrm{C}$, a similar change in the spectra is observed compared to the spectra from heating the chloride complex to $320^{\circ} \mathrm{C}$. The $\mathrm{Cr}_{3} \mathrm{O}$ peaks of the trinuclear complex are replaced by peaks at 636,558 and $515 \mathrm{~cm}^{-1}$ with shoulders at $625,616,574$ and $497 \mathrm{~cm}^{-1}$. The thiocyanate peak at $2120 \mathrm{~cm}^{-1}$ shifts to 2089

$\mathrm{cm}^{-1}$ indicating that the anion is not fully removed or decomposed. The remaining peaks remain relatively unchanged apart from the appearance of two peaks at 1550 and 1506 $\mathrm{cm}^{-1}$.

In previous papers, the chromium olation polymer such as the benzoate, $\left[\mathrm{Cr}_{2 \mathrm{n}}\left\{(\mathrm{OH})\left(\mathrm{O}_{2} \mathrm{CC}_{6} \mathrm{H}_{5}\right)_{2}\right\}_{2 \mathrm{n}-1}\right]\left(\mathrm{NO}_{3}\right)_{3-\mathrm{x}} \cdot\left(\mathrm{O}_{2} \mathrm{CC}_{6} \mathrm{H}_{5}\right)_{\mathrm{x}} \cdot 6 \mathrm{H}_{2} \mathrm{O}$, has been described as a trinuclear complex ${ }^{[59]}$. By observing the spectra of the chromium benzoate olation polymer, it can be observed that it is in fact not trinuclear. The characteristic $\mathrm{M}_{3} \mathrm{O}$ peaks are not observed and there is only a single broad peak at $532 \mathrm{~cm}^{-1}$, most likely due to a $\mathrm{Cr}_{2}(\mathrm{OH})$ vibration, seen below $650 \mathrm{~cm}^{-1}$. Another difference is in the values of $\Delta\left(\mathrm{CO}_{2}\right)$ where the value is smaller than that for the trinuclear chromium complex $\left(113 \mathrm{~cm}^{-1}\right.$ compared to $\left.158 \mathrm{~cm}^{-1}\right)$.

\subsection{Thermal Analysis Results}

Eleven precursors used in the high temperature synthesis were analysed using EGA-MS and TGA:

- $\left[\mathrm{Fe}_{3} \mathrm{O}\left(\mathrm{O}_{2} \mathrm{CCH}_{3}\right)_{6}\left(\mathrm{H}_{2} \mathrm{O}\right)_{3}\right] \mathrm{NO}_{3}$;

- $\left[\mathrm{Fe}_{3} \mathrm{O}\left(\mathrm{O}_{2} \mathrm{CPh}\right)_{6}\left(\mathrm{H}_{2} \mathrm{O}\right)_{3}\right] \mathrm{X},\left(\mathrm{X}=\mathrm{NO}_{3}^{-}, \mathrm{Cl}\right)$

- $\quad\left[\mathrm{Fe}_{2}^{\mathrm{III}}{ }_{2} \mathrm{Fe}^{\mathrm{II}} \mathrm{O}\left(\mathrm{O}_{2} \mathrm{CPh}\right)_{6}\left(\mathrm{H}_{2} \mathrm{O}\right)_{3}\right]$; 
- $\left[\mathrm{Fe}_{3} \mathrm{O}\left(\mathrm{O}_{2} \mathrm{CC}_{6} \mathrm{H}_{4}-3-\mathrm{Cl}_{6}\left(\mathrm{H}_{2} \mathrm{O}\right)_{3}\right] \mathrm{X},\left(\mathrm{X}=\mathrm{NO}_{3}{ }^{-}, \mathrm{Cl}^{-}\right)\right.$;

- $\left[\mathrm{Cr}_{3} \mathrm{O}\left(\mathrm{O}_{2} \mathrm{CPh}\right)_{6}\left(\mathrm{H}_{2} \mathrm{O}\right)_{3}\right] \mathrm{X},\left(\mathrm{X}=\mathrm{NO}_{3}^{-}, \mathrm{Cl}^{-}, \mathrm{SCN}^{\top}\right)$;

- $\left[\mathrm{Cr}_{3} \mathrm{O}\left(\mathrm{O}_{2} \mathrm{CC}_{6} \mathrm{H}_{4}-3-\mathrm{Cl}\right)_{6}\left(\mathrm{H}_{2} \mathrm{O}\right)_{3}\right] \mathrm{NO}_{3}$

- $\left[\mathrm{Cr}_{2 \mathrm{n}}\left\{(\mathrm{OH})\left(\mathrm{O}_{2} \mathrm{CPh}\right)_{2}\right\}_{2 \mathrm{n}-1}\right]\left(\mathrm{NO}_{3}\right)_{3-\mathrm{x}} \cdot\left(\mathrm{O}_{2} \mathrm{CC}_{6} \mathrm{H}_{5}\right)_{\mathrm{x}} \cdot \mathrm{yH} \mathrm{H}_{2} \mathrm{O}$.

EGA-MS was used to determine the nature of the gaseous products that were evolved. TGA was used to confirm these observations and to determine when any gases not detected by the EGA evolved from the sample. Using the above complexes, the influence on the final product of the metals, carboxylate ligands, anions and the nuclearity of the precursor complex could be studied. The EGA-MS of $\mathrm{Fe}\left(\mathrm{NO}_{3}\right)_{3} \cdot 9 \mathrm{H}_{2} \mathrm{O}$ and $\mathrm{Cr}\left(\mathrm{NO}_{3}\right)_{3} \cdot 9 \mathrm{H}_{2} \mathrm{O}$ were also obtained in order to compare the results with the trinuclear complexes that contained a nitrate anion. A table of common $\mathrm{m} / \mathrm{z}$ signals from the EGAMS and their corresponding ion fragments are shown in Table 5.

Table 5: Possible ion fragments and corresponding $\mathrm{m} / \mathrm{z}$ values.

\begin{tabular}{ll}
\hline Ion fragment & $\mathrm{m} / \mathbf{z}$ \\
$\mathrm{H}_{2}^{+}$ & 2 \\
$\mathrm{C}^{+}$ & 12 \\
$\mathrm{O}^{+}$ & 16 \\
$\mathrm{CO}_{2}^{+}$ & 22 \\
$\mathrm{NO}^{+}, \mathrm{CH}_{2} \mathrm{O}^{+}$ & 30 \\
$\mathrm{O}_{2}^{+}, \mathrm{S}^{+}, \mathrm{CH}_{3} \mathrm{OH}^{+}$ & 32 \\
$\mathrm{Cl}^{+}$ & 35 \\
$\mathrm{HCl}^{+}$ & 36 \\
$\mathrm{~N}_{2} \mathrm{O}^{+}, \mathrm{CO}_{2}^{+}$ & 44 \\
$\mathrm{CH}_{3} \mathrm{COCH}_{3}^{+}$ & 58 \\
$\mathrm{CH}_{3} \mathrm{CO}_{2}^{+}$ & 59 \\
$\mathrm{C}_{6} \mathrm{H}_{6}^{+}$ & 78 \\
\end{tabular}


For $\mathrm{m} / \mathrm{z}$ signals that could belong to more than one ion fragment, the actual ion fragment that is produced was determined by studying the isotope and fragment pattern of the signals. For example, a signal due to $\mathrm{CO}_{2}(\mathrm{~m} / \mathrm{z}=44)$ will have a coinciding signal $1.1 \%$ of its intensity at $\mathrm{m} / \mathrm{z}=45$ due to ${ }^{13} \mathrm{CO}_{2}$ (Figure 20). For larger ion fragments, the signal may have a signal due to further splitting of the ion fragment, such as the $\mathrm{m} / \mathrm{z}=15\left(\mathrm{CH}_{3}\right)$ signal that results from the fragmentation of acetone.

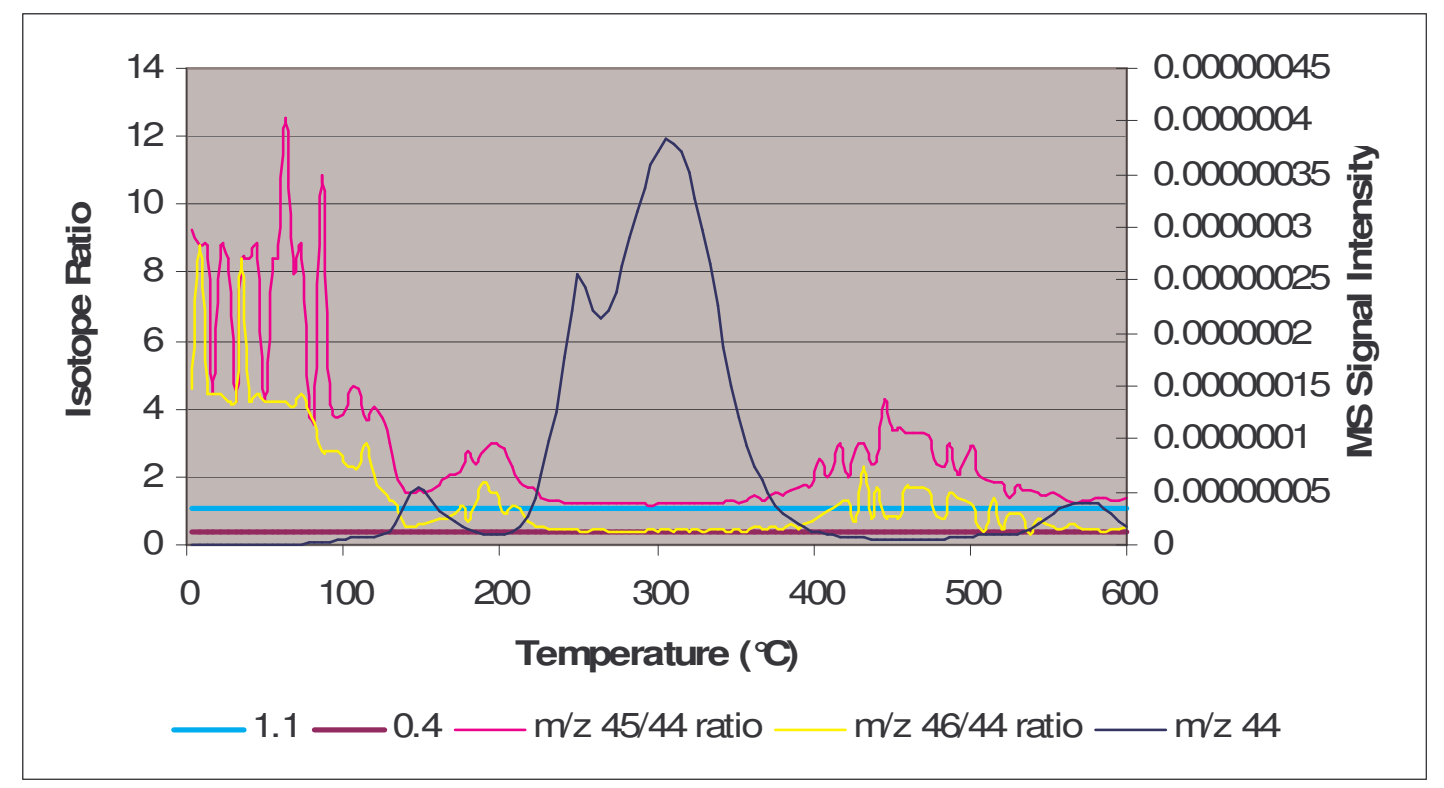

Figure 20: Isotope ratios of a $\mathrm{CO}_{2}$ signal $-{ }^{13} \mathrm{CO}_{2} \mathrm{~m} / \mathrm{z}=45(1.1)$ and ${ }^{18} \mathrm{OCOm} / \mathrm{z}=46(0.4)$

Because the EGA-MS studies were conducted under a nitrogen atmosphere there is little possibility of combustion of the organic moieties, the $\mathrm{CO}_{2}$ signal was considered to be due to the fragmentation of the carboxylate ligands. For the complexes with benzoate and 3chlorobenzoate bridging ligands, a signal corresponding to benzene $\left(\mathrm{C}_{6} \mathrm{H}_{6}{ }^{+}, \mathrm{m} / \mathrm{z}=78\right)$ was approximately coincident with the appearance of the $\mathrm{CO}_{2}$ signal. The much higher boiling point of benzene compared to the other evolved gases causes it to condense in the tube linking the furnace to the mass spectrometer which is at room temperature. This causes the benzene signal to be observed later than the $\mathrm{CO}_{2}$ signal and is broadened due to the benzene condensing and evaporating along the tube. For the acetate bridging ligand, the $\mathrm{CH}_{3} \mathrm{CO}_{2}{ }^{+}(\mathrm{m} / \mathrm{z}=59)$ and $\mathrm{CH}_{3} \mathrm{COCH}_{3}{ }^{+}(\mathrm{m} / \mathrm{z}=58$, from the rearrangement of the acetate fragment) ions were used as an indication as to when the acetate is removed and 
decomposed. The much higher boiling point of acetone compared to the other evolved gases causes it to condense in the tube linking the furnace to the mass spectrometer. This causes the acetone signal to be observed later than the $\mathrm{CO}_{2}$ signal and is broadened due to the acetone condensing and evaporating along the tube. Decomposition of the nitrate, chloride and thiocyanate anions were studied by observing $\mathrm{NO}^{+}, \mathrm{Cl}^{+}$and $\mathrm{S}^{+}$signals, respectively. Using this information, the pattern of the EGA-MS signals were used to determine the sequence of ligand loss and the temperature at which this occurred during heating.

The TGA and EGA-MS data have been displayed as a single graph with the TGA measured as the percent of the sample mass (left hand axis, black line) and the EGA-MS as the mass spectrometer signal intensity (right hand axis, coloured lines). Several signals of the EGA-MS have been scaled up in order to better compare the signals (scaling factor is in brackets). 


\subsubsection{Iron complexes}

\subsubsection{1 $\left[\mathrm{Fe}_{3} \mathrm{O}\left(\mathrm{O}_{2} \mathrm{CCH}_{3}\right)_{6}\left(\mathrm{H}_{2} \mathrm{O}\right)_{3}\right] \mathrm{NO}_{3}$}

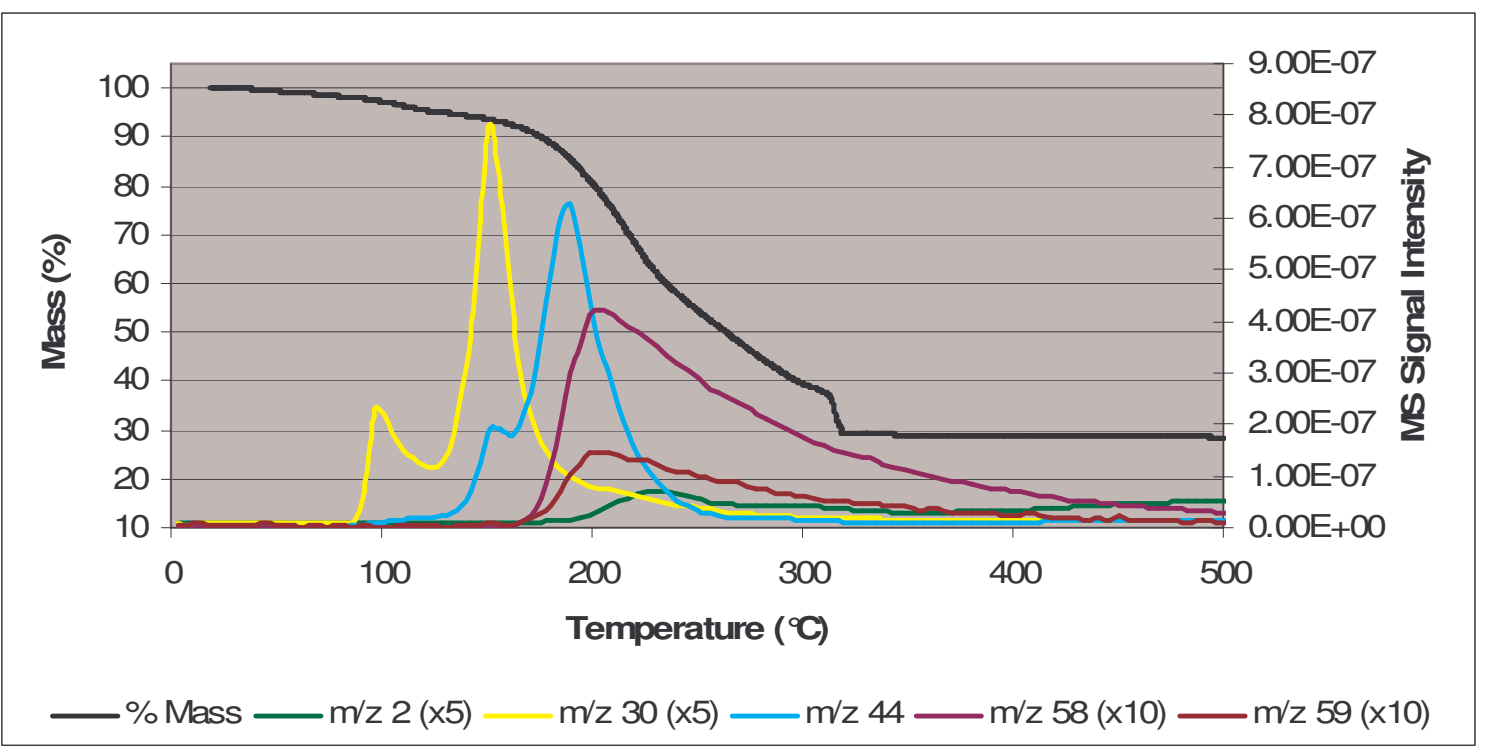

Figure 21: TGA and EGA-MS of $\left[\mathrm{Fe}_{3} \mathrm{O}\left(\mathrm{O}_{2} \mathrm{CCH}_{3}\right)_{6}\left(\mathrm{H}_{2} \mathrm{O}\right)_{3}\right] \mathrm{NO}_{3}$

The combined thermal analysis of $\left[\mathrm{Fe}_{3} \mathrm{O}\left(\mathrm{O}_{2} \mathrm{CCH}_{3}\right)_{6}\left(\mathrm{H}_{2} \mathrm{O}\right)_{3}\right] \mathrm{NO}_{3}$ is shown in Figure 21. Between $26-97^{\circ} \mathrm{C}$ there is a slow mass loss of $2.4 \%$ which corresponds to loss of a single water molecule $($ calc. $=2.8 \%)$. This is followed by a small step between $97-121^{\circ} \mathrm{C}$ with a mass loss of $2.1 \%$ which corresponds to the partial decomposition of the nitrate anion (calc.: $\left.0.2 \mathrm{NO}_{3}=1.9 \%\right)$. The EGA-MS indicates that the nitrate decomposes $(\mathrm{NO}, \mathrm{m} / \mathrm{z}=$ 30; $\mathrm{N}_{2} \mathrm{O}, \mathrm{m} / \mathrm{z}=44$ ) in two steps, one step between $87-124^{\circ} \mathrm{C}$ and the second between $124-297^{\circ} \mathrm{C}$ (confirmed by isotope studies of NO). The sample continues to lose mass with a change in rate at $159^{\circ} \mathrm{C}$ when the sample begins to lose mass more rapidly. The sample continues at the same rate until it reaches $230^{\circ} \mathrm{C}$ where the rate slows slightly to a temperature of $313^{\circ} \mathrm{C}$. The total mass loss of this step is $58.5 \%$ which corresponds to the decomposition of the remaining nitrate and six acetate ligands. The signal due to evolution of $\mathrm{CO}_{2}(\mathrm{~m} / \mathrm{z}=44)$ starts at $129^{\circ} \mathrm{C}$, peaks at $190^{\circ} \mathrm{C}$ and then ends at $264^{\circ} \mathrm{C}$. The final mass, $37.0 \%$ of the original mass, corresponds with the expected formation of the ferric oxide, $\mathrm{Fe}_{2} \mathrm{O}_{3}(36.6 \%)$. 
Due to difficulties in crystallising the sample used in the analysis it contained trace amounts of impurities such as toluene and pyridine. This resulted in the TGA not being as accurate as calculated. From the EGA-MS of $\left[\mathrm{Fe}_{3} \mathrm{O}\left(\mathrm{O}_{2} \mathrm{CCH}_{3}\right)_{6}\left(\mathrm{H}_{2} \mathrm{O}\right)_{3}\right] \mathrm{NO}_{3}$ it is observed that the nitrate anion and acetate ligands decompose in the same temperature range. The separate components of this decomposition were therefore unable to be clearly resolved in the TGA.

\subsubsection{2 $\left[\mathrm{Fe}_{3} \mathrm{O}\left(\mathrm{O}_{2} \mathrm{CPh}\right)_{6}\left(\mathrm{H}_{2} \mathrm{O}\right)_{3}\right] \mathrm{NO}_{3} \cdot 2 \mathrm{MeOH}$}

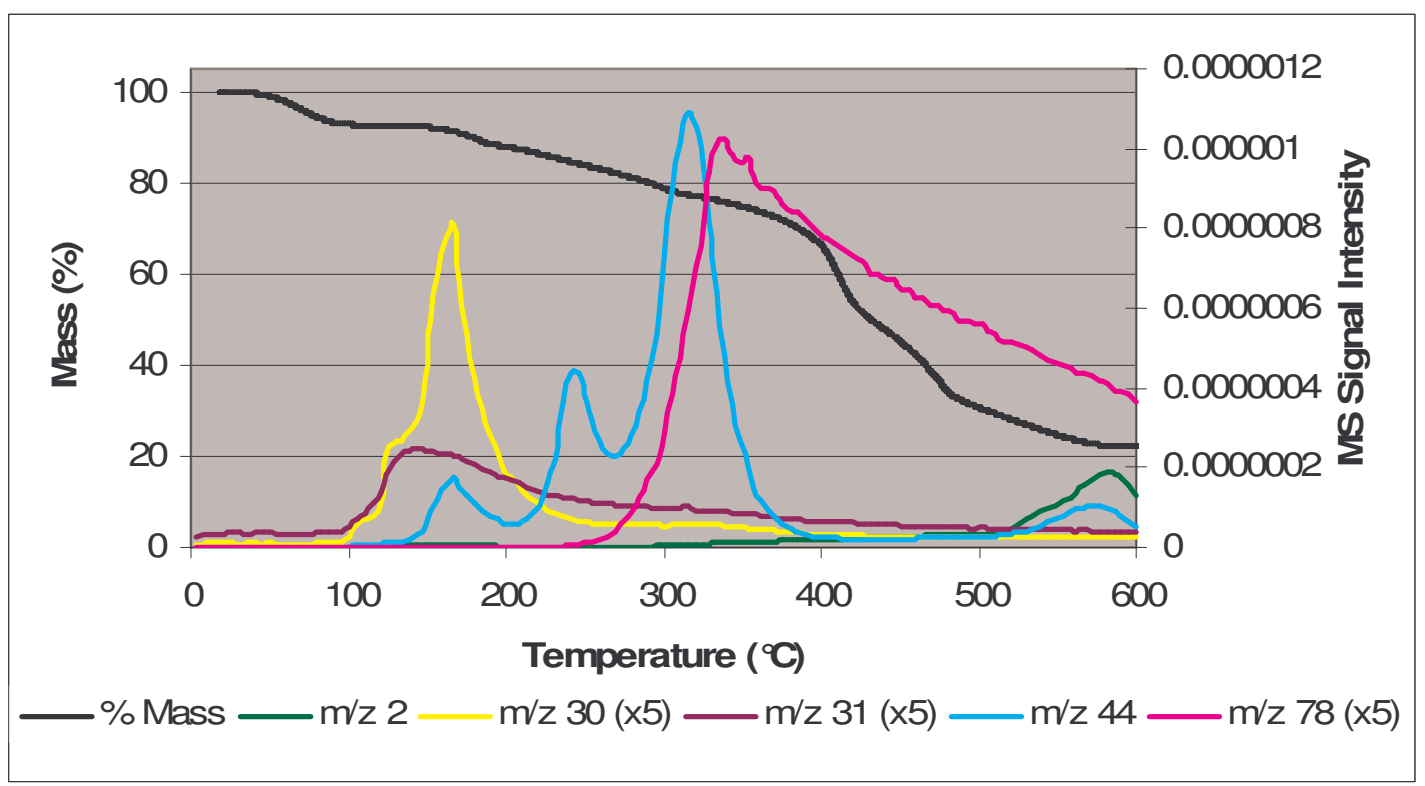

Figure 22: TGA and EGA-MS of $\left[\mathrm{Fe}_{3} \mathrm{O}\left(\mathrm{O}_{2} \mathrm{CC}_{6} \mathrm{H}_{5}\right)_{6}\left(\mathrm{H}_{2} \mathrm{O}\right)_{3}\right] \mathrm{NO}_{3} \cdot 2 \mathrm{MeOH}$

The TGA of $\left[\mathrm{Fe}_{3} \mathrm{O}\left(\mathrm{O}_{2} \mathrm{CC}_{6} \mathrm{H}_{5}\right)_{6}\left(\mathrm{H}_{2} \mathrm{O}\right)_{3}\right] \mathrm{NO}_{3} \cdot 2 \mathrm{MeOH}$ (Figure 22) begins with a $7.3 \%$ mass loss between $36-105^{\circ} \mathrm{C}$. This corresponds to the loss of two methanol molecules and one water molecule $\left(\mathrm{MeOH}+\mathrm{H}_{2} \mathrm{O}=7.8 \%\right)$. The absence of any signals in the EGA-MS (Figure 22) during this temperature range can be explained by the condensation of the methanol in the tube connecting the furnace and mass spectrometer. This results in the methanol not being detected immediately. The loss of the water molecule can not be detected due to water being absorbed by the silica capillary of the mass spectrometer. 
The loss of methanol and water is followed by the decomposition of the nitrate anion. The majority of the nitrate decomposition is accompanied by a mass loss of $4.8 \%$ between $105-$ $201{ }^{\circ} \mathrm{C}\left(0.8 \mathrm{NO}_{3}=4.7\right)$ and peaks due to $\mathrm{NO}(\mathrm{m} / \mathrm{z}=30)$ and $\mathrm{N}_{2} \mathrm{O}(\mathrm{m} / \mathrm{z}=44)$ in the EGAMS observed between $100-200^{\circ} \mathrm{C}$. The EGA-MS indicates that that nitrate decomposition ceases at $230^{\circ} \mathrm{C}$ and that from $200^{\circ} \mathrm{C}$ the decomposition of the nitrate overlaps with the evolution of $\mathrm{CO}_{2}(\mathrm{~m} / \mathrm{z}=44)$. The observation of two overlapping peaks in the signal due to $\mathrm{CO}_{2}$ indicates that the decomposition of the benzoate ligands occurs via at least two different processes. The first $\mathrm{CO}_{2}$ peak appears at $209^{\circ} \mathrm{C}$ and peaks at $246^{\circ} \mathrm{C}$. At $269^{\circ} \mathrm{C}$, a second evolution of $\mathrm{CO}_{2}$ is observed which has a maximum at $316^{\circ} \mathrm{C}$ and the evolution ceases at $404^{\circ} \mathrm{C}$. A signal due to the benzene $(\mathrm{m} / \mathrm{z}=78)$ appears at $218^{\circ} \mathrm{C}$. The corresponding mass loss of $25.4 \%$ between $201-403^{\circ} \mathrm{C}$ corresponds to the decomposition of the remaining nitrate anion and benzoate ligands $\left(0.2 \mathrm{NO}_{3}+4 \mathrm{CO}_{2}+\mathrm{C}_{6} \mathrm{H}_{5}=25.3 \%\right)$.

Above $400^{\circ} \mathrm{C}$ in the EGA-MS, no gases are observed yet the sample continues to lose significant mass in the TGA. Between $403-592^{\circ} \mathrm{C}$ the mass is lost at three different rates indicating that at least three different processes are occurring. This may be explained by the evolution of different organic products formed by the thermal decomposition of the benzoate ligands. These organic products must have a molecular weight greater than 100 because they are not detected by the mass spectrometer.

A third $\mathrm{CO}_{2}$ peak above $516^{\circ} \mathrm{C}$ and a $\mathrm{H}_{2}(\mathrm{~m} / \mathrm{z}=2)$ signal beginning at $524^{\circ} \mathrm{C}$ is due to decomposition of iron formate that is produced during the heating process ${ }^{[110]}$. The final mass, $22.3 \%$ of the original mass, corresponds to the formation of the iron oxide, $\mathrm{Fe}_{2} \mathrm{O}_{3}$ $(22.7 \%)$. 


\subsubsection{3 $\left[\mathrm{Fe}_{3} \mathrm{O}\left(\mathrm{O}_{2} \mathrm{CC}_{6} \mathrm{H}_{5}\right)_{6}\left(\mathrm{H}_{2} \mathrm{O}\right)_{3}\right] \mathrm{Cl}$}

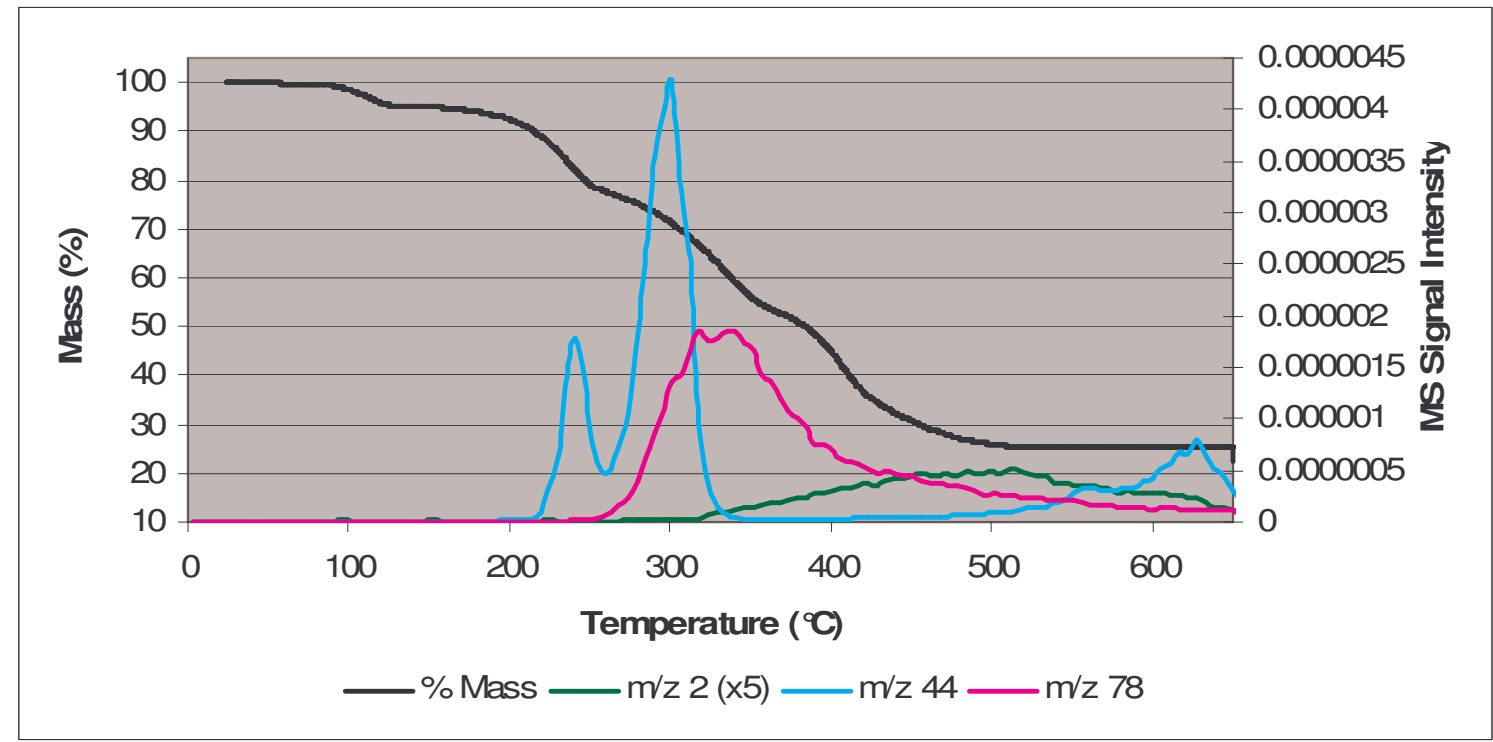

Figure 23: TGA and EGA-MS of $\left[\mathrm{Fe}_{3} \mathrm{O}\left(\mathrm{O}_{2} \mathrm{CC}_{6} \mathrm{H}_{5}\right)_{6}\left(\mathrm{H}_{2} \mathrm{O}\right)_{3}\right] \mathrm{Cl}$

A comparison of the TGA and EGA-MS of $\left[\mathrm{Fe}_{3} \mathrm{O}\left(\mathrm{O}_{2} \mathrm{CC}_{6} \mathrm{H}_{5}\right)_{6}\left(\mathrm{H}_{2} \mathrm{O}\right)_{3}\right] \mathrm{Cl}$ is shown in Figure

23. The total mass loss in the TGA between $20-169^{\circ} \mathrm{C}$ of $5.5 \%$ corresponds to the loss of a single water molecule and the chloride anion, most likely as $\mathrm{HCl}\left(\mathrm{H}_{2} \mathrm{O}+\mathrm{HCl}=5.6 \%\right)$. The absence of a signal due to the chloride in the EGA-MS indicates that the chlorine is not ionised in the positive mode mass spectrometer.

The benzoate ligand is observed to decompose with two $\mathrm{CO}_{2}$ peaks as was observed for the nitrate complex. The initial $\mathrm{CO}_{2}$ peak evolves between $213-263^{\circ} \mathrm{C}$ and peaks at $241^{\circ} \mathrm{C}$. Between $197-249^{\circ} \mathrm{C}$ there is a mass loss of $15.5 \%$ which corresponds to the decomposition of some of the benzoate ligands $\left(2 \mathrm{CO}_{2}+0.8 \mathrm{C}_{6} \mathrm{H}_{5}=15.6 \%\right)$. At $263^{\circ} \mathrm{C}$, a second evolution of $\mathrm{CO}_{2}$ is observed which has a maximum at $302^{\circ} \mathrm{C}$ and ceases evolving at $335^{\circ} \mathrm{C}$. The mass loss between $249-368^{\circ} \mathrm{C}$ of $26.2 \%$ corresponds to the decomposition of the remaining benzoate ligands $\left(3 \mathrm{CO}_{2}+1.5 \mathrm{C}_{6} \mathrm{H}_{5}=25.9 \%\right)$. 
The final step between $368-523^{\circ} \mathrm{C}$ with a mass loss of $27.5 \%$ corresponds to the evolution of the organic material decomposition by-products. Evolution of $\mathrm{CO}_{2}$ from the decomposition of iron formate and/or carbonate is seen to evolve above $500^{\circ} \mathrm{C}$. The final mass, $25.5 \%$ of the original mass, corresponds to the formation of the iron oxide, $\mathrm{Fe}_{2} \mathrm{O}_{3}$ $(24.9 \%)$.

\subsubsection{4 $\left[\mathrm{Fe}^{\mathrm{III}}{ }_{2} \mathrm{Fe} \mathrm{II} \mathrm{O}\left(\mathrm{O}_{2} \mathrm{CC}_{6} \mathrm{H}_{5}\right)_{6}\left(\mathrm{H}_{2} \mathrm{O}\right)_{3}\right] \cdot 2 \mathrm{H}_{2} \mathrm{O}$}

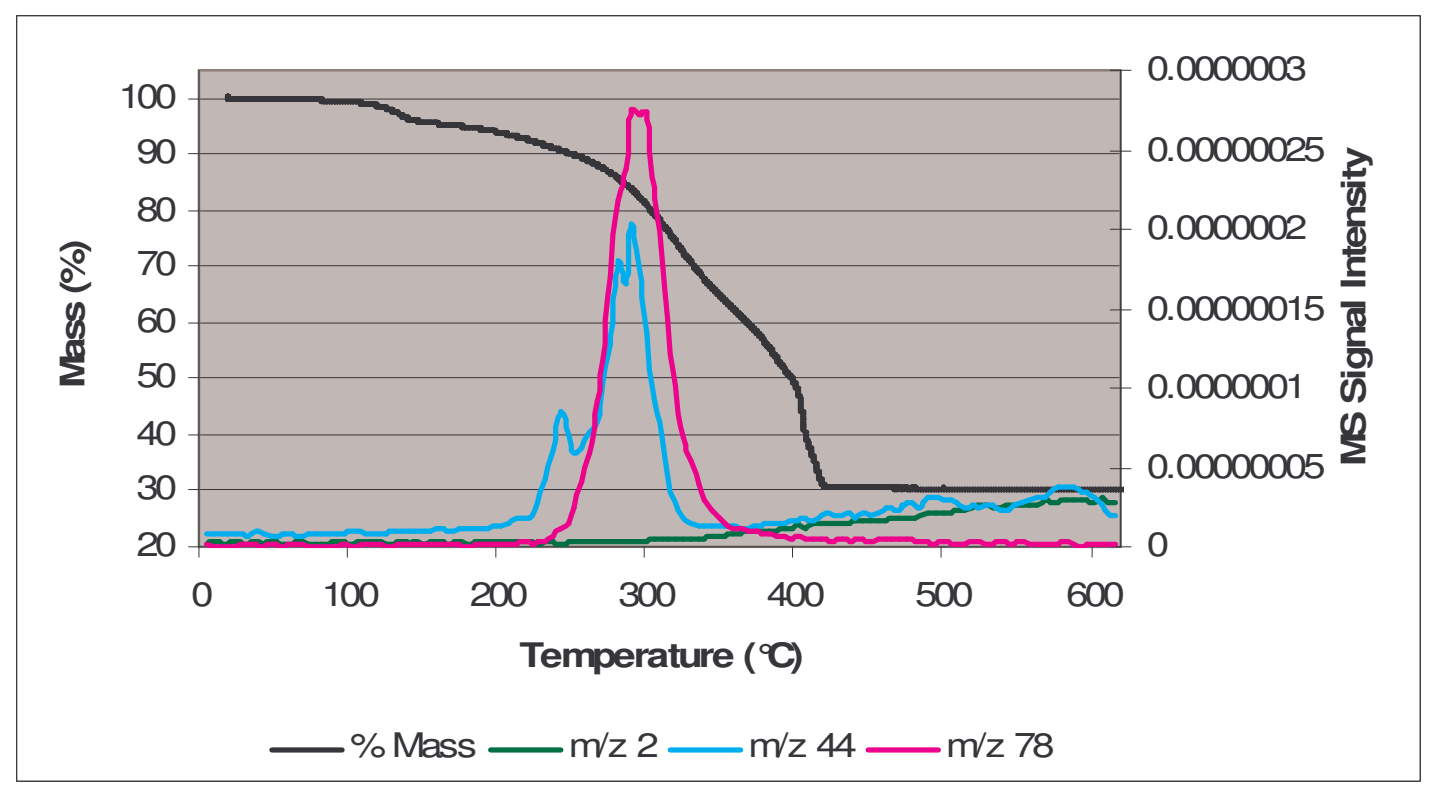

Figure 24: TGA and EGA-MS of $\left[\mathrm{Fe}^{\mathrm{III}}{ }_{2} \mathrm{Fe}^{\mathrm{II}} \mathrm{O}\left(\mathrm{O}_{2} \mathrm{CC}_{6} \mathrm{H}_{5}\right)_{6}\left(\mathrm{H}_{2} \mathrm{O}\right)_{3}\right] \cdot 2 \mathrm{H}_{2} \mathrm{O}$

A comparison of the TGA and EGA-MS of $\left[\mathrm{Fe}_{2} \mathrm{FeO}\left(\mathrm{O}_{2} \mathrm{CC}_{6} \mathrm{H}_{5}\right)_{6}\left(\mathrm{H}_{2} \mathrm{O}\right)_{3}\right]$ is shown in Figure

24. The EGA-MS does not contain a signal below $200^{\circ} \mathrm{C}$ but the TGA indicates there is a loss of $5.5 \%$ between $20-191^{\circ} \mathrm{C}$ which corresponds to the loss of three water molecules (5.6\%). Above $200^{\circ} \mathrm{C}$ the $\mathrm{CO}_{2}$ signal indicates that the benzoate ligands decompose via at least two different processes. The initial $\mathrm{CO}_{2}$ peak evolves between $224-253^{\circ} \mathrm{C}$ and peaks at $243^{\circ} \mathrm{C}$. At $253^{\circ} \mathrm{C}$, a second evolution of $\mathrm{CO}_{2}$ is observed with a maximum at $287^{\circ} \mathrm{C}$ and that ceases at $336^{\circ} \mathrm{C}$. The mass loss between $191-329^{\circ} \mathrm{C}$ of $23.3 \%$ corresponds to the decomposition of the benzoate ligands $\left(3 \mathrm{CO}_{2}+1.3 \mathrm{C}_{6} \mathrm{H}_{5}=23.3 \%\right)$. 
The TGA indicates there are two more steps between $329-401{ }^{\circ} \mathrm{C}(21.6 \%)$ and $401-420^{\circ} \mathrm{C}$ $(18.6 \%)$ which corresponds to the evolution of the organic material decomposition by-products. The final mass, $31.0 \%$ of the original mass, corresponds to the formation of the iron oxide, $\mathrm{Fe}_{2} \mathrm{O}_{3}(23.9 \%)$ with impurities such as iron carbonate and formate which are observed to begin decomposing at $500^{\circ} \mathrm{C}$.

\subsubsection{5 $\left[\mathrm{Fe}_{3} \mathrm{O}\left(\mathrm{O}_{2} \mathrm{CC}_{6} \mathrm{H}_{4}-3-\mathrm{Cl}\right)_{6}\left(\mathrm{H}_{2} \mathrm{O}\right)_{3}\right] \mathrm{NO}_{3} \cdot \mathrm{MeOH}$}

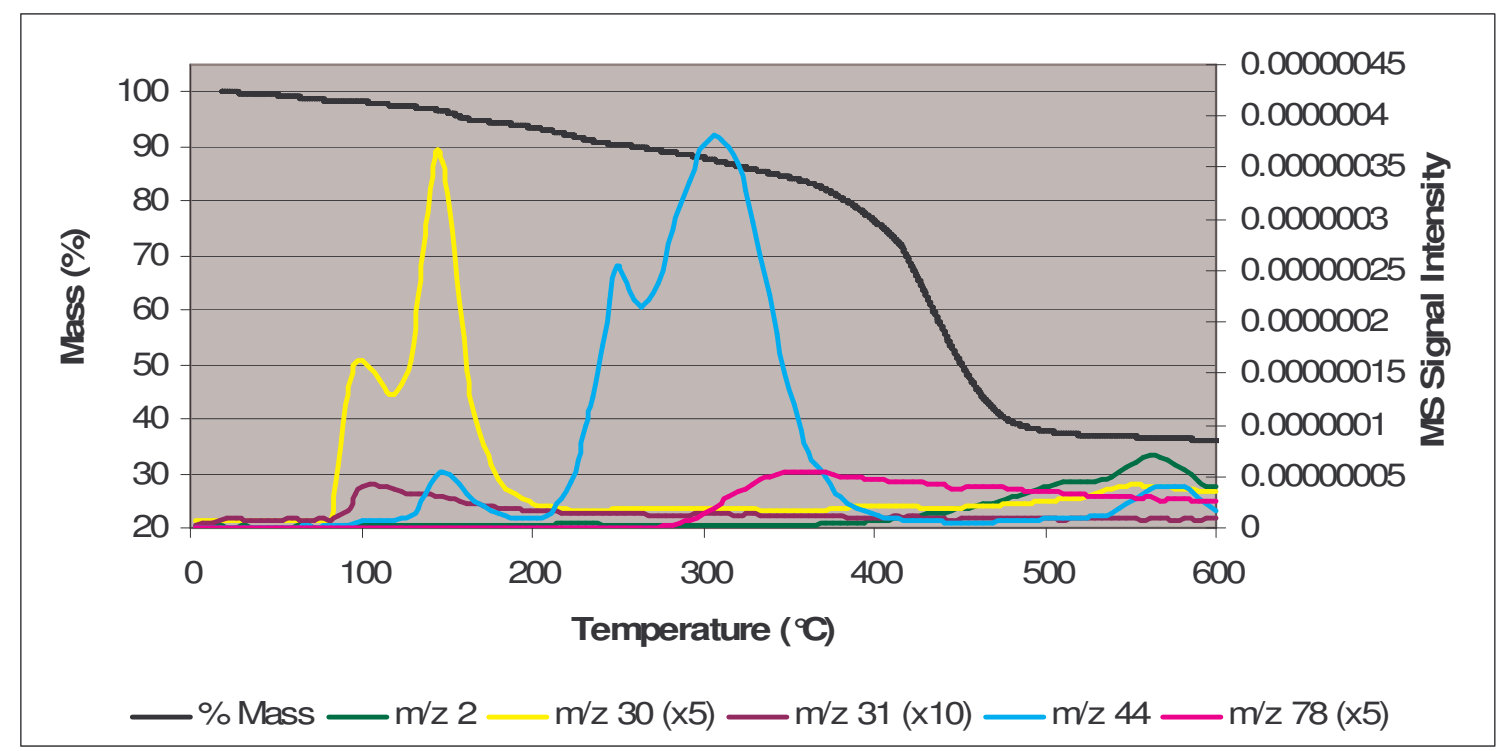

Figure 25: TGA and EGA-MS of $\left[\mathrm{Fe}_{3} \mathrm{O}\left(\mathrm{O}_{2} \mathrm{CC}_{6} \mathrm{H}_{4}-3-\mathrm{Cl}\right)_{6}\left(\mathrm{H}_{2} \mathrm{O}\right)_{3}\right] \mathrm{NO}_{3} \cdot \mathrm{MeOH}$

A comparison of the TGA and EGA-MS of $\left[\mathrm{Fe}_{3} \mathrm{O}\left(\mathrm{O}_{2} \mathrm{CC}_{6} \mathrm{H}_{4}-3-\mathrm{Cl}\right)_{6}\left(\mathrm{H}_{2} \mathrm{O}\right)_{3}\right] \mathrm{NO}_{3} \cdot \mathrm{MeOH}$ is shown in Figure 25. The TGA signal begins with a $2.5 \%$ mass loss between $20-120^{\circ} \mathrm{C}$ which corresponds to the loss of one methanol molecule $(2.5 \%)$. The absence of any signals in the EGA-MS during the lower part of this temperature range may be explained by the condensation of the methanol in the tube connecting the furnace and mass spectrometer. The methanol is first observed at $82^{\circ} \mathrm{C}$ before peaking at $106^{\circ} \mathrm{C}$ and then tailing off. 
Following the loss of methanol there is a mass loss in the TGA of 3.5\% between 120 $188^{\circ} \mathrm{C}$ corresponding to partial decomposition of the nitrate anion $\left(0.7 \mathrm{NO}_{3}=3.4 \%\right)$. The total decomposition of the nitrate anion is observed in the EGA-MS as signals due to NO $(\mathrm{m} / \mathrm{z}=30)$ and $\mathrm{N}_{2} \mathrm{O}(\mathrm{m} / \mathrm{z}=44)$ observed between $120-204^{\circ} \mathrm{C}$. The observation of two overlapping peaks in the signal due to $\mathrm{CO}_{2}(\mathrm{~m} / \mathrm{z}=44)$ indicates that the removal and decomposition of the 3-chlorobenzoate ligands occurs via at least two different processes. The first $\mathrm{CO}_{2}$ peak appears at $204^{\circ} \mathrm{C}$ and peaks at $255^{\circ} \mathrm{C}$. At $264^{\circ} \mathrm{C}$, a second evolution of $\mathrm{CO}_{2}$ is observed which has a maximum at $306^{\circ} \mathrm{C}$ before the ceasing at $427^{\circ} \mathrm{C}$. A signal due to the benzene $(\mathrm{m} / \mathrm{z}=78)$ is seen to begin to evolve at $292^{\circ} \mathrm{C}$. The mass loss in the TGA of $24.3 \%$ between $188-419^{\circ} \mathrm{C}$ corresponds to the decomposition of the remaining nitrate and the benzoate ligands $\left(0.3 \mathrm{NO}_{3}+4 \mathrm{CO}_{2}+\mathrm{C}_{6} \mathrm{H}_{4} \mathrm{Cl}=24.3 \%\right)$.

The final step between $419-505^{\circ} \mathrm{C}$ of $32.2 \%$ corresponds to the evolution of the organic material decomposition by-products. Evolution of $\mathrm{CO}_{2}, \mathrm{HCO}_{2}$ and $\mathrm{H}_{2}$ from the decomposition of iron formate is observed to evolve above $500^{\circ} \mathrm{C}$. The final mass, $35.0 \%$ of the original mass, corresponds to the formation of the iron oxide, $\mathrm{Fe}_{2} \mathrm{O}_{3}(18.9 \%)$ with decomposition product impurities.

The formation of the hexanuclear iron complex, $\left[\mathrm{Fe}_{6} \mathrm{O}_{2}(\mathrm{OH})_{2}\left(\mathrm{O}_{2} \mathrm{CC}_{6} \mathrm{H}_{4}-3-\mathrm{Cl}_{12}\left(\mathrm{H}_{2} \mathrm{O}\right)_{2}\right]\right.$, from $\left[\mathrm{Fe}_{3} \mathrm{O}\left(\mathrm{O}_{2} \mathrm{CC}_{6} \mathrm{H}_{4}-3-\mathrm{Cl}\right)_{6}\left(\mathrm{H}_{2} \mathrm{O}\right)_{3}\right] \mathrm{NO}_{3} \cdot \mathrm{MeOH}$ is consistent with the TGA and EGA-MS analysis of the precursor. Below $200^{\circ} \mathrm{C}$ the EGA-MS indicates that the processes that are occurring is the evolution of methanol and the decomposition of the nitrate which are not seen in the final product. No $\mathrm{CO}_{2}$ peak is observed from the decomposition of the carboxylate as expected as the complex does not lose any carboxylate molecules on going from the trinuclear to hexanuclear complex. The EGA-MS is also consistent with the infrared data where there are no stretching frequencies due to the methanol and nitrate. 


\subsubsection{6 $\left[\mathrm{Fe}_{3} \mathrm{O}\left(\mathrm{O}_{2} \mathrm{CC}_{6} \mathrm{H}_{4}-3-\mathrm{Cl}\right)_{6}\left(\mathrm{H}_{2} \mathrm{O}\right)_{3}\right] \mathrm{Cl} \cdot \mathrm{H}_{2} \mathrm{O}$}

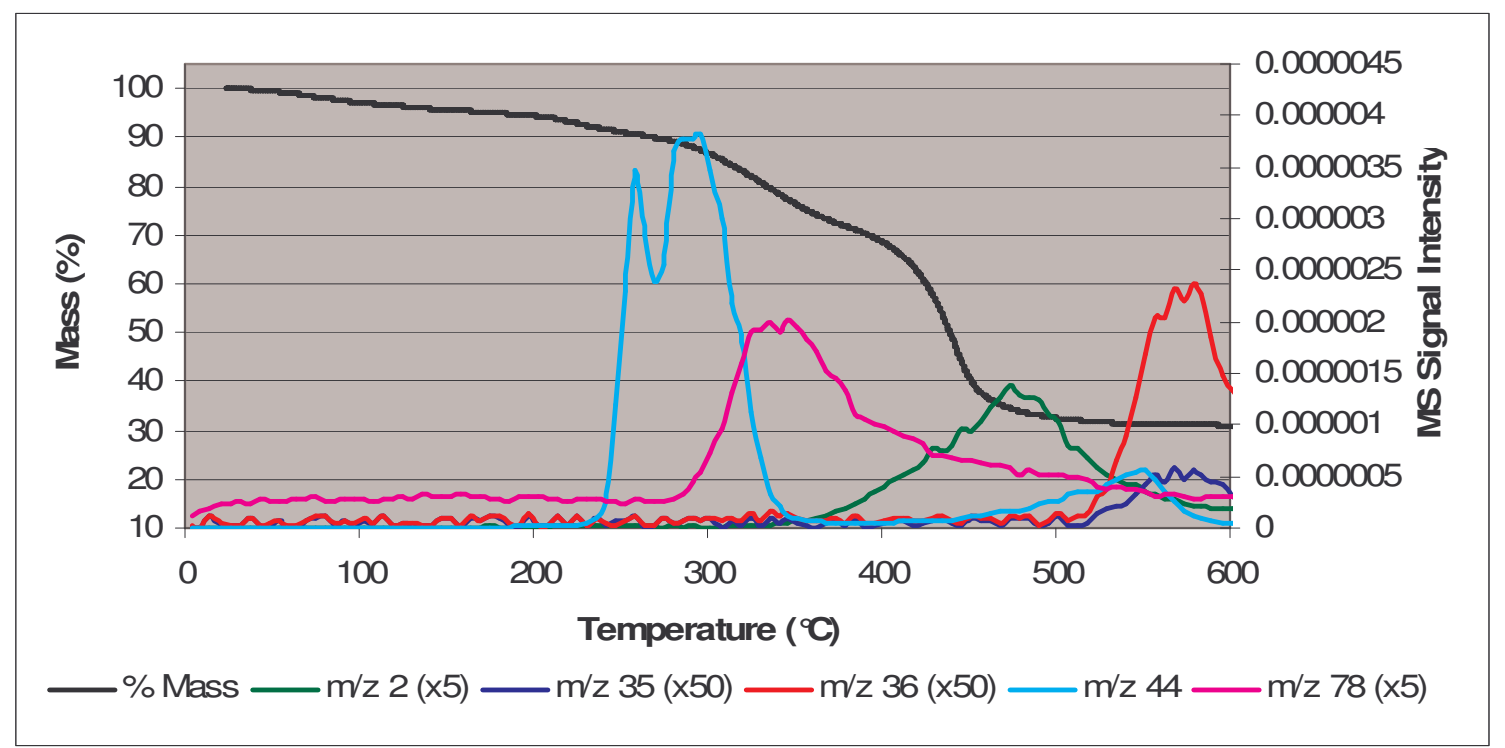

Figure 26: TGA and EGA-MS of $\left[\mathrm{Fe}_{3} \mathrm{O}\left(\mathrm{O}_{2} \mathrm{CC}_{6} \mathrm{H}_{4}-3-\mathrm{Cl}\right)_{6}\left(\mathrm{H}_{2} \mathrm{O}\right)_{3}\right] \mathrm{Cl} \cdot \mathrm{H}_{2} \mathrm{O}$

A comparison of the TGA and EGA-MS of $\left[\mathrm{Fe}_{3} \mathrm{O}\left(\mathrm{O}_{2} \mathrm{CC}_{6} \mathrm{H}_{4}-3-\mathrm{Cl}\right)_{6}\left(\mathrm{H}_{2} \mathrm{O}\right)_{3}\right] \mathrm{Cl} \cdot \mathrm{H}_{2} \mathrm{O}$ is shown in Figure 26. Between the temperatures of $20-202^{\circ} \mathrm{C}$, the sample loses $4.2 \%$ which corresponds to the loss of a single water molecule and the chloride anion (4.4\%). The absence of a signal due to the chloride in the EGA-MS indicates that the chlorine is not ionised in the positive mode mass spectrometer.

The $\mathrm{CO}_{2}$ signal indicates that the 3-chlorobenzoate decomposes via two different processes as was observed for the nitrate complex. The initial $\mathrm{CO}_{2}$ peak evolves between $231-269^{\circ} \mathrm{C}$ and peaks at $258^{\circ} \mathrm{C}$. Between $202-295^{\circ} \mathrm{C}$ there is a mass loss of $5.6 \%$ which corresponds to the decomposition of some of the benzoate ligands $\left(1.6 \mathrm{CO}_{2}=5.7 \%\right)$. At $258^{\circ} \mathrm{C}$, a second evolution of $\mathrm{CO}_{2}$ is observed which has a maximum at $291^{\circ} \mathrm{C}$ and ceases evolving at $352^{\circ} \mathrm{C}$. The mass loss between $295-357^{\circ} \mathrm{C}$ of $13.3 \%$ corresponds to the decomposition of the remaining benzoate ligands $\left(2.4 \mathrm{CO}_{2}+0.5 \mathrm{C}_{6} \mathrm{H}_{5} \mathrm{Cl}=13.2 \%\right)$.

The final step between $414-460^{\circ} \mathrm{C}$ of $41.4 \%$ corresponds to the evolution of the organic material decomposition by-products. $\mathrm{CO}_{2}$, from the decomposition of iron formate, and 
chloride ions in the form of $\mathrm{HCl}$, most likely from the chlorobenzoate, are seen to evolve above $500^{\circ} \mathrm{C}$. The final mass, $35.5 \%$ of the original mass, corresponds to the formation of the iron oxide, $\mathrm{Fe}_{2} \mathrm{O}_{3}(19.9 \%)$, with decomposition product impurities.

\subsubsection{Chromium complexes}

\subsubsection{1 $\left[\mathrm{Cr}_{3} \mathrm{O}\left(\mathrm{O}_{2} \mathrm{CPh}\right)_{6}\left(\mathrm{H}_{2} \mathrm{O}\right)_{3}\right] \mathrm{NO}_{3} \cdot \mathrm{CH}_{3} \mathrm{COCH}_{3}$}

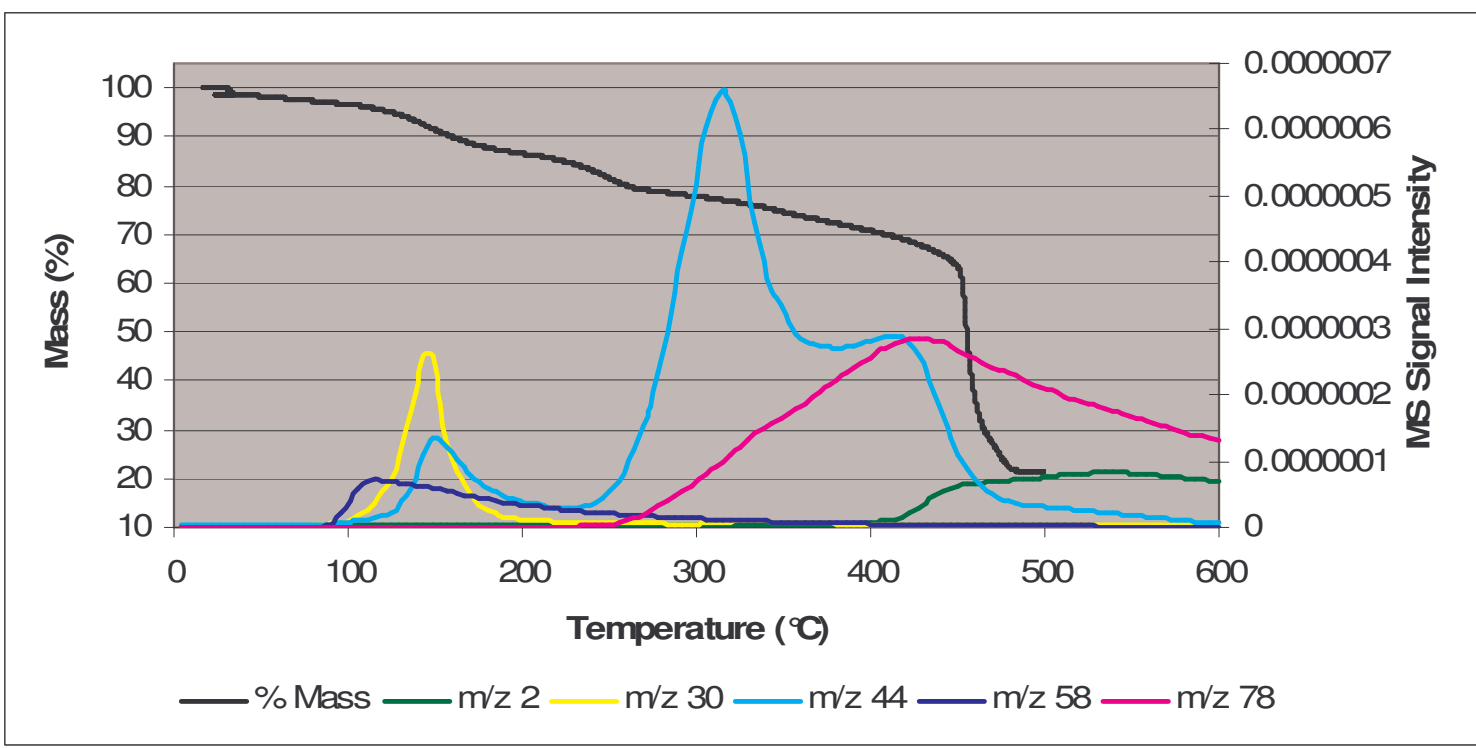

Figure 27: TGA and EGA-MS of $\left[\mathrm{Cr}_{3} \mathrm{O}\left(\mathrm{O}_{2} \mathrm{CC}_{6} \mathrm{H}_{5}\right)_{6}\left(\mathrm{H}_{2} \mathrm{O}\right)_{3}\right] \mathrm{NO}_{3} \cdot \mathrm{CH}_{3} \mathrm{COCH}_{3}$

A comparison of the TGA and EGA-MS of $\left[\mathrm{Cr}_{3} \mathrm{O}\left(\mathrm{O}_{2} \mathrm{CC}_{6} \mathrm{H}_{5}\right)_{6}\left(\mathrm{H}_{2} \mathrm{O}\right)_{3}\right] \mathrm{NO}_{3} \cdot \mathrm{CH}_{3} \mathrm{COCH}_{3}$ is shown in Figure 27. In the TGA there is a slow mass loss of $4.8 \%$ between $44-125^{\circ} \mathrm{C}$ which corresponds to the loss of the majority of the acetone of crystallisation $\left(0.9 \mathrm{CH}_{3} \mathrm{COCH}_{3}=4.9 \%\right)$. The absence of any signals in the EGA-MS during this temperature range may be explained by the condensation of the acetone in the tube connecting the furnace and mass spectrometer. In the EGA-MS the acetone $(\mathrm{m} / \mathrm{z}=58)$ signal is first observed at $87^{\circ} \mathrm{C}$ and peaks at $\sim 110^{\circ} \mathrm{C}$ before tailing off. Between $125-185^{\circ} \mathrm{C}$ there is a mass loss of $7.8 \%$ which corresponds to the decomposition of the nitrate anion and the remaining acetone and the loss of a single water molecule $\left(0.1 \mathrm{CH}_{3} \mathrm{COCH}_{3}+\mathrm{NO}_{3}\right.$ $+\mathrm{H}_{2} \mathrm{O}=8.0 \%$ ). The $\mathrm{m} / \mathrm{z}=44$ signal related to the nitrate anion decomposition is more 
intense and broader than usual due to the addition of a $\mathrm{CO}_{2}$ signal from the decomposition of the acetone.

The observation of two overlapping peaks in the EGA-MS signal due to $\mathrm{CO}_{2}(\mathrm{~m} / \mathrm{z}=44)$ indicates that the decomposition of the benzoate ligands occurs via at least two different processes. Following the loss of the nitrate and acetone, there is a mass loss of $8.2 \%$ between $185-268^{\circ} \mathrm{C}$ which corresponds to the decomposition of some of the benzoate ligands $\left(2 \mathrm{CO}_{2}=8.2 \%\right)$. The initial $\mathrm{CO}_{2}$ peak evolves between $237-380^{\circ} \mathrm{C}$ and peaks at $316^{\circ} \mathrm{C}$. At $380^{\circ} \mathrm{C}$, a second evolution of $\mathrm{CO}_{2}$ is observed which has a maximum at $414^{\circ} \mathrm{C}$ before evolution ceases at $488^{\circ} \mathrm{C}$. A constant, gentle mass loss of $16.0 \%$ between 261 $450^{\circ} \mathrm{C}$ corresponds to the decomposition of the remaining benzoate ligands $\left(3 \mathrm{CO}_{2}+\right.$ $\left.0.5 \mathrm{C}_{6} \mathrm{H}_{6}=15.9 \%\right)$

From $450-483^{\circ} \mathrm{C}$ there is a rapid mass loss of $42.2 \%$ of the total mass which is not observed in the EGA-MS. This mass loss is most likely due to the evolution of high $\left(\mathrm{M}_{\mathrm{r}}>100 \mathrm{~g} \cdot \mathrm{mol}^{-1}\right)$ molecular weight organic material formed during the decomposition of the ligands. The final mass of the sample, $20.9 \%$ of the original mass, corresponds to the formation of the chromium oxide, $\mathrm{Cr}_{2} \mathrm{O}_{3}(21.3 \%)$. 


\subsubsection{2 $\left[\mathrm{Cr}_{3} \mathrm{O}\left(\mathrm{O}_{2} \mathrm{CPh}\right)_{6}\left(\mathrm{H}_{2} \mathrm{O}\right)_{3}\right] \mathrm{Cl}$}

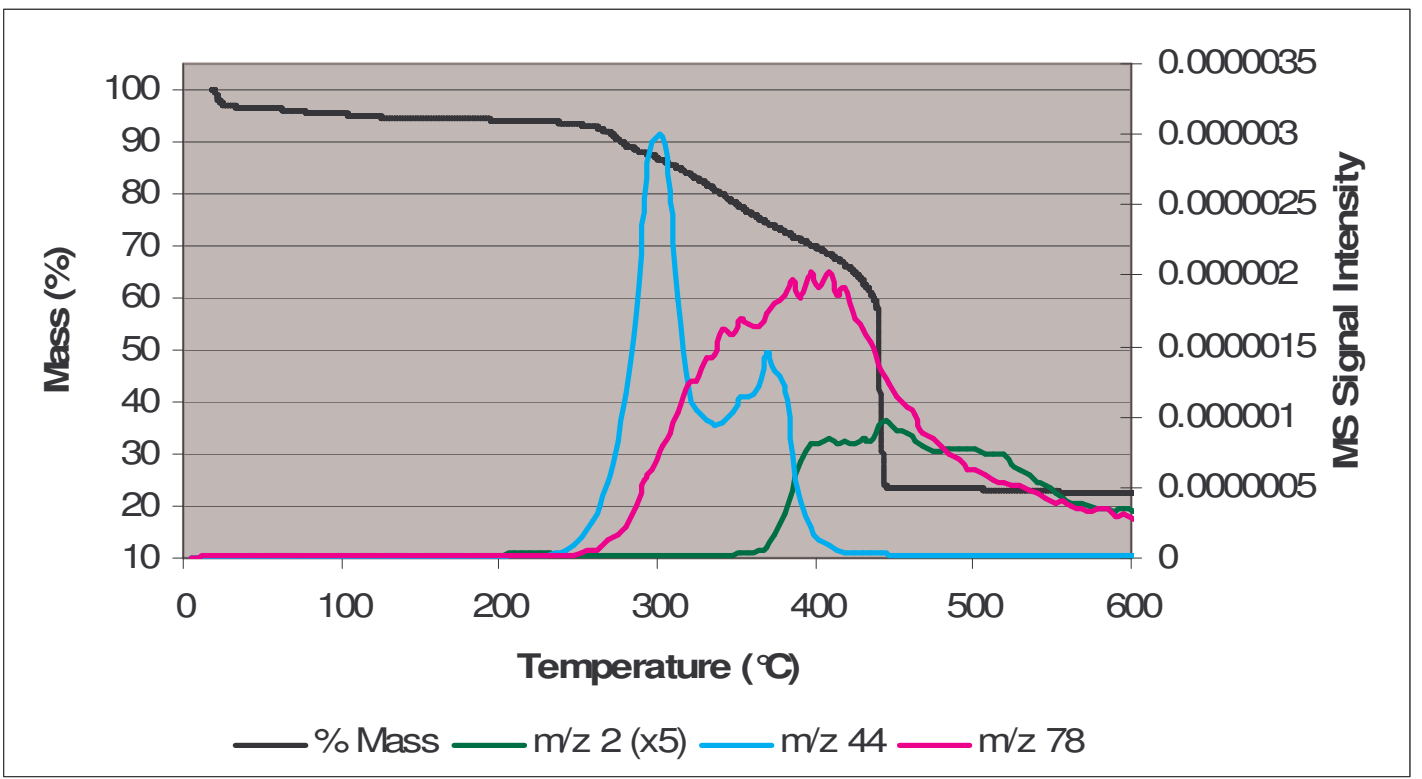

Figure 28: TGA and EGA-MS of $\left[\mathrm{Cr}_{3} \mathrm{O}\left(\mathrm{O}_{2} \mathrm{CC}_{6} \mathrm{H}_{5}\right)_{6}\left(\mathrm{H}_{2} \mathrm{O}\right)_{3}\right] \mathrm{Cl} \cdot 1.5 \mathrm{H}_{2} \mathrm{O}$

A comparison of the TGA and EGA-MS of $\left[\mathrm{Cr}_{3} \mathrm{O}\left(\mathrm{O}_{2} \mathrm{CC}_{6} \mathrm{H}_{5}\right)_{6}\left(\mathrm{H}_{2} \mathrm{O}\right)_{3}\right] \mathrm{Cl} \cdot 1.5 \mathrm{H}_{2} \mathrm{O}$ is shown in Figure 28. The TGA results reveal that there is a gradual mass loss of $4.4 \%$ between $20-266^{\circ} \mathrm{C}$ followed by a more rapid mass loss of $3.3 \%$ between $266-279^{\circ} \mathrm{C}$. The total mass loss of $7.7 \%$ corresponds to the loss of two water molecules and the chloride anion $\left(2.5 \mathrm{H}_{2} \mathrm{O}+\mathrm{Cl}=7.9 \%\right)$. The absence of any chloride signal in the EGA-MS may be explained by the mass spectrometer not being in a positive ion mode.

The observation of two overlapping peaks in the $\mathrm{CO}_{2}(\mathrm{~m} / \mathrm{z}=44)$ signal of the EGA-MS indicates that the removal and decomposition of the benzoate ligands occurs via two different processes. The first $\mathrm{CO}_{2}$ peak is observed between $237-342^{\circ} \mathrm{C}$ with a maximum at $303^{\circ} \mathrm{C}$. Above $342^{\circ} \mathrm{C}$, a second evolution of $\mathrm{CO}_{2}$ is observed which peaks at $369^{\circ} \mathrm{C}$ and ceases evolving at $419^{\circ} \mathrm{C}$. Between $279-424^{\circ} \mathrm{C}$ there is a mass loss of $23.4 \%$ which corresponds to the decomposition of the benzoate ligands $\left(4 \mathrm{CO}_{2}+0.8 \mathrm{C}_{6} \mathrm{H}_{6}=23.5 \%\right)$. 
From $424-446^{\circ} \mathrm{C}$ there is a rapid mass loss of $42.7 \%$ which is not observed in the EGA-MS. This mass loss is most likely due to the evolution of high $\left(\mathrm{M}_{\mathrm{r}}>100 \mathrm{~g} \cdot \mathrm{mol}^{-1}\right)$ molecular weight organic material formed from the decomposition of the benzoate ligands. The final mass of the sample, $22.8 \%$ of the original mass, corresponds to the formation of the chromium oxide, $\mathrm{Cr}_{2} \mathrm{O}_{3}(23.1 \%)$.

\subsubsection{3 $\left[\mathrm{Cr}_{3} \mathrm{O}\left(\mathrm{O}_{2} \mathrm{CPh}\right)_{6}\left(\mathrm{H}_{2} \mathrm{O}\right)_{3}\right] \mathrm{SCN}$}

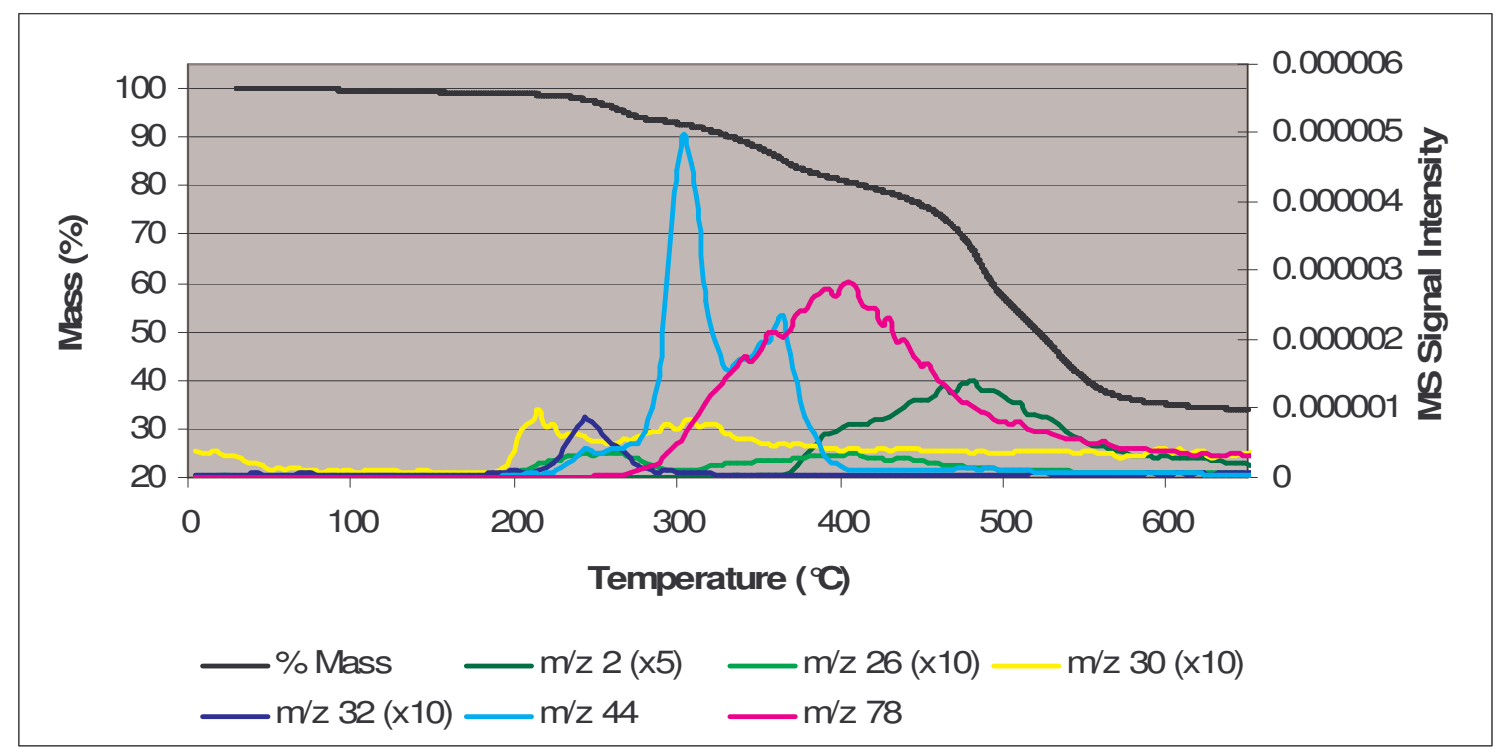

Figure 29: TGA and EGA-MS of $\left[\mathrm{Cr}_{3} \mathrm{O}\left(\mathrm{O}_{2} \mathrm{CC}_{6} \mathrm{H}_{5}\right)_{6}\left(\mathrm{H}_{2} \mathrm{O}\right)_{3}\right] \mathrm{SCN}$

The nitrogen carrier gas used in the analysis of $\left[\mathrm{Cr}_{3} \mathrm{O}\left(\mathrm{O}_{2} \mathrm{CC}_{6} \mathrm{H}_{5}\right)_{6}\left(\mathrm{H}_{2} \mathrm{O}\right)_{3}\right] \mathrm{SCN}$ was oxygen free so as to allow analysis of the $\mathrm{m} / \mathrm{z}=32$ signal. This allowed the $\mathrm{S}$ peak to be clearly observed and was confirmed as such by ${ }^{32} \mathrm{~S} /{ }^{34} \mathrm{~S}$ isotope ratios.

A comparison of the TGA and EGA-MS of $\left[\mathrm{Cr}_{3} \mathrm{O}\left(\mathrm{O}_{2} \mathrm{CC}_{6} \mathrm{H}_{5}\right)_{6}\left(\mathrm{H}_{2} \mathrm{O}\right)_{3}\right] \mathrm{SCN}$ is shown in Figure 29. Between $20-227^{\circ} \mathrm{C}$, there is a gradual mass loss of $1.5 \%$ which corresponds to the loss of a single water molecule $(1.8 \%)$. This is followed by a mass loss of $4.4 \%$ between $227-277^{\circ} \mathrm{C}$ which corresponds to the partial decomposition of the SCN anion $(0.8 \mathrm{SCN}=4.6 \%)$. The thiocyanate anion is observed to decompose via at least three 
different processes between $200-300^{\circ} \mathrm{C}$. A signal due to $\mathrm{NO}(\mathrm{m} / \mathrm{z}=30)$ evolves between $187-253^{\circ} \mathrm{C}$ and $253-360^{\circ} \mathrm{C}, \mathrm{CN}(\mathrm{m} / \mathrm{z}=26)$ between $196-295^{\circ} \mathrm{C}$, and $\mathrm{S}(\mathrm{m} / \mathrm{z}=32)$ between $210-281^{\circ} \mathrm{C}$ each with a maximum at 215,252 and $243^{\circ} \mathrm{C}$ respectively.

The EGA contains the same $\mathrm{CO}_{2}(\mathrm{~m} / \mathrm{z}=44)$ signal pattern as the other chromium benzoate complexes with two overlapping peaks in the $\mathrm{m} / \mathrm{z}=44$ signal. The initial $\mathrm{CO}_{2}$ peak evolves between $267-332^{\circ} \mathrm{C}$ and peaks at $304^{\circ} \mathrm{C}$. Above $332^{\circ} \mathrm{C}$, a second evolution of $\mathrm{CO}_{2}$ is observed which peaks at $365^{\circ} \mathrm{C}$ before evolution ceases at $408^{\circ} \mathrm{C}$. Between $277-450^{\circ} \mathrm{C}$ there is a mass loss of $18.0 \%$ which corresponds to the decomposition of the remaining thiocyanate anion and the benzoate ligands $\left(0.2 \mathrm{SCN}+4 \mathrm{CO}_{2}=18.6 \%\right)$.

This is followed by a greater rate of mass loss between $450-592^{\circ} \mathrm{C}$ with a mass loss of $40.7 \%$ which again is not observed in the EGA-MS. The final mass of the sample, $33.8 \%$ of the original mass, is higher than that expected for the formation of the chromium oxide, $\mathrm{Cr}_{2} \mathrm{O}_{3}(23.1 \%)$. From the TGA it can be seen that the sample is still losing mass so there is most likely organic product still remaining in the sample. 


\subsubsection{4 $\left[\mathrm{Cr}_{3} \mathrm{O}\left(\mathrm{O}_{2} \mathrm{CC}_{6} \mathrm{H}_{4}-3-\mathrm{Cl}\right)_{6}\left(\mathrm{H}_{2} \mathrm{O}\right)_{3}\right] \mathrm{NO}_{3} \cdot 2 \mathrm{CH}_{3} \mathrm{COCH}_{3}$}

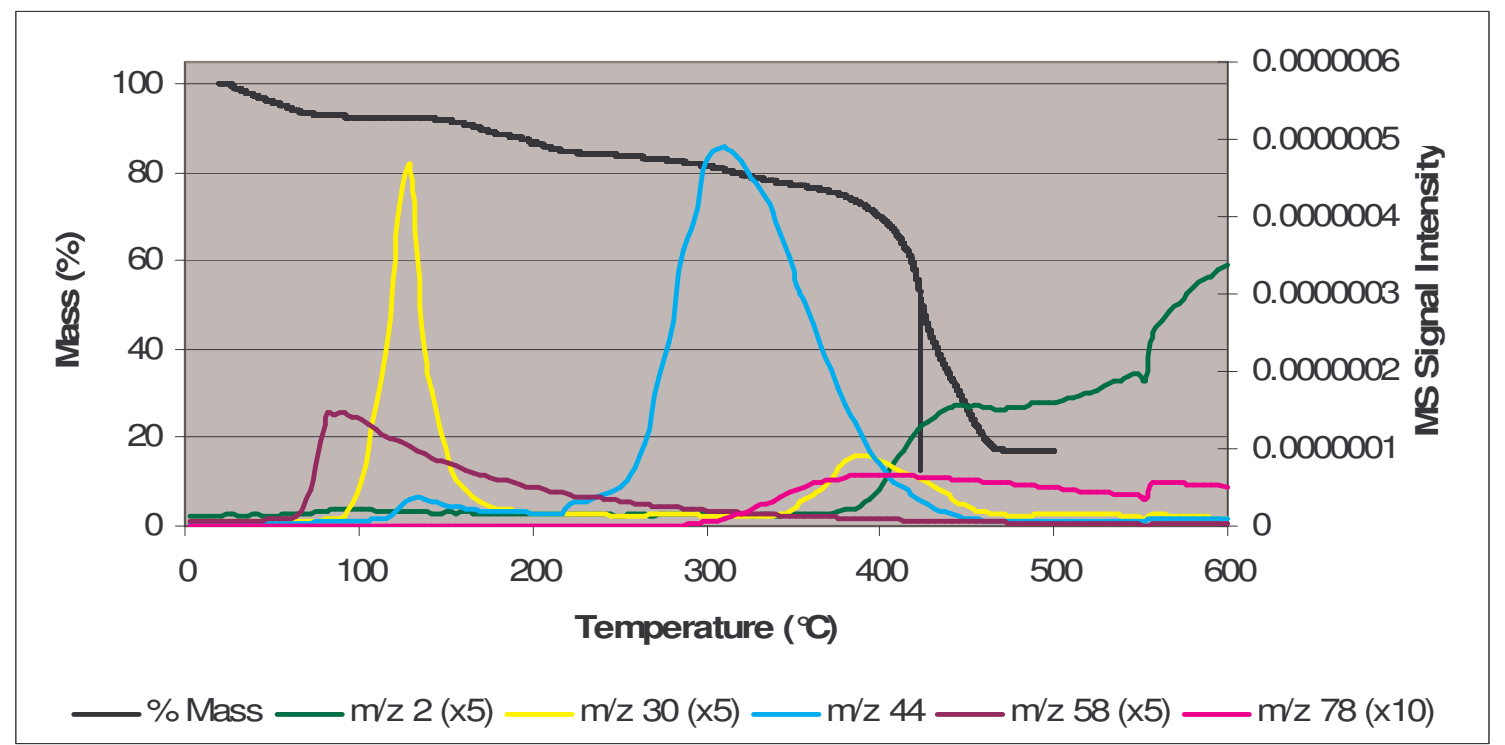

Figure 30: TGA and EGA-MS of $\left[\mathrm{Cr}_{3} \mathrm{O}\left(\mathrm{O}_{2} \mathrm{CC}_{6} \mathrm{H}_{4}-3-\mathrm{Cl}_{6}\left(\mathrm{H}_{2} \mathrm{O}\right)_{3}\right] \mathrm{NO}_{3} \cdot 2 \mathrm{CH}_{3} \mathrm{COCH}_{3}\right.$

A comparison of the TGA and EGA-MS of $\left[\mathrm{Cr}_{3} \mathrm{O}\left(\mathrm{O}_{2} \mathrm{CC}_{6} \mathrm{H}_{4}-3-\mathrm{Cl}\right)_{6}{ }^{-}\right.$ $\left.\left(\mathrm{H}_{2} \mathrm{O}\right)_{3}\right] \mathrm{NO}_{3} \cdot 2 \mathrm{CH}_{3} \mathrm{COCH}_{3}$ is shown in Figure 30. In the TGA there is a mass loss of $7.3 \%$ between $25-93^{\circ} \mathrm{C}$ which corresponds to the loss of the majority of the acetones of crystallisation $\left(1.6 \mathrm{CH}_{3} \mathrm{COCH}_{3}=7.0 \%\right)$. The absence of any signals in the EGA-MS over this temperature range can be explained by the condensation of the acetone in the tube connecting the furnace and mass spectrometer. The acetone $(\mathrm{m} / \mathrm{z}=58)$ is observed in the EGA-MS at $64^{\circ} \mathrm{C}$ and peaks at $\sim 88^{\circ} \mathrm{C}$ before tailing off. Between $93-223^{\circ} \mathrm{C}$ there is a mass loss of $7.5 \%$ which corresponds to the decomposition of the nitrate anion, the loss of a single water molecule and the loss of the remaining acetone $\left(0.4 \mathrm{CH}_{3} \mathrm{COCH}_{3}+\mathrm{NO}_{3}+\right.$ $\mathrm{H}_{2} \mathrm{O}=7.7 \%$.

Unlike the chromium benzoate complex, where the benzoate decomposes via two different processes, the $\mathrm{CO}_{2}$ signal indicates that the 3-chlorobenzoate ligand decomposes via a single process. The $\mathrm{CO}_{2}$ signal in the EGA-MS is first observed at $218^{\circ} \mathrm{C}$ and peaks at $311^{\circ} \mathrm{C}$ before the evolution ceases at $470^{\circ} \mathrm{C}$. Following the decomposition of the nitrate and loss of the water and acetone molecules, there is a mass loss of $34.0 \%$ between 
$223-424^{\circ} \mathrm{C}$. This mass loss corresponds to the decomposition of the benzoate ligands $\left(6 \mathrm{CO}_{2}+1.7 \mathrm{C}_{6} \mathrm{H}_{5} \mathrm{Cl}=34.0 \%\right)$.

Between $424-469^{\circ} \mathrm{C}$ the sample continues to lose $33.4 \%$ of its mass which is not observed in the EGA-MS. The final mass of the sample, $17.2 \%$ of the original mass, corresponds to the formation of the chromium oxide, $\mathrm{Cr}_{2} \mathrm{O}_{3}(17.1 \%)$.

The absence of the formation of a higher nuclearity chromium complex when $\left[\mathrm{Cr}_{3} \mathrm{O}\left(\mathrm{O}_{2} \mathrm{CC}_{6} \mathrm{H}_{4}-3-\mathrm{Cl}\right)_{6}\left(\mathrm{H}_{2} \mathrm{O}\right)_{3}\right] \mathrm{NO}_{3} \cdot 2 \mathrm{CH}_{3} \mathrm{COCH}_{3}$ is heated at $110^{\circ} \mathrm{C}$ is consistent with the TGA and EGA-MS) analysis of the precursor. At $110^{\circ} \mathrm{C}$ the EGA-MS indicates that the sample has lost acetone and the decomposition of the nitrate has just begun. The TGA confirms that the sample has lost two acetone molecules of crystallisation and some of the nitrate anion. When the crude material was recrystallised from methanol a methanol of crystallization was incorporated.

3.3.2.5 $\left[\mathrm{Cr}_{2 n}\left\{(\mathrm{OH})\left(\mathrm{O}_{2} \mathrm{CC}_{6} \mathrm{H}_{5}\right)_{2}\right\}_{2 n-1}\right]\left(\mathrm{NO}_{3}\right)_{3-x^{\circ}} \cdot\left(\mathrm{O}_{2} \mathrm{CC}_{6} \mathrm{H}_{5}\right)_{x} \cdot \mathrm{yH} \mathrm{H}_{2} \mathrm{O}(\mathrm{n} \geq 1)$

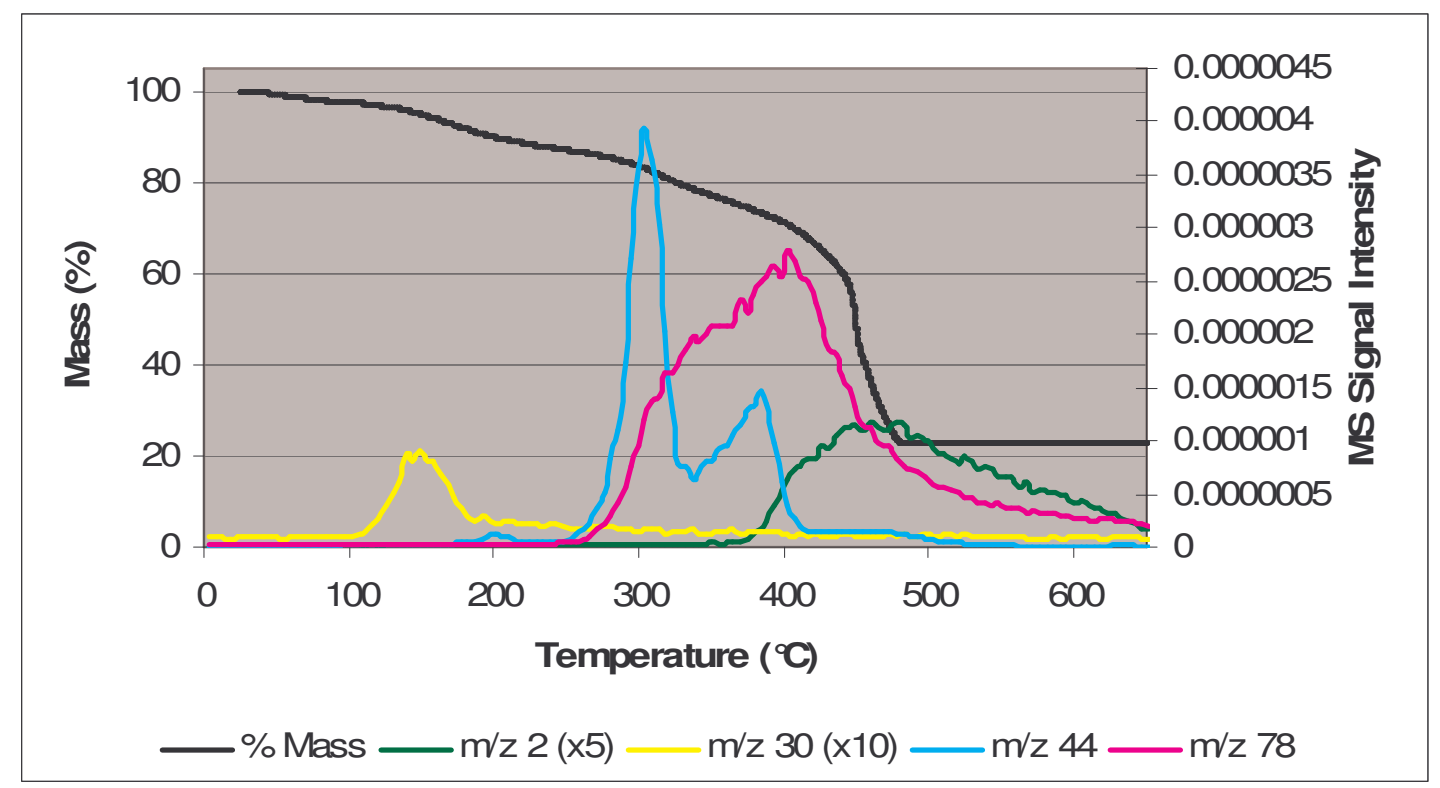

Figure 31: TGA and EGA-MS of $\left[\mathrm{Cr}_{2 \mathrm{n}}\left\{(\mathrm{OH})\left(\mathrm{O}_{2} \mathrm{CPh}\right)_{2}\right\}_{2 \mathrm{n}-1}\right]\left(\mathrm{NO}_{3}\right)_{3-\mathrm{x}} \cdot\left(\mathrm{O}_{2} \mathrm{CPh}\right)_{\mathrm{x}} \cdot \mathrm{yH}_{2} \mathrm{O}$ 
Thermal analysis was obtained for the blue chromium benzoate polymeric product $\left[\mathrm{Cr}_{2 \mathrm{n}}\left\{(\mathrm{OH})(\mathrm{O} 2 \mathrm{CPh})_{2}\right\}_{2 \mathrm{n}-1}\right]\left(\mathrm{NO}_{3}\right)_{3-\mathrm{x}} \cdot\left(\mathrm{O}_{2} \mathrm{CPh}\right)_{\mathrm{x}} \mathrm{yH}_{2} \mathrm{O}$ (Figure 31). Because the exact composition of the product is unknown, mass losses in the TGA can not be associated with any decomposition products.

From the EGA-MS the nitrate $(\mathrm{NO}, \mathrm{m} / \mathrm{z}=30)$ is observed to begin decomposing at $103^{\circ} \mathrm{C}$ and peaking at $\sim 150^{\circ} \mathrm{C}$ before evolution ceases at $206^{\circ} \mathrm{C}$. This is followed by the decomposition of the carboxylate ligands as observed by the evolution of $\mathrm{CO}_{2}(\mathrm{~m} / \mathrm{z}=44)$ which gives a signal with two peaks in a similar pattern that is observed for the other chromium benzoate complexes. The first $\mathrm{CO}_{2}$ peak evolves between $253-342^{\circ} \mathrm{C}$ and peaks at $304^{\circ} \mathrm{C}$. Above $342^{\circ} \mathrm{C}$, a second evolution of $\mathrm{CO}_{2}$ is observed which has a maximum at $384^{\circ} \mathrm{C}$ before evolution ceases at $417^{\circ} \mathrm{C}$. The coincident benzene signal $(\mathrm{m} / \mathrm{z}=78)$ confirms this as to be from the decomposition of the benzoate ligand.

\subsection{Thermal Analysis Discussion}

By comparing the EGA-MS and TGA of the different complexes, the effects of different precursor structural features on the final product isolated can be determined.

\subsubsection{Carboxylate ligands}

The trinuclear complexes that were analysed by EGA-MS and TGA contained three different carboxylate bridging ligands - acetate, benzoate and 3-chlorobenzoate. By comparing the $\mathrm{CO}_{2}$ signals of iron acetate, benzoate and 3-chlorobenzoate nitrate complexes, two different patterns are observed for the decomposition of the ligand. The $\mathrm{CO}_{2}$ signal from the acetate complex has a single peak between $130-260^{\circ} \mathrm{C}$ whereas the benzoate and 3-chlorobenzoate complexes' $\mathrm{CO}_{2}$ signal have two peaks between $200-250^{\circ} \mathrm{C}$. 
The initial $\mathrm{CO}_{2}$ peak of 3-chlorobenzoate is observed at slightly higher temperatures than that seen for the benzoate. The second peak occurs at the same temperature. This difference in the $\mathrm{CO}_{2}$ signal is also seen in the comparison of the iron benzoate and 3chlorobenzoate chloride complexes.

The $\mathrm{CO}_{2}$ signal patterns of the chromium benzoate and 3-chlorobenzoate nitrate complexes, unlike the iron complexes, are observed to be different from each other. The $\mathrm{CO}_{2}$ from the benzoate complex evolves in two steps between $231-488^{\circ} \mathrm{C}$ whereas with 3-chlorobenzoate the $\mathrm{CO}_{2}$ evolves in a single signal between $218-470^{\circ} \mathrm{C}$.

From the comparison of the different complexes, it can be seen that the acetate, benzoate and 3-chlorobenzoate carboxylate ligands decompose in distinct patterns.

\subsubsection{Anions}

Complexes that contained nitrate, chloride or thiocyanate anions were analysed in order to determine if the anion had an effect on the decomposition. EGA-MS of Fe(III) and $\mathrm{Cr}(\mathrm{III})$ nitrate salts indicates that the nitrate decomposes between $50-220^{\circ} \mathrm{C}$ in three steps which might correspond to the decomposition of the three nitrate anions. The single nitrate of the trinuclear complexes decomposes in a single step between $100-200^{\circ} \mathrm{C}$. The exception to this observation was the decomposition of the nitrate anion in the iron acetate complex, $\left[\mathrm{Fe}_{3} \mathrm{O}\left(\mathrm{O}_{2} \mathrm{CCH}_{3}\right)_{6}\left(\mathrm{H}_{2} \mathrm{O}\right)_{3}\right] \mathrm{NO}_{3}$, which is seen to decompose in two steps. The explanation for this is unclear. It has been reported that the decomposition of metal nitrates may produce nitrous oxide $\left(\mathrm{N}_{2} \mathrm{O}, \mathrm{m} / \mathrm{z}=44\right)^{[121]}$. However, EGA-MS isotope and fragmentation patterns of the iron(III) and chromium(III) nitrates have indicated that the $\mathrm{m} / \mathrm{z}=44$ signal not only consists of $\mathrm{N}_{2} \mathrm{O}$ but also $\mathrm{CO}_{2}$. The source of the $\mathrm{CO}_{2}$ is not clear 
but $\mathrm{CO}_{2}$ can be absorbed from the atmosphere by the acidic nature of iron(III) nitrate but this is not expected to occur for the chromium(III) nitrate. A similar study has shown that the $\mathrm{m} / \mathrm{z}=44$ signal is due to $\mathrm{CO}_{2}$ as well as $\mathrm{N}_{2} \mathrm{O}$ in the trinuclear nitrate complexes. As it is unlikely that the carboxylate decomposes at this low temperature, it is possible that a small amount of $\mathrm{CO}_{2}$ may also be absorbed by the trinuclear complexes.

In the iron and chromium complexes with a chloride anion neither the chloride anion nor $\mathrm{HCl}$ was observed in the EGA-MS below $200^{\circ} \mathrm{C}$. However, the TGA data suggests that the chlorine is removed at temperatures below $200^{\circ} \mathrm{C}$. The EGA-MS of $\left[\mathrm{Fe}_{3} \mathrm{O}\left(\mathrm{O}_{2} \mathrm{CC}_{6} \mathrm{H}_{4^{-}}\right.\right.$ 3- $\left.\mathrm{Cl})_{6}\left(\mathrm{H}_{2} \mathrm{O}\right)_{3}\right] \mathrm{Cl} \cdot \mathrm{H}_{2} \mathrm{O}$ shows a $\mathrm{m} / \mathrm{z}=36$ signal which corresponds to $\mathrm{HCl}$ evolving above $518^{\circ} \mathrm{C}$. This signal is confirmed as $\mathrm{HCl}$ due to a coincident $\mathrm{Cl}(\mathrm{m} / \mathrm{z}=35)$ signal and the correct ${ }^{37} \mathrm{Cl} /{ }^{35} \mathrm{Cl}$ isotope ratio. It should be noted that it is not possible to determine from the EGA-MS or TGA if the chloride is from the anion or from the chlorine of the 3chlorobenzoate. However, the fact that these signals are not observed in the corresponding chloride salt benzoate complexes indicates that the signal is most likely from the ligand and not the anion.

From the analysis of $\left[\mathrm{Cr}_{3} \mathrm{O}\left(\mathrm{O}_{2} \mathrm{CC}_{6} \mathrm{H}_{5}\right)_{6}\left(\mathrm{H}_{2} \mathrm{O}\right)_{3}\right] \mathrm{SCN}$ EGA-MS data, the thiocyanate anion is observed to decompose in at least three different steps between $200-300^{\circ} \mathrm{C}$. A signal due to $\mathrm{NO}(\mathrm{m} / \mathrm{z}=30)$ appears at $187^{\circ} \mathrm{C}, \mathrm{CN}(\mathrm{m} / \mathrm{z}=26)$ at $196^{\circ} \mathrm{C}$ and $\mathrm{S}(\mathrm{m} / \mathrm{z}=32)$ at $210^{\circ} \mathrm{C}$ each with a maximum at 215,252 and $243^{\circ} \mathrm{C}$ respectively. The $\mathrm{m} / \mathrm{z}=32$ signal was confirmed as being due to sulfur and not oxygen impurities of the nitrogen carrier gas by the observation of the correct ${ }^{32} \mathrm{~S} /{ }^{34} \mathrm{~S}$ isotope ratios. These three different signals appearing at different temperatures indicate that the thiocyanate ion does not decompose in a concerted step. With the absence of oxygen in the nitrogen carrier gas, the presence of NO suggests that the thiocyanate is reacting with the trinuclear complex. Because the 
carboxylate decomposition pattern remains essentially unchanged it can assumed that only a small amount of the complex reacts with the thiocyanate. However, it would be expected that the decomposition of the thiocyanate affects the yield of the product formed.

Although the different anions are observed to decompose in different ways, the decomposition pattern of the carboxylate ligand remains the same. This suggests that the decomposition of the anion has little or no effect on the decomposition of the bridging ligands. Infrared spectroscopy confirms this observation. The infrared spectra of trinuclear complexes that contain different anions heated to similar temperatures have very similar or the same stretching frequencies. This suggests that the same product is formed regardless of the anion. The decomposition of the iron mixed-valent complex, $\left[\mathrm{Fe}_{3}^{\mathrm{III}}{ }_{3} \mathrm{Fe}^{\mathrm{II}} \mathrm{O}\left(\mathrm{O}_{2} \mathrm{CC}_{6} \mathrm{H}_{5}\right)_{6}\left(\mathrm{H}_{2} \mathrm{O}\right)_{3}\right]$, which contains no counter ion is very similar to the iron(III) benzoate complex. Although the decomposition of the carboxylate remains unaffected, the yield of the product isolated is expected to be affected by the decomposition of the anion.

\subsubsection{Solvent of crystallisation}

The trinuclear complexes that were analysed contained acetone, methanol or water molecules of crystallisation. Unfortunately, the temperature at which water is removed can not be determined due to it being absorbed onto the silica capillary of the mass spectrometer.

Some of the iron trinuclear complexes analysed contained methanol solvent/s of crystallisation. In the EGA of $\left[\mathrm{Fe}_{3} \mathrm{O}\left(\mathrm{O}_{2} \mathrm{CC}_{6} \mathrm{H}_{5}\right)_{6}\left(\mathrm{H}_{2} \mathrm{O}\right)_{3}\right] \mathrm{NO}_{3} \cdot 2 \mathrm{MeOH}$ and $\left[\mathrm{Fe}_{3} \mathrm{O}\left(\mathrm{O}_{2} \mathrm{CC}_{6} \mathrm{H}_{4}-3-\mathrm{Cl}\right)_{6}\left(\mathrm{H}_{2} \mathrm{O}\right)_{3}\right] \mathrm{NO}_{3} \cdot \mathrm{MeOH}$, methanol is observed to begin evolving at 
below $100^{\circ} \mathrm{C}\left(92^{\circ} \mathrm{C}\right.$ and $87^{\circ} \mathrm{C}$ for each complex respectively). The evolution of methanol was observed from the coincident $\mathrm{m} / \mathrm{z}=31\left(\mathrm{CH}_{3} \mathrm{O}^{+}\right)$and $\mathrm{m} / \mathrm{z}=30\left(\mathrm{CH}_{2} \mathrm{O}^{+}\right)$signal. The signals from methanol are broadened due to condensation problems so these signals have long tails.

Some of the chromium trinuclear complexes contained acetone solvents of crystallisation. From the EGA of $\left[\mathrm{Cr}_{3} \mathrm{O}\left(\mathrm{O}_{2} \mathrm{CC}_{6} \mathrm{H}_{5}\right)_{6}\left(\mathrm{H}_{2} \mathrm{O}\right)_{3}\right] \mathrm{NO}_{3} \cdot \mathrm{CH}_{3} \mathrm{COCH}_{3}$ and $\left[\mathrm{Cr}_{3} \mathrm{O}\left(\mathrm{O}_{2} \mathrm{CC}_{6} \mathrm{H}_{4}-3-\mathrm{Cl}\right)_{6}\left(\mathrm{H}_{2} \mathrm{O}\right)_{3}\right] \mathrm{NO}_{3} \cdot 2 \mathrm{CH}_{3} \mathrm{COCH}_{3}$, the acetone $(\mathrm{m} / \mathrm{z}=58)$ is observed to begin evolving between $60-90^{\circ} \mathrm{C}$. Again, this signal is broadened due to condensation problems. A water signal is not observed due to the water being absorbed onto the capillary of the mass spectrometer.

Signals from the anion and ligand decomposition remain unchanged in the presence of different solvents of crystallisation indicating that the solvent of crystallisation has no effect on the remaining entities of the precursor complex.

\subsubsection{Metal type}

Comparison of the thermal analysis of iron and chromium complexes containing either a nitrate or chloride anion indicates that the metal does not influence the decomposition of the anion. Regardless of the metal ion of the complex, the nitrate is seen to decompose between $100-200^{\circ} \mathrm{C}$ and the chloride is lost (most likely as $\mathrm{HCl}$ ) below $200^{\circ} \mathrm{C}$.

Comparison of the thermal analysis of iron and chromium complexes containing either a benzoate or 3-chlorobenzoate bridging ligand indicates that the metal has an influence on the decomposition of the ligand. The $\mathrm{CO}_{2}$ signal from the decomposition of the 
carboxylate ligands shows that the different metals give different signal patterns. Both the iron and chromium benzoates have a $\mathrm{CO}_{2}$ signal with a peak beginning at $\sim 250^{\circ} \mathrm{C}$ and peaking at $\sim 320^{\circ} \mathrm{C}$. The second peak, when present, is observed at different temperatures for the different metals. The iron benzoate and 3-chlorobenzote complexes have an initial peak which appears at $\sim 200^{\circ} \mathrm{C}$. This is compared to the chromium benzoate complexes which have a peak that appears at $\sim 350^{\circ} \mathrm{C}$ after the peak at $\sim 250^{\circ} \mathrm{C}$. The chromium 3chlorobenzoate complex only contains the single $\mathrm{CO}_{2}$ peak at $250^{\circ} \mathrm{C}$.

\subsubsection{Precursor structure}

Previous investigators ${ }^{[59,64,66]}$ of the high temperature synthesis have reported the use of what they claimed to be chromium trinuclear complexes as precursors. However, the colour (blue) and low synthesis temperature of the precursor suggest that it is in fact either a dinuclear complex or an olation polymer. The detection of the trinuclear complex in the mass spectrum ${ }^{[59]}$ of the benzoate precursor may be explained by the $\mathrm{CH}_{2} \mathrm{Cl}_{2} / \mathrm{MeOH}$ solvent system used - the dinuclear/olation product is soluble in $\mathrm{CH}_{2} \mathrm{Cl}_{2}$ but insoluble in $\mathrm{MeOH}$ whereas the trinuclear complex is soluble in both solvents. An EGA-MS analysis of the chromium benzoate polymer, $\left[\mathrm{Cr}_{2 \mathrm{n}}\left\{(\mathrm{OH})\left(\mathrm{O}_{2} \mathrm{CPh}\right)_{2}\right\}_{2 \mathrm{n}-1}\right]\left(\mathrm{NO}_{3}\right)_{3-\mathrm{x}} \cdot\left(\mathrm{O}_{2} \mathrm{CPh}\right)_{\mathrm{x}} \mathrm{yH}_{2} \mathrm{O}$, was obtained and compared to the chromium benzoate trinuclear complex, $\left[\mathrm{Cr}_{3} \mathrm{O}\left(\mathrm{O}_{2} \mathrm{CPh}\right)_{6}\left(\mathrm{H}_{2} \mathrm{O}\right)_{3}\right] \mathrm{NO}_{3} \cdot \mathrm{CH}_{3} \mathrm{COCH}_{3}$, to determine what influence, if any, the nuclearity has on the final product. The EGA-MS analyses show that the two complexes decompose in a similar pattern with the nitrate decomposing between $100-200^{\circ} \mathrm{C}$ followed by two $\mathrm{CO}_{2}$ peaks due to the benzoate between $250-500^{\circ} \mathrm{C}$. The major difference was seen in the nitrate decomposition where the NO peak is less intense in the chromium polymer EGA-MS compared to that of the chromium 
trinuclear complex. This indicates that the chromium polymer has $n \geq 3$ as this would give a smaller ratio of nitrate anions to ligands compared to the trinuclear complex.

Previous reports of heating a chromium olation polymer to temperatures of $\sim 200^{\circ} \mathrm{C}$ have resulted in the formation of chromium wheels in low yields ${ }^{[59,64]}$. It would be expected that the formation of a wheel is more likely to occur from the rearrangement of the olation polymer rather than the breaking of the trinuclear core. One of the chromium wheels that has been characterized by X-ray crystallography co-crystallised with a chromium trinuclear complex $^{[64]}$ which indicates that when the chromium polymer is heated at lower temperatures, the formation of the trinuclear complex can occur. This may be expected as the formation of trinuclear from dinuclear complexes is a known reaction ${ }^{[69]}$ as is the formation of linear complexes from trinuclear complexes ${ }^{[122]}$. The thermal analysis of the precursors indicates that at higher furnace temperatures the decomposition patterns of the different precursors are the same. This decomposition pattern is expected to form the same products, most likely the thermodynamically stable product. For example, the same $\mathrm{Cr}_{12}$ cage structure is formed when either an olation polymer ${ }^{[6]]}$ or trinuclear complex ${ }^{[65]}$ is used as a precursor.

\subsubsection{Thermal mechanism}

From the previously reported thermal analysis studies of iron, iron/manganese and iron/copper formate, acetate and propanoate complexes, two reactions have been proposed to occur during the heating process ${ }^{[111,123]}$. The peaks in the $\mathrm{CO}_{2}$ signal that are observed in the EGA-MS of the complexes might be due to these two different process. 


\subsubsection{Thermal hydrolysis}

At lower temperatures, hydrolysis of the carboxylate can occur resulting in the formation of the carboxylic acid and a hydroxide bridge between two metal centres. The water involved in the hydrolysis reaction is probably the terminal water ligand because the water molecule of crystallization has already been lost or was not present in the first place. The carboxylic acid would then remain in the crude material, possibly coordinated to the metal as a monodentate ligand, until the furnace reaches the boiling point of the acid (benzoic/3chlorobenzoic acid $\sim 250^{\circ} \mathrm{C}$, acetic acid $\left.=118^{\circ} \mathrm{C}\right)^{[124]}$. This is consistent with the $\mathrm{CO}_{2}$ signal first appearing at $\sim 120^{\circ} \mathrm{C}$ and $\sim 250^{\circ} \mathrm{C}$ in the acetate and benzoate/3-chlorobenzoate complexes respectively. Evidence of the formation and evolution of the carboxylic acid is observed by the formation of the acid (identified by IR) at the cool end of the furnace tube during the synthesis. Further evidence is seen in the EGA-MS of the iron acetate complex, $\left[\mathrm{Fe}_{3} \mathrm{O}\left(\mathrm{O}_{2} \mathrm{CCH}_{3}\right)_{6}\left(\mathrm{H}_{2} \mathrm{O}\right)_{3}\right] \mathrm{NO}_{3}$, which contains a signal due to acetic acid. If the temperature of the furnace does not reach the boiling point of the acid it is possible that it may recombine with the crude materials upon cooling to form a higher nuclearity product.

The formation of $\left[\mathrm{Fe}_{6} \mathrm{O}_{2}(\mathrm{OH})_{2}\left(\mathrm{O}_{2} \mathrm{CC}_{6} \mathrm{H}_{4}-3-\mathrm{Cl}\right)_{12}\left(\mathrm{H}_{2} \mathrm{O}\right)_{2}\right]$ from $\left[\mathrm{Fe}_{3} \mathrm{O}\left(\mathrm{O}_{2} \mathrm{CC}_{6} \mathrm{H}_{4}-3-\mathrm{Cl}\right)_{6}\right.$ $\left.\left(\mathrm{H}_{2} \mathrm{O}\right)_{3}\right] \mathrm{NO}_{3}$ may be explained by a thermal hydrolysis process. At $200^{\circ} \mathrm{C}$, the EGA-MS of $\left[\mathrm{Fe}_{3} \mathrm{O}\left(\mathrm{O}_{2} \mathrm{CC}_{6} \mathrm{H}_{4}-3-\mathrm{Cl}\right)_{6}\left(\mathrm{H}_{2} \mathrm{O}\right)_{3}\right] \mathrm{NO}_{3}$ indicates that the nitrate has decomposed but not the bridging ligands as is expected for the formation of the $\mathrm{Fe}_{6}$ complex. Thermal hydrolysis of the bridging ligands could form the hydroxide bridge between the metal ions as well as a 3-chlorobenzoic acid molecule. Because the temperature is lower than the boiling point of the acid, the acid remains in the solid sample. When the sample is cooled down, the acid may re-associate with the complex to form the higher nuclearity complex. It cannot be determined if the hydroxide bridge forms between two trinuclear units initially or when the crude is cooled. 


\subsubsection{Reductive elimination}

A second reaction that has been proposed is the reductive elimination of the carboxylate where two carboxylate bridges combine to form the carboxylic acid, carbon dioxide and a reactive organic species along with the reduction of $\mathrm{M}(\mathrm{III}) \rightarrow \mathrm{M}(\mathrm{II})$. The initial step of this process is the homolytic cleavage of the $\mathrm{M}-\mathrm{O}$ or $\mathrm{C}-\mathrm{O}$ bond of the carboxylate bridge giving rise to an organic radical as well as either a $\mathrm{M}(\mathrm{II})$ or a $\mathrm{M}(\mathrm{III})-\mathrm{O}$ radical (Figure 32). The $\mathrm{M}(\mathrm{II})$ and $\mathrm{M}(\mathrm{III})-\mathrm{O}$ radical may react together to form the $\mathrm{M}(\mathrm{III})-\mathrm{O}-\mathrm{M}(\mathrm{III})$ bond that is seen in the higher nuclearity product as well as the final metal oxide. The organic radicals react with each other to give rise to other organic molecules including the carboxylic acid as well as the reactive organic species. The reactive species then form larger organic moieties such as propionate which has been observed from the heating of iron acetate due to the formation of a carbene reactive species ${ }^{[123]}$. The formation of propionate $(\mathrm{m} / \mathrm{z}=74)$ was observed in the EGA-MS of the iron acetate complex in this research work however the signal was of very low intensity and is not considered conclusive. The formation of carbene is also expected to form ethane but the nitrogen carrier gas results in a swamping of the $\mathrm{m} / \mathrm{z}=28$ signal and so it was not observed in this work. The reductive elimination of benzoate and 3-chlorobenzoate would be expected to form a benzyne/benzyne derivative reactive species which can then go on to form larger molecular weight organic products such as polycyclic aromatic hydrocarbons (PAHs). This explains the mass loss observed in the TGA of the compounds that has no corresponding EGA-MS signal. 
<smiles>[M]OC1([R])CCOC1</smiles>

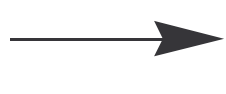<smiles>[M]OC([R])OC1=CCC1</smiles><smiles>[M]OCC([R])O[M]</smiles><smiles>[M]OC([2H])O</smiles>

Figure 32: Formation of organic and metal radicals from the homolytic cleavage of the carboxylate bridging ligand.

The initial $\mathrm{CO}_{2}$ peak in the EGA-MS of iron benzoate/3-chlorobenzoate beginning at $\sim 200^{\circ} \mathrm{C}$ may be explained by the reductive elimination process whilst with $\mathrm{Cr}(\mathrm{III})$, this process could occur in the benzoate complexes at a higher temperature and explains the second $\mathrm{CO}_{2}$ peak above $\sim 350^{\circ} \mathrm{C}$. However, as the formation of $\mathrm{Cr}(\mathrm{II})$ is unlikely to occur, it is also possible that a different process is occurring in the chromium complexes. The mechanism for the reductive elimination of a benzoate ligand is shown in Figure 33. This mechanism has been simplified as it is also possible for attack to occur at the para hydrogen atom. The chlorine atom on the 3-chlorobenzoate ligand is expected to influence the reductive elimination process as it would be harder to remove an ortho hydrogen. This is observed in the EGA-MS of the iron 3-chlorobenzoate complexes where the initial $\mathrm{CO}_{2}$ peak is of lower intensity compared to the benzoate complexes and appears as more of a shoulder to the peak at $250^{\circ} \mathrm{C}$. If the attack did occur at the para hydrogen atom then it would be expected that a chlorine radical would be formed yet products of this reaction, such as $\mathrm{HCl}$, are not see in the EGA-MS. For the chromium 3-chlorobenzoate complex, a second $\mathrm{CO}_{2}$ peak is not observed which indicates that the ligand decomposes before the reductive elimination step can occur. 

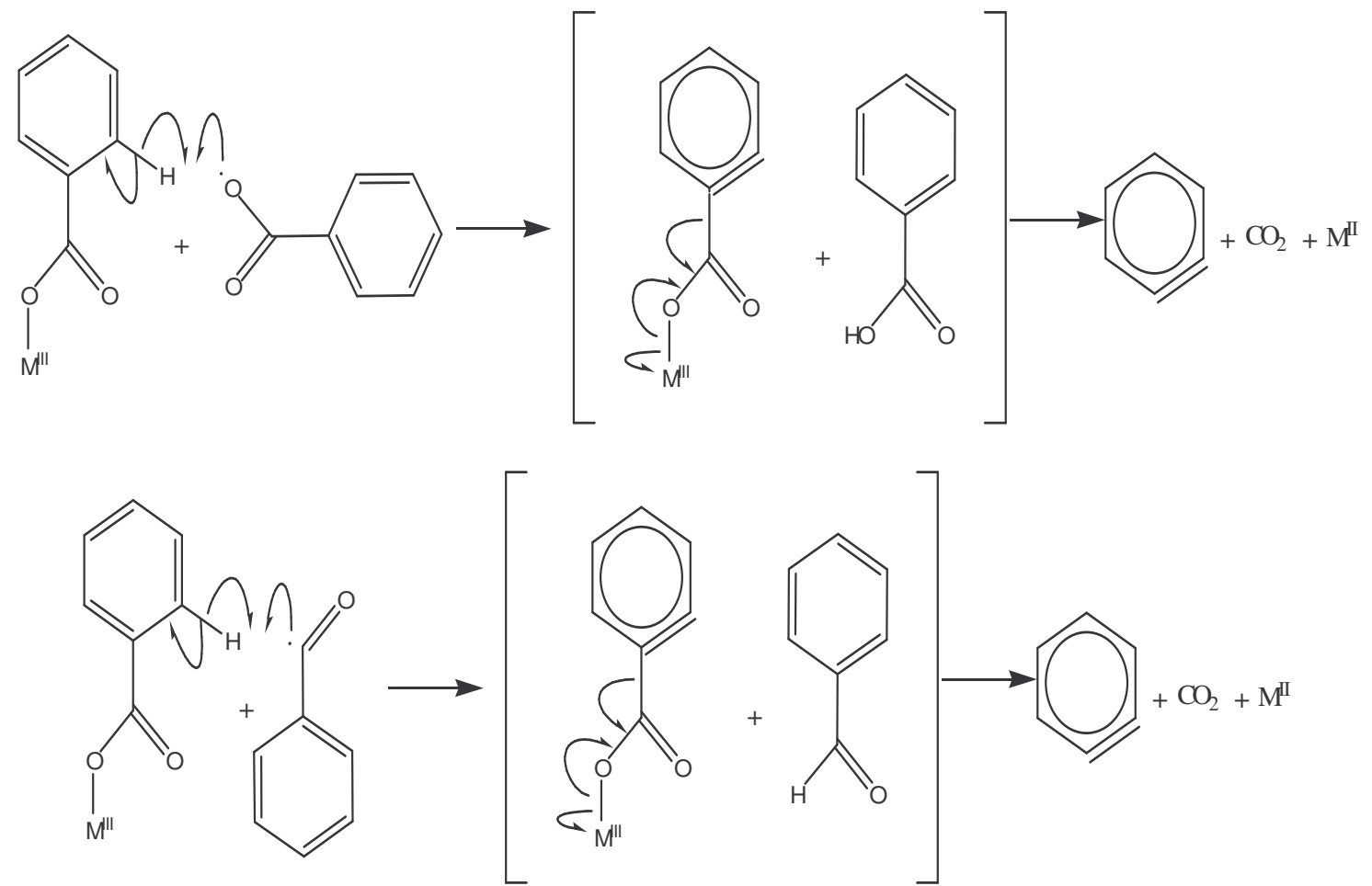

Figure 33: Proposed mechanism for the reductive elimination of a benzoate ligand. 


\section{Conclusions}

\subsection{High Temperature Synthesis}

This research has shown that use of thermal analytical techniques, EGA-MS and TGA, are an effective way of determining the processes that are occurring at different temperatures during the heating process. From the thermal analysis of different precursors to the high temperature synthesis, it is observed that the product is influenced by the carboxylate ligand and the metal ion present in the precursor. Factors such as the anion and solvent of crystallisation are seen to have no influence during the synthesis on the product formed whilst the nuclearity of the precursor has no influence at higher temperatures.

By comparing the EGA-MS and TGA of the different complexes the general nature of the decomposition process during heating was determined. Initially at the lower temperature range, the solvent of crystallisation, if present, is removed followed by the removal of the terminal ligands and decomposition of the anion. Next, the bridging ligand is removed and decomposes followed by signals due to decomposition of the remaining products as the metal oxide is formed at higher temperatures. Depending on the nature of the precursor, these processes may overlap during the heating process.

During the high temperature synthesis, numerous reactions are expected to occur. Two reactions that have been proposed to occur are the thermal hydrolysis and the reductive elimination of the carboxylate bridging ligands. Signals seen in the EGA-MS and TGA are consistent with these two reactions. However, the reductive elimination reaction is expected to give the metal in the +2 oxidation state whereas the final isolated products of 
the heating process contain metal ions in the +3 oxidation state. This means that other redox reactions may be occurring that have not yet been accounted for.

Because the synthesis of the higher nuclearity complexes rely on the decomposition of the precursor, the ability to control what product is formed is difficult due to the formation of side products. This research has shown that thermal analytical techniques may be used in order to determine the optimal temperature at which the high temperature synthesis should undergo. It is possible to predict that precursors that contain low boiling point bridging ligands will require a lower synthesis temperature to form complexes of the same nuclearity and structure than precursors that have a higher boiling point ligand. For example, when a chromium 2-methylpropanoate precursor is heated at $400^{\circ} \mathrm{C}$ a $\mathrm{Cr}_{12}$ complex, $\left[\mathrm{Cr}_{12} \mathrm{O}_{8}(\mathrm{OH})_{4}\left(\mathrm{O}_{2} \mathrm{CCHMe}_{2}\right)_{16}\left(\mathrm{HO}_{2} \mathrm{CCHMe}_{2}\right)_{4}\right]$, is formed ${ }^{[66]}$ compared to when a chromium benzoate precursor is heated to the same temperature to form a $\mathrm{Cr}_{8}$ complex, $\left[\mathrm{Cr}_{8} \mathrm{O}_{4}\left(\mathrm{O}_{2} \mathrm{CPh}\right)_{16}\right]^{[59]}$. This may be explained by the lower boiling point of the 2methylpropanoic acid compared to the benzoic acid $\left(154.7^{\circ} \mathrm{C} \text { and } 249^{\circ} \mathrm{C} \text { respectively }\right)^{[124]}$ where the benzoate complex would be expected to form a $\mathrm{Cr}_{12}$ complex at higher temperatures.

Although high nuclearity iron complexes formed via the high temperature synthesis may alternatively be synthesised using solvothermal techniques with higher yields, the chromium complexes formed using this method have not yet been synthesised by any other method. This means that the high temperature synthesis may be used as a method to form chromium complexes of a certain nuclearity and structure. At lower temperatures, the nuclearity of the precursor can influence the nuclearity and structure of the product formed. Chromium polymer precursors form wheel structures compared to the trinuclear precursors which form cages or winged structures. However, with higher furnace 
temperatures, the nuclearity of the complex has no effect on the product. The anion of the precursor has no effect on the nuclearity and structure of the product although it is expected that it will have an effect on the yield. This is because as the anion decomposes it is most likely to react somehow with the precursor e.g. when metal nitrates decompose, a metal oxide is formed.

Previous research has proposed that upon going from a $\mathrm{Fe}_{3}$ starting material to a $\mathrm{Fe}_{11}$ product, the synthesis goes through a $\mathrm{Fe}_{6}$ intermediate ${ }^{[53]}$. A comparison of the infrared spectra of the products of heating iron precursors indicate that below $300^{\circ} \mathrm{C}$, the majority of the product in the crude material is the hexanuclear winged complex. Above this temperature and the majority of the product is the undecanuclear cage complex. It is proposed that the thermal hydrolysis of the carboxylate bridge at the lower temperatures leads to the formation of the hexanuclear complex. At higher temperatures, the reductive elimination of the ligands may occur leading to the formation of the undecanuclear complex. A similar study of the chromium products indicates that two structures are formed by either heating the precursor at below or above $300^{\circ} \mathrm{C}$.

\subsection{Future Work}

Research into the high temperature synthesis of polynuclear complexes is in its infancy which means that there is a large area of research yet to be explored. This work has opened up a new area of research into the formation of higher nuclearity complexes by using the high temperature synthesis.

Only three different carboxylate ligands and three different anions were used during the current research. A larger number of ligands and anions need to be analysed in order to 
confirm that the product is only influenced by the carboxylate ligand. Precursors with different boiling point carboxylate ligands need to be compared in order to show that the boiling point of the ligand does play a part in the formation of the product. In order to determine if the signals in the EGA-MS are due to the reductive elimination process, ligands that will not undergo reductive elimination could be used. Halogenated derivatives of the carboxylates would not be expected to undergo reductive elimination as there is no hydrogen to be removed. For example, the formation of benzyne will only occur with attack at the ortho and para hydrogen atoms. This means that the EGA-MS of a complex containing 2,4,6-trichlorobenzoate ligands would not be expected to have a reductive elimination signal when compared to the analogous benzoate complex. It is predicted that complexes of this sort would only contain a single $\mathrm{CO}_{2}$ peak in the EGA-MS evolving at the boiling point of the ligand.

The EGA-MS in this research was conducted under nitrogen. If the EGA-MS was run under $\operatorname{argon}(\mathrm{m} / \mathrm{z}=40)$, signals due to $\mathrm{CO}(\mathrm{m} / \mathrm{z}=28)$ and $\mathrm{N}(\mathrm{m} / \mathrm{z}=14)$ would be able to be observed. A $\mathrm{m} / \mathrm{z}=28$ signal would be expected to coincide with the reductive elimination step but not observed, or at a much lower intensity, during the 'boiling' step of the carboxylate ligand. The $\mathrm{m} / \mathrm{z}=14$ signal can be used as conformation of the nitrogen containing gases that are evolved. Another limitation to the EGA-MS experiments was that evolved gases with a molecular weight greater than $100 \mathrm{~g} \cdot \mathrm{mol}^{-1}$ could not be detected. Future experiments may be prepared with a higher molecular weight detection limit so that gases with a molecular weight greater than 100 g.mol ${ }^{-1}$ can be detected.

In order for a SMM to be used in a practical application, it must first be arranged onto a solid surface in an ordered fashion. Previous research has used SMMs with thioether derived carboxylate bridges anchored to a gold surface ${ }^{[125,126]}$ or with long chain carboxylate 
ligands anchored onto a silicon or silica surface ${ }^{[127]}$. Although the ligand is removed and decomposes during the high temperature synthesis, it is observed that the chlorine on the 3-chlorobenzoate complex survives the high temperatures of the synthesis. This means that higher nuclearity complexes, that are potentially SMMs, may be synthesised containing a substituent which is a point of further synthesis. Modification of this ligand may enable incorporation of the polynuclear complex into a polymer or to anchor onto a solid surface.

During the thermal decomposition of metal nitrates, it is postulated that the nitrate binds directly to the metal ion which causes a weakening of the $\mathrm{N}-\mathrm{O}$ bond causing it to break forming $\mathrm{NO}_{2}$ gas and a metal oxygen bond ${ }^{[128]}$. The absence of a $\mathrm{NO}_{2}$ signal in the decomposition of the trinuclear nitrate complexes indicates that the nitrate of the trinuclear complexes decompose in a different way from the metal nitrates. In order to determine if the trinuclear nitrate complexes decompose in a similar way, isotope studies may be preformed in order to observe the source of the oxygen in the product. Use of $\mathrm{N}^{18} \mathrm{O}_{3}$ as an anion would allow such a study as any ${ }^{18} \mathrm{O}$ present in the product will indicate that the nitrate plays a part in the formation of the product. 


\section{References}

[1] R. F. Weinland, Berichte der Deutschen Chemischen Gesellschaft 1908, 41, 3236.

[2] A. Werner, Berichte der Deutschen Chemischen Gesellschaft 1909, 41, 3447.

[3] R. F. Weinland and H. Spanagel, Chemische Berichte 1916, 49, 1003.

[4] R. F. Weinland and E. Gussmann, Zeitschrift fuer Anorganische und Allgemeine Chemie 1910, 67, 250.

[5] L. A. Welo, Philosophical Magazine 1928, 6, 481.

[6] L. E. Orgel, Nature 1960, 187, 504.

[7] B. N. Figgis and G. B. Robertson, Nature 1965, 205, 694.

[8] H. Hatop, M. Ferbinteanu, H. W. Roesky, F. Cimpoesu, M. Schiefer, H.-G. Schmidt and M. Noltemeyer, Inorganic Chemistry 2002, 41, 1022.

[9] K. Doeppert and U. Thewalt, Journal of Organometallic Chemistry 1986, 301, 41.

[10] S. L. Castro, W. E. Streib, J.-S. Sun and G. Christou, Inorganic Chemistry 1996, 35, 4462 .

[11] E. Gonzalez-Vergara, J. Hegenauer, P. Saltman, M. Sabat and J. A. Ibers, Inorganica Chimica Acta 1982, 66, 115.

[12] A. R. E. Baikie, M. B. Hursthouse, D. B. New and P. Thornton, Journal of the Chemical Society, Chemical Communications 1978, 2, 62.

[13] J. Li, S. Yang, F. Zhang, Z. Tang, S. Ma, Q. Shi, Q. Wu and Z. Huang, Inorganica Chimica Acta 1999, 294, 109.

[14] A. M. Bond, R. J. H. Clark, D. G. Humphrey, P. Panayiotopoulos, B. W. Skelton and A. H. White, Journal of the Chemical Society, Dalton Transactions: Inorganic Chemistry 1998, 1845. 
[15] V. M. Lynch, J. W. Sibert, J. L. Sessler and B. E. Davis, Acta Crystallographica, Section C: Crystal Structure Communications 1991, C47, 866.

[16] K. S. Gavrilenko, Y. L. Gal, O. Cador, S. Golhen and L. Ouahab, Chemical Communications 2007, 280.

[17] A. Spencer and G. Wilkinson, Journal of the Chemical Society, Dalton Transactions: Inorganic Chemistry 1974, 8, 786.

[18] O. Almog, A. Bino and D. Garfinkel-Shweky, Inorganica Chimica Acta 1993, 213, 99.

[19] S. Davis and R. S. Drago, Inorganic Chemistry 1988, 27, 4759.

[20] Y. Sasaki, A. Nagasawa, A. Tokiwa-Yamamoto and T. Ito, Inorganica Chimica Acta 1993, 212, 175.

[21] M. K. Johnson, D. B. Powell and R. D. Cannon, Spectrochimica Acta Part A: Molecular Spectroscopy 1981, 37, 995.

[22] A. N. Belyaev, S. A. Simanova, V. I. Bashmakov and N. M. Burmistrova, Zhurnal Prikladnoi Khimii (Sankt-Peterburg) 1994, 67, 2054.

[23] H. Puschmann in Trinuclear Carboxylate Complexes of First Row Transition Metals, Victoria University, Wellington, 1999, p. 174.

[24] F. A. Cotton and W. Wang, Inorganic Chemistry 1982, 21, 2675.

[25] J. B. Vincent, Inorganic Chemistry 1994, 33, 5604.

[26] S. Shova, D. Prodius, V. Mereacre, Y. A. Simonov, J. Lipkowski and C. Turta, Inorganic Chemistry Communications 2004, 7, 292.

[27] H. Xu, J. Li, J. Zou, Z. Xu, X. You, G. Guo, J. Huang and H. Zhuang, Polyhedron 1997, 16, 1371.

[28] A. B. Blake and A. Yavari, Journal of the Chemical Society, Chemical Communications 1982, 1247. 
[29] C. Stadler, J. Daub, J. Koehler, R. W. Saalfrank, V. Coropceanu, V. Schuenemann, C. Ober, A. X. Trautwein, S. F. Parker, M. Poyraz, T. Inomata and R. D. Cannon, Journal of the Chemical Society, Dalton Transactions 2001, 3373.

[30] R. P. White, L. M. Wilson, D. J. Williamson, G. R. Moore, U. A. Jayasooriya and R. D. Cannon, Spectrochimica Acta Part A: Molecular Spectroscopy 1990, 46, 917.

[31] G. Losada, M. A. Mendiola and M. T. Sevilla, Inorganica Chimica Acta 1997, 225, 125.

[32] A. B. Edwards, J. M. Charnock, C. D. Garner and A. B. Blake, Journal of the Chemical Society, Dalton Transactions 1995, 2515.

[33] K. I. Turta, S. G. Shova, F. K. Zhovmir, V. M. Mereacre, D. N. Prodius, M. Gdaniec, I. G. Kadelnik and Y. A. Simonov, Zhurnal Neorganicheskoi Khimii 2003, 48,891 .

[34] R. D. Cannon, U. A. Jayassooriya, L. Montri, A. K. Saad, E. Karu, S. K. Bollen, W. R. Sanderson, A. K. Powell and A. B. Blake, Journal of the Chemical Society, Dalton Transactions: Inorganic Chemistry (1972-1999) 1993, 2005.

[35] S. W. Ng, Acta Crystallographica, Section E: Stucture reports online 2004, 60, 738.

[36] R. F. Weinland and P. Dinkelacker, Chemische Berichte 1910, 42, 2997.

[37] R. F. Weinland, Chemische Berichte 1909, 41, 3236.

[38] Z. J. Zhong, J.-Q. Tao, H. Li, X.-Z. You and T. C. W. Mak, Polyhedron 1997, 16, 1719.

[39] T. Nakamoto, M. Katada and H. Sano, Inorganica Chimica Acta 1999, 291, 127.

[40] B. P. Baranwal and T. Fatma, Journal of Molecular Structure 2005, 750, 72. 
[41] H. Kato, K. Nakata, A. Nagasawa, T. Yamaguchi, Y. Sasaki and T. Ito, Bulletin of the Chemical Society of Japan 1991, 64, 3463.

[42] K. I. Turte, A. G. Lazaresku, A. O. Solonenko and I. V. Dranka, Russian Journal of Coordination Chemistry (Translation of Koordinatsionnaya Khimiya) 1998, 24, 94.

[43] K. Asamaki, T. Nakamoto, S. Kawata, H. Sano, M. Katada and K. Endo, Inorganica Chimica Acta 1995, 236, 155.

[44] J. B. Vincent, H. R. Chang, K. Folting, J. C. Huffman, G. Christou and D. N. Hendrickson, Journal of the American Chemical Society 1987, 109, 5703.

[45] F. A. Cotton, G. E. Lewis and G. N. Mott, inorganic Chemistry 1982, 21, 3127.

[46] M. A. Kiskin, I. G. Fomina, G. G. Aleksandrov, A. A. Sidorov, V. M. Novotortsev, Y. G. Shvedenkov, I. L. Eremenko and I. I. Moiseev, Inorganic Chemistry Communications 2004, 7, 734.

[47] P. Christian, G. Rajaraman, A. Harrison, M. Helliwell, J. J. W. McDouall, J. Raftery and R. E. P. Winpenny, Dalton Transactions 2004, 16, 2550.

[48] R. F. Weinland and H. Holtmeier, Zeitschrift fuer Anorganische und Allgemeine Chemie 1928, 173, 49.

[49] T. Lis, Acta Crystallographica, Section B: Structural Crystallography and Crystal Chemistry 1980, B36, 2042.

[50] J. B. Vincent, C. Christmas, H. R. Chang, Q. Li, P. D. W. Boyd, J. C. Huffman, D. N. Hendrickson and G. Christou, Journal of the American Chemical Society 1989, 111, 2086.

[51] C. Christmas, J. B. Vincent, H. R. Chang, J. C. Huffman, G. Christou and D. N. Hendrickson, Journal of the American Chemical Society 1988, 110, 823. 
[52] H. J. Eppley, S. M. J. Aubin, W. E. Streib, J. C. Bollinger, D. N. Hendrickson and G. Christou, Inorganic Chemistry 1997, 36, 109.

[53] W. Micklitz and S. J. Lippard, Inorganic Chemistry 1988, 27, 3067.

[54] S. M. Gorun, G. C. Papaefthymiou, R. B. Frankel and S. J. Lippard, Journal of the American Chemical Society 1987, 109, 3337.

[55] N. V. Gerbeleu, A. S. Batsanov, G. A. Timko, Y. T. Struchkov, K. M. Indrichan and G. A. Popovich, Doklady Akademii Nauk SSSR 1989, 307, 118.

[56] A. S. Batsanov, G. A. Timko, Y. T. Struchkov, N. V. Gerbeleu and K. M. Indrichan, Koordinatsionnaya Khimiya 1991, 17, 662.

[57] F. E. Mabbs, E. J. L. McInnes, M. Murrie, S. Parsons, G. M. Smith, C. C. Wilson and R. E. P. Winpenny, Chemical Communications 1999, 643.

[58] A. C. Royer, R. D. Rogers, D. L. Arrington, S. C. Street and J. B. Vincent, Polyhedron 2002, 21, 155.

[59] I. M. Atkinson, C. Benelli, M. Murrie, S. Parsons and R. E. P. Winpenny, Chemical Communications 1999, 5, 285.

[60] W. Priebsch, D. Rehder and M. Von Oeynhausen, Chemische Berichte 1991, 124, 761.

[61] R. H. Laye, M. Murrie, S. Ochsenbein, A. R. Bell, S. J. Teat, J. Raftery, H.-U. Gudel and E. J. L. McInnes, Chemistry - A European Journal 2003, 9, 6215.

[62] R. Sessoli, H.-L. Tsai, A. R. Schake, S. Wang, J. B. Vincent, K. Folting, D. Gatteschi, G. Christou and D. N. Hendrickson, Journal of the American Chemical Society 1993, 115, 1804.

[63] E. C. Sanudo, A. A. Smith, P. V. Mason, M. Helliwell, G. Aromı and R. E. P. Winpenny, Dalton Transactions 2006, 1981. 
[64] R. A. Coxall, A. Parkin, S. Parsons, A. A. Smith, G. A. Timco and R. E. P. Winpenny, Journal of Solid State Chemistry 2001, 159, 321.

[65] M. Eshel and A. Bino, Inorganica Chimica Acta 2002, 329, 45.

[66] S. Parsons, A. A. Smith and R. E. P. Winpenny, Chemical Communications 2000, 579.

[67] A. A. Smith, R. A. Coxall, A. Harrison, M. Helliwell, S. Parsons and R. E. P. Winpenny, Polyhedron 2004, 23, 1557.

[68] G. A. Timco, A. S. Batsanov, F. K. Larsen, C. A. Muryn, J. Overgaard, S. J. Teat and R. E. P. Winpenny, Chemical Communications 2005, 3649.

[69] P. N. Turowski, A. Bino and S. J. Lippard, Angewandte Chemie, International Edition in English 1990, 29, 811.

[70] M. Ardon, A. Bino and K. Michelsen, Journal of the American Chemical Society 1987, 109, 1986.

[71] V. H. Crawford, H. W. Richardson, J. R. Wasson, D. J. Hodgson and W. E. Hatfield, Inorganic Chemistry 1976, 15, 2107.

[72] R. E. P. Winpenny in Guide to Magnetism, Vol. 2003.

[73] O. Kahn, Molecular Magnetism, VCH Publishers, 1993, p. 241.

[74] R. Sessoli, D. Gatteschi, A. Caneschi and M. A. Novak, Nature 1993, 365, 141.

[75] S. L. Castro, Z. Sun, C. M. Grant, J. C. Bollinger, D. N. Hendrickson and G. Christou, Journal of the American Chemical Society 1998, 120, 2365.

[76] E. Rodrı'guez, M. Gich, A. Roig, E. Molins, N. Nedelko, A. S. lawska-Waniewska and A. Szewczyk, Polyhedron 2006, 25, 113.

[77] D. Gatteschi, R. Sessoli and A. Cornia, Chemical Communications 2000, 725.

[78] S. J. Langley, M. Helliwell, R. Sessoli, P. Rosa, W. Wernsdorfer and R. E. P. Winpenny, Chemical Communications (Cambridge) 2005, 5029. 
[79] A. Bell, G. Aromı, S. J. Teat, W. Wernsdorferd and R. E. P. Winpenny, Chemical Communications 2005, 2808.

[80] A. J. Wu, J. E. Penner-Hahn and V. L. Pecoraro, Chemical Reviews 2004, 104, 903.

[81] S. Mukhopadhyay, S. K. Mandal, S. Bhaduri and W. H. Armstrong, Chemical Reviews 2004, 104, 3981.

[82] S. M. Gorun and S. J. Lippard, Nature (London) 1986, 319, 666.

[83] W. Micklitz, V. McKee, R. L. Rardin, L. E. Pence, G. C. Papaefthymiou, S. G. Bott and S. J. Lippard, Journal of the American Chemical Society 1994, 116, 8061.

[84] D. L. Hasten, M. Hegsted, M. J. Keenan and G. S. Morris, Nutrition Research (New York) 1997, 17, 1175.

[85] Y. Sun, B. J. Clodfelder, A. A. Shute, T. Irvin and J. B. Vincent, Journal of Biological Inorganic Chemistry 2002, 7, 852.

[86] P.-G. Lassahn, V. Lozan, G. A. Timco, P. Christian, C. Janiak and R. E. P. Winpenny, Journal of Catalysis 2004, 222, 260.

[87] B. Singh, J. R. Long, F. F. d. Biani, D. Gatteschi and P. Stavropoulos, Journal of the American Chemical Society 1997, 119, 7030.

[88] D. Ogrin, J. Ramon Colorado, B. Maruyama, M. J. Pender, R. E. Smalleya and A. R. Barron, Dalton Transactions 2006, 229.

[89] L. Thomas, F. Lionti, R. Ballou, D. Gatteschi, R. Sessoli and B. Barbara, Nature (London) 1996, 383, 145.

[90] H. Andres, R. Basler, A. J. Blake, C. Cadiou, G. Chaboussant, C. M. Grant, H.-U. Gudel, M. Murrie, S. Parsons, C. Paulsen, F. Semadini, V. Villar, W. 
Wernsdorfer and R. E. P. Winpenny, Chemistry - A European Journal 2002, 8, 4867.

[91] C. Cadiou, M. Murrie, C. Paulsen, V. Villar, W. Wernsdorfer and R. E. P. Winpenny, Chemical Communications 2001, 2666.

[92] C. Sangregorio, T. Ohm, C. Paulsen, R. Sessoli and D. Gatteschi, Physical Review Letters 1997, 78, 4645.

[93] G. Christou in Single-Molecule Magnets: A Molecular Approach to Nanoscale Materials, Hobart, Tasmania, 2007.

[94] D. Gatteschi and R. Sessoli, Angewandte Chemie, International Edition 2003, 42, 268.

[95] M. Affronte, I. Casson, M. Evangelisti, A. Candini, S. Carretta, C. A. Muryn, S. J. Teat, G. A. Timco, W. Wernsdorfer and R. E. P. Winpenny, Angewandte Chemie, International Edition 2005, 44, 6496.

[96] M. Affronte, F. Troiani, A. Ghirri, A. Candini, M. Evangelisti, S. Carretta, P. Santini, G. Amoretti, S. Piligkos, G. Timco and R. E. P. Winpenny, Polyhedron $\mathbf{2 0 0 5}, 24,2562$.

[97] M. N. Leuenberger and D. Loss, Nature (London) 2004, 410, 789.

[98] F. Troiani, A. Ghirri, M. Affronte, S. Carretta, P. Santini, G. Amoretti, S. Piligkos, G. Timco and R. E. P. Winpenny, Physical Review Letters 2005, 94, 207208/1.

[99] R. F. Weinland and H. Reihlen, Zeitschrift fuer Anorganische und Allgemeine Chemie 1913, 82, 426.

[100] I. A. Gass, C. J. Milios, A. G. Whittaker, F. P. A. Fabiani, S. Parsons, M. Murrie, S. P. Perlepes and E. K. Brechin, Inorganic Chemistry 2006, 45, 5281.

[101] R. H. Beer and S. J. Lippard, Inorganic Chemistry 1993, 32, 1030. 
[102] A. Harton, K. Terrell, J. C. Huffman, C. MacDonald, A. Beatty, S. Li, C. J. O'Connor and J. B. Vincent, Inorganic Chemistry 1997, 36, 4875.

[103] M. M. Glass, K. Belmore and J. B. Vincent, Polyhedron 1993, 12, 133.

[104] A. van den Bergen, R. Colton, M. Percy and B. O. West, Inorganic Chemistry 1993, 32, 3408.

[105] C. F. Ijames, R. C. Dutky and H. M. Fales, Journal of the American Society for Mass Spectrometry 1995, 6, 1226.

[106] G. I. Dzardimalieva and A. D. Pomogailo, Khimicheskii Zhurnal Armenii 1999, $52,9$.

[107] K. S. Gavrilenko, A. Addison, L. Thompson and V. V. Pavlishchuk, Theoretical and Experimental Chemistry (Translation of Teoreticheskaya $i$ Eksperimental'naya Khimiya) 2004, 40, 214.

[108] R. D. Cannon and R. P. White, Progress in Inorganic Chemistry 1988, 36, 195.

[109] K. Nakamoto, Infrared and Raman spectra of inorganic and coordination compounds, Wiley, New York, 1978, p. 448.

[110] T. Arii, Y. Sawada, K. Iizumi, K. Kudaka and S. Seki, Thermochimica Acta 2000, 352-353, 53.

[111] F. Kenfack and H. Langbein, Thermochimica Acta 2005, 426, 61.

[112] H. Vrubel, T. Hasegawa, E. d. Oliveira and F. S. Nunes, Inorganic Chemistry Communications 2006, 9, 208.

[113] G. M. Sheldrick in SHELX97, Programs for crystal structure refinement, Vol. Germany, 1997.

[114] C. F. Macrae, P. R. Edgington, P. McCabe, E. Pidcock, G. P. Shields, R. Taylor, M. Towler and J. v. d. Streek, Journal of Applied Crystallography 2006, 39, 453. 
[115] T. Fujihara, J. Aonahata, S. Kumakura, A. Nagasawa, K. Murakami and T. Ito, Inorganic Chemistry 1998, 37, 3779.

[116] J. P. Bourke, E. Karu and R. D. Cannon, Inorganic Chemistry 1996, 35, 1577.

[117] A. Vlachos, V. Psycharis, C. P. Raptopoulou, N. Lalioti, Y. Sanakis, G. Diamantopoulos, M. Fardis, M. Karayanni, G. Papavassiliou and A. Terzis, Inorganica Chimica Acta 2004, 357, 3162.

[118] M. A. Kiskin, I. G. Fomina, A. A. Sidorov, G. G. Aleksandrov, O. Y. Poshenkina, Z. V. Dobrokhotova, V. N. Ikorskii, Y. G. Shvedenkov, V. M. Novotortsev, I. L. Eremenko and I. I. Moiseev, Russian Chemical Bulletin, International Edition 2004, 53, 2508.

[119] W. Micklitz, S. G. Bott, J. G. Bentsen and S. J. Lippard, Journal of the American Chemical Society 1989, 111, 372.

[120] C. Canada-Vilalta, T. A. O'Brien, E. K. Brechin, M. Pink, E. R. Davidson and G. Christou, Inorganic Chemistry 2004, 43, 5505.

[121] A. Malecki and B. Malecka, Thermochimica Acta 2006, 446, 113.

[122] A. Harton, K. Terrell, J. C. Huffman, C. MacDonald, A. Beatty, S. Li, C. J. O’Connor and J. B. Vincent, Inorganic Chemistry 1997, 36, 4875.

[123] H. Langbein, S. Christen and G. Bonsdorf, Thermochimica Acta 1999, 327, 173.

[124] G. Aylward and T. Findlay, SI Chemical Data, Wiley, 1998, p. 188.

[125] L. Zobbi, M. Mannini, M. Pacchioni, G. Chastanet, D. Bonacchi, C. Zanardi, R. Biagi, U. D. Pennino, D. Gatteschi, A. Cornia and R. Sessoli, Chemical Communications 2005, 1640.

[126] A. Cornia, A. C. Fabretti, M. Pacchioni, L. Zobbi, D. Bonacchi, A. Caneschi, D. Gatteschi, R. Biagi, U. d. Pennino, V. D. Renzi, L. Gurevich and H. S. J. V. d. Zant, Journal of Magnetism and Magnetic Materials 2004, 272-276, 725. 
[127] G. G. Condorelli, A. Motta, I. L. Fragala, F. Giannazzo, V. Raineri, A. Caneschi and D. Gatteschi, Angewandte Chemie International Edition 2004, 43, 4081.

[128] S. Yuvaraj, L. Fan-Yuan, C. Tsong-Huei and Y. Chuin-Tih, Journal of Physical Chemistry, B 2003, 107, 1044. 


\section{Appendices}

\subsection{X-ray Crystal Data}

\subsection{1 $\left[\mathrm{Fe}_{3} \mathrm{O}\left(\mathrm{O}_{2} \mathrm{CC}_{6} \mathrm{H}_{4}-3-\mathrm{Cl}\right)_{6}\left(\mathrm{H}_{2} \mathrm{O}\right)_{3}\right] \mathrm{NO}_{3} \cdot \mathrm{H}_{2} \mathrm{O}$}

\subsubsection{Crystal data and structure refinement.}

\begin{tabular}{|c|c|}
\hline Empirical formula & C42 H32 Cl6 Fe3 N O20 \\
\hline Formula weight & 1297.00 \\
\hline Temperature & $273(2) \mathrm{K}$ \\
\hline Wavelength & $0.71073 \AA$ \\
\hline Crystal system, space group & Monoclinic, $C 2 / c$ \\
\hline \multirow[t]{3}{*}{ Unit cell dimensions } & $\mathrm{a}=21.212(4) \AA$ \\
\hline & $\mathrm{b}=10.9832(19) \AA \quad \beta=90^{\circ}$ \\
\hline & $\mathrm{c}=21.254(4) \AA \quad \gamma=90^{\circ}$ \\
\hline Volume & $4951.7(15) \AA^{3}$ \\
\hline Z & 4 \\
\hline Calculated density & $1.740 \mathrm{Mg} / \mathrm{m}^{3}$ \\
\hline Absorption coefficient & $1.274 \mathrm{~mm}^{-1}$ \\
\hline $\mathrm{F}(000)$ & 2628 \\
\hline Crystal size & $0.35 \times 0.29 \times 0.15 \mathrm{~mm}$ \\
\hline Theta range for data collection & 1.92 to $30.19^{\circ}$ \\
\hline Limiting indices & $-30 \leq h \leq 29,-15 \leq k \leq 15,-29 \leq l \leq 13$ \\
\hline Reflections collected / unique & $43925 / 9992[\mathrm{R}(\mathrm{int})=0.0311]$ \\
\hline Completeness to theta $=30.19$ & $97.8 \%$ \\
\hline Absorption correction & None \\
\hline Refinement method & Full-matrix least-squares on $F^{2}$ \\
\hline Data / restraints / parameters & 9992 / 1 / 712 \\
\hline Goodness-of-fit on $F^{2}$ & 1.198 \\
\hline Final $\mathrm{R}$ indices $[\mathrm{I}>2 \sigma(\mathrm{I})]$ & $R_{1}=0.0481, w R_{2}=0.1230$ \\
\hline$R$ indices (all data) & $R_{1}=0.0555, w R_{2}=0.1353$ \\
\hline
\end{tabular}


Absolute structure parameter

Largest diff. peak and hole
$0.350(17)$

0.881 and -0.978 e. $\AA^{-3}$

\subsubsection{Atomic coordinates $\left(\times 10^{4}\right)$ and equivalent isotropic displacement parameters $\left(\AA^{2} \times 10^{3}\right)$}

$\mathrm{U}_{\text {eq }}$ is defined as one third of the trace of the orthogonalized $\mathrm{U}_{\mathrm{ij}}$ tensor.

$\begin{array}{llllll}\text { Atom Label } & \mathrm{x} & \mathrm{y} & \mathrm{z} & \mathrm{U}_{\mathrm{eq}}\end{array}$

\begin{tabular}{|c|c|c|c|c|}
\hline $\mathrm{Fe}(1)$ & $7808(1)$ & $3257(1)$ & $9692(1)$ & $14(1)$ \\
\hline $\mathrm{Fe}(2)$ & $9205(1)$ & 1985(1) & $9587(1)$ & $15(1)$ \\
\hline $\mathrm{Fe}(3)$ & $9055(1)$ & $4631(1)$ & $10306(1)$ & $20(1)$ \\
\hline $\mathrm{Cl}(1)$ & $8287(1)$ & $1670(1)$ & $11652(1)$ & $31(1)$ \\
\hline $\mathrm{Cl}(2)$ & $11103(1)$ & 2033(2) & $10322(1)$ & $57(1)$ \\
\hline $\mathrm{Cl}(3)$ & $10644(5)$ & $5934(10)$ & $12073(6)$ & $114(5)$ \\
\hline $\mathrm{Cl}\left(3^{\prime}\right)$ & 10591(3) & $5710(5)$ & 11992(3) & $35(1)$ \\
\hline $\mathrm{Cl}(4)$ & $8673(5)$ & $-1430(9)$ & $13511(5)$ & $42(2)$ \\
\hline $\mathrm{Cl}\left(4^{\prime}\right)$ & $8550(6)$ & $-1418(12)$ & $13375(7)$ & $96(5)$ \\
\hline $\mathrm{Cl}(5)$ & $9657(4)$ & $8453(4)$ & 12051(3) & $37(1)$ \\
\hline $\mathrm{Cl}\left(5^{\prime}\right)$ & $9670(4)$ & $8641(10)$ & $12207(6)$ & $112(5)$ \\
\hline $\mathrm{Cl}(6)$ & 8981(4) & 1893(9) & $13447(6)$ & $66(3)$ \\
\hline $\mathrm{Cl}(6 \mathrm{~A})$ & $8959(2)$ & $1919(4)$ & $13412(4)$ & $23(1)$ \\
\hline $\mathrm{O}(1)$ & $8691(2)$ & $3303(3)$ & $9855(2)$ & $16(1)$ \\
\hline $\mathrm{O}(11)$ & $7885(2)$ & $2884(3)$ & $8767(2)$ & $21(1)$ \\
\hline $\mathrm{O}(12)$ & $7715(2)$ & 1471(3) & $9853(2)$ & $21(1)$ \\
\hline $\mathrm{O}(13)$ & $7568(2)$ & $3607(3)$ & $10574(2)$ & $26(1)$ \\
\hline $\mathrm{O}(14)$ & $7730(2)$ & $5033(3)$ & $9470(2)$ & $22(1)$ \\
\hline $\mathrm{O}(21)$ & $8788(2)$ & 1831(3) & $8736(2)$ & $18(1)$ \\
\hline $\mathrm{O}(22)$ & $8674(2)$ & $639(3)$ & $9935(2)$ & $18(1)$ \\
\hline $\mathrm{O}(23)$ & $9674(2)$ & 1933(3) & $10395(2)$ & $24(1)$ \\
\hline $\mathrm{O}(24)$ & $9854(2)$ & $3006(3)$ & $9160(2)$ & $25(1)$ \\
\hline $\mathrm{O}(31)$ & $9552(2)$ & $3673(4)$ & $10936(2)$ & $29(1)$ \\
\hline
\end{tabular}




\begin{tabular}{|c|c|c|c|c|}
\hline $\mathrm{O}(32)$ & $9798(2)$ & $4741(3)$ & $9709(2)$ & $30(1)$ \\
\hline $\mathrm{O}(33)$ & $8356(2)$ & $4753(3)$ & $10950(2)$ & $24(1)$ \\
\hline $\mathrm{O}(34)$ & $8637(2)$ & $5908(3)$ & $9766(2)$ & $26(1)$ \\
\hline OW1 & $6838(2)$ & $3203(3)$ & $9557(2)$ & $22(1)$ \\
\hline OW2 & $9801(2)$ & $522(3)$ & $9333(2)$ & $24(1)$ \\
\hline OW3 & $9464(2)$ & $6155(4)$ & 10739(2) & $39(1)$ \\
\hline ON1 & $9911(2)$ & $8380(5)$ & $10090(3)$ & $46(1)$ \\
\hline ON2 & 10669(4) & $7211(5)$ & $10369(4)$ & $86(3)$ \\
\hline ON3 & 10861(3) & $8886(7)$ & $9913(4)$ & $76(2)$ \\
\hline OCW1 & $6190(5)$ & $5067(10)$ & 10158(6) & $134(4)$ \\
\hline$C(10)$ & $8295(2)$ & 2251(4) & $8484(2)$ & $16(1)$ \\
\hline$C(11)$ & $6823(2)$ & $1923(4)$ & $12818(2)$ & $18(1)$ \\
\hline$C(12)$ & $7427(2)$ & $2006(4)$ & $12571(2)$ & $18(1)$ \\
\hline$C(13)$ & $7535(2)$ & $1621(4)$ & $11956(3)$ & $21(1)$ \\
\hline$C(14)$ & $7041(3)$ & $1222(6)$ & $11580(3)$ & $33(1)$ \\
\hline$C(15)$ & 6439(3) & $1159(7)$ & 11829(3) & $38(2)$ \\
\hline$C(16)$ & 6333(3) & $1494(5)$ & $12448(3)$ & $28(1)$ \\
\hline$C(20)$ & $8082(2)$ & 618(4) & $10001(2)$ & $16(1)$ \\
\hline$C(21)$ & $7798(2)$ & $-489(4)$ & $10272(3)$ & $17(1)$ \\
\hline$C(22)$ & $12158(2)$ & $709(4)$ & 10185(3) & $22(1)$ \\
\hline$C(23)$ & 11893(2) & $1737(5)$ & 10448(3) & $29(1)$ \\
\hline C(24) & $12248(3)$ & $2538(5)$ & 10807(4) & $37(2)$ \\
\hline$C(25)$ & $7883(3)$ & $-2320(5)$ & 10886(4) & $36(1)$ \\
\hline$C(26)$ & $8165(2)$ & $-1311(4)$ & 10613(3) & $24(1)$ \\
\hline$C(30)$ & $7814(2)$ & $4305(4)$ & $10980(2)$ & $20(1)$ \\
\hline C(31) & $7410(3)$ & $4612(4)$ & 11534(3) & $28(1)$ \\
\hline C(32) & 6781(3) & $4277(5)$ & $11526(3)$ & $32(1)$ \\
\hline$C(33)$ & $11406(4)$ & $5386(6)$ & $12038(4)$ & $45(2)$ \\
\hline C(34) & $11648(5)$ & $4779(8)$ & $12533(4)$ & $63(3)$ \\
\hline C(35) & $7258(6)$ & $5542(8)$ & $12551(4)$ & $65(3)$ \\
\hline$C(36)$ & $7650(4)$ & $5247(5)$ & 12039(3) & $41(2)$ \\
\hline$C(40)$ & $8114(2)$ & $5905(4)$ & $9485(2)$ & $19(1)$ \\
\hline$C(41)$ & 7934(3) & $7046(4)$ & $9139(2)$ & $22(1)$ \\
\hline$C(42)$ & $7317(3)$ & $7233(5)$ & $8971(3)$ & $32(1)$ \\
\hline
\end{tabular}




$\begin{array}{lllll}\mathrm{C}(43) & 7847(4) & -1712(5) & 13655(4) & 42(2) \\ \mathrm{C}(44) & 7619(4) & -876(5) & 8479(3) & 44(2) \\ \mathrm{C}(45) & 8239(4) & -1069(5) & 8645(3) & 37(2) \\ \mathrm{C}(46) & 8406(3) & 7880(5) & 8985(3) & 29(1) \\ \mathrm{C}(50) & 9698(2) & 2554(5) & 10891(3) & 23(1) \\ \mathrm{C}(51) & 9891(3) & 1897(6) & 11476(3) & 27(1) \\ \mathrm{C}(52) & 9757(2) & 651(6) & 11503(3) & 30(1) \\ \mathrm{C}(53) & 9865(3) & 10030(7) & 12054(4) & 39(2) \\ \mathrm{C}(54) & 10137(4) & 10602(8) & 12561(4) & 52(2) \\ \mathrm{C}(55) & 10295(4) & 1802(9) & 12519(3) & 57(2) \\ \mathrm{C}(56) & 10155(3) & 2473(6) & 11982(3) & 37(2) \\ \mathrm{C}(60) & 9971(2) & 4122(5) & 9236(3) & 23(1) \\ \mathrm{C}(61) & 10333(2) & 4757(5) & 8738(3) & 25(1) \\ \mathrm{C}(62) & 10503(2) & 5982(5) & 8810(3) & 27(1) \\ \mathrm{C}(63) & 9184(2) & 3434(5) & 13330(3) & 30(1) \\ \mathrm{C}(64) & 9035(3) & 4026(7) & 12773(4) & 40(2) \\ \mathrm{C}(65) & 9211(3) & 5241(6) & 12703(4) & 39(2) \\ \mathrm{C}(66) & 10473(3) & 4143(5) & 8178(3) & 31(1) \\ \mathrm{N}(1) & 10482(2) & 8175(4) & 10128(3) & 34(1)\end{array}$

\subsubsection{Bond lengths $[\AA \AA]$ and angles [ ${ }^{\circ}$.}

\section{Bond Lengths}

$\begin{array}{llll}\mathrm{Fe}(1)-\mathrm{O}(1) & 1.905(3) & \mathrm{Fe}(2)-\mathrm{O}(23) & 1.984(4) \\ \mathrm{Fe}(1)-\mathrm{O}(11) & 2.015(4) & \mathrm{Fe}(2)-\mathrm{O}(24) & 1.994(4) \\ \mathrm{Fe}(1)-\mathrm{O}(12) & 2.002(3) & \mathrm{Fe}(2)-\mathrm{OW} 2 & 2.115(4) \\ \mathrm{Fe}(1)-\mathrm{O}(13) & 1.980(4) & \mathrm{Fe}(3)-\mathrm{O}(1) & 1.908(3) \\ \mathrm{Fe}(1)-\mathrm{O}(14) & 2.013(3) & \mathrm{Fe}(3)-\mathrm{O}(31) & 2.003(4) \\ \mathrm{Fe}(1)-\mathrm{OW} 1 & 2.079(3) & \mathrm{Fe}(3)-\mathrm{O}(32) & 2.026(4) \\ \mathrm{Fe}(2)-\mathrm{O}(1) & 1.900(3) & \mathrm{Fe}(3)-\mathrm{O}(33) & 2.023(4) \\ \mathrm{Fe}(2)-\mathrm{O}(21) & 2.021(4) & \mathrm{Fe}(3)-\mathrm{O}(34) & 2.018(4) \\ \mathrm{Fe}(2)-\mathrm{O}(22) & 2.001(3) & \mathrm{Fe}(3)-\mathrm{OW} 3 & 2.098(4)\end{array}$




\begin{tabular}{|c|c|c|c|}
\hline $\mathrm{Cl}(1)-\mathrm{C}(13)$ & $1.724(5)$ & $C(13)-C(14)$ & $1.388(8)$ \\
\hline $\mathrm{Cl}(6)-\mathrm{C}(63)$ & $1.764(11)$ & $C(14)-C(15)$ & $1.385(9)$ \\
\hline $\mathrm{Cl}(2)-\mathrm{C}(23)$ & $1.728(6)$ & $C(16)-C(15)$ & $1.385(9)$ \\
\hline $\mathrm{Cl}(3)-\mathrm{C}(33)$ & $1.726(14)$ & $C(50)-C(51)$ & $1.495(8)$ \\
\hline $\mathrm{Cl}(4)-\mathrm{C}(43)$ & $1.807(13)$ & $C(10)-C(11)^{4}$ & $1.482(7)$ \\
\hline $\mathrm{Cl}(5)-\mathrm{C}(53)$ & $1.788(9)$ & $\mathrm{C}(61)-\mathrm{C}(66)$ & $1.398(9)$ \\
\hline $\mathrm{O}(22)-\mathrm{C}(20)$ & $1.263(6)$ & $C(61)-C(62)$ & $1.401(8)$ \\
\hline $\mathrm{O}(23)-\mathrm{C}(50)$ & $1.256(7)$ & $C(61)-C(60)$ & $1.482(8)$ \\
\hline $\mathrm{O}(32)-\mathrm{C}(60)$ & $1.269(7)$ & $C(45)-C(44)$ & $1.378(11)$ \\
\hline $\mathrm{O}(14)-\mathrm{C}(40)$ & $1.258(6)$ & $C(45)-C(46)^{5}$ & $1.407(8)$ \\
\hline $\mathrm{O}(34)-\mathrm{C}(40)$ & $1.259(6)$ & $C(23)-C(24)$ & $1.387(9)$ \\
\hline $\mathrm{O}(21)-\mathrm{C}(10)$ & $1.264(6)$ & $C(26)-C(25)$ & $1.388(8)$ \\
\hline $\mathrm{O}(33)-\mathrm{C}(30)$ & $1.252(6)$ & $\mathrm{Cl}\left(4^{\prime}\right)-\mathrm{C}(43)$ & $1.639(15)$ \\
\hline $\mathrm{O}(11)-\mathrm{C}(10)$ & $1.264(6)$ & $C(64)-C(63)$ & $1.387(10)$ \\
\hline $\mathrm{O}(24)-\mathrm{C}(60)$ & $1.261(6)$ & $C(64)-C(65)$ & $1.393(10)$ \\
\hline $\mathrm{O}(12)-\mathrm{C}(20)$ & $1.258(5)$ & $C(46)-C(45)^{6}$ & $1.407(8)$ \\
\hline$C(31)-C(36)$ & $1.377(9)$ & $C(63)-C(62)^{7}$ & $1.377(8)$ \\
\hline$C(31)-C(32)$ & $1.384(9)$ & $\mathrm{C}(63)-\mathrm{Cl}(6 \mathrm{~A})$ & $1.740(7)$ \\
\hline$C(31)-C(30)$ & $1.495(8)$ & $\mathrm{N}(1)-\mathrm{ON} 3$ & $1.211(8)$ \\
\hline $\mathrm{C}(12)-\mathrm{C}(11)$ & $1.388(7)$ & $\mathrm{N}(1)-\mathrm{ON} 2$ & $1.242(7)$ \\
\hline$C(12)-C(13)$ & $1.392(7)$ & $C(51)-C(56)$ & $1.368(9)$ \\
\hline $\mathrm{O}(31)-\mathrm{C}(50)$ & $1.272(7)$ & $C(51)-C(52)$ & $1.398(9)$ \\
\hline ON1-N(1) & $1.233(6)$ & $\mathrm{C}(66)-\mathrm{C}(65)^{8}$ & $1.389(9)$ \\
\hline $\mathrm{C}(40)-\mathrm{C}(41)$ & $1.502(7)$ & $\mathrm{C}(62)-\mathrm{C}(63)^{8}$ & $1.377(8)$ \\
\hline $\mathrm{C}(21)-\mathrm{C}(22)^{1}$ & $1.391(6)$ & $\mathrm{Cl}\left(5^{\prime}\right)-\mathrm{C}(53)$ & $1.614(12)$ \\
\hline$C(21)-C(26)$ & $1.395(7)$ & $C(52)-C(53)^{5}$ & $1.374(9)$ \\
\hline$C(21)-C(20)$ & $1.474(6)$ & $C(32)-C(33)^{9}$ & $1.397(9)$ \\
\hline $\mathrm{O}(13)-\mathrm{C}(30)$ & $1.267(7)$ & $C(55)-C(54)^{5}$ & $1.363(13)$ \\
\hline$C(22)-C(23)$ & $1.380(7)$ & $C(55)-C(56)$ & $1.390(10)$ \\
\hline$C(22)-C(21)^{2}$ & $1.391(6)$ & $C(65)-C(66)^{7}$ & $1.389(9)$ \\
\hline$C(11)-C(16)$ & $1.384(7)$ & $\mathrm{C}(42)-\mathrm{C}(43)^{10}$ & $1.383(8)$ \\
\hline$C(11)-C(10)^{3}$ & $1.482(7)$ & $C(33)-C(34)$ & $1.347(13)$ \\
\hline$C(41)-C(42)$ & $1.372(8)$ & $C(33)-C(32)^{11}$ & $1.397(9)$ \\
\hline$C(41)-C(46)$ & $1.395(7)$ & $\mathrm{C}(33)-\mathrm{Cl}\left(3^{\prime}\right)$ & $1.768(10)$ \\
\hline
\end{tabular}




$\begin{array}{llll}\mathrm{C}(44)-\mathrm{C}(43)^{4} & 1.401(10) & \mathrm{C}(25)-\mathrm{C}(24)^{1} & 1.380(9) \\ \mathrm{C}(43)-\mathrm{C}(42)^{12} & 1.383(8) & \mathrm{C}(54)-\mathrm{C}(55)^{6} & 1.363(13) \\ \mathrm{C}(43)-\mathrm{C}(44)^{3} & 1.401(10) & \mathrm{C}(24)-\mathrm{C}(25)^{2} & 1.380(9) \\ \mathrm{C}(53)-\mathrm{C}(54) & 1.374(12) & \mathrm{C}(34)-\mathrm{C}(35)^{11} & 1.341(14) \\ \mathrm{C}(53)-\mathrm{C}(52)^{6} & 1.374(9) & \mathrm{C}(35)-\mathrm{C}(34)^{9} & 1.341(14) \\ \mathrm{C}(36)-\mathrm{C}(35) & 1.408(12) & & \end{array}$

\section{Bond Angles}

$\mathrm{Fe}(1)-\mathrm{O}(1)-\mathrm{Fe}(2)$

$\mathrm{Fe}(1)-\mathrm{O}(1)-\mathrm{Fe}(3)$

$\mathrm{Fe}(2)-\mathrm{O}(1)-\mathrm{Fe}(3)$

$\mathrm{O}(1)-\mathrm{Fe}(1)-\mathrm{O}(13)$

$\mathrm{O}(1)-\mathrm{Fe}(1)-\mathrm{O}(12)$

$\mathrm{O}(13)-\mathrm{Fe}(1)-\mathrm{O}(12)$

$\mathrm{O}(1)-\mathrm{Fe}(1)-\mathrm{O}(14)$

$\mathrm{O}(13)-\mathrm{Fe}(1)-\mathrm{O}(14)$

$\mathrm{O}(12)-\mathrm{Fe}(1)-\mathrm{O}(14)$

$\mathrm{O}(1)-\mathrm{Fe}(1)-\mathrm{O}(11)$

$\mathrm{O}(13)-\mathrm{Fe}(1)-\mathrm{O}(11)$

$\mathrm{O}(12)-\mathrm{Fe}(1)-\mathrm{O}(11)$

$\mathrm{O}(14)-\mathrm{Fe}(1)-\mathrm{O}(11)$

$\mathrm{O}(1)-\mathrm{Fe}(1)-\mathrm{OW} 1$

$\mathrm{O}(13)-\mathrm{Fe}(1)-\mathrm{OW} 1$

$\mathrm{O}(12)-\mathrm{Fe}(1)-\mathrm{OW} 1$

$\mathrm{O}(14)-\mathrm{Fe}(1)-\mathrm{OW} 1$

$\mathrm{O}(11)-\mathrm{Fe}(1)-\mathrm{OW} 1$

$\mathrm{O}(1)-\mathrm{Fe}(2)-\mathrm{O}(23)$

$\mathrm{O}(1)-\mathrm{Fe}(2)-\mathrm{O}(24)$

$\mathrm{O}(23)-\mathrm{Fe}(2)-\mathrm{O}(24)$

$\mathrm{O}(1)-\mathrm{Fe}(2)-\mathrm{O}(22)$

$\mathrm{O}(23)-\mathrm{Fe}(2)-\mathrm{O}(22)$

$\mathrm{O}(24)-\mathrm{Fe}(2)-\mathrm{O}(22)$

$\mathrm{O}(1)-\mathrm{Fe}(2)-\mathrm{O}(21)$

$\mathrm{O}(23)-\mathrm{Fe}(2)-\mathrm{O}(21)$

\begin{tabular}{|c|c|c|}
\hline 119.32(17) & $\mathrm{O}(24)-\mathrm{Fe}(2)-\mathrm{O}(21)$ & $86.63(16)$ \\
\hline $120.64(17)$ & $\mathrm{O}(22)-\mathrm{Fe}(2)-\mathrm{O}(21)$ & $91.27(15)$ \\
\hline 120.01(17) & $\mathrm{O}(1)-\mathrm{Fe}(2)-\mathrm{OW} 2$ & $177.15(16)$ \\
\hline $94.32(16)$ & $\mathrm{O}(23)-\mathrm{Fe}(2)-\mathrm{OW} 2$ & $84.26(15)$ \\
\hline $95.26(13)$ & $\mathrm{O}(24)-\mathrm{Fe}(2)-\mathrm{OW} 2$ & $84.14(16)$ \\
\hline $90.17(16)$ & $\mathrm{O}(22)-\mathrm{Fe}(2)-\mathrm{OW} 2$ & $82.54(14)$ \\
\hline $95.62(14)$ & $\mathrm{O}(21)-\mathrm{Fe}(2)-\mathrm{OW} 2$ & $88.21(15)$ \\
\hline $90.70(16)$ & $\mathrm{O}(1)-\mathrm{Fe}(3)-\mathrm{O}(31)$ & $98.46(15)$ \\
\hline $168.99(14)$ & $\mathrm{O}(1)-\mathrm{Fe}(3)-\mathrm{O}(34)$ & $93.92(14)$ \\
\hline $95.95(15)$ & $\mathrm{O}(31)-\mathrm{Fe}(3)-\mathrm{O}(34)$ & $167.62(16)$ \\
\hline 169.72(15) & $\mathrm{O}(1)-\mathrm{Fe}(3)-\mathrm{O}(33)$ & $95.34(14)$ \\
\hline $88.59(16)$ & $\mathrm{O}(31)-\mathrm{Fe}(3)-\mathrm{O}(33)$ & $88.13(17)$ \\
\hline $88.59(16)$ & $\mathrm{O}(34)-\mathrm{Fe}(3)-\mathrm{O}(33)$ & $90.91(16)$ \\
\hline $177.38(17)$ & $\mathrm{O}(1)-\mathrm{Fe}(3)-\mathrm{O}(32)$ & $92.70(15)$ \\
\hline $83.14(16)$ & $\mathrm{O}(31)-\mathrm{Fe}(3)-\mathrm{O}(32)$ & $92.35(18)$ \\
\hline $84.13(13)$ & $\mathrm{O}(34)-\mathrm{Fe}(3)-\mathrm{O}(32)$ & $86.87(17)$ \\
\hline $85.08(13)$ & $\mathrm{O}(33)-\mathrm{Fe}(3)-\mathrm{O}(32)$ & $171.79(15)$ \\
\hline $86.58(15)$ & $\mathrm{O}(1)-\mathrm{Fe}(3)-\mathrm{OW} 3$ & $175.92(18)$ \\
\hline $92.89(15)$ & $\mathrm{O}(31)-\mathrm{Fe}(3)-\mathrm{OW} 3$ & $84.73(17)$ \\
\hline $95.99(15)$ & $\mathrm{O}(34)-\mathrm{Fe}(3)-\mathrm{OW} 3$ & $82.90(16)$ \\
\hline $93.71(17)$ & $\mathrm{O}(33)-\mathrm{Fe}(3)-\mathrm{OW} 3$ & $87.29(18)$ \\
\hline $97.40(14)$ & $\mathrm{O}(32)-\mathrm{Fe}(3)-\mathrm{OW} 3$ & $84.59(19)$ \\
\hline $86.65(15)$ & $\mathrm{C}(20)-\mathrm{O}(22)-\mathrm{Fe}(2)$ & $127.9(3)$ \\
\hline $166.57(15)$ & $\mathrm{C}(50)-\mathrm{O}(23)-\mathrm{Fe}(2)$ & $137.0(3)$ \\
\hline $94.64(14)$ & $\mathrm{C}(60)-\mathrm{O}(32)-\mathrm{Fe}(3)$ & $133.5(3)$ \\
\hline $172.39(14)$ & $\mathrm{C}(40)-\mathrm{O}(14)-\mathrm{Fe}(1)$ & $132.8(3)$ \\
\hline
\end{tabular}




\begin{tabular}{|c|c|c|c|}
\hline $\mathrm{C}(40)-\mathrm{O}(34)-\mathrm{Fe}(3)$ & $130.9(3)$ & $\mathrm{O}(33)-\mathrm{C}(30)-\mathrm{C}(31)$ & $118.5(5)$ \\
\hline $\mathrm{C}(10)-\mathrm{O}(21)-\mathrm{Fe}(2)$ & $135.4(3)$ & $\mathrm{O}(13)-\mathrm{C}(30)-\mathrm{C}(31)$ & $115.9(5)$ \\
\hline $\mathrm{C}(30)-\mathrm{O}(33)-\mathrm{Fe}(3)$ & $132.9(4)$ & $\mathrm{O}(11)-\mathrm{C}(10)-\mathrm{O}(21)$ & $124.6(5)$ \\
\hline $\mathrm{C}(10)-\mathrm{O}(11)-\mathrm{Fe}(1)$ & $129.1(3)$ & $\mathrm{O}(11)-\mathrm{C}(10)-\mathrm{C}(11)^{4}$ & $118.2(4)$ \\
\hline $\mathrm{C}(60)-\mathrm{O}(24)-\mathrm{Fe}(2)$ & $128.6(4)$ & $\mathrm{O}(21)-\mathrm{C}(10)-\mathrm{C}(11)^{4}$ & $17.1(4)$ \\
\hline $\mathrm{C}(20)-\mathrm{O}(12)-\mathrm{Fe}(1)$ & $135.3(3)$ & $C(66)-C(61)-C(62)$ & $120.1(5)$ \\
\hline$C(36)-C(31)-C(32)$ & $120.0(6)$ & $C(66)-C(61)-C(60)$ & $119.4(5)$ \\
\hline$C(36)-C(31)-C(30)$ & $121.0(6)$ & $C(62)-C(61)-C(60)$ & $120.4(6)$ \\
\hline$C(32)-C(31)-C(30)$ & $118.9(5)$ & $C(44)-C(45)-C(46)^{5}$ & $119.8(6)$ \\
\hline$C(11)-C(12)-C(13)$ & 119.1(5) & $C(22)-C(23)-C(24)$ & $121.3(5)$ \\
\hline $\mathrm{C}(50)-\mathrm{O}(31)-\mathrm{Fe}(3)$ & $125.8(4)$ & $\mathrm{C}(22)-\mathrm{C}(23)-\mathrm{Cl}(2)$ & $119.2(4)$ \\
\hline $\mathrm{O}(14)-\mathrm{C}(40)-\mathrm{O}(34)$ & $125.7(4)$ & $\mathrm{C}(24)-\mathrm{C}(23)-\mathrm{Cl}(2)$ & $119.5(4)$ \\
\hline $\mathrm{O}(14)-\mathrm{C}(40)-\mathrm{C}(41)$ & $117.3(5)$ & $C(25)-C(26)-C(21)$ & $119.6(5)$ \\
\hline $\mathrm{O}(34)-\mathrm{C}(40)-\mathrm{C}(41)$ & $117.0(4)$ & $C(63)-C(64)-C(65)$ & $118.6(6)$ \\
\hline$C(22)^{1}-C(21)-C(26)$ & $120.1(4)$ & $\mathrm{O}(24)-\mathrm{C}(60)-\mathrm{O}(32)$ & $24.4(5)$ \\
\hline$C(22)^{1}-C(21)-C(20)$ & $119.4(4)$ & $\mathrm{O}(24)-\mathrm{C}(60)-\mathrm{C}(61)$ & $117.9(5)$ \\
\hline$C(26)-C(21)-C(20)$ & $120.6(4)$ & $\mathrm{O}(32)-\mathrm{C}(60)-\mathrm{C}(61)$ & $117.7(5)$ \\
\hline $\mathrm{C}(30)-\mathrm{O}(13)-\mathrm{Fe}(1)$ & $131.0(3)$ & $\mathrm{O}(12)-\mathrm{C}(20)-\mathrm{O}(22)$ & $125.0(4)$ \\
\hline$C(23)-C(22)-C(21)^{2}$ & $119.2(5)$ & $\mathrm{O}(12)-\mathrm{C}(20)-\mathrm{C}(21)$ & $117.3(4)$ \\
\hline$C(16)-C(11)-C(12)$ & $120.0(5)$ & $\mathrm{O}(22)-\mathrm{C}(20)-\mathrm{C}(21)$ & $117.7(4)$ \\
\hline$C(16)-C(11)-C(10)^{3}$ & $119.9(5)$ & $C(41)-C(46)-C(45)^{6}$ & $118.6(6)$ \\
\hline$C(12)-C(11)-C(10)^{3}$ & $120.0(5)$ & $C(62)^{7}-C(63)-C(64)$ & $121.6(6)$ \\
\hline$C(42)-C(41)-C(46)$ & $121.6(5)$ & $\mathrm{C}(62)^{7}-\mathrm{C}(63)-\mathrm{Cl}(6 \mathrm{~A})$ & $120.3(6)$ \\
\hline$C(42)-C(41)-C(40)$ & 119.7(5) & $\mathrm{C}(64)-\mathrm{C}(63)-\mathrm{Cl}(6 \mathrm{~A})$ & $118.1(5)$ \\
\hline$C(46)-C(41)-C(40)$ & $118.7(5)$ & $\mathrm{C}(62)^{7}-\mathrm{C}(63)-\mathrm{Cl}(6)$ & $117.4(7)$ \\
\hline$C(14)-C(13)-C(12)$ & $120.9(5)$ & $\mathrm{C}(64)-\mathrm{C}(63)-\mathrm{Cl}(6)$ & $121.0(6)$ \\
\hline $\mathrm{C}(14)-\mathrm{C}(13)-\mathrm{Cl}(1)$ & $119.5(4)$ & $\mathrm{Cl}(6 \mathrm{~A})-\mathrm{C}(63)-\mathrm{Cl}(6)$ & $3.0(6)$ \\
\hline $\mathrm{C}(12)-\mathrm{C}(13)-\mathrm{Cl}(1)$ & $119.6(4)$ & ON3-N(1)-ON1 & $120.7(6)$ \\
\hline$C(15)-C(14)-C(13)$ & $119.4(6)$ & ON3-N(1)-ON2 & $119.5(7)$ \\
\hline$C(11)-C(16)-C(15)$ & $120.5(5)$ & ON1-N(1)-ON2 & $119.8(7)$ \\
\hline $\mathrm{O}(23)-\mathrm{C}(50)-\mathrm{O}(31)$ & $125.4(5)$ & $C(56)-C(51)-C(52)$ & $120.2(6)$ \\
\hline $\mathrm{O}(23)-\mathrm{C}(50)-\mathrm{C}(51)$ & $116.6(5)$ & $C(56)-C(51)-C(50)$ & $22.9(6)$ \\
\hline $\mathrm{O}(31)-\mathrm{C}(50)-\mathrm{C}(51)$ & $118.0(5)$ & $C(52)-C(51)-C(50)$ & $116.8(5)$ \\
\hline $\mathrm{O}(33)-\mathrm{C}(30)-\mathrm{O}(13)$ & $125.6(5)$ & $C(65)^{8}-C(66)-C(61)$ & $119.1(6)$ \\
\hline
\end{tabular}




$\begin{array}{llll}\mathrm{C}(63)^{8}-\mathrm{C}(62)-\mathrm{C}(61) & 119.3(6) & \mathrm{C}(42)^{12}-\mathrm{C}(43)-\mathrm{Cl}\left(4^{\prime}\right) & 124.8(7) \\ \mathrm{C}(53)^{5}-\mathrm{C}(52)-\mathrm{C}(51) & 119.1(7) & \mathrm{C}(44)^{3}-\mathrm{C}(43)-\mathrm{Cl}\left(4^{\prime}\right) & 114.6(7) \\ \mathrm{C}(31)-\mathrm{C}(32)-\mathrm{C}(33)^{9} & 118.0(7) & \mathrm{C}(42)^{12}-\mathrm{C}(43)-\mathrm{Cl}(4) & 118.1(7) \\ \mathrm{C}(54)^{5}-\mathrm{C}(55)-\mathrm{C}(56) & 121.0(8) & \mathrm{C}(44)^{3}-\mathrm{C}(43)-\mathrm{Cl}(4) & 121.8(6) \\ \mathrm{C}(14)-\mathrm{C}(15)-\mathrm{C}(16) & 120.0(6) & \mathrm{Cl}\left(4^{\prime}\right)-\mathrm{C}(43)-\mathrm{Cl}(4) & 11.7(8) \\ \mathrm{C}(66)^{7}-\mathrm{C}(65)-\mathrm{C}(64) & 121.2(7) & \mathrm{C}(54)-\mathrm{C}(53)-\mathrm{C}(52)^{6} & 120.8(7) \\ \mathrm{C}(51)-\mathrm{C}(56)-\mathrm{C}(55) & 119.2(7) & \mathrm{C}(54)-\mathrm{C}(53)-\mathrm{Cl}\left(5^{\prime}\right) & 112.4(7) \\ \mathrm{C}(41)-\mathrm{C}(42)-\mathrm{C}(43)^{10} & 119.5(6) & \mathrm{C}(52)^{6}-\mathrm{C}(53)-\mathrm{Cl}\left(5^{\prime}\right) & 126.7(8) \\ \mathrm{C}(34)-\mathrm{C}(33)-\mathrm{C}(32)^{11} & 121.5(8) & \mathrm{C}(54)-\mathrm{C}(53)-\mathrm{Cl}(5) & 123.3(6) \\ \mathrm{C}(34)-\mathrm{C}(33)-\mathrm{Cl}(3) & 119.7(8) & \mathrm{C}(52)^{6}-\mathrm{C}(53)-\mathrm{Cl}(5) & 115.9(6) \\ \mathrm{C}(32)^{11}-\mathrm{C}(33)-\mathrm{Cl}(3) & 118.3(8) & \mathrm{Cl}\left(5^{\prime}\right)-\mathrm{C}(53)-\mathrm{Cl}(5) & 11.9(6) \\ \mathrm{C}(34)-\mathrm{C}(33)-\mathrm{Cl}\left(3^{\prime}\right) & 121.0(7) & \mathrm{C}(31)^{\prime}-\mathrm{C}(36)-\mathrm{C}(35) & 120.0(8) \\ \mathrm{C}(32)^{11}-\mathrm{C}(33)-\mathrm{Cl}\left(3^{\prime}\right) & 117.4(7) & \mathrm{C}(24)^{1}-\mathrm{C}(25)-\mathrm{C}(26) & 120.6(5) \\ \mathrm{Cl}(3)-\mathrm{C}(33)-\mathrm{Cl}\left(3^{\prime}\right) & 10.4(4) & \mathrm{C}(55)^{6}-\mathrm{C}(54)-\mathrm{C}(53) & 119.5(7) \\ \mathrm{C}(45)-\mathrm{C}(44)-\mathrm{C}(43)^{4} & 20.3(5) & \mathrm{C}(25)^{2}-\mathrm{C}(24)-\mathrm{C}(23) & 119.2(5) \\ \mathrm{C}(42)^{12}-\mathrm{C}(43)-\mathrm{C}(44)^{3} & 120.1(7) & \mathrm{C}(35)^{11}-\mathrm{C}(34)-\mathrm{C}(33) & 121.3(8) \\ \mathrm{C}(34)^{9}-\mathrm{C}(35)-\mathrm{C}(36) & 119.2(8) & & \end{array}$

Symmetry transformations used to generate equivalent atoms:

$\begin{array}{lll}{ }^{1} \mathrm{x}-1 / 2,-\mathrm{y}, \mathrm{z} ; & { }^{2} \mathrm{x}+1 / 2,-\mathrm{y}, \mathrm{z} ; & { }^{3}-\mathrm{x}+3 / 2, \mathrm{y}, \mathrm{z}+1 / 2 ; \\ { }^{4}-\mathrm{x}+3 / 2, \mathrm{y}, \mathrm{z}-1 / 2 ; & { }^{5} \mathrm{x}, \mathrm{y}-1, \mathrm{z} ; & { }^{6} \mathrm{x}, \mathrm{y}+1, \mathrm{z} ; \\ { }^{7}-\mathrm{x}+2,-\mathrm{y}+1, \mathrm{z}+1 / 2 ; & { }^{8}-\mathrm{x}+2,-\mathrm{y}+1, \mathrm{z}-1 / 2 ; & { }^{9} \mathrm{x}-1 / 2,-\mathrm{y}+1, \mathrm{z} ; \\ { }^{10}-\mathrm{x}+3 / 2, \mathrm{y}+1, \mathrm{z}-1 / 2 ; & { }^{11} \mathrm{x}+1 / 2,-\mathrm{y}+1, \mathrm{z} ; & { }^{12}-\mathrm{x}+3 / 2, \mathrm{y}-1, \mathrm{z}+1 / 2 .\end{array}$

\subsection{2 $\left[\mathrm{Cr}_{3} \mathrm{O}\left(\mathrm{O}_{2} \mathrm{CC}_{6} \mathrm{H}_{4}-3-\mathrm{Cl}\right)_{6}\left(\mathrm{H}_{2} \mathrm{O}\right)_{3}\right] \mathrm{NO}_{3} \cdot \mathrm{H}_{2} \mathrm{O}$}

\subsubsection{Crystal data and structure refinement.}

Empirical formula

Formula weight

Temperature

Wavelength

Crystal system, space group
C42 H32 Cl6 Cr3 N O20

1221.37

273(2) K

$0.71073 \AA$

Orthorhombic, Pca2 1 
Unit cell dimensions

Volume

Z

Calculated density

Absorption coefficient

$\mathrm{F}(000)$

Crystal size

Theta range for data collection

Limiting indices

Reflections collected / unique

Completeness to theta $=30.43$

Absorption correction

Refinement method

Data / restraints / parameters

Goodness-of-fit on $F^{2}$

Final $R$ indices $[\mathrm{I}>2 \operatorname{sigma}(\mathrm{I})]$

$\mathrm{R}$ indices (all data)

Absolute structure parameter

Largest diff. peak and hole

$$
\begin{array}{ll}
\mathrm{a}=21.2756(8) \AA & \alpha=90^{\circ} \\
\mathrm{b}=10.9534(4) \AA & \beta=90^{\circ} \\
\mathrm{c}=21.4030(9) \AA & \gamma=90^{\circ}
\end{array}
$$$$
\text { 4987.8(3) } \AA^{3}
$$

4

$1.626 \mathrm{Mg} / \mathrm{m}^{3}$

$1.038 \mathrm{~mm}^{-1}$

2460

$0.45 \times 0.21 \times 0.10 \mathrm{~mm}$

1.86 to $30.43^{\circ}$

$-30 \leq h \leq 29,-15 \leq k \leq 14,-27 \leq l \leq 30$

$75091 / 13963[\mathrm{R}$ (int) $=0.0610]$

$98.5 \%$

None

Full-matrix least-squares on $\mathrm{F}^{2}$

$13963 / 1 / 705$

1.157

$R_{1}=0.0583, w R_{2}=0.1425$

$R_{1}=0.1177, w R_{2}=0.1804$

$0.40(2)$

1.210 and -1.208 e. $\AA^{-3}$

\subsubsection{Atomic coordinates $\left(\times 10^{4}\right)$ and equivalent isotropic displacement parameters $\left(\AA^{2} \times 10^{3}\right)$}

$\mathrm{U}_{\text {eq }}$ is defined as one third of the trace of the orthogonalized $\mathrm{U}_{\mathrm{ij}}$ tensor.

\begin{tabular}{ccccl} 
Atom Label & $\mathrm{x}$ & $\mathrm{y}$ & $\mathrm{z}$ & $\mathrm{U}_{\text {eq }}$ \\
\hline $\mathrm{Cr}(1)$ & $7252(1)$ & $3279(1)$ & $7(1)$ & $21(1)$ \\
$\mathrm{Cr}(3)$ & $5861(1)$ & $1989(1)$ & $95(1)$ & $26(1)$ \\
$\mathrm{Cr}(2)$ & $6007(1)$ & $4661(1)$ & $-592(1)$ & $36(1)$ \\
$\mathrm{Cl}(1)$ & $4381(2)$ & $5851(3)$ & $-2396(2)$ & $176(3)$ \\
$\mathrm{Cl}(3)$ & $8291(1)$ & $1753(2)$ & $3037(1)$ & $49(1)$
\end{tabular}




\begin{tabular}{|c|c|c|c|c|}
\hline $\mathrm{Cl}(4)$ & $3958(1)$ & $2048(2)$ & $-577(2)$ & $83(1)$ \\
\hline $\mathrm{Cl}(2)$ & $3534(5)$ & $1396(10)$ & $1430(6)$ & $137(6)$ \\
\hline $\mathrm{Cl}\left(2^{\prime}\right)$ & $3694(4)$ & 1371(8) & $1160(3)$ & $60(2)$ \\
\hline $\mathrm{Cl}(6)$ & $4746(3)$ & $1504(5)$ & $2632(3)$ & $57(1)$ \\
\hline $\mathrm{Cl}\left(6^{\prime}\right)$ & $4710(3)$ & $1100(8)$ & 2355(4) & $85(2)$ \\
\hline $\mathrm{Cl}(5)$ & $9013(1)$ & 1939(2) & $1288(1)$ & $69(1)$ \\
\hline $\mathrm{O}(1)$ & $6375(2)$ & $3321(3)$ & $-160(2)$ & $27(1)$ \\
\hline OW1 & $8198(2)$ & $3246(4)$ & 161(2) & $29(2)$ \\
\hline OW2 & $5615(3)$ & $6164(4)$ & $-1037(3)$ & $64(2)$ \\
\hline OW3 & $5285(2)$ & $538(4)$ & $355(2)$ & $44(2)$ \\
\hline ON1 & $5151(2)$ & $-1593(5)$ & $-390(2)$ & $52(1)$ \\
\hline ON2 & $9418(5)$ & $2794(6)$ & $-668(5)$ & $149(5)$ \\
\hline ON3 & $9208(3)$ & $1124(9)$ & $-172(5)$ & $128(4)$ \\
\hline OCW1 & $8857(5)$ & $4971(10)$ & $-518(5)$ & $132(3)$ \\
\hline $\mathrm{O}(11)$ & $7489(2)$ & $3664(4)$ & $-853(2)$ & $40(1)$ \\
\hline $\mathrm{O}(13)$ & $7166(2)$ & $2865(3)$ & $900(2)$ & $27(1)$ \\
\hline $\mathrm{O}(14)$ & $7365(2)$ & 1538(3) & $-192(2)$ & $32(1)$ \\
\hline $\mathrm{O}(12)$ & $7316(2)$ & $5015(3)$ & $249(2)$ & $30(1)$ \\
\hline $\mathrm{O}(31)$ & $5225(2)$ & $3014(4)$ & $503(3)$ & $51(2)$ \\
\hline $\mathrm{O}(33)$ & $6251(2)$ & $1839(3)$ & $930(2)$ & $34(1)$ \\
\hline $\mathrm{O}(34)$ & $6401(2)$ & $702(3)$ & $-248(2)$ & $32(1)$ \\
\hline $\mathrm{O}(32)$ & $5414(2)$ & 1904(4) & $-702(2)$ & $46(2)$ \\
\hline $\mathrm{O}(23)$ & $5296(2)$ & 4804(4) & $-2(3)$ & $60(2)$ \\
\hline $\mathrm{O}(21)$ & $6679(2)$ & $4757(3)$ & $-1227(2)$ & $41(2)$ \\
\hline $\mathrm{O}(22)$ & $6419(2)$ & $5885(3)$ & $-67(2)$ & $46(2)$ \\
\hline $\mathrm{O}(24)$ & $5509(2)$ & $3697(4)$ & $-1200(2)$ & $47(2)$ \\
\hline$C(10)$ & $7221(3)$ & $4328(5)$ & $-1262(2)$ & $35(1)$ \\
\hline $\mathrm{C}(11)$ & $7607(5)$ & $4620(5)$ & $-1831(3)$ & $56(2)$ \\
\hline$C(12)$ & $8251(4)$ & $4258(6)$ & $-1847(4)$ & $65(2)$ \\
\hline$C(13)$ & $3578(7)$ & $5436(10)$ & $-2372(6)$ & $120(6)$ \\
\hline$C(14)$ & $8323(14)$ & $5190(20)$ & $-2848(9)$ & $196(17)$ \\
\hline$C(15)$ & $7752(13)$ & $5479(14)$ & $-2863(6)$ & $162(12)$ \\
\hline$C(16)$ & $7357(7)$ & $5226(7)$ & $-2323(3)$ & $90(4)$ \\
\hline$C(20)$ & $6943(3)$ & $5891(4)$ & $219(2)$ & $24(2)$ \\
\hline
\end{tabular}




\begin{tabular}{|c|c|c|c|c|}
\hline$C(21)$ & $7107(3)$ & $7035(4)$ & $565(2)$ & $30(1)$ \\
\hline$C(22)$ & $7709(3)$ & $7239(5)$ & $738(3)$ & $41(1)$ \\
\hline$C(23)$ & $7861(4)$ & $-1691(6)$ & $1052(4)$ & $66(3)$ \\
\hline$C(24)$ & $7392(5)$ & $-866(6)$ & $1221(4)$ & $65(2)$ \\
\hline$C(25)$ & $6778(4)$ & $-1071(6)$ & 1038(3) & $47(2)$ \\
\hline$C(26)$ & $6634(3)$ & $7876(5)$ & $698(3)$ & $34(1)$ \\
\hline$C(30)$ & $6741(2)$ & $2244(4)$ & $1171(2)$ & $22(1)$ \\
\hline$C(31)$ & $6856(3)$ & $1925(5)$ & $1843(2)$ & $24(2)$ \\
\hline$C(32)$ & $7456(3)$ & $2037(4)$ & $2105(2)$ & $26(2)$ \\
\hline C(33) & $7545(3)$ & $1655(5)$ & $2716(3)$ & $36(1)$ \\
\hline$C(34)$ & $7056(4)$ & $1214(7)$ & $3080(3)$ & $50(2)$ \\
\hline$C(35)$ & $6461(4)$ & $1113(7)$ & $2815(3)$ & $51(2)$ \\
\hline$C(36)$ & $6359(3)$ & $1460(5)$ & $2200(3)$ & $39(1)$ \\
\hline$C(40)$ & $6989(2)$ & $680(4)$ & $-318(2)$ & $22(1)$ \\
\hline$C(41)$ & $7276(2)$ & $-461(4)$ & $-568(2)$ & $27(2)$ \\
\hline$C(42)$ & $7906(3)$ & $-689(5)$ & $-476(3)$ & $32(1)$ \\
\hline$C(43)$ & $8169(3)$ & $-1734(5)$ & $-724(3)$ & $41(1)$ \\
\hline$C(44)$ & $7823(3)$ & $-2564(6)$ & $-1066(4)$ & $47(2)$ \\
\hline$C(45)$ & $7193(3)$ & $-2314(6)$ & $-1161(3)$ & $46(2)$ \\
\hline$C(46)$ & $6911(3)$ & $-1284(5)$ & $-902(3)$ & $37(1)$ \\
\hline$C(50)$ & $5104(3)$ & $4147(5)$ & $445(3)$ & $40(2)$ \\
\hline$C(51)$ & $4718(3)$ & $4734(6)$ & $935(3)$ & $43(2)$ \\
\hline C(52) & $9551(3)$ & $4042(6)$ & $884(4)$ & $46(2)$ \\
\hline C(53) & $9224(3)$ & $3489(7)$ & $1358(4)$ & $56(2)$ \\
\hline$C(54)$ & $9042(4)$ & $4140(8)$ & $1887(5)$ & $66(2)$ \\
\hline$C(55)$ & 4211(4) & $4641(8)$ & 1924(5) & $68(2)$ \\
\hline$C(56)$ & $4543(3)$ & $4056(7)$ & $1452(4)$ & $56(2)$ \\
\hline$C(60)$ & $5358(3)$ & $2570(5)$ & $-1176(3)$ & $39(1)$ \\
\hline$C(61)$ & $5124(3)$ & $1990(6)$ & $-1749(3)$ & $43(1)$ \\
\hline$C(62)$ & $5240(3)$ & $750(7)$ & $-1830(4)$ & $53(2)$ \\
\hline$C(63)$ & $4920(4)$ & $-183(9)$ & 2622(5) & $71(3)$ \\
\hline$C(64)$ & $5209(5)$ & $-798(11)$ & 2151(4) & $83(3)$ \\
\hline$C(65)$ & $4653(5)$ & 2011(11) & $-2769(4)$ & $84(3)$ \\
\hline
\end{tabular}




$\begin{array}{lllll}\mathrm{C}(66) & 4828(4) & 2623(8) & -2225(3) & 57(2) \\ \mathrm{N}(1) & 4581(3) & -1807(5) & -413(4) & 63(2)\end{array}$

\subsubsection{Bond lengths $[\AA]$ and angles [ ${ }^{\circ}$.}

\section{Bond Lengths}

\begin{tabular}{|c|c|c|c|}
\hline $\mathrm{Cr}(1)-\mathrm{O}(1)$ & $1.899(4)$ & ON1-N(1) & $1.235(7)$ \\
\hline $\mathrm{Cr}(1)-\mathrm{O}(11)$ & $1.955(4)$ & $\mathrm{ON} 2-\mathrm{N}(1)^{2}$ & $1.261(10)$ \\
\hline $\mathrm{Cr}(1)-\mathrm{O}(14)$ & $1.969(4)$ & $\mathrm{ON} 3-\mathrm{N}(1)^{2}$ & $1.206(11)$ \\
\hline $\mathrm{Cr}(1)-\mathrm{O}(13)$ & $1.972(4)$ & $\mathrm{O}(11)-\mathrm{C}(10)$ & $1.273(7)$ \\
\hline $\mathrm{Cr}(1)-\mathrm{O}(12)$ & $1.975(3)$ & $\mathrm{O}(13)-\mathrm{C}(30)$ & $1.272(6)$ \\
\hline Cr(1)-OW1 & $2.040(4)$ & $\mathrm{O}(14)-\mathrm{C}(40)$ & $1.263(6)$ \\
\hline $\mathrm{Cr}(3)-\mathrm{O}(1)$ & $1.903(4)$ & $\mathrm{O}(12)-\mathrm{C}(20)$ & $1.248(6)$ \\
\hline $\mathrm{Cr}(3)-\mathrm{O}(32)$ & $1.954(4)$ & $\mathrm{O}(31)-\mathrm{C}(50)$ & $1.274(7)$ \\
\hline $\mathrm{Cr}(3)-\mathrm{O}(34)$ & $1.960(4)$ & $\mathrm{O}(33)-\mathrm{C}(30)$ & $1.246(6)$ \\
\hline $\mathrm{Cr}(3)-\mathrm{O}(31)$ & $1.963(4)$ & $\mathrm{O}(34)-\mathrm{C}(40)$ & $1.259(6)$ \\
\hline $\mathrm{Cr}(3)-\mathrm{O}(33)$ & $1.978(4)$ & $\mathrm{O}(32)-\mathrm{C}(60)$ & $1.255(7)$ \\
\hline $\mathrm{Cr}(3)-\mathrm{OW} 3$ & $2.083(5)$ & $\mathrm{O}(23)-\mathrm{C}(50)$ & $1.264(9)$ \\
\hline $\mathrm{Cr}(2)-\mathrm{O}(1)$ & $1.904(3)$ & $\mathrm{O}(21)-\mathrm{C}(10)$ & $1.249(8)$ \\
\hline $\mathrm{Cr}(2)-\mathrm{O}(22)$ & $1.957(4)$ & $\mathrm{O}(22)-\mathrm{C}(20)$ & $1.271(7)$ \\
\hline $\mathrm{Cr}(2)-\mathrm{O}(21)$ & $1.973(5)$ & $\mathrm{O}(24)-\mathrm{C}(60)$ & $1.277(7)$ \\
\hline $\mathrm{Cr}(2)-\mathrm{O}(23)$ & $1.978(6)$ & $C(10)-C(11)$ & $1.502(9)$ \\
\hline $\mathrm{Cr}(2)-\mathrm{O}(24)$ & $1.982(4)$ & $C(11)-C(16)$ & $1.354(12)$ \\
\hline $\mathrm{Cr}(2)-\mathrm{OW} 2$ & $2.076(4)$ & $C(11)-C(12)$ & $1.426(12)$ \\
\hline $\mathrm{Cl}(1)-\mathrm{C}(13)$ & $1.768(17)$ & $C(12)-C(13)^{3}$ & $1.363(12)$ \\
\hline Cl(3)-C(33) & $1.734(7)$ & $C(13)-C(14)^{4}$ & $1.34(3)$ \\
\hline $\mathrm{Cl}(4)-\mathrm{C}(43)^{1}$ & $1.741(6)$ & $C(13)-C(12)^{4}$ & $1.363(12)$ \\
\hline $\mathrm{Cl}(2)-\mathrm{Cl}\left(2^{\prime}\right)$ & $0.672(16)$ & $C(14)-C(15)$ & $1.26(3)$ \\
\hline $\mathrm{Cl}(2)-\mathrm{C}(23)^{1}$ & $1.675(13)$ & $C(14)-C(13)^{3}$ & $1.34(3)$ \\
\hline $\mathrm{Cl}\left(2^{\prime}\right)-\mathrm{C}(23)^{1}$ & $1.821(12)$ & $C(15)-C(16)$ & $1.46(2)$ \\
\hline $\mathrm{Cl}(6)-\mathrm{Cl}\left(6^{\prime}\right)$ & $0.744(8)$ & $\mathrm{C}(30)-\mathrm{C}(31)$ & $1.500(7)$ \\
\hline $\mathrm{Cl}(6)-\mathrm{C}(63)$ & $1.884(12)$ & $C(31)-C(32)$ & $1.397(8)$ \\
\hline $\mathrm{Cl}\left(6^{\prime}\right)-\mathrm{C}(63)$ & $1.582(12)$ & $C(31)-C(36)$ & $1.401(8)$ \\
\hline $\mathrm{Cl}(5)-\mathrm{C}(53)$ & $1.763(7)$ & $C(32)-C(33)$ & $1.387(8)$ \\
\hline
\end{tabular}




$\begin{array}{llll}\mathrm{C}(33)-\mathrm{C}(34) & 1.385(10) & \mathrm{C}(26)-\mathrm{C}(25)^{5} & 1.397(8) \\ \mathrm{C}(34)-\mathrm{C}(35) & 1.392(10) & \mathrm{C}(60)-\mathrm{C}(61) & 1.468(8) \\ \mathrm{C}(35)-\mathrm{C}(36) & 1.388(9) & \mathrm{C}(61)-\mathrm{C}(66) & 1.384(9) \\ \mathrm{C}(40)-\mathrm{C}(41) & 1.490(7) & \mathrm{C}(61)-\mathrm{C}(62) & 1.391(10) \\ \mathrm{C}(41)-\mathrm{C}(42) & 1.377(7) & \mathrm{C}(62)-\mathrm{C}(63)^{7} & 1.369(10) \\ \mathrm{C}(41)-\mathrm{C}(46) & 1.389(8) & \mathrm{C}(63)-\mathrm{C}(64) & 1.360(15) \\ \mathrm{C}(42)-\mathrm{C}(43) & 1.380(8) & \mathrm{C}(63)-\mathrm{C}(62)^{8} & 1.369(10) \\ \mathrm{C}(43)-\mathrm{C}(44) & 1.381(9) & \mathrm{C}(64)-\mathrm{C}(65)^{8} & 1.372(16) \\ \mathrm{C}(43)-\mathrm{Cl}(4)^{2} & 1.741(6) & \mathrm{C}(65)-\mathrm{C}(64)^{7} & 1.372(16) \\ \mathrm{C}(44)-\mathrm{C}(45) & 1.383(9) & \mathrm{C}(65)-\mathrm{C}(66) & 1.395(11) \\ \mathrm{C}(45)-\mathrm{C}(46) & 1.393(8) & \mathrm{C}(50)-\mathrm{C}(51) & 1.479(9) \\ \mathrm{C}(20)-\mathrm{C}(21) & 1.497(7) & \mathrm{C}(51)-\mathrm{C}(56) & 1.384(11) \\ \mathrm{C}(21)-\mathrm{C}(22) & 1.353(8) & \mathrm{C}(51)-\mathrm{C}(52)^{4} & 1.392(9) \\ \mathrm{C}(21)-\mathrm{C}(26) & 1.393(8) & \mathrm{C}(52)-\mathrm{C}(53) & 1.372(10) \\ \mathrm{C}(22)-\mathrm{C}(23)^{5} & 1.390(9) & \mathrm{C}(52)-\mathrm{C}(51)^{3} & 1.392(9) \\ \mathrm{C}(23)-\mathrm{C}(22)^{6} & 1.390(9) & \mathrm{C}(53)-\mathrm{C}(54) & 1.391(14) \\ \mathrm{C}(23)-\mathrm{C}(24) & 1.394(11) & \mathrm{C}(54)-\mathrm{C}(55)^{3} & 1.385(12) \\ \mathrm{C}(23)-\mathrm{Cl}(2)^{2} & 1.675(13) & \mathrm{C}(55)-\mathrm{C}(54)^{4} & 1.385(12) \\ \mathrm{C}(23)-\mathrm{Cl}(2)^{2}{ }^{2} & 1.821(12) & \mathrm{C}(55)-\mathrm{C}(56) & 1.389(12) \\ \mathrm{C}(24)-\mathrm{C}(25) & 1.382(11) & \mathrm{N}(1)-\mathrm{ON} 3^{1} & 1.206(11) \\ \mathrm{C}(25)-\mathrm{C}(26)^{6} & 1.397(8) & \mathrm{N}(1)-\mathrm{ON} 2^{1} & 1.261(10) \\ & & & \\ & & & \end{array}$

\section{Bond Angles}

$\begin{array}{llll}\mathrm{O}(1)-\mathrm{Cr}(1)-\mathrm{O}(11) & 94.12(17) & \mathrm{O}(11)-\mathrm{Cr}(1)-\mathrm{OW} 1 & 84.30(19) \\ \mathrm{O}(1)-\mathrm{Cr}(1)-\mathrm{O}(14) & 95.87(15) & \mathrm{O}(14)-\mathrm{Cr}(1)-\mathrm{OW} 1 & 84.11(16) \\ \mathrm{O}(11)-\mathrm{Cr}(1)-\mathrm{O}(14) & 88.47(18) & \mathrm{O}(13)-\mathrm{Cr}(1)-\mathrm{OW} 1 & 86.04(17) \\ \mathrm{O}(1)-\mathrm{Cr}(1)-\mathrm{O}(13) & 95.53(15) & \mathrm{O}(12)-\mathrm{Cr}(1)-\mathrm{OW} 1 & 84.62(17) \\ \mathrm{O}(11)-\mathrm{Cr}(1)-\mathrm{O}(13) & 170.32(17) & \mathrm{O}(1)-\mathrm{Cr}(3)-\mathrm{O}(32) & 93.81(17) \\ \mathrm{O}(14)-\mathrm{Cr}(1)-\mathrm{O}(13) & 89.91(17) & \mathrm{O}(1)-\mathrm{Cr}(3)-\mathrm{O}(34) & 96.16(16) \\ \mathrm{O}(1)-\mathrm{Cr}(1)-\mathrm{O}(12) & 95.42(15) & \mathrm{O}(32)-\mathrm{Cr}(3)-\mathrm{O}(34) & 85.70(18) \\ \mathrm{O}(11)-\mathrm{Cr}(1)-\mathrm{O}(12) & 91.25(18) & \mathrm{O}(1)-\mathrm{Cr}(3)-\mathrm{O}(31) & 94.87(18) \\ \mathrm{O}(14)-\mathrm{Cr}(1)-\mathrm{O}(12) & 168.70(16) & \mathrm{O}(32)-\mathrm{Cr}(3)-\mathrm{O}(31) & 94.6(2) \\ \mathrm{O}(13)-\mathrm{Cr}(1)-\mathrm{O}(12) & 88.47(17) & \mathrm{O}(34)-\mathrm{Cr}(3)-\mathrm{O}(31) & 168.92(19) \\ \mathrm{O}(1)-\mathrm{Cr}(1)-\mathrm{OW} 1 & 178.42(18) & \mathrm{O}(1)-\mathrm{Cr}(3)-\mathrm{O}(33) & 94.65(15)\end{array}$




\begin{tabular}{|c|c|c|c|}
\hline $\mathrm{O}(32)-\mathrm{Cr}(3)-\mathrm{O}(33)$ & $171.41(17)$ & $\mathrm{C}(50)-\mathrm{O}(31)-\mathrm{Cr}(3)$ & $130.8(5)$ \\
\hline $\mathrm{O}(34)-\mathrm{Cr}(3)-\mathrm{O}(33)$ & $91.88(16)$ & $\mathrm{C}(30)-\mathrm{O}(33)-\mathrm{Cr}(3)$ & $134.2(4)$ \\
\hline $\mathrm{O}(31)-\mathrm{Cr}(3)-\mathrm{O}(33)$ & $86.24(19)$ & $\mathrm{C}(40)-\mathrm{O}(34)-\mathrm{Cr}(3)$ & $129.8(3)$ \\
\hline $\mathrm{O}(1)-\mathrm{Cr}(3)-\mathrm{OW} 3$ & $178.62(18)$ & $\mathrm{C}(60)-\mathrm{O}(32)-\mathrm{Cr}(3)$ & $136.4(4)$ \\
\hline $\mathrm{O}(32)-\mathrm{Cr}(3)-\mathrm{OW} 3$ & $84.85(19)$ & $\mathrm{C}(50)-\mathrm{O}(23)-\mathrm{Cr}(2)$ & $133.2(4)$ \\
\hline $\mathrm{O}(34)-\mathrm{Cr}(3)-\mathrm{OW} 3$ & $84.07(17)$ & $\mathrm{C}(10)-\mathrm{O}(21)-\mathrm{Cr}(2)$ & $133.7(4)$ \\
\hline $\mathrm{O}(31)-\mathrm{Cr}(3)-\mathrm{OW} 3$ & $84.9(2)$ & $\mathrm{C}(20)-\mathrm{O}(22)-\mathrm{Cr}(2)$ & 132.3(3) \\
\hline $\mathrm{O}(33)-\mathrm{Cr}(3)-\mathrm{OW} 3$ & $86.70(17)$ & $\mathrm{C}(60)-\mathrm{O}(24)-\mathrm{Cr}(2)$ & $128.6(4)$ \\
\hline $\mathrm{O}(1)-\mathrm{Cr}(2)-\mathrm{O}(22)$ & $93.70(16)$ & $\mathrm{O}(21)-\mathrm{C}(10)-\mathrm{O}(11)$ & $126.0(5)$ \\
\hline $\mathrm{O}(1)-\mathrm{Cr}(2)-\mathrm{O}(21)$ & $94.49(17)$ & $\mathrm{O}(21)-\mathrm{C}(10)-\mathrm{C}(11)$ & $118.3(6)$ \\
\hline $\mathrm{O}(22)-\mathrm{Cr}(2)-\mathrm{O}(21)$ & $92.0(2)$ & $\mathrm{O}(11)-\mathrm{C}(10)-\mathrm{C}(11)$ & $115.7(6)$ \\
\hline $\mathrm{O}(1)-\mathrm{Cr}(2)-\mathrm{O}(23)$ & $93.73(18)$ & $C(16)-C(11)-C(12)$ & 119.7(8) \\
\hline $\mathrm{O}(22)-\mathrm{Cr}(2)-\mathrm{O}(23)$ & $85.5(2)$ & $C(16)-C(11)-C(10)$ & $121.3(9)$ \\
\hline $\mathrm{O}(21)-\mathrm{Cr}(2)-\mathrm{O}(23)$ & $171.55(19)$ & $C(12)-C(11)-C(10)$ & $119.0(7)$ \\
\hline $\mathrm{O}(1)-\mathrm{Cr}(2)-\mathrm{O}(24)$ & $97.37(16)$ & $C(13)^{3}-C(12)-C(11)$ & $116.2(11)$ \\
\hline $\mathrm{O}(22)-\mathrm{Cr}(2)-\mathrm{O}(24)$ & $168.89(17)$ & $C(14)^{4}-C(13)-C(12)^{4}$ & $123.0(17)$ \\
\hline $\mathrm{O}(21)-\mathrm{Cr}(2)-\mathrm{O}(24)$ & $87.97(19)$ & $\mathrm{C}(14)^{4}-\mathrm{C}(13)-\mathrm{Cl}(1)$ & $120.0(12)$ \\
\hline $\mathrm{O}(23)-\mathrm{Cr}(2)-\mathrm{O}(24)$ & $92.9(2)$ & $\mathrm{C}(12)^{4}-\mathrm{C}(13)-\mathrm{Cl}(1)$ & $117.0(13)$ \\
\hline $\mathrm{O}(1)-\mathrm{Cr}(2)-\mathrm{OW} 2$ & $177.89(19)$ & $C(15)-C(14)-C(13)^{3}$ & $122.7(17)$ \\
\hline $\mathrm{O}(22)-\mathrm{Cr}(2)-\mathrm{OW} 2$ & $84.27(18)$ & $C(14)-C(15)-C(16)$ & $119.3(17)$ \\
\hline $\mathrm{O}(21)-\mathrm{Cr}(2)-\mathrm{OW} 2$ & $86.2(2)$ & $C(11)-C(16)-C(15)$ & $119.0(15)$ \\
\hline $\mathrm{O}(23)-\mathrm{Cr}(2)-\mathrm{OW} 2$ & $85.5(2)$ & $\mathrm{O}(33)-\mathrm{C}(30)-\mathrm{O}(13)$ & $126.6(5)$ \\
\hline $\mathrm{O}(24)-\mathrm{Cr}(2)-\mathrm{OW} 2$ & 84.65(19) & $\mathrm{O}(33)-\mathrm{C}(30)-\mathrm{C}(31)$ & $116.8(4)$ \\
\hline $\mathrm{Cl}\left(2^{\prime}\right)-\mathrm{Cl}(2)-\mathrm{C}(23)^{1}$ & $91.4(18)$ & $\mathrm{O}(13)-\mathrm{C}(30)-\mathrm{C}(31)$ & $116.6(4)$ \\
\hline $\mathrm{Cl}(2)-\mathrm{Cl}\left(2^{\prime}\right)-\mathrm{C}(23)^{1}$ & $66.9(16)$ & $C(32)-C(31)-C(36)$ & $120.2(5)$ \\
\hline $\mathrm{Cl}\left(6^{\prime}\right)-\mathrm{Cl}(6)-\mathrm{C}(63)$ & $55.2(9)$ & $C(32)-C(31)-C(30)$ & $120.8(5)$ \\
\hline $\mathrm{Cl}(6)-\mathrm{Cl}\left(6^{\prime}\right)-\mathrm{C}(63)$ & 102.1(10) & $C(36)-C(31)-C(30)$ & $118.9(5)$ \\
\hline $\mathrm{Cr}(1)-\mathrm{O}(1)-\mathrm{Cr}(3)$ & $119.49(18)$ & $C(33)-C(32)-C(31)$ & $118.4(5)$ \\
\hline $\mathrm{Cr}(1)-\mathrm{O}(1)-\mathrm{Cr}(2)$ & $120.89(19)$ & $C(34)-C(33)-C(32)$ & $122.2(6)$ \\
\hline $\mathrm{Cr}(3)-\mathrm{O}(1)-\mathrm{Cr}(2)$ & $119.60(19)$ & $\mathrm{C}(34)-\mathrm{C}(33)-\mathrm{Cl}(3)$ & $119.1(5)$ \\
\hline $\mathrm{C}(10)-\mathrm{O}(11)-\mathrm{Cr}(1)$ & $130.9(4)$ & $\mathrm{C}(32)-\mathrm{C}(33)-\mathrm{Cl}(3)$ & $118.7(5)$ \\
\hline $\mathrm{C}(30)-\mathrm{O}(13)-\mathrm{Cr}(1)$ & $129.2(3)$ & $\mathrm{C}(33)-\mathrm{C}(34)-\mathrm{C}(35)$ & $118.8(5)$ \\
\hline $\mathrm{C}(40)-\mathrm{O}(14)-\mathrm{Cr}(1)$ & 133.6(3) & $C(36)-C(35)-C(34)$ & $120.4(6)$ \\
\hline $\mathrm{C}(20)-\mathrm{O}(12)-\mathrm{Cr}(1)$ & 133.1(3) & $C(35)-C(36)-C(31)$ & $119.9(6)$ \\
\hline
\end{tabular}




\begin{tabular}{|c|c|c|c|}
\hline $\mathrm{O}(34)-\mathrm{C}(40)-\mathrm{O}(14)$ & $126.1(5)$ & $\mathrm{O}(24)-\mathrm{C}(60)-\mathrm{C}(61)$ & $118.0(6)$ \\
\hline $\mathrm{O}(34)-\mathrm{C}(40)-\mathrm{C}(41)$ & $117.8(4)$ & $C(66)-C(61)-C(62)$ & $118.5(7)$ \\
\hline $\mathrm{O}(14)-\mathrm{C}(40)-\mathrm{C}(41)$ & $116.1(4)$ & $C(66)-C(61)-C(60)$ & $123.6(7)$ \\
\hline$C(42)-C(41)-C(46)$ & $120.0(5)$ & $C(62)-C(61)-C(60)$ & $117.8(6)$ \\
\hline$C(42)-C(41)-C(40)$ & $120.0(5)$ & $C(63)^{7}-C(62)-C(61)$ & $120.4(8)$ \\
\hline$C(46)-C(41)-C(40)$ & $120.0(5)$ & $C(64)-C(63)-C(62)^{8}$ & $121.4(9)$ \\
\hline$C(41)-C(42)-C(43)$ & $119.4(5)$ & $C(64)-C(63)-C l\left(6^{\prime}\right)$ & $107.4(8)$ \\
\hline$C(44)-C(43)-C(42)$ & $122.2(5)$ & $\mathrm{C}(62)^{8}-\mathrm{C}(63)-\mathrm{Cl}\left(6^{\prime}\right)$ & $130.0(9)$ \\
\hline $\mathrm{C}(44)-\mathrm{C}(43)-\mathrm{Cl}(4)^{2}$ & $118.7(5)$ & $\mathrm{C}(64)-\mathrm{C}(63)-\mathrm{Cl}(6)$ & $125.6(7)$ \\
\hline $\mathrm{C}(42)-\mathrm{C}(43)-\mathrm{Cl}(4)^{2}$ & $119.1(5)$ & $\mathrm{C}(62)^{8}-\mathrm{C}(63)-\mathrm{Cl}(6)$ & $112.8(8)$ \\
\hline$C(43)-C(44)-C(45)$ & $117.7(5)$ & $\mathrm{Cl}\left(6^{\prime}\right)-\mathrm{C}(63)-\mathrm{Cl}(6)$ & $22.7(3)$ \\
\hline$C(44)-C(45)-C(46)$ & $121.3(5)$ & $C(63)-C(64)-C(65)^{8}$ & $119.0(7)$ \\
\hline$C(41)-C(46)-C(45)$ & $119.3(5)$ & $C(64)^{7}-C(65)-C(66)$ & $120.8(9)$ \\
\hline $\mathrm{O}(12)-\mathrm{C}(20)-\mathrm{O}(22)$ & $125.4(5)$ & $C(61)-C(66)-C(65)$ & 119.7(9) \\
\hline $\mathrm{O}(12)-\mathrm{C}(20)-\mathrm{C}(21)$ & $118.0(5)$ & $\mathrm{O}(23)-\mathrm{C}(50)-\mathrm{O}(31)$ & $124.3(6)$ \\
\hline $\mathrm{O}(22)-\mathrm{C}(20)-\mathrm{C}(21)$ & $116.6(5)$ & $\mathrm{O}(23)-\mathrm{C}(50)-\mathrm{C}(51)$ & $117.9(5)$ \\
\hline$C(22)-C(21)-C(26)$ & $121.3(5)$ & $\mathrm{O}(31)-\mathrm{C}(50)-\mathrm{C}(51)$ & $117.8(7)$ \\
\hline$C(22)-C(21)-C(20)$ & $119.6(5)$ & $C(56)-C(51)-C(52)^{4}$ & $120.7(7)$ \\
\hline$C(26)-C(21)-C(20)$ & 119.1(5) & $C(56)-C(51)-C(50)$ & $118.9(6)$ \\
\hline$C(21)-C(22)-C(23)^{5}$ & $119.4(6)$ & $C(52)^{4}-C(51)-C(50)$ & $120.3(7)$ \\
\hline$C(22)^{6}-C(23)-C(24)$ & $120.4(7)$ & $C(53)-C(52)-C(51)^{3}$ & $119.8(8)$ \\
\hline $\mathrm{C}(22)^{6}-\mathrm{C}(23)-\mathrm{Cl}(2)^{2}$ & $126.5(7)$ & $C(52)-C(53)-C(54)$ & $121.1(7)$ \\
\hline $\mathrm{C}(24)-\mathrm{C}(23)-\mathrm{Cl}(2)^{2}$ & $111.2(6)$ & $\mathrm{C}(52)-\mathrm{C}(53)-\mathrm{Cl}(5)$ & $119.3(7)$ \\
\hline $\mathrm{C}(22)^{6}-\mathrm{C}(23)-\mathrm{Cl}\left(2^{\prime}\right)^{2}$ & $116.7(7)$ & $\mathrm{C}(54)-\mathrm{C}(53)-\mathrm{Cl}(5)$ & $119.5(6)$ \\
\hline $\mathrm{C}(24)-\mathrm{C}(23)-\mathrm{Cl}\left(2^{\prime}\right)^{2}$ & $122.6(6)$ & $C(55)^{3}-C(54)-C(53)$ & $117.9(8)$ \\
\hline $\mathrm{Cl}(2)^{2}-\mathrm{C}(23)-\mathrm{Cl}\left(2^{\prime}\right)^{2}$ & $21.7(6)$ & $C(54)^{4}-C(55)-C(56)$ & $122.3(10)$ \\
\hline$C(25)-C(24)-C(23)$ & $119.9(6)$ & $C(51)-C(56)-C(55)$ & $118.1(7)$ \\
\hline$C(24)-C(25)-C(26)^{6}$ & 119.2(6) & $\mathrm{ON} 3^{1}-\mathrm{N}(1)-\mathrm{ON} 1$ & $120.8(8)$ \\
\hline$C(21)-C(26)-C(25)^{5}$ & $119.6(6)$ & $\mathrm{ON} 3^{1}-\mathrm{N}(1)-\mathrm{ON} 2^{1}$ & $122.3(9)$ \\
\hline $\mathrm{O}(32)-\mathrm{C}(60)-\mathrm{O}(24)$ & $124.8(5)$ & ON1-N(1)-ON2 ${ }^{1}$ & $116.8(9)$ \\
\hline $\mathrm{O}(32)-\mathrm{C}(60)-\mathrm{C}(61)$ & $117.2(5)$ & & \\
\hline
\end{tabular}

Symmetry transformations used to generate equivalent atoms:

${ }^{1} \mathrm{x}-1 / 2,-\mathrm{y}, \mathrm{z} ; \quad{ }^{2} \mathrm{x}+1 / 2,-\mathrm{y}, \mathrm{z} ; \quad{ }^{3} \mathrm{x}+1 / 2,-\mathrm{y}+1, \mathrm{z}$; 


$$
\begin{array}{lll}
{ }^{4} \mathrm{x}-1 / 2,-\mathrm{y}+1, \mathrm{z} ; & { }^{5} \mathrm{x}, \mathrm{y}+1, \mathrm{z} ; & { }^{6} \mathrm{x}, \mathrm{y}-1, \mathrm{z} ; \\
{ }^{7} \mathrm{x}+1,-\mathrm{y}, \mathrm{z}-1 / 2 ; & { }^{8}-\mathrm{x}+1,-\mathrm{y}, \mathrm{z}+1 / 2 . &
\end{array}
$$

\subsection{3 $\left[\mathrm{Cr}_{3} \mathrm{O}\left(\mathrm{O}_{2} \mathrm{CC}_{6} \mathrm{H}_{4}-3-\mathrm{Cl}\right)_{6}\left(\mathrm{H}_{2} \mathrm{O}\right)_{3}\right] \mathrm{NO}_{3} \cdot \mathrm{MeOH}$}

\subsubsection{Crystal data and structure refinement.}

Empirical formula

Formula weight

Temperature

Wavelength

Crystal system, space group

Unit cell dimensions

Volume

Z

Calculated density

Absorption coefficient

$\mathrm{F}(000)$

Crystal size

Theta range for data collection

Limiting indices

Reflections collected / unique

Completeness to theta $=28.24$

Absorption correction

Refinement method

Data / restraints / parameters

Goodness-of-fit on $F^{2}$

Final $R$ indices $[\mathrm{I}>2 \sigma(\mathrm{I})]$

$R$ indices (all data)

Largest diff. peak and hole
C43 H34 Cl6 Cr3 N O20

1253.41

273(2) K

$0.71073 \AA$

Orthorhombic, Pbca

$\mathrm{a}=21.1426(8) \AA \quad \alpha=90^{\circ}$

$\mathrm{b}=21.6319(9) \AA \quad \beta=90^{\circ}$

$\mathrm{c}=21.9931(8) \AA \quad \gamma=90^{\circ}$

10058.6(7) $\AA^{3}$

4

$0.828 \mathrm{Mg} / \mathrm{m}^{3}$

$0.517 \mathrm{~mm}^{-1}$

2532

$0.45 \times 0.45 \times 0.12 \mathrm{~mm}$

1.63 to $28.24^{\circ}$

$-28 \leq h \leq 28,-28 \leq k \leq 28,-29 \leq l \leq 29$

$141999 / 12335[\mathrm{R}(\mathrm{int})=0.0846]$

$99.2 \%$

None

Full-matrix least-squares on $F^{2}$

$12335 / 0 / 715$

1.133

$R_{1}=0.0839, w R_{2}=0.2294$

$R_{1}=0.1248, w R_{2}=0.2742$

4.801 and -1.687 e. $\AA^{-3}$ 


\subsubsection{Atomic coordinates $\left(\times 10^{4}\right)$ and equivalent isotropic displacement parameters $\left(\AA^{2} \times 10^{3}\right)$}

$\mathrm{U}_{\mathrm{eq}}$ is defined as one third of the trace of the orthogonalized $\mathrm{U}_{\mathrm{ij}}$ tensor.

Atom Label

$\mathrm{y}$

Z

$\mathrm{U}_{\text {eq }}$

\begin{tabular}{|c|c|c|c|c|}
\hline $\operatorname{Cr}(1)$ & $8329(1)$ & $7816(1)$ & 2271(1) & $22(1)$ \\
\hline $\operatorname{Cr}(2)$ & $8330(1)$ & $8019(1)$ & $772(1)$ & $24(1)$ \\
\hline $\operatorname{Cr}(3)$ & $9493(1)$ & $7253(1)$ & $1448(1)$ & $25(1)$ \\
\hline $\mathrm{Cl}(1)$ & $6841(1)$ & $5960(1)$ & $3048(1)$ & $51(1)$ \\
\hline $\mathrm{Cl}(2)$ & 10044(1) & $7066(1)$ & $-428(1)$ & $51(1)$ \\
\hline $\mathrm{Cl}(3)$ & $8060(2)$ & $9715(1)$ & $-669(1)$ & $40(1)$ \\
\hline $\mathrm{Cl}\left(3^{\prime}\right)$ & $9812(4)$ & $9657(3)$ & $1762(3)$ & $98(2)$ \\
\hline $\mathrm{Cl}(4)$ & $10002(3)$ & $5004(3)$ & 1092(3) & $213(4)$ \\
\hline $\mathrm{Cl}(5)$ & $11114(5)$ & $5596(1)$ & $19(2)$ & $280(5)$ \\
\hline $\mathrm{Cl}(6)$ & $7035(1)$ & $6469(1)$ & $59(1)$ & $62(1)$ \\
\hline $\mathrm{O}(1)$ & $8714(2)$ & $7694(2)$ & $1496(2)$ & $24(1)$ \\
\hline $\mathrm{O}(11)$ & $8115(2)$ & $8694(2)$ & $2116(2)$ & $41(1)$ \\
\hline $\mathrm{O}(12)$ & $7485(2)$ & $7539(2)$ & 1993(2) & $28(1)$ \\
\hline $\mathrm{O}(13)$ & $8480(2)$ & 6981(2) & $2612(2)$ & $28(1)$ \\
\hline $\mathrm{O}(14)$ & $9124(2)$ & $8130(2)$ & $2649(2)$ & $37(1)$ \\
\hline $\mathrm{O}(21)$ & $8120(2)$ & $8845(2)$ & $1106(2)$ & $32(1)$ \\
\hline $\mathrm{O}(22)$ & $7474(2)$ & $7737(2)$ & $989(2)$ & $33(1)$ \\
\hline $\mathrm{O}(23)$ & $8472(2)$ & $7251(2)$ & $300(2)$ & $33(1)$ \\
\hline $\mathrm{O}(24)$ & $9107(2)$ & $8403(2)$ & $450(2)$ & $35(1)$ \\
\hline $\mathrm{O}(31)$ & $9187(2)$ & $6684(2)$ & $808(2)$ & $35(1)$ \\
\hline $\mathrm{O}(32)$ & $9875(2)$ & $7819(2)$ & $857(2)$ & $37(1)$ \\
\hline $\mathrm{O}(33)$ & $9282(2)$ & $6608(2)$ & $2055(2)$ & $34(1)$ \\
\hline $\mathrm{O}(34)$ & $9909(2)$ & $7763(2)$ & $2069(2)$ & $36(1)$ \\
\hline OW1 & $7886(2)$ & $7985(2)$ & $3085(2)$ & $34(1)$ \\
\hline OW3 & $10355(2)$ & $6792(2)$ & $1388(2)$ & $37(1)$ \\
\hline OW2 & $7912(2)$ & $8350(2)$ & $-6(2)$ & $35(1)$ \\
\hline ON1 & $7447(2)$ & $7762(2)$ & $-1002(2)$ & $36(1)$ \\
\hline
\end{tabular}




\begin{tabular}{|c|c|c|c|c|}
\hline ON2 & $11541(3)$ & $7468(3)$ & $1425(3)$ & $59(1)$ \\
\hline ON3 & $11570(3)$ & $6858(4)$ & $667(3)$ & $77(2)$ \\
\hline$C(10)$ & $8059(3)$ & $9023(3)$ & $1644(3)$ & $30(1)$ \\
\hline$C(11)$ & $7887(3)$ & $9698(2)$ & $1748(3)$ & $30(1)$ \\
\hline$C(12)$ & $8076(3)$ & $9977(3)$ & $2288(3)$ & $34(1)$ \\
\hline$C(13)$ & $7090(3)$ & $5594(3)$ & $2383(3)$ & $34(1)$ \\
\hline$C(14)$ & $7444(3)$ & 5918(3) & $1960(3)$ & $35(1)$ \\
\hline$C(15)$ & $7633(3)$ & $5636(3)$ & $1422(3)$ & $35(1)$ \\
\hline$C(16)$ & $7551(3)$ & $10020(3)$ & $1305(3)$ & $32(1)$ \\
\hline$C(20)$ & $7213(2)$ & $7576(2)$ & $1479(2)$ & $24(1)$ \\
\hline$C(21)$ & $6516(2)$ & $7442(3)$ & $1457(2)$ & $26(1)$ \\
\hline$C(22)$ & $6158(3)$ & $7685(3)$ & $983(3)$ & $30(1)$ \\
\hline$C(23)$ & $10508(3)$ & $7567(3)$ & $4014(3)$ & $38(1)$ \\
\hline$C(24)$ & $10227(3)$ & $7196(3)$ & $3584(3)$ & $41(2)$ \\
\hline$C(25)$ & 10587(3) & $6946(3)$ & $3118(3)$ & $40(1)$ \\
\hline$C(26)$ & $6233(3)$ & $7079(3)$ & 1911(3) & $31(1)$ \\
\hline$C(30)$ & $8899(2)$ & $6581(2)$ & 2493(2) & $26(1)$ \\
\hline$C(31)$ & $8957(3)$ & $6023(3)$ & $2905(3)$ & $33(1)$ \\
\hline$C(32)$ & $8529(3)$ & $9049(3)$ & $-1607(3)$ & $37(1)$ \\
\hline$C(33)$ & $8591(4)$ & $9574(3)$ & $-1247(3)$ & $48(2)$ \\
\hline$C(34)$ & $9070(4)$ & $10002(3)$ & $-1339(4)$ & $53(2)$ \\
\hline$C(35)$ & $9501(4)$ & $9910(3)$ & $-1801(5)$ & $60(2)$ \\
\hline$C(36)$ & $9442(3)$ & $5599(3)$ & $2811(3)$ & $43(2)$ \\
\hline$C(40)$ & $9686(3)$ & $8116(3)$ & $2474(2)$ & $29(1)$ \\
\hline$C(41)$ & 10138(3) & $8559(3)$ & $2765(3)$ & $35(1)$ \\
\hline$C(42)$ & $9920(4)$ & $8975(4)$ & $3201(3)$ & $51(2)$ \\
\hline$C(43)$ & $9658(5)$ & 4404(4) & 1558(4) & $66(2)$ \\
\hline$C(44)$ & $10957(5)$ & $9426(4)$ & $3253(5)$ & $73(3)$ \\
\hline$C(45)$ & 11174(4) & $9012(4)$ & $2828(5)$ & $68(3)$ \\
\hline$C(46)$ & $10770(3)$ & $8569(3)$ & 2587(4) & $50(2)$ \\
\hline$C(50)$ & $8784(3)$ & $6767(3)$ & $391(2)$ & $28(1)$ \\
\hline$C(51)$ & $8682(3)$ & $6235(3)$ & $-34(3)$ & $34(1)$ \\
\hline$C(52)$ & $8838(6)$ & $5641(4)$ & $142(4)$ & $68(3)$ \\
\hline C(53) & $11310(9)$ & $4844(4)$ & $247(5)$ & $112(5)$ \\
\hline
\end{tabular}




$\begin{array}{lllll}\text { C(54) } & 8453(8) & 5261(5) & -805(4) & 104(5) \\ \text { C(55) } & 8323(5) & 5843(4) & -1003(4) & 66(2) \\ \text { C(56) } & 8412(4) & 6332(4) & -605(3) & 47(2) \\ \text { C(60) } & 9674(3) & 8252(3) & 521(2) & 29(1) \\ \text { C(61) } & 10170(3) & 8617(3) & 184(3) & 33(1) \\ \text { C(62) } & 10796(3) & 8439(3) & 225(3) & 37(1) \\ \text { C(63) } & 11247(3) & 8770(3) & -100(3) & 42(2) \\ \text { C(64) } & 11087(4) & 9266(4) & -461(4) & 57(2) \\ \text { C(65) } & 10466(4) & 9450(5) & -491(5) & 78(3) \\ \text { C(66) } & 9993(3) & 9115(4) & -175(4) & 56(2) \\ \text { OM1 } & 6886(6) & 6008(15) & -1987(18) & 810(40) \\ \text { CM1 } & 7250(20) & 5863(18) & -1310(17) & 410(30) \\ \text { N(1) } & 11851(3) & 7188(3) & 1029(3) & 40(1)\end{array}$

\subsubsection{Bond lengths $[\AA]$ and angles $\left[{ }^{\circ}\right]$.}

\section{Bond Lengths}

$\begin{array}{llll}\mathrm{Cr}(1)-\mathrm{O}(1) & 1.907(4) & \mathrm{Cr}(2)-\mathrm{O}(23) & 1.981(4) \\ \mathrm{Cr}(1)-\mathrm{O}(12) & 1.979(4) & \mathrm{Cr}(2)-\mathrm{O}(21) & 1.985(4) \\ \mathrm{Cr}(1)-\mathrm{O}(11) & 1.983(4) & \mathrm{Cr}(2)-\mathrm{O} 2 & 2.055(4) \\ \mathrm{Cr}(1)-\mathrm{O}(13) & 1.980(4) & \mathrm{Cl}(4)-\mathrm{C}(43) & 1.808(10) \\ \mathrm{Cr}(1)-\mathrm{O}(14) & 1.995(4) & \mathrm{Cl}\left(3^{\prime}\right)-\mathrm{C}(35)^{1} & 1.730(10) \\ \mathrm{Cr}(1)-\mathrm{OW} 1 & 2.053(4) & \mathrm{Cl}(3)-\mathrm{C}(33) & 1.724(8) \\ \mathrm{Cr}(3)-\mathrm{O}(1) & 1.907(4) & \mathrm{Cl}(2)-\mathrm{C}(23)^{2} & 1.760(6) \\ \mathrm{Cr}(3)-\mathrm{O}(32) & 1.958(4) & \mathrm{Cl}(1)-\mathrm{C}(13) & 1.745(6) \\ \mathrm{Cr}(3)-\mathrm{O}(34) & 1.963(4) & \mathrm{Cl}(6)-\mathrm{C}(63)^{3} & 1.746(7) \\ \mathrm{Cr}(3)-\mathrm{O}(31) & 1.977(4) & \mathrm{Cl}(5)-\mathrm{C}(53) & 1.752(11) \\ \mathrm{Cr}(3)-\mathrm{O}(33) & 1.983(4) & \mathrm{O}(14)-\mathrm{C}(40) & 1.249(7) \\ \mathrm{Cr}(3)-\mathrm{OW} 3 & 2.082(4) & \mathrm{O}(13)-\mathrm{C}(30) & 1.266(7) \\ \mathrm{Cr}(2)-\mathrm{O}(1) & 1.920(4) & \mathrm{O}(12)-\mathrm{C}(20) & 1.271(6) \\ \mathrm{Cr}(2)-\mathrm{O}(22) & 1.968(4) & \mathrm{O}(11)-\mathrm{C}(10) & 1.266(7) \\ \mathrm{Cr}(2)-\mathrm{O}(24) & 1.972(4) & \mathrm{O}(34)-\mathrm{C}(40) & 1.265(7)\end{array}$




\begin{tabular}{|c|c|c|c|}
\hline $\mathrm{O}(33)-\mathrm{C}(30)$ & $1.259(7)$ & $C(23)-C(24)$ & $1.376(10)$ \\
\hline $\mathrm{O}(31)-\mathrm{C}(50)$ & $1.266(7)$ & $C(23)-C(22)^{9}$ & $1.398(8)$ \\
\hline $\mathrm{O}(32)-\mathrm{C}(60)$ & $1.267(7)$ & $\mathrm{C}(23)-\mathrm{Cl}(2)^{7}$ & $1.760(6)$ \\
\hline $\mathrm{O}(23)-\mathrm{C}(50)$ & $1.255(7)$ & $C(24)-C(25)$ & $1.387(10)$ \\
\hline $\mathrm{O}(24)-\mathrm{C}(60)$ & $1.252(7)$ & $C(25)-C(26)^{9}$ & $1.396(8)$ \\
\hline $\mathrm{O}(22)-\mathrm{C}(20)$ & $1.261(6)$ & $C(26)-C(25)^{8}$ & $1.396(8)$ \\
\hline $\mathrm{O}(21)-\mathrm{C}(10)$ & $1.249(7)$ & $C(10)-C(11)$ & $1.521(8)$ \\
\hline ON1-N(1) ${ }^{3}$ & $1.267(7)$ & $\mathrm{C}(11)-\mathrm{C}(12)$ & $1.391(8)$ \\
\hline ON2-N(1) & $1.247(7)$ & $C(11)-C(16)$ & $1.393(8)$ \\
\hline ON3-N(1) & $1.223(8)$ & $C(12)-C(13)^{10}$ & $1.395(8)$ \\
\hline $\mathrm{N}(1)-\mathrm{ON} 1^{4}$ & $1.267(7)$ & $C(13)-C(14)$ & $1.385(9)$ \\
\hline$C(40)-C(41)$ & $1.498(8)$ & $C(13)-C(12)^{11}$ & $1.395(8)$ \\
\hline$C(41)-C(46)$ & $1.392(10)$ & $\mathrm{C}(14)-\mathrm{C}(15)$ & $1.391(10)$ \\
\hline C(41)-C(42) & $1.393(10)$ & $C(15)-C(16)^{11}$ & $1.411(8)$ \\
\hline$C(42)-C(43)^{5}$ & $1.393(10)$ & $C(16)-C(15)^{10}$ & $1.411(8)$ \\
\hline$C(43)-C(44)^{6}$ & $1.365(14)$ & $C(60)-C(61)$ & $1.506(8)$ \\
\hline$C(43)-C(42)^{6}$ & $1.393(10)$ & $C(61)-C(62)$ & $1.382(9)$ \\
\hline$C(44)-C(43)^{5}$ & $1.365(14)$ & $C(61)-C(66)$ & $1.388(10)$ \\
\hline$C(44)-C(45)$ & $1.374(14)$ & $C(62)-C(63)$ & $1.391(9)$ \\
\hline$C(45)-C(46)$ & $1.389(10)$ & $C(63)-C(64)$ & $1.377(11)$ \\
\hline C(30)-C(31) & $1.516(7)$ & $\mathrm{C}(63)-\mathrm{Cl}(6)^{4}$ & $1.746(7)$ \\
\hline$C(31)-C(36)$ & $1.391(9)$ & $C(64)-C(65)$ & $1.374(12)$ \\
\hline$C(31)-C(32)^{7}$ & $1.413(9)$ & $C(65)-C(66)$ & $1.417(10)$ \\
\hline C(32)-C(33) & $1.391(9)$ & $C(50)-C(51)$ & $1.497(7)$ \\
\hline$C(32)-C(31)^{2}$ & $1.413(9)$ & $C(51)-C(52)$ & $1.382(10)$ \\
\hline C(33)-C(34) & $1.386(11)$ & $C(51)-C(56)$ & $1.395(9)$ \\
\hline C(34)-C(35) & $1.379(12)$ & $C(52)-C(53)^{12}$ & $1.390(12)$ \\
\hline$C(35)-C(36)^{2}$ & $1.399(10)$ & $C(53)-C(54)^{12}$ & $1.344(15)$ \\
\hline $\mathrm{C}(35)-\mathrm{Cl}\left(3^{\prime}\right)^{1}$ & $1.730(10)$ & $C(53)-C(52)^{12}$ & $1.390(12)$ \\
\hline$C(36)-C(35)^{7}$ & $1.399(10)$ & $C(54)-C(53)^{12}$ & $1.344(15)$ \\
\hline$C(20)-C(21)$ & $1.502(7)$ & $C(54)-C(55)$ & $1.361(14)$ \\
\hline$C(21)-C(22)$ & $1.392(8)$ & $C(55)-C(56)$ & $1.386(10)$ \\
\hline$C(21)-C(26)$ & $1.405(8)$ & OM1-CM1 & $1.70(4)$ \\
\hline$C(22)-C(23)^{8}$ & $1.398(8)$ & & \\
\hline
\end{tabular}




\section{Bond Angles}

\begin{tabular}{|c|c|c|c|}
\hline $\mathrm{O}(1)-\mathrm{Cr}(1)-\mathrm{O}(12)$ & $93.84(15)$ & $\mathrm{O}(22)-\mathrm{Cr}(2)-\mathrm{O}(24)$ & $169.45(18)$ \\
\hline $\mathrm{O}(1)-\mathrm{Cr}(1)-\mathrm{O}(11)$ & $94.34(17)$ & $\mathrm{O}(1)-\mathrm{Cr}(2)-\mathrm{O}(23)$ & $93.70(16)$ \\
\hline $\mathrm{O}(12)-\mathrm{Cr}(1)-\mathrm{O}(11)$ & $91.74(19)$ & $\mathrm{O}(22)-\mathrm{Cr}(2)-\mathrm{O}(23)$ & $90.41(18)$ \\
\hline $\mathrm{O}(1)-\mathrm{Cr}(1)-\mathrm{O}(13)$ & $98.34(16)$ & $\mathrm{O}(24)-\mathrm{Cr}(2)-\mathrm{O}(23)$ & $92.29(18)$ \\
\hline $\mathrm{O}(12)-\mathrm{Cr}(1)-\mathrm{O}(13)$ & $89.26(16)$ & $\mathrm{O}(1)-\mathrm{Cr}(2)-\mathrm{O}(21)$ & $96.70(16)$ \\
\hline $\mathrm{O}(11)-\mathrm{Cr}(1)-\mathrm{O}(13)$ & $167.19(17)$ & $\mathrm{O}(22)-\mathrm{Cr}(2)-\mathrm{O}(21)$ & 88.98(18) \\
\hline $\mathrm{O}(1)-\mathrm{Cr}(1)-\mathrm{O}(14)$ & $93.46(16)$ & $\mathrm{O}(24)-\mathrm{Cr}(2)-\mathrm{O}(21)$ & $86.53(18)$ \\
\hline $\mathrm{O}(12)-\mathrm{Cr}(1)-\mathrm{O}(14)$ & $172.58(17)$ & $\mathrm{O}(23)-\mathrm{Cr}(2)-\mathrm{O}(21)$ & $169.60(17)$ \\
\hline $\mathrm{O}(11)-\mathrm{Cr}(1)-\mathrm{O}(14)$ & $86.4(2)$ & $\mathrm{O}(1)-\mathrm{Cr}(2)-\mathrm{OW} 2$ & $178.95(17)$ \\
\hline $\mathrm{O}(13)-\mathrm{Cr}(1)-\mathrm{O}(14)$ & $91.00(18)$ & $\mathrm{O}(22)-\mathrm{Cr}(2)-\mathrm{OW} 2$ & $85.09(17)$ \\
\hline $\mathrm{O}(1)-\mathrm{Cr}(1)-\mathrm{OW} 1$ & $176.80(18)$ & $\mathrm{O}(24)-\mathrm{Cr}(2)-\mathrm{OW} 2$ & $84.96(17)$ \\
\hline $\mathrm{O}(12)-\mathrm{Cr}(1)-\mathrm{OW} 1$ & $84.87(17)$ & $\mathrm{O}(23)-\mathrm{Cr}(2)-\mathrm{OW} 2$ & $85.47(17)$ \\
\hline $\mathrm{O}(11)-\mathrm{Cr}(1)-\mathrm{OW} 1$ & $82.78(19)$ & $\mathrm{O}(21)-\mathrm{Cr}(2)-\mathrm{OW} 2$ & $84.14(17)$ \\
\hline $\mathrm{O}(13)-\mathrm{Cr}(1)-\mathrm{OW} 1$ & $84.59(18)$ & $\mathrm{Cr}(3)-\mathrm{O}(1)-\mathrm{Cr}(1)$ & 119.14(19) \\
\hline $\mathrm{O}(14)-\mathrm{Cr}(1)-\mathrm{OW} 1$ & $87.77(18)$ & $\mathrm{Cr}(3)-\mathrm{O}(1)-\mathrm{Cr}(2)$ & $120.11(18)$ \\
\hline $\mathrm{O}(1)-\mathrm{Cr}(3)-\mathrm{O}(32)$ & $94.60(17)$ & $\mathrm{Cr}(1)-\mathrm{O}(1)-\mathrm{Cr}(2)$ & $120.7(2)$ \\
\hline $\mathrm{O}(1)-\mathrm{Cr}(3)-\mathrm{O}(34)$ & $93.86(17)$ & $\mathrm{C}(40)-\mathrm{O}(14)-\mathrm{Cr}(1)$ & $131.6(4)$ \\
\hline $\mathrm{O}(32)-\mathrm{Cr}(3)-\mathrm{O}(34)$ & $85.8(2)$ & $\mathrm{C}(30)-\mathrm{O}(13)-\mathrm{Cr}(1)$ & 131.0(3) \\
\hline $\mathrm{O}(1)-\mathrm{Cr}(3)-\mathrm{O}(31)$ & $93.93(17)$ & $\mathrm{C}(20)-\mathrm{O}(12)-\mathrm{Cr}(1)$ & $131.6(3)$ \\
\hline $\mathrm{O}(32)-\mathrm{Cr}(3)-\mathrm{O}(31)$ & 93.01(19) & $\mathrm{C}(10)-\mathrm{O}(11)-\mathrm{Cr}(1)$ & $134.6(4)$ \\
\hline $\mathrm{O}(34)-\mathrm{Cr}(3)-\mathrm{O}(31)$ & $172.20(18)$ & $\mathrm{C}(40)-\mathrm{O}(34)-\mathrm{Cr}(3)$ & $131.5(4)$ \\
\hline $\mathrm{O}(1)-\mathrm{Cr}(3)-\mathrm{O}(33)$ & $96.87(16)$ & $\mathrm{C}(30)-\mathrm{O}(33)-\mathrm{Cr}(3)$ & $133.8(4)$ \\
\hline $\mathrm{O}(32)-\mathrm{Cr}(3)-\mathrm{O}(33)$ & 168.37(18) & $\mathrm{C}(50)-\mathrm{O}(31)-\mathrm{Cr}(3)$ & $130.4(4)$ \\
\hline $\mathrm{O}(34)-\mathrm{Cr}(3)-\mathrm{O}(33)$ & $91.53(19)$ & $\mathrm{C}(60)-\mathrm{O}(32)-\mathrm{Cr}(3)$ & $135.4(4)$ \\
\hline $\mathrm{O}(31)-\mathrm{Cr}(3)-\mathrm{O}(33)$ & $88.12(19)$ & $\mathrm{C}(50)-\mathrm{O}(23)-\mathrm{Cr}(2)$ & 134.1(4) \\
\hline $\mathrm{O}(1)-\mathrm{Cr}(3)-\mathrm{OW} 3$ & $178.58(17)$ & $\mathrm{C}(60)-\mathrm{O}(24)-\mathrm{Cr}(2)$ & $130.0(4)$ \\
\hline $\mathrm{O}(32)-\mathrm{Cr}(3)-\mathrm{OW} 3$ & 84.11(18) & $\mathrm{C}(20)-\mathrm{O}(22)-\mathrm{Cr}(2)$ & 134.1(4) \\
\hline $\mathrm{O}(34)-\mathrm{Cr}(3)-\mathrm{OW} 3$ & $85.45(18)$ & $\mathrm{C}(10)-\mathrm{O}(21)-\mathrm{Cr}(2)$ & $130.6(4)$ \\
\hline $\mathrm{O}(31)-\mathrm{Cr}(3)-\mathrm{OW} 3$ & $86.75(18)$ & ON3-N(1)-ON2 & $118.8(6)$ \\
\hline $\mathrm{O}(33)-\mathrm{Cr}(3)-\mathrm{OW} 3$ & $84.39(17)$ & ON3-N(1)-ON1 ${ }^{4}$ & $120.3(6)$ \\
\hline $\mathrm{O}(1)-\mathrm{Cr}(2)-\mathrm{O}(22)$ & $94.29(16)$ & $\mathrm{ON} 2-\mathrm{N}(1)-\mathrm{ON} 1^{4}$ & $120.9(6)$ \\
\hline $\mathrm{O}(1)-\mathrm{Cr}(2)-\mathrm{O}(24)$ & $95.71(17)$ & $\mathrm{O}(14)-\mathrm{C}(40)-\mathrm{O}(34)$ & $125.9(5)$ \\
\hline
\end{tabular}




\begin{tabular}{|c|c|c|c|}
\hline $\mathrm{O}(14)-\mathrm{C}(40)-\mathrm{C}(41)$ & $117.4(5)$ & $C(24)-C(23)-C(22)^{9}$ & $122.3(6)$ \\
\hline $\mathrm{O}(34)-\mathrm{C}(40)-\mathrm{C}(41)$ & $116.7(5)$ & $\mathrm{C}(24)-\mathrm{C}(23)-\mathrm{Cl}(2)^{7}$ & $120.1(5)$ \\
\hline$C(46)-C(41)-C(42)$ & $120.1(6)$ & $\mathrm{C}(22) 9-\mathrm{C}(23)-\mathrm{Cl}(2)^{7}$ & $117.5(5)$ \\
\hline$C(46)-C(41)-C(40)$ & $120.2(6)$ & $C(23)-C(24)-C(25)$ & $119.9(6)$ \\
\hline$C(42)-C(41)-C(40)$ & 119.7(6) & $C(24)-C(25)-C(26)^{9}$ & $119.4(6)$ \\
\hline$C(41)-C(42)-C(43)^{5}$ & 118.6(8) & $C(25)^{8}-C(26)-C(21)$ & $119.9(6)$ \\
\hline $\mathrm{C}(44)^{6}-\mathrm{C}(43)-\mathrm{C}(42)^{6}$ & $121.2(8)$ & $\mathrm{O}(21)-\mathrm{C}(10)-\mathrm{O}(11)$ & $126.4(5)$ \\
\hline $\mathrm{C}(44)^{6}-\mathrm{C}(43)-\mathrm{Cl}(4)$ & $122.1(6)$ & $\mathrm{O}(21)-\mathrm{C}(10)-\mathrm{C}(11)$ & $117.5(5)$ \\
\hline $\mathrm{C}(42)^{6}-\mathrm{C}(43)-\mathrm{Cl}(4)$ & $115.8(7)$ & $\mathrm{O}(11)-\mathrm{C}(10)-\mathrm{C}(11)$ & $116.0(5)$ \\
\hline$C(43)^{5}-C(44)-C(45)$ & $120.2(7)$ & $C(12)-C(11)-C(16)$ & $121.7(5)$ \\
\hline$C(44)-C(45)-C(46)$ & $120.2(8)$ & $C(12)-C(11)-C(10)$ & $118.5(5)$ \\
\hline$C(41)-C(46)-C(45)$ & $119.6(7)$ & $C(16)-C(11)-C(10)$ & $119.8(5)$ \\
\hline $\mathrm{O}(13)-\mathrm{C}(30)-\mathrm{O}(33)$ & $125.3(5)$ & $C(11)-C(12)-C(13)^{10}$ & $118.1(6)$ \\
\hline $\mathrm{O}(13)-\mathrm{C}(30)-\mathrm{C}(31)$ & $118.5(5)$ & $C(14)-C(13)-C(12)^{11}$ & $121.3(6)$ \\
\hline $\mathrm{O}(33)-\mathrm{C}(30)-\mathrm{C}(31)$ & $116.2(5)$ & $\mathrm{C}(14)-\mathrm{C}(13)-\mathrm{Cl}(1)$ & $119.7(5)$ \\
\hline$C(36)-C(31)-C(32)^{7}$ & $120.9(6)$ & $\mathrm{C}(12)^{11}-\mathrm{C}(13)-\mathrm{Cl}(1)$ & $119.0(5)$ \\
\hline$C(36)-C(31)-C(30)$ & 119.7(6) & $C(13)-C(14)-C(15)$ & $120.3(6)$ \\
\hline$C(32)^{7}-C(31)-C(30)$ & $119.4(5)$ & $C(14)-C(15)-C(16)^{11}$ & $119.4(6)$ \\
\hline$C(33)-C(32)-C(31)^{2}$ & $117.5(6)$ & $C(11)-C(16)-C(15)^{10}$ & $119.1(6)$ \\
\hline C(34)-C(33)-C(32) & $122.1(7)$ & $\mathrm{O}(24)-\mathrm{C}(60)-\mathrm{O}(32)$ & $125.8(5)$ \\
\hline $\mathrm{C}(34)-\mathrm{C}(33)-\mathrm{Cl}(3)$ & $117.8(5)$ & $\mathrm{O}(24)-\mathrm{C}(60)-\mathrm{C}(61)$ & $118.0(5)$ \\
\hline $\mathrm{C}(32)-\mathrm{C}(33)-\mathrm{Cl}(3)$ & $120.1(6)$ & $\mathrm{O}(32)-\mathrm{C}(60)-\mathrm{C}(61)$ & $116.2(5)$ \\
\hline$C(35)-C(34)-C(33)$ & $119.6(6)$ & $C(62)-C(61)-C(66)$ & $120.8(6)$ \\
\hline$C(34)-C(35)-C(36)^{2}$ & $120.3(7)$ & $C(62)-C(61)-C(60)$ & $119.3(6)$ \\
\hline $\mathrm{C}(34)-\mathrm{C}(35)-\mathrm{Cl}\left(3^{\prime}\right)^{1}$ & 116.1(6) & $C(66)-C(61)-C(60)$ & $120.0(6)$ \\
\hline $\mathrm{C}(36)^{2}-\mathrm{C}(35)-\mathrm{Cl}\left(3^{\prime}\right)^{1}$ & $122.1(7)$ & $\mathrm{C}(61)-\mathrm{C}(62)-\mathrm{C}(63)$ & $118.7(6)$ \\
\hline$C(35)^{7}-C(36)-C(31)$ & $119.6(7)$ & $C(64)-C(63)-C(62)$ & $121.9(6)$ \\
\hline $\mathrm{O}(22)-\mathrm{C}(20)-\mathrm{O}(12)$ & $125.5(5)$ & $\mathrm{C}(64)-\mathrm{C}(63)-\mathrm{Cl}(6)^{4}$ & $119.7(5)$ \\
\hline $\mathrm{O}(22)-\mathrm{C}(20)-\mathrm{C}(21)$ & $117.0(5)$ & $\mathrm{C}(62)-\mathrm{C}(63)-\mathrm{Cl}(6)^{4}$ & $118.4(5)$ \\
\hline $\mathrm{O}(12)-\mathrm{C}(20)-\mathrm{C}(21)$ & $117.5(5)$ & $C(65)-C(64)-C(63)$ & $119.3(7)$ \\
\hline$C(22)-C(21)-C(26)$ & $120.8(5)$ & $C(64)-C(65)-C(66)$ & $120.1(8)$ \\
\hline$C(22)-C(21)-C(20)$ & $119.0(5)$ & $C(61)-C(66)-C(65)$ & $119.1(7)$ \\
\hline$C(26)-C(21)-C(20)$ & $120.2(5)$ & $\mathrm{O}(23)-\mathrm{C}(50)-\mathrm{O}(31)$ & $126.0(5)$ \\
\hline$C(21)-C(22)-C(23)^{8}$ & $117.5(6)$ & $\mathrm{O}(23)-\mathrm{C}(50)-\mathrm{C}(51)$ & $117.8(5)$ \\
\hline
\end{tabular}




$\begin{array}{llll}\mathrm{O}(31)-\mathrm{C}(50)-\mathrm{C}(51) & 116.2(5) & \mathrm{C}(54)^{12}-\mathrm{C}(53)-\mathrm{Cl}(5) & 120.4(7) \\ \mathrm{C}(52)-\mathrm{C}(51)-\mathrm{C}(56) & 119.4(6) & \mathrm{C}(52)^{12}-\mathrm{C}(53)-\mathrm{Cl}(5) & 118.1(8) \\ \mathrm{C}(52)-\mathrm{C}(51)-\mathrm{C}(50) & 120.3(6) & \mathrm{C}(53)^{12}-\mathrm{C}(54)-\mathrm{C}(55) & 121.5(8) \\ \mathrm{C}(56)-\mathrm{C}(51)-\mathrm{C}(50) & 120.3(6) & \mathrm{C}(54)-\mathrm{C}(55)-\mathrm{C}(56) & 118.5(8) \\ \mathrm{C}(51)-\mathrm{C}(52)-\mathrm{C}(53)^{12} & 118.3(8) & \mathrm{C}(51)-\mathrm{C}(56)-\mathrm{C}(55) & 120.6(7) \\ \mathrm{C}(54)^{12}-\mathrm{C}(53)-\mathrm{C}(52)^{12} & 121.3(9) & & \end{array}$

Symmetry transformations used to generate equivalent atoms:
${ }^{1}-\mathrm{x}+2,-\mathrm{y}+2,-\mathrm{z}$;
${ }^{2} \mathrm{x},-\mathrm{y}+3 / 2, \mathrm{z}-1 / 2$
${ }^{3} \mathrm{x}-1 / 2,-\mathrm{y}+3 / 2,-\mathrm{z}$;
${ }^{4} \mathrm{x}+1 / 2,-\mathrm{y}+3 / 2,-\mathrm{z}$
${ }^{5}-\mathrm{x}+2, \mathrm{y}+1 / 2,-\mathrm{z}+1 / 2$;
${ }^{6}-\mathrm{x}+2, \mathrm{y}-1 / 2,-\mathrm{z}+1 / 2$;
${ }^{7} \mathrm{x},-\mathrm{y}+3 / 2, \mathrm{z}+1 / 2$;
${ }^{8} \mathrm{x}-1 / 2, \mathrm{y},-\mathrm{z}+1 / 2$;
${ }^{9} \mathrm{x}+1 / 2, \mathrm{y},-\mathrm{z}+1 / 2$
${ }^{10}-x+3 / 2, y+1 / 2, z ;$
${ }^{11}-\mathrm{x}+3 / 2, \mathrm{y}-1 / 2, \mathrm{z}$;
$12-x+2,-y+1,-z$.

\subsection{4 $\left[\mathrm{Fe}_{6} \mathrm{O}_{2}(\mathrm{OH})_{2}\left(\mathrm{O}_{2} \mathrm{CC}_{6} \mathrm{H}_{4}-3-\mathrm{Cl}\right)_{12}\left(\mathrm{H}_{2} \mathrm{O}\right)_{2}\right] 3 \mathrm{MeCN}$}

\subsubsection{Crystal data and structure refinement.}

Empirical formula

Formula weight

Temperature

Wavelength

Crystal system, space group

Unit cell dimensions

Volume

Z

Calculated density

Absorption coefficient

$\mathrm{F}(000)$

Crystal size

Theta range for data collection

Limiting indices

Reflections collected / unique
C90 H63 Cl12 Fe6 N3 O30

1265.61

273(2) K

$0.71073 \AA$

Orthorhombic, Pca2 1

$\mathrm{a}=30.1319(8) \AA \quad \alpha=90^{\circ}$

$\mathrm{b}=14.8342(4) \AA \quad \beta=115.3500(10)^{\circ}$

$\mathrm{c}=25.9512(6) \AA \quad \gamma=90^{\circ}$

10482.8(5) $\AA$ ^3

8

$1.604 \mathrm{Mg} / \mathrm{m}^{3}$

$1.981 \mathrm{~mm}^{-1}$

5029

$0.97 \times 0.65 \times 0.28 \mathrm{~mm}$

1.50 to $33.59^{\circ}$

$-46 \leq h \leq 45,-21 \leq k \leq 23,-38 \leq l \leq 40$

$106723 / 20502[R($ int $)=0.0382]$ 
Completeness to theta $=33.59 \quad 98.9 \%$

Absorption correction None

Refinement method Full-matrix least-squares on $F^{2}$

Data / restraints / parameters 20502/0/764

Goodness-of-fit on $F^{2} \quad 1.070$

Final $R$ indices $[I>2 \sigma(I)] \quad R_{1}=0.0546, w R_{2}=0.1502$

$R$ indices (all data) $\quad R_{1}=0.1002, w R_{2}=0.1950$

Largest diff. peak and hole $\quad 1.960$ and -1.085 e. $\AA^{-3}$

\subsubsection{Atomic coordinates $\left(\times 10^{4}\right)$ and equivalent isotropic displacement parameters $\left(\AA^{2} \times 10^{3}\right)$}

$\mathrm{U}_{\text {eq }}$ is defined as one third of the trace of the orthogonalized $\mathrm{U}_{\mathrm{ij}}$ tensor.

\begin{tabular}{|c|c|c|c|c|}
\hline Atom Label & $\mathrm{x}$ & $\mathrm{y}$ & z & $\mathrm{U}_{\mathrm{eq}}$ \\
\hline $\mathrm{Fe}(1)$ & 4881(1) & 2913(1) & $8366(1)$ & $23(1)$ \\
\hline $\mathrm{Fe}(2)$ & $3848(1)$ & 1781(1) & $8002(1)$ & $28(1)$ \\
\hline $\mathrm{Fe}(3)$ & $4072(1)$ & $2622(1)$ & $6962(1)$ & $29(1)$ \\
\hline $\mathrm{Cl}(1)$ & $6046(1)$ & $3899(1)$ & $11153(1)$ & $61(1)$ \\
\hline $\mathrm{Cl}\left(1^{\prime}\right)$ & $2304(2)$ & $3885(6)$ & 4333(3) & $148(4)$ \\
\hline $\mathrm{Cl}(2)$ & $3199(1)$ & $1296(1)$ & $4970(1)$ & $32(1)$ \\
\hline $\mathrm{Cl}\left(2^{\prime}\right)$ & $3654(1)$ & $1876(6)$ & $3059(2)$ & 203(4) \\
\hline $\mathrm{Cl}(3)$ & 2292(4) & $2818(6)$ & $8369(3)$ & $183(5)$ \\
\hline $\mathrm{Cl}\left(3^{\prime}\right)$ & $2473(3)$ & $3012(5)$ & $8425(2)$ & $115(3)$ \\
\hline $\mathrm{Cl}(4)$ & $5195(1)$ & $2074(1)$ & $10299(1)$ & $56(1)$ \\
\hline $\mathrm{Cl}(5)$ & $1909(4)$ & $-1454(7)$ & $5016(4)$ & $97(3)$ \\
\hline $\mathrm{Cl}\left(5^{\prime}\right)$ & $1736(4)$ & $-1523(8)$ & $4809(4)$ & $100(3)$ \\
\hline $\mathrm{Cl}(6)$ & $5121(4)$ & 2492(4) & $11525(2)$ & $117(2)$ \\
\hline $\mathrm{Cl}\left(6^{\prime}\right)$ & $5194(5)$ & 2278(4) & $11713(2)$ & $138(3)$ \\
\hline $\mathrm{O}(1)$ & $4270(1)$ & 2431(1) & $7777(1)$ & $26(1)$ \\
\hline $\mathrm{O}(2)$ & $5290(1)$ & $2371(2)$ & $8026(1)$ & $35(1)$ \\
\hline $\mathrm{O}(11)$ & $5503(1)$ & $3446(1)$ & 8974(1) & $30(1)$ \\
\hline $\mathrm{O}(12)$ & $4772(1)$ & $4121(2)$ & $7969(1)$ & $41(1)$ \\
\hline
\end{tabular}




\begin{tabular}{|c|c|c|c|c|}
\hline $\mathrm{O}(13)$ & $4558(1)$ & $3461(2)$ & $8843(1)$ & $34(1)$ \\
\hline $\mathrm{O}(14)$ & $5028(1)$ & 1812(1) & $8872(1)$ & $32(1)$ \\
\hline $\mathrm{O}(21)$ & $3644(1)$ & $837(2)$ & 7388(1) & $42(1)$ \\
\hline $\mathrm{O}(22)$ & $3206(1)$ & $2427(2)$ & $7513(1)$ & $40(1)$ \\
\hline $\mathrm{O}(23)$ & $3912(1)$ & $2561(2)$ & $8670(1)$ & $35(1)$ \\
\hline $\mathrm{O}(24)$ & $4356(1)$ & $943(2)$ & $8536(1)$ & $37(1)$ \\
\hline $\mathrm{O}(31)$ & $3830(1)$ & $2937(2)$ & $6118(1)$ & $39(1)$ \\
\hline $\mathrm{O}(32)$ & $4170(1)$ & $3955(2)$ & $7093(1)$ & $40(1)$ \\
\hline $\mathrm{O}(33)$ & $3892(1)$ & $1306(2)$ & $6739(1)$ & $54(1)$ \\
\hline $\mathrm{O}(34)$ & $3359(1)$ & $2806(3)$ & $6775(1)$ & $62(1)$ \\
\hline OW1 & $3388(1)$ & $1014(2)$ & $8260(1)$ & $43(1)$ \\
\hline$C(10)$ & 4044(1) & $3281(2)$ & $5842(1)$ & $28(1)$ \\
\hline $\mathrm{C}(11)$ & $3728(1)$ & $3536(2)$ & $5237(1)$ & $30(1)$ \\
\hline$C(12)$ & 3944(1) & $3625(2)$ & $4862(1)$ & $37(1)$ \\
\hline$C(13)$ & $6339(2)$ & $3857(3)$ & 10697(1) & $49(1)$ \\
\hline$C(14)$ & $3169(2)$ & 4037(3) & $4110(1)$ & $58(1)$ \\
\hline$C(15)$ & 2954(1) & $3960(3)$ & $4484(2)$ & $56(1)$ \\
\hline$C(16)$ & $3231(1)$ & $3691(3)$ & $5048(1)$ & $44(1)$ \\
\hline$C(20)$ & $3079(1)$ & $2709(2)$ & 7011(1) & $34(1)$ \\
\hline$C(21)$ & 2447(1) & $2042(2)$ & $3341(1)$ & $31(1)$ \\
\hline$C(22)$ & 2587(1) & 1816(2) & $3909(1)$ & $37(1)$ \\
\hline$C(23)$ & $3066(1)$ & $1570(3)$ & $4248(1)$ & $46(1)$ \\
\hline$C(24)$ & $3411(1)$ & $1555(3)$ & $4029(2)$ & $57(1)$ \\
\hline$C(25)$ & $3269(1)$ & 1785(3) & $3461(2)$ & $57(1)$ \\
\hline$C(26)$ & 2786(1) & $2034(3)$ & $3116(2)$ & $45(1)$ \\
\hline$C(30)$ & $3695(1)$ & $749(2)$ & 6936(1) & $38(1)$ \\
\hline$C(31)$ & $3495(1)$ & $-89(3)$ & 6601(1) & $47(1)$ \\
\hline$C(32)$ & $3194(2)$ & $-640(3)$ & $6753(2)$ & $66(1)$ \\
\hline C(33) & 2988(3) & $-1395(4)$ & $6420(2)$ & $90(2)$ \\
\hline$C(34)$ & $3086(3)$ & $-1618(4)$ & $5960(2)$ & $87(2)$ \\
\hline$C(35)$ & $3388(2)$ & $-1079(3)$ & $5821(2)$ & $71(1)$ \\
\hline$C(36)$ & $3587(2)$ & $-300(3)$ & $6135(2)$ & $56(1)$ \\
\hline$C(40)$ & 4804(1) & $1089(2)$ & $8854(1)$ & $29(1)$ \\
\hline$C(41)$ & 5084(1) & $339(2)$ & $9240(1)$ & $32(1)$ \\
\hline
\end{tabular}




\begin{tabular}{lllll} 
C(42) & $5155(1)$ & $437(2)$ & $10728(1)$ & $35(1)$ \\
C(43) & $4890(1)$ & $1116(2)$ & $10360(1)$ & $40(1)$ \\
C(44) & $4390(1)$ & $1039(3)$ & $10031(1)$ & $45(1)$ \\
C(45) & $4154(1)$ & $-264(3)$ & $5070(1)$ & $44(1)$ \\
C(46) & $5587(1)$ & $431(2)$ & $9568(1)$ & $38(1)$ \\
C(50) & $4215(1)$ & $3166(2)$ & $8949(1)$ & $29(1)$ \\
C(51) & $4161(1)$ & $3557(2)$ & $9451(1)$ & $34(1)$ \\
C(52) & $3744(2)$ & $3363(2)$ & $9525(2)$ & $48(1)$ \\
C(53) & $1288(2)$ & $-1280(3)$ & $4997(2)$ & $73(2)$ \\
C(54) & $4085(3)$ & $4229(3)$ & $10403(2)$ & $84(2)$ \\
C(55) & $4493(2)$ & $4410(3)$ & $10321(2)$ & $67(1)$ \\
C(56) & $4535(2)$ & $4079(2)$ & $9842(1)$ & $46(1)$ \\
C(60) & $4453(1)$ & $4416(2)$ & $7509(1)$ & $34(1)$ \\
C(61) & $4398(1)$ & $5420(2)$ & $7440(2)$ & $46(1)$ \\
C(62) & $4624(2)$ & $5977(3)$ & $7896(2)$ & $62(1)$ \\
C(63) & $4558(3)$ & $6917(4)$ & $7811(3)$ & $91(2)$ \\
C(64) & $4279(3)$ & $7259(4)$ & $7273(3)$ & $104(2)$ \\
C(65) & $4054(3)$ & $6715(4)$ & $6831(3)$ & $93(2)$ \\
C(66) & $4109(2)$ & $5783(3)$ & $6905(2)$ & $64(1)$ \\
CA11 & $7067(2)$ & $4957(3)$ & $12375(2)$ & $65(1)$ \\
CA12 & $6622(2)$ & $5482(6)$ & $12158(4)$ & $75(3)$ \\
CA21 & $2692(2)$ & $796(3)$ & $9068(2)$ & $60(1)$ \\
CA22 & $2204(2)$ & $434(4)$ & $8921(4)$ & $100(2)$ \\
CA31 & 5000 & $37(4)$ & 7500 & $60(2)$ \\
CA32 & $4924(6)$ & $-277(10)$ & $7005(4)$ & $92(4)$ \\
NA11 & $2427(1)$ & $409(3)$ & $7547(2)$ & $72(1)$ \\
NA21 & $3059(2)$ & $1088(3)$ & $9165(2)$ & $71(1)$ \\
NA31 & $4832(3)$ & $341(6)$ & $6997(4)$ & $62(2)$ \\
\hline
\end{tabular}




\subsubsection{Bond lengths $[\AA ̊]$ and angles $\left[^{\circ}\right]$.}

\section{Bond Lengths}

\begin{tabular}{|c|c|c|c|}
\hline $\mathrm{Fe}(1)-\mathrm{O}(1)$ & $1.9550(17)$ & $\mathrm{O}(11)-\mathrm{C}(10)^{1}$ & $1.262(3)$ \\
\hline $\mathrm{Fe}(1)-\mathrm{O}(2)$ & $1.968(2)$ & $\mathrm{O}(13)-\mathrm{C}(50)$ & $1.255(3)$ \\
\hline $\mathrm{Fe}(1)-\mathrm{O}(12)$ & $2.022(2)$ & $\mathrm{O}(23)-\mathrm{C}(50)$ & $1.264(4)$ \\
\hline $\mathrm{Fe}(1)-\mathrm{O}(14)$ & $2.022(2)$ & $\mathrm{O}(24)-\mathrm{C}(40)$ & $1.261(3)$ \\
\hline $\mathrm{Fe}(1)-\mathrm{O}(11)$ & $2.0259(18)$ & $C(21)-C(26)$ & $1.379(4)$ \\
\hline $\mathrm{Fe}(1)-\mathrm{O}(13)$ & $2.043(2)$ & $C(21)-C(22)$ & $1.389(4)$ \\
\hline $\mathrm{Fe}(2)-\mathrm{O}(1)$ & $1.8777(18)$ & $\mathrm{C}(21)-\mathrm{C}(20)^{4}$ & $1.498(4)$ \\
\hline $\mathrm{Fe}(2)-\mathrm{O}(24)$ & $1.999(2)$ & $\mathrm{O}(2)-\mathrm{Fe}(3)^{1}$ & $1.9443(19)$ \\
\hline $\mathrm{Fe}(2)-\mathrm{O}(21)$ & $2.009(2)$ & $\mathrm{O}(12)-\mathrm{C}(60)$ & $1.248(3)$ \\
\hline $\mathrm{Fe}(2)-\mathrm{O}(23)$ & $2.023(2)$ & $\mathrm{O}(33)-\mathrm{C}(30)$ & $1.247(4)$ \\
\hline $\mathrm{Fe}(2)-\mathrm{O}(22)$ & $2.042(2)$ & $\mathrm{O}(21)-\mathrm{C}(30)$ & $1.254(4)$ \\
\hline Fe(2)-OW1 & $2.114(2)$ & $\mathrm{O}(32)-\mathrm{C}(60)$ & $1.254(4)$ \\
\hline $\mathrm{Fe}(3)-\mathrm{O}(2)^{1}$ & $1.9443(19)$ & $\mathrm{O}(34)-\mathrm{C}(20)$ & $1.245(3)$ \\
\hline $\mathrm{Fe}(3)-\mathrm{O}(1)$ & $1.9568(17)$ & $C(22)-C(23)$ & $1.379(4)$ \\
\hline $\mathrm{Fe}(3)-\mathrm{O}(32)$ & $2.007(2)$ & $\mathrm{C}(50)-\mathrm{C}(51)$ & $1.497(4)$ \\
\hline $\mathrm{Fe}(3)-\mathrm{O}(34)$ & $2.010(2)$ & $C(20)-C(21)^{4}$ & $1.498(4)$ \\
\hline $\mathrm{Fe}(3)-\mathrm{O}(33)$ & $2.042(3)$ & $C(11)-C(16)$ & $1.380(4)$ \\
\hline $\mathrm{Fe}(3)-\mathrm{O}(31)$ & 2.0441(19) & $\mathrm{C}(11)-\mathrm{C}(12)$ & $1.391(4)$ \\
\hline $\mathrm{Cl}(4)-\mathrm{C}(43)$ & $1.736(3)$ & $C(41)-C(42)^{5}$ & $1.381(4)$ \\
\hline $\mathrm{Cl}(2)-\mathrm{C}(23)$ & $1.787(4)$ & $C(41)-C(46)$ & $1.390(4)$ \\
\hline $\mathrm{Cl}(6)-\mathrm{Cl}\left(6^{\prime}\right)$ & $0.544(7)$ & $C(41)-C(40)$ & $1.494(4)$ \\
\hline $\mathrm{Cl}(6)-\mathrm{C}(63)^{2}$ & $1.801(9)$ & $C(46)-C(45)^{1}$ & $1.388(4)$ \\
\hline $\mathrm{Cl}(5)-\mathrm{Cl}\left(5^{\prime}\right)$ & $0.576(18)$ & $C(42)-C(41)^{5}$ & $1.381(4)$ \\
\hline $\mathrm{Cl}(5)-\mathrm{C}(53)$ & $1.865(11)$ & $C(42)-C(43)$ & $1.383(4)$ \\
\hline $\mathrm{Cl}(1)-\mathrm{C}(13)$ & $1.755(4)$ & $C(51)-C(52)$ & $1.382(5)$ \\
\hline $\mathrm{Cl}(3)-\mathrm{Cl}\left(3^{\prime}\right)$ & $0.576(19)$ & $C(51)-C(56)$ & $1.385(5)$ \\
\hline $\mathrm{Cl}(3)-\mathrm{C}(33)^{3}$ & $1.664(8)$ & $C(60)-C(61)$ & $1.500(5)$ \\
\hline $\mathrm{C}(10)-\mathrm{O}(31)$ & $1.257(3)$ & $C(16)-C(15)$ & $1.396(4)$ \\
\hline $\mathrm{C}(10)-\mathrm{O}(11)^{1}$ & $1.262(3)$ & $C(26)-C(25)$ & $1.391(5)$ \\
\hline$C(10)-C(11)$ & $1.494(3)$ & C(30)-C(31) & $1.490(5)$ \\
\hline $\mathrm{O}(22)-\mathrm{C}(20)$ & $1.259(3)$ & $C(44)-C(45)^{6}$ & $1.379(5)$ \\
\hline $\mathrm{O}(14)-\mathrm{C}(40)$ & $1.258(3)$ & $C(44)-C(43)$ & $1.382(5)$ \\
\hline
\end{tabular}




\begin{tabular}{|c|c|c|c|}
\hline$C(61)-C(62)$ & $1.364(6)$ & CA11-CA12 & $1.442(7)$ \\
\hline$C(61)-C(66)$ & $1.393(5)$ & $C(62)-C(63)$ & $1.412(8)$ \\
\hline$C(45)-C(44)^{7}$ & $1.379(5)$ & $C(35)-C(34)$ & $1.372(7)$ \\
\hline $\mathrm{C}(45)-\mathrm{C}(46)^{1}$ & $1.388(4)$ & $C(54)-C(55)$ & $1.361(8)$ \\
\hline$C(56)-C(55)$ & $1.391(5)$ & $C(54)-C(53)^{3}$ & $1.383(9)$ \\
\hline$C(25)-C(24)$ & $1.389(6)$ & $\mathrm{C}(53)-\mathrm{C}(54)^{10}$ & $1.383(8)$ \\
\hline $\mathrm{C}(25)-\mathrm{Cl}\left(2^{\prime}\right)$ & $1.870(6)$ & $\mathrm{C}(53)-\mathrm{C}(52)^{10}$ & $1.391(5)$ \\
\hline$C(52)-C(53)^{3}$ & $1.391(5)$ & $\mathrm{C}(53)-\mathrm{Cl}\left(5^{\prime}\right)$ & $1.658(11)$ \\
\hline$C(23)-C(24)$ & $1.381(6)$ & $C(66)-C(65)$ & $1.395(7)$ \\
\hline $\mathrm{C}(12)-\mathrm{C}(13)^{1}$ & $1.375(4)$ & $C(33)-C(34)$ & $1.386(7)$ \\
\hline$C(31)-C(36)$ & $1.388(5)$ & $\mathrm{C}(33)-\mathrm{Cl}(3)^{10}$ & $1.664(8)$ \\
\hline$C(31)-C(32)$ & $1.396(5)$ & $\mathrm{C}(33)-\mathrm{Cl}\left(3^{\prime}\right)^{10}$ & $1.828(8)$ \\
\hline NA21-CA21 & $1.111(6)$ & $C(65)-C(64)$ & $1.328(10)$ \\
\hline NA11-CA11 ${ }^{8}$ & $1.120(5)$ & $C(63)-C(64)$ & $1.383(10)$ \\
\hline$C(36)-C(35)$ & $1.393(6)$ & $\mathrm{C}(63)-\mathrm{Cl}\left(6^{\prime}\right)^{2}$ & $1.650(9)$ \\
\hline $\mathrm{C}(14)-\mathrm{C}(13)^{1}$ & $1.375(6)$ & $\mathrm{C}(63)-\mathrm{Cl}(6)^{2}$ & $1.801(9)$ \\
\hline$C(14)-C(15)$ & $1.384(6)$ & $\mathrm{Cl}\left(3^{\prime}\right)-\mathrm{C}(33)^{3}$ & $1.828(8)$ \\
\hline$C(13)-C(14)^{1}$ & $1.375(6)$ & $\mathrm{Cl}\left(6^{\prime}\right)-\mathrm{C}(63)^{2}$ & $1.650(9)$ \\
\hline$C(13)-C(12)^{1}$ & $1.375(4)$ & CA31-NA31 ${ }^{1}$ & $1.263(8)$ \\
\hline CA21-CA22 & $1.456(8)$ & CA31-NA31 & $1.263(8)$ \\
\hline $\mathrm{C}(15)-\mathrm{Cl}\left(1^{\prime}\right)$ & $1.828(9)$ & CA31-CA32 & $1.292(9)$ \\
\hline$C(32)-C(33)$ & $1.388(6)$ & CA31-CA32 & $1.292(10)$ \\
\hline CA11-NA11 ${ }^{9}$ & $1.120(5)$ & & \\
\hline
\end{tabular}

\section{Bond Angles}

$\begin{array}{llll}\mathrm{O}(1)-\mathrm{Fe}(1)-\mathrm{O}(2) & 93.50(8) & \mathrm{O}(14)-\mathrm{Fe}(1)-\mathrm{O}(11) & 86.37(8) \\ \mathrm{O}(1)-\mathrm{Fe}(1)-\mathrm{O}(12) & 91.86(8) & \mathrm{O}(1)-\mathrm{Fe}(1)-\mathrm{O}(13) & 94.99(8) \\ \mathrm{O}(2)-\mathrm{Fe}(1)-\mathrm{O}(12) & 97.50(10) & \mathrm{O}(2)-\mathrm{Fe}(1)-\mathrm{O}(13) & 170.46(8) \\ \mathrm{O}(1)-\mathrm{Fe}(1)-\mathrm{O}(14) & 94.82(8) & \mathrm{O}(12)-\mathrm{Fe}(1)-\mathrm{O}(13) & 86.58(10) \\ \mathrm{O}(2)-\mathrm{Fe}(1)-\mathrm{O}(14) & 87.46(9) & \mathrm{O}(14)-\mathrm{Fe}(1)-\mathrm{O}(13) & 87.50(9) \\ \mathrm{O}(12)-\mathrm{Fe}(1)-\mathrm{O}(14) & 171.43(9) & \mathrm{O}(11)-\mathrm{Fe}(1)-\mathrm{O}(13) & 83.90(8) \\ \mathrm{O}(1)-\mathrm{Fe}(1)-\mathrm{O}(11) & 178.34(8) & \mathrm{O}(1)-\mathrm{Fe}(2)-\mathrm{O}(24) & 96.65(8) \\ \mathrm{O}(2)-\mathrm{Fe}(1)-\mathrm{O}(11) & 87.70(8) & \mathrm{O}(1)-\mathrm{Fe}(2)-\mathrm{O}(21) & 97.44(9) \\ \mathrm{O}(12)-\mathrm{Fe}(1)-\mathrm{O}(11) & 86.84(9) & \mathrm{O}(24)-\mathrm{Fe}(2)-\mathrm{O}(21) & 89.97(10)\end{array}$




\begin{tabular}{|c|c|c|c|}
\hline $\mathrm{O}(1)-\mathrm{Fe}(2)-\mathrm{O}(23)$ & $98.30(8)$ & $\mathrm{O}(31)-\mathrm{C}(10)-\mathrm{C}(11)$ & $116.7(2)$ \\
\hline $\mathrm{O}(24)-\mathrm{Fe}(2)-\mathrm{O}(23)$ & 89.91(9) & $\mathrm{O}(11)^{1}-\mathrm{C}(10)-\mathrm{C}(11)$ & $116.5(2)$ \\
\hline $\mathrm{O}(21)-\mathrm{Fe}(2)-\mathrm{O}(23)$ & $164.17(9)$ & $\mathrm{C}(20)-\mathrm{O}(22)-\mathrm{Fe}(2)$ & 125.94(19) \\
\hline $\mathrm{O}(1)-\mathrm{Fe}(2)-\mathrm{O}(22)$ & $98.76(8)$ & $\mathrm{C}(40)-\mathrm{O}(14)-\mathrm{Fe}(1)$ & $134.39(17)$ \\
\hline $\mathrm{O}(24)-\mathrm{Fe}(2)-\mathrm{O}(22)$ & $164.56(9)$ & $\mathrm{C}(10)^{1}-\mathrm{O}(11)-\mathrm{Fe}(1)$ & $135.19(17)$ \\
\hline $\mathrm{O}(21)-\mathrm{Fe}(2)-\mathrm{O}(22)$ & $86.95(10)$ & $\mathrm{C}(50)-\mathrm{O}(13)-\mathrm{Fe}(1)$ & $130.05(19)$ \\
\hline $\mathrm{O}(23)-\mathrm{Fe}(2)-\mathrm{O}(22)$ & $88.97(9)$ & $\mathrm{C}(10)-\mathrm{O}(31)-\mathrm{Fe}(3)$ & $131.85(17)$ \\
\hline $\mathrm{O}(1)-\mathrm{Fe}(2)-\mathrm{OW} 1$ & $178.21(10)$ & $\mathrm{C}(50)-\mathrm{O}(23)-\mathrm{Fe}(2)$ & $132.62(18)$ \\
\hline $\mathrm{O}(24)-\mathrm{Fe}(2)-\mathrm{OW} 1$ & $81.78(9)$ & $\mathrm{C}(40)-\mathrm{O}(24)-\mathrm{Fe}(2)$ & $129.28(19)$ \\
\hline $\mathrm{O}(21)-\mathrm{Fe}(2)-\mathrm{OW} 1$ & $81.72(10)$ & $C(26)-C(21)-C(22)$ & $120.2(3)$ \\
\hline $\mathrm{O}(23)-\mathrm{Fe}(2)-\mathrm{OW} 1$ & $82.60(10)$ & $C(26)-C(21)-C(20)^{4}$ & $121.8(3)$ \\
\hline $\mathrm{O}(22)-\mathrm{Fe}(2)-\mathrm{OW} 1$ & $82.80(10)$ & $C(22)-C(21)-C(20)^{4}$ & $118.0(2)$ \\
\hline $\mathrm{O}(2)^{1}-\mathrm{Fe}(3)-\mathrm{O}(1)$ & $96.50(8)$ & $\mathrm{Fe}(3)^{1}-\mathrm{O}(2)-\mathrm{Fe}(1)$ & $135.95(11)$ \\
\hline $\mathrm{O}(2)^{1}-\mathrm{Fe}(3)-\mathrm{O}(32)$ & $96.56(10)$ & $\mathrm{C}(60)-\mathrm{O}(12)-\mathrm{Fe}(1)$ & $133.5(2)$ \\
\hline $\mathrm{O}(1)-\mathrm{Fe}(3)-\mathrm{O}(32)$ & $90.23(8)$ & $\mathrm{C}(30)-\mathrm{O}(33)-\mathrm{Fe}(3)$ & $129.2(2)$ \\
\hline $\mathrm{O}(2)^{1}-\mathrm{Fe}(3)-\mathrm{O}(34)$ & $167.90(10)$ & $\mathrm{C}(30)-\mathrm{O}(21)-\mathrm{Fe}(2)$ & $134.1(2)$ \\
\hline $\mathrm{O}(1)-\mathrm{Fe}(3)-\mathrm{O}(34)$ & $94.53(8)$ & $\mathrm{C}(60)-\mathrm{O}(32)-\mathrm{Fe}(3)$ & $132.84(19)$ \\
\hline $\mathrm{O}(32)-\mathrm{Fe}(3)-\mathrm{O}(34)$ & $88.33(13)$ & $\mathrm{C}(20)-\mathrm{O}(34)-\mathrm{Fe}(3)$ & $138.26(19)$ \\
\hline $\mathrm{O}(2)^{1}-\mathrm{Fe}(3)-\mathrm{O}(33)$ & $87.88(11)$ & $C(23)-C(22)-C(21)$ & $120.0(3)$ \\
\hline $\mathrm{O}(1)-\mathrm{Fe}(3)-\mathrm{O}(33)$ & $95.09(9)$ & $\mathrm{O}(13)-\mathrm{C}(50)-\mathrm{O}(23)$ & $125.6(2)$ \\
\hline $\mathrm{O}(32)-\mathrm{Fe}(3)-\mathrm{O}(33)$ & $172.66(11)$ & $\mathrm{O}(13)-\mathrm{C}(50)-\mathrm{C}(51)$ & $117.4(3)$ \\
\hline $\mathrm{O}(34)-\mathrm{Fe}(3)-\mathrm{O}(33)$ & $86.21(14)$ & $\mathrm{O}(23)-\mathrm{C}(50)-\mathrm{C}(51)$ & $116.9(2)$ \\
\hline $\mathrm{O}(2)^{1}-\mathrm{Fe}(3)-\mathrm{O}(31)$ & $87.64(8)$ & $\mathrm{O}(34)-\mathrm{C}(20)-\mathrm{O}(22)$ & $125.1(2)$ \\
\hline $\mathrm{O}(1)-\mathrm{Fe}(3)-\mathrm{O}(31)$ & $174.14(10)$ & $\mathrm{O}(34)-\mathrm{C}(20)-\mathrm{C}(21)^{4}$ & $115.7(2)$ \\
\hline $\mathrm{O}(32)-\mathrm{Fe}(3)-\mathrm{O}(31)$ & $85.17(10)$ & $\mathrm{O}(22)-\mathrm{C}(20)-\mathrm{C}(21)^{4}$ & 119.1(2) \\
\hline $\mathrm{O}(34)-\mathrm{Fe}(3)-\mathrm{O}(31)$ & $81.74(9)$ & $C(16)-C(11)-C(12)$ & $119.8(3)$ \\
\hline $\mathrm{O}(33)-\mathrm{Fe}(3)-\mathrm{O}(31)$ & $89.19(10)$ & $C(16)-C(11)-C(10)$ & $121.4(3)$ \\
\hline $\mathrm{Cl}\left(6^{\prime}\right)-\mathrm{Cl}(6)-\mathrm{C}(63)^{2}$ & $65.3(14)$ & $C(12)-C(11)-C(10)$ & $118.8(2)$ \\
\hline $\mathrm{Cl}\left(5^{\prime}\right)-\mathrm{Cl}(5)-\mathrm{C}(53)$ & $60.4(18)$ & $C(42)^{5}-C(41)-C(46)$ & $120.4(3)$ \\
\hline $\mathrm{Fe}(2)-\mathrm{O}(1)-\mathrm{Fe}(1)$ & 118.68(9) & $C(42)^{5}-C(41)-C(40)$ & $120.0(2)$ \\
\hline $\mathrm{Fe}(2)-\mathrm{O}(1)-\mathrm{Fe}(3)$ & 118.52(9) & $C(46)-C(41)-C(40)$ & $119.5(3)$ \\
\hline $\mathrm{Fe}(1)-\mathrm{O}(1)-\mathrm{Fe}(3)$ & $122.79(9)$ & $C(45)^{1}-C(46)-C(41)$ & 119.3(3) \\
\hline $\mathrm{Cl}\left(3^{\prime}\right)-\mathrm{Cl}(3)-\mathrm{C}(33)^{3}$ & $97.2(14)$ & $C(41)^{5}-C(42)-C(43)$ & 119.1(3) \\
\hline $\mathrm{O}(31)-\mathrm{C}(10)-\mathrm{O}(11)^{1}$ & $126.8(2)$ & $C(52)-C(51)-C(56)$ & 121.1(3) \\
\hline
\end{tabular}




\begin{tabular}{|c|c|c|c|}
\hline$C(52)-C(51)-C(50)$ & $119.0(3)$ & $C(13)^{1}-C(14)-C(15)$ & $119.0(3)$ \\
\hline$C(56)-C(51)-C(50)$ & $119.9(3)$ & $C(23)-C(24)-C(25)$ & 119.1(3) \\
\hline $\mathrm{O}(14)-\mathrm{C}(40)-\mathrm{O}(24)$ & $125.3(2)$ & $C(14)^{1}-C(13)-C(12)^{1}$ & $121.2(3)$ \\
\hline $\mathrm{O}(14)-\mathrm{C}(40)-\mathrm{C}(41)$ & $117.9(2)$ & $\mathrm{C}(14)^{1}-\mathrm{C}(13)-\mathrm{Cl}(1)$ & $121.6(3)$ \\
\hline $\mathrm{O}(24)-\mathrm{C}(40)-\mathrm{C}(41)$ & $116.8(2)$ & $\mathrm{C}(12)^{1}-\mathrm{C}(13)-\mathrm{Cl}(1)$ & $117.1(3)$ \\
\hline $\mathrm{O}(12)-\mathrm{C}(60)-\mathrm{O}(32)$ & $126.4(3)$ & NA21-CA21-CA22 & $177.8(6)$ \\
\hline $\mathrm{O}(12)-\mathrm{C}(60)-\mathrm{C}(61)$ & 117.6(3) & $C(14)-C(15)-C(16)$ & $120.6(3)$ \\
\hline $\mathrm{O}(32)-\mathrm{C}(60)-\mathrm{C}(61)$ & $116.0(3)$ & $C(14)-C(15)-C l\left(1^{\prime}\right)$ & $129.3(4)$ \\
\hline$C(11)-C(16)-C(15)$ & $119.5(3)$ & $\mathrm{C}(16)-\mathrm{C}(15)-\mathrm{Cl}\left(1^{\prime}\right)$ & $108.3(4)$ \\
\hline$C(21)-C(26)-C(25)$ & 119.3(3) & $C(33)-C(32)-C(31)$ & $117.9(4)$ \\
\hline $\mathrm{O}(33)-\mathrm{C}(30)-\mathrm{O}(21)$ & $125.9(3)$ & NA11 ${ }^{9}$-CA11-CA12 & $176.2(7)$ \\
\hline $\mathrm{O}(33)-\mathrm{C}(30)-\mathrm{C}(31)$ & 117.3(3) & $C(61)-C(62)-C(63)$ & $118.6(5)$ \\
\hline $\mathrm{O}(21)-\mathrm{C}(30)-\mathrm{C}(31)$ & 116.8(3) & $C(34)-C(35)-C(36)$ & $119.8(4)$ \\
\hline$C(45)^{6}-C(44)-C(43)$ & $118.9(3)$ & $C(55)-C(54)-C(53)^{3}$ & $119.4(4)$ \\
\hline$C(62)-C(61)-C(66)$ & $119.8(4)$ & $C(54)^{10}-C(53)-C(52)^{10}$ & $122.1(4)$ \\
\hline$C(62)-C(61)-C(60)$ & $120.6(3)$ & $\mathrm{C}(54)^{10}-\mathrm{C}(53)-\mathrm{Cl}\left(5^{\prime}\right)$ & $113.6(5)$ \\
\hline$C(66)-C(61)-C(60)$ & $119.6(4)$ & $\mathrm{C}(52)^{10}-\mathrm{C}(53)-\mathrm{Cl}\left(5^{\prime}\right)$ & $123.8(6)$ \\
\hline$C(44)-C(43)-C(42)$ & $121.4(3)$ & $\mathrm{C}(54)^{10}-\mathrm{C}(53)-\mathrm{Cl}(5)$ & $125.5(4)$ \\
\hline $\mathrm{C}(44)-\mathrm{C}(43)-\mathrm{Cl}(4)$ & $119.4(2)$ & $\mathrm{C}(52)^{10}-\mathrm{C}(53)-\mathrm{Cl}(5)$ & $112.0(5)$ \\
\hline $\mathrm{C}(42)-\mathrm{C}(43)-\mathrm{Cl}(4)$ & 119.2(3) & $\mathrm{Cl}\left(5^{\prime}\right)-\mathrm{C}(53)-\mathrm{Cl}(5)$ & $17.6(5)$ \\
\hline$C(44)^{7}-C(45)-C(46)^{1}$ & $120.8(3)$ & $C(61)-C(66)-C(65)$ & $120.5(5)$ \\
\hline$C(51)-C(56)-C(55)$ & $119.9(4)$ & $C(34)-C(33)-C(32)$ & $121.7(4)$ \\
\hline$C(24)-C(25)-C(26)$ & $120.8(3)$ & $\mathrm{C}(34)-\mathrm{C}(33)-\mathrm{Cl}(3)^{10}$ & $116.1(4)$ \\
\hline $\mathrm{C}(24)-\mathrm{C}(25)-\mathrm{Cl}\left(2^{\prime}\right)$ & $128.8(3)$ & $\mathrm{C}(32)-\mathrm{C}(33)-\mathrm{Cl}(3)^{10}$ & $121.0(4)$ \\
\hline$C(26)-C(25)-C l\left(2^{\prime}\right)$ & $110.3(3)$ & $\mathrm{C}(34)-\mathrm{C}(33)-\mathrm{Cl}\left(3^{\prime}\right)^{10}$ & $122.4(4)$ \\
\hline$C(51)-C(52)-C(53)^{3}$ & $117.4(4)$ & $\mathrm{C}(32)-\mathrm{C}(33)-\mathrm{Cl}\left(3^{\prime}\right)^{10}$ & $115.5(4)$ \\
\hline$C(22)-C(23)-C(24)$ & $120.6(3)$ & $\mathrm{Cl}(3)^{10}-\mathrm{C}(33)-\mathrm{Cl}\left(3^{\prime}\right)^{10}$ & $18.2(6)$ \\
\hline $\mathrm{C}(22)-\mathrm{C}(23)-\mathrm{Cl}(2)$ & $115.6(3)$ & $C(54)-C(55)-C(56)$ & $120.1(5)$ \\
\hline$C(24)-C(23)-C l(2)$ & $123.8(3)$ & $\mathrm{C}(35)-\mathrm{C}(34)-\mathrm{C}(33)$ & $119.9(4)$ \\
\hline$C(13)^{1}-C(12)-C(11)$ & $119.8(3)$ & $C(64)-C(65)-C(66)$ & $119.8(6)$ \\
\hline$C(36)-C(31)-C(32)$ & $120.7(3)$ & $C(64)-C(63)-C(62)$ & $120.3(5)$ \\
\hline$C(36)-C(31)-C(30)$ & $121.0(3)$ & $\mathrm{C}(64)-\mathrm{C}(63)-\mathrm{Cl}\left(6^{\prime}\right)^{2}$ & $112.0(5)$ \\
\hline$C(32)-C(31)-C(30)$ & 118.3(3) & $\mathrm{C}(62)-\mathrm{C}(63)-\mathrm{Cl}\left(6^{\prime}\right)^{2}$ & $127.6(6)$ \\
\hline$C(31)-C(36)-C(35)$ & $120.0(4)$ & $\mathrm{C}(64)-\mathrm{C}(63)-\mathrm{Cl}(6)^{2}$ & $129.2(5)$ \\
\hline
\end{tabular}




\begin{tabular}{|c|c|c|c|}
\hline $\mathrm{C}(62)-\mathrm{C}(63)-\mathrm{Cl}(6)^{2}$ & $110.5(5)$ & NA31 ${ }^{1}$-CA31-NA31 & $138.3(10)$ \\
\hline $\mathrm{Cl}\left(6^{\prime}\right)^{2}-\mathrm{C}(63)-\mathrm{Cl}(6)^{2}$ & $17.4(3)$ & NA31 ${ }^{1}$-CA31-CA32 & $43.9(7)$ \\
\hline$C(65)-C(64)-C(63)$ & $120.9(5)$ & NA31-CA31-CA321 & 167.9(9) \\
\hline $\mathrm{Cl}(5)-\mathrm{Cl}\left(5^{\prime}\right)-\mathrm{C}(53)$ & 102.1(19) & NA31'-CA31-CA32 & $167.9(9)$ \\
\hline $\mathrm{Cl}(3)-\mathrm{Cl}\left(3^{\prime}\right)-\mathrm{C}(33)^{3}$ & 64.6(11) & NA31-CA31-CA32 & $43.9(7)$ \\
\hline $\mathrm{Cl}(6)-\mathrm{Cl}\left(6^{\prime}\right)-\mathrm{C}(63)^{2}$ & $97.3(16)$ & CA $32^{1}-\mathrm{CA} 31-\mathrm{CA} 32$ & $137.7(15)$ \\
\hline
\end{tabular}

Symmetry transformations used to generate equivalent atoms:
${ }^{1}-\mathrm{x}+1, \mathrm{y},-\mathrm{z}+3 / 2$
$2-x+1,-y+1,-z+2$;
$3-x+1 / 2, y+1 / 2,-z+3 / 2$
${ }^{4}-\mathrm{x}+1 / 2,-\mathrm{y}+1 / 2,-\mathrm{z}+1$
${ }^{5}-\mathrm{x}+1,-\mathrm{y},-\mathrm{z}+2$;
${ }^{6} \mathrm{x},-\mathrm{y}, \mathrm{z}+1 / 2$;
${ }^{7} \mathrm{x},-\mathrm{y}, \mathrm{z}-1 / 2$;
${ }^{8} \mathrm{x}-1 / 2,-\mathrm{y}+1 / 2, \mathrm{z}-1 / 2$;
${ }^{9} \mathrm{x}+1 / 2,-\mathrm{y}+1 / 2, \mathrm{z}+1 / 2$
${ }^{10}-x+1 / 2, y-1 / 2,-z+3 / 2$. 